\title{
WestVirginiaUniversity
}

THE RESEARCH REPOSITORY @ WVU

Graduate Theses, Dissertations, and Problem Reports

2005

\section{Thermal stresses in the superstructure of integral abutment bridges}

Kevyn C. McBride

West Virginia University

Follow this and additional works at: https://researchrepository.wvu.edu/etd

\section{Recommended Citation}

McBride, Kevyn C., "Thermal stresses in the superstructure of integral abutment bridges" (2005). Graduate Theses, Dissertations, and Problem Reports. 1858.

https://researchrepository.wvu.edu/etd/1858

This Thesis is protected by copyright and/or related rights. It has been brought to you by the The Research Repository @ WVU with permission from the rights-holder(s). You are free to use this Thesis in any way that is permitted by the copyright and related rights legislation that applies to your use. For other uses you must obtain permission from the rights-holder(s) directly, unless additional rights are indicated by a Creative Commons license in the record and/ or on the work itself. This Thesis has been accepted for inclusion in WVU Graduate Theses, Dissertations, and Problem Reports collection by an authorized administrator of The Research Repository @ WVU. For more information, please contact researchrepository@mail.wvu.edu. 
Thermal Stresses in the Superstructure of Integral Abutment Bridges

Kevyn C. McBride

\begin{abstract}
Thesis submitted to the
College of Engineering and Mineral Resources

at West Virginia University

in partial fulfillment of the requirements

for the degree of
\end{abstract}

\author{
Master of Science \\ in \\ Mechanical Engineering \\ Samir N. Shoukry, Ph.D., Chair \\ Jacky Prucz, Ph.D. \\ Kenneth Means, Ph.D. \\ Gergis W. William, Ph.D.
}

Department of Mechanical and Aerospace Engineering

Morgantown, West Virginia

2005

Keywords: Finite Element Modeling, Integral Abutment Bridges,

Thermal Stresses, Bridge Instrumentation 


\title{
ABSTRACT \\ Thermal Stresses in the Superstructure of Integral Abutment Bridges
}

\author{
Kevyn C. McBride
}

Integral abutment bridges (IAB) have become a popular alternative to expansion joint bridges mainly due to their lower maintenance and repair costs. Although no specific guidelines exist for integral abutment bridge design, standards primarily used assume the volumetric changes of IAB under thermal loading occur free of constraint. This study examines the validity of this assumption and determines the effect of changing temperature on the state of stress in the superstructure of an IAB. The effect of changing thermal conditions on the Evansville Bridge in Preston County, West Virginia is investigated using an extensive bridge instrumentation system along with a detailed finite element analysis. The research shows that temperature loads do, in fact, induce stresses in the superstructure of an IAB. Although these stresses do not cause catastrophic failure of the structure, they will increase maintenance costs by creating additional cracking within the bridge deck and significantly increasing girder stresses. 


\section{ACKNOWLEDGEMENTS}

First of all, I would like to express my sincere thanks to my academic advisor and research advisor Dr. Samir N. Shoukry for providing me with the opportunity to study and work with his outstanding research group. Dr. Shoukry, thank you so very much for your guidance, encouragement, and support throughout my studies.

Another very special thank you goes out to Dr. Gergis William and Mr. Mourad Riad, without whose help the completion of this work would have never been possible. I deeply appreciate the time you two have spent guiding, counseling, directing, and befriending me during this research.

My most sincere thank you goes out to my family. Jordan and Kent, thank you for all of the support you gave me in so many different ways throughout this process. Mom and dad, without your love, encouragement, guidance, support, and understanding during the good times as well as the bad I would have never have made it through. I love you all.

Finally, I would like to extend my appreciation to the West Virginia Department of Highways for providing financial support that made this study possible. 


\section{TABLE OF CONTENTS}

$\begin{array}{ll}\text { ABSTRACT } & \text { ii } \\ \text { ACKNOWLEDGEMENTS } & \text { iii } \\ \text { TABLE OF CONTENTS } & \text { iv } \\ \text { LIST OF TABLES } & \text { vi } \\ \text { LIST OF FIGURES } & \text { vi }\end{array}$

CHAPTER ONE INTRODUCTION 1

1.1 Background 1

1.2 Problem Statement 2

1.3 Research Objectives 2

1.4 Thesis Outline 3

CHAPTER TWO LITERATURE REVIEW 6

2.1 Introduction 6

2.2 FE Studies of Load Distribution Factor 6

$\begin{array}{ll}2.3 \text { FE Investigation of Bridge Capacity } & 11\end{array}$

2.4 Bridge Design Using the Finite Element Method 12

2.5 Using Finite Element in Determining Bridge Strength 13 and Stability

2.6 FE Models Developed to Predict Global Behavior and Bridge 15 Response

2.7 FE Models Verifying Structural Health Monitoring Procedures $\quad 17$

2.8 FE Models of Integral Abutment Bridges 18

2.8.1 Soil-Abutment Interaction $\quad 19$

2.8.2 Soil-Pile Interaction $\quad 19$

$\begin{array}{ll}2.8 .3 \text { Bridge Idealization } & 20\end{array}$

CHAPTER THREE FINITE ELEMENT MODEL OF EVANSVILLE 23 BRIDGE

$\begin{array}{ll}3.1 \text { Introduction } & 23\end{array}$

\begin{tabular}{ll} 
3.2 Bridge Structural Model & 23 \\
\hline .3 Material Model & 26
\end{tabular}

$\begin{array}{ll}3.3 \text { Material Model } & 26\end{array}$

$\begin{array}{ll}3.4 \text { Boundary Conditions } & 27\end{array}$

3.5 Soil-Abutment Interaction 28

3.6 Soil-Pile Interaction $\quad 34$

$\begin{array}{ll}3.7 \text { Contact Interfaces } & 37\end{array}$

3.8 Loading Conditions 41

3.9 Modeling Sequence $\quad 41$

3.10 Gravity Loading $\quad 42$

3.11 Ambient Temperature Loading $\quad 44$

CHAPTER FOUR EVANSVILLE BRIDGE INSTRUMENTATION 45

4.1 Introduction $\quad 45$ 
4.2 Instrumented Bridge Section 45

4.3 Instrumentation $\quad 48$

4.4 Data Acquisition System $\quad 52$

CHAPTER FIVE FINITE ELEMENT MODEL VALIDATION 54

5.1 Introduction 54

5.2 Sensor Data Interpretation $\quad 54$

5.3 Model Validation $\quad 55$

5.3.1 Gravity Load $\quad 55$

5.3.2 Temperature Load $\quad 58$

5.4 Conclusions 65

CHAPTER SIX EFFECT OF CHANGING THERMAL CONDITIONS 67 ON EVANSVILLE BRIDGE

6.1 Introduction $\quad 67$

6.2 Abutment Movement 67

6.3 Backfill Constraint $\quad 70$

6.4 Experimentally Measured Girder Stresses 73

6.5 Stresses in the Bridge Deck 79

6.6 Early Age Cracking 83

6.7 Conclusions 91

CHAPTER SEVEN INVESTIGATION OF LIVE LOADING ON 93 EVANSVILLE BRIDGE

7.1 Introduction 93

7.2 Characterization of Live Loading 93

7.3 Effect of AASHTO HS20-44 Truck Loading on Girders 96

7.4 Stability and Yield Ratio Analysis $\quad 99$

7.5 Effect of AASHTO HS20-44 Truck Loading on Bridge Deck 108

7.6 Conclusions 110

CHAPTER EIGHT CONCLUSIONS AND RECOMMENDATIONS 111

8.1 Conclusions 111

8.2 Further Work 113

$\begin{array}{ll}\text { REFERENCES } & 115\end{array}$

$\begin{array}{ll}\text { APPENDIX A } & 123\end{array}$ 


\section{LIST OF TABLES}

Table 3.1 Material Properties Used in FE Model 27

Table 3.2 Minimum Active and Maximum Passive Earth Pressures 29

Table 3.3 Actions at Each Time Step of FE Analysis 42 


\section{LIST OF FIGURES}

Figure 3.1 Finite Element Mesh of Evansville Bridge 24

Figure 3.2 Relationship between Abutment Movement and Earth Pressure 31 Coefficient

Figure 3.3 F-d Curves for Nonlinear Spring Elements Representing Soil 32 Abutment Interaction

Figure 3.4 Example of Nonlinear Spring Attached to Abutments 33

Figure 3.5 P-y Curves Used with Nonlinear Springs to Model Soil- 36

Figure 3.6 Example of Nonlinear Springs Attached to Abutment Piles 37

Figure 3.7 Strain Profiles for Composite Sections with Full and Partial 38

Composite Action Subjected to Bending Moment

Figure 3.8 Strain Profiles Induced by Temperature Loading along Girder 39

Figure 3.9 Coordinate of Deck Nodes After Initial Displacement 43

Figure 4.1 Evansville Bridge in Preston County, WV Following Phase 146 of Construction

$\begin{array}{lll}\text { Figure 4.2 Instrumentation Plan } & 47\end{array}$

Figure 4.3 Typical Instrumented Section within Evansville Bridge Deck 49

Figure 4.4 Displacement Transducers Installed on Evansville Bridge $\quad 50$

Figure 4.5 Inclinometer Installed on Bottom Flange of Girder 51

Figure 4.6 Thermistor Tree in Bridge Deck 51

Figure 4.7 Data Acquisition System 52

Figure 5.1 Strain Histories for Middle Girder at Mid-Span 1 Highlighting 56 Effect of Deck Weight

Figure 5.2 Bending Moment Profile along Middle Girder Induced by 58

Concrete Deck Weight

Figure 5.3 Comparison of Longitudinal and Transverse Strains due to 59

Figure 5.4 Comparison of Longitudinal and Transverse Strains due to 60

Figure 5.5 Comparison of Longitudinal and Transverse Strains due to 61

Figure 5.6 Comparison of Longitudinal and Transverse Strains due to 62 Temperature Change at Mid-Span 2

Figure 5.7 Comparison of Longitudinal Strain in the Middle Girder due to 63

Figure 5.8 Comparison of Longitudinal Strain in the Middle Girder due to 64 Temperature Change at Pier 1 (a-b) and Mid-Span 1 (c-d)

Figure 6.1 Time Histories of Ambient Temperature and Span Length 68

Figure 6.2 Change in Edge Span Length During First Month of Data 69 Collection 
Figure 6.3 Change in Length of Span 1 due to Uniform Temperature

Changes

Figure 6.4 Experimentally Measured Longitudinal Stress on Middle

Girder Near Abutment 1 and at Mid-Span 1

Figure 6.5 Experimentally Measured Longitudinal Stress on Middle Girder at Pier 1 and Mid-Span 2

Figure 6.6 Axial Stress Time Histories for Middle Girder

Figure 6.7

Comparison of Axial Stresses Induced in Girder 2 by

79

Changing Thermal Conditions

Figure 6.8 Longitudinal Stress Time Histories for Concrete Reinforced Deck above Girder 1

Figure 6.9 Longitudinal Stress Time Histories for Concrete Reinforced 82 Deck above Girder 2

Figure 6.10 Longitudinal Stress Time Histories for Concrete Reinforced 83 Deck above Girder 3

Figure 6.11 Early Age Stress Versus Temperature Change at Mid-Span 1 85

Figure 6.12 Early Age Stress Versus Temperature Change at Pier 1 86

Figure 6.13 Early Age Stress Versus Temperature Change at Mid-Span 287

Figure 6.14 Magnitude of Longitudinal Stress Caused by Constrained 88

Figure 6.15 FE and Experimental Values for Longitudinal Stress in Deck 90 Cross Section Above Girder 2

Figure 6.16 FE Measured Longitudinal Stress plus Initial Drying Shrinkage 91

Figure 7.1 Wheel Loads in AASHTO HS20-44 94

Figure 7.2 Location of Wheel Loads Along the Longitudinal Axis 95 to Induce Maximum Bending Moment at (a) Mid-Span 1, (b) Pier 1, and (c) Mid-Span 2

Figure 7.3 Axial, Bending, and Total Stress in Girder Cross Section Induced by Structure Weight, Temperature Decrease, and AASHTO Truck Loading

Figure 7.4 Axial, Bending, and Total Stress in Girder Cross Section Induced by Structure Weight, Temperature Increase, and AASHTO Truck Loading

Figure 7.5 AASHTO Stability Ratio Requirement with $k_{b}=1.0$ for dead and Live Loading (a) Plus Temperature Decrease (b) and Increase

Figure 7.6 AASHTO Yield Ratio Requirement for dead and Live Loading (a) Plus Temperature Decrease (b) and Increase

Figure 7.7 Deformed Shape of Middle Girder Under Self-Weight, Truck 103 Loading and (a) $-20^{\circ} \mathrm{C}$ Temperature Loading and (b) $20^{\circ} \mathrm{C}$ Temperature Loading

Figure 7.8 Deflection Shape of Girder 2 under Self-Weight, Truck Loading, 103 and $20^{\circ} \mathrm{C}$ Temperature Load (a) or $-20^{\circ} \mathrm{C}$ Temperature Load 
Figure 7.9 AASHTO Stability Ratio Requirement with $k_{b}=0.588$ for dead and Live Loading (a) Plus Temperature Decrease (b) and Increase

Figure 7.10 Longitudinal Stresses in Bridge Deck Under Self-Weight,

Figure A.1 Evansville Bridge Subjected to Girder Weight Loading

Figure A.2 Evansville Bridge Subjected to Girder and Deck Weight

Figure A.4 Evansville Bridge Subjected to Girder and Deck Weight

Figure A.4 Evansville Bridge Subjected to Girder and Deck Weight

Figure A.5 Evansville Bridge Subjected to Gravity Loading and $-5^{\circ} \mathrm{C}$

Figure A.6 Evansville Bridge Subjected to Gravity Loading and $-10^{\circ} \mathrm{C}$

Figure A.7 Evansville Bridge Subjected to Gravity Loading and $-15^{\circ} \mathrm{C}$

Figure A.8 Evansville Bridge Subjected to Gravity Loading and $-20^{\circ} \mathrm{C}$

Figure A.9 Evansville Bridge Subjected to Gravity Loading and $5^{\circ} \mathrm{C}$

Figure A.10 Evansville Bridge Subjected to Gravity Loading and $10^{\circ} \mathrm{C}$

Figure A.11 Evansville Bridge Subjected to Gravity Loading and $15^{\circ} \mathrm{C}$

Figure A.12 Evansville Bridge Subjected to Gravity Loading and $20^{\circ} \mathrm{C}$

Figure A.13 Evansville Bridge Subjected to Gravity Loading, $-20^{\circ} \mathrm{C}$ Uniform

Temperature, and AASHTO Truck Loading to Induce Maximum Bending Moment at Mid-Span 1 (disp x 350)

Figure A.14 Evansville Bridge Subjected to Gravity Loading, $-20^{\circ} \mathrm{C}$ Uniform Temperature, and AASHTO Truck Loading to Induce Maximum Bending Moment at Pier 1 (disp x 350)

Figure A.15 Evansville Bridge Subjected to Gravity Loading, $-20^{\circ} \mathrm{C}$ Uniform Temperature, and AASHTO Truck Loading to Induce Maximum Bending Moment at Mid-Span 2 (disp x 350)

Figure A.16 Evansville Bridge Subjected to Gravity Loading, $20^{\circ} \mathrm{C}$ Uniform Temperature, and AASHTO Truck Loading to Induce Maximum Bending Moment at Mid-Span 1 (disp x 350)

Figure A.17 Evansville Bridge Subjected to Gravity Loading, $20^{\circ} \mathrm{C}$ Uniform Temperature, and AASHTO Truck Loading to Induce Maximum Bending Moment at Pier 1 (disp x 350) 
Figure A.18 Evansville Bridge Subjected to Gravity Loading, $20^{\circ} \mathrm{C}$ Uniform

Temperature, and AASHTO Truck Loading to Induce

Maximum Bending Moment at Mid-Span 2 (disp x 350) 


\section{CHAPTER ONE}

\section{INTRODUCTION}

\subsection{Background}

In recent years, integral abutment bridges have become more widely used as an alternative to bridges with expansion joints. Integral abutment bridges consist of a superstructure connected monolithically with the abutment walls. Hence, changing thermal conditions causing the superstructure to expand and contract will initiate movements at the abutments. To accommodate these thermal movements and provide vertical support for the structure, the bridge abutments are supported by piles driven into the soil with their weak axis oriented perpendicular to the longitudinal axis of the bridge to allow for bending. However, soil backfill is placed behind the abutment walls and will provide resistance to the expansion of the structure.

The main advantage of constructing integral abutment bridge systems is that they have no expansion joints. Expansion joints can be detrimental from an economic standpoint due to the needed maintenance and repair costs from vehicle induced damage to ensure adequate operation (Civjan et al., 2004). In addition, corrosion damage can occur on expansion joints as a result of water and deicing salt runoff, resulting in further maintenance costs. Griemann et al. (1986) also pointed out that integral abutment bridges have lower construction costs compared to expansion joint bridges. However, integral abutment bridges do not solve all bridge problems in that deck cracking in integral abutment bridges is still present as well as a cracking of the connection between the deck and the abutment (Burke, 1999).

The biggest uncertainty in the analysis and design of an integral abutment bridge is the reaction of the soil behind the abutment walls and next to the foundation piles (Faraji et al., 2001). The magnitude of the soil forces on the bridge system can become significant as the bridge expands and contracts under temperature loading. Because temperature loading is not usually considered during bridge superstructure design, the stresses from 
the soil backfill and constrained bridge movement are not accounted for when determining the stability of the bridge.

\subsection{Problem Statement}

Currently, there are no explicit guidelines regarding the design of integral abutment bridges. Furthermore, the AASHTO Standard Specifications for Highway Bridges (AASHTO 2002) assumes that the lateral movement of the integral abutments relieves all axial thermal stresses in the structure. However, it has been shown by Lawever et al. (2000) that the measured bridge response due to temperature changes was as large as that due to live loading. Most previous studies of thermal loading on integral abutment bridges have concentrated on the reaction of the abutment-soil-pile system rather than on the bridge superstructure. The impact of changing thermal conditions will have on the overall bridge performance needs to be studied. Additional stresses placed upon the structure could increase the stress of the bridge girders to critical levels and lead to instability of the bridge as well as increasing stresses in the bridge deck to a level that may further contribute to deck cracking, which will significantly affect the durability of the bridge.

An instrumentation system was developed by Dr. Samir Shoukry and his research team designed to measure the temperature induced response of an in-service integral abutment bridge (Shoukry et al., 2005). The Evansville Bridge is a continuous three-span integral abutment bridge located along WV Route 92 in Preston County, West Virginia. The data recorded by this instrumentation gives thorough insight into the effect that seasonal as well as daily temperature changes will have on an integral abutment bridge.

\subsection{Research Objectives}

The main objective of this study is to investigate the effect that changing thermal loading conditions will have on an integral abutment bridge and determine if these effects are 
significant enough to consider including temperature loading during the bridge design. To achieve these means, the following objective must be satisfied:

1. Develop a detailed 3D-FE bridge model that accurately simulates the behavior of the Evansville Bridge when compared to the data gathered from the aforementioned instrumentation system.

a. The model shall include a method for modeling the deck-girder interface so that the stiffness can be varied to match in-service conditions.

b. A technique will be developed to accurately simulate the non-linear response of the soil to the movement of the abutments and piles.

c. The loading sequence on the bridge must simulate the actual sequence of bridge construction to optimize the output of the model.

2. Investigate the effect of the soil backfill on the condition of the girders.

3. Compare the magnitude of the temperature induced stresses in the girder to the stresses caused by dead-weight and live loading.

4. Determine if the addition of thermal loading to design loading conditions will affect the stability of the bridge girders.

5. Explore the stress levels in the reinforced concrete bridge deck under dead weight, vehicle, and temperature loading in an attempt to locate the areas of the deck susceptible to cracking.

\subsection{Thesis Outline}

The methodology followed during this research is described by the work presented in the subsequent chapters and is outlined as follows: 
Chapter two includes a thorough literature review on the different approaches and software packages used in creating FE bridge models along with the myriad of analysis done with the models. Of particular interest was the modeling of integral abutment bridges as well as how to simulate the soil effects on the bridge. This section served to identify the state-of-the-art in an attempt to make improvements on the current techniques.

Chapter three provides a detailed description of the FE bridge model created for this study. This includes a description of the structural idealization, boundary conditions, material models, loading conditions, and soil-structure interaction.

In chapter four, the instrumentation system placed on the Evansville Bridge is presented along with the data acquisition system implemented to retrieve and store the data from the sensors.

Chapter five presents the validation of the FE model through comparison with experimental data measured by the instrumentation system. The longitudinal girder strains under both gravity and temperature loading measured experimentally and by the FE analysis are used for validation and exhibit an excellent agreement. Additionally, 3DFE computed longitudinal strains match well with experimental recorded longitudinal strains under only temperature loading. The outstanding agreement between the two sets of values indicates the validity of the finite element model in predicting the response of the Evansville Bridge.

Chapter six investigates the effects of changing thermal conditions on the Evansville Bridge. This investigation is performed using the output from the instrumentation on the bridge as well as the results from the FE model. Uniform temperature and gravity loading are applied to the FE model. The results conclude that, contrary to design assumptions, the integral abutment design does not allow the bridge to expand and contract freely under temperature loads and this will lead to additional stresses in the 
structure. Also, the stress levels in the bridge deck are high enough from constrained drying shrinkage as well as thermal loads to cause cracking at several locations.

In chapter seven, AASHTO (2002) HS20-44 standard truck loading is added to the gravity and temperature loads already in place on the FE model in an effort to determine the stability of the structure. The mode of buckling of the girder is identified and is used to check the AASHTO stability and yield requirements for the bridge under the current loading. Although the girders satisfy the stability and yield requirements, the study shows that the magnitude of stresses caused by constraining the structure from expansion under temperature loading are comparable to those caused by gravity and vehicle loading. Stress levels in the bridge deck indicate that concrete cracking is very likely under vehicle loading during the winter months.

Chapter eight presents the conclusions and recommendations that are derived from this study. 


\section{CHAPTER TWO \\ LITERATURE REVIEW}

\subsection{Introduction}

The most widely used numerical analysis technique in engineering analysis is the finite element method. The finite element method can be used over a broad range of engineering applications, from the analysis of the specific part of a structure to the analysis of the entire structure. The analysis of full scale bridges is one area where the finite element method becomes a very useful tool. The finite element method can be applied to bridges in numerous different ways such as determining the overall deterioration of the structure, checking the structures adherence to design guidelines and specifications, determining the overall dynamic characteristics of the structure, as well as many others. It is in the idealization phase of the analysis, the selection of the finite element models, that the greatest differences in approaches are encountered (Tarhini and Frederick, 1992).

The literature review in the following pages will present different finite element software used to model bridges, ways that have been used to idealize the individual parts of a bridge when doing a FE analysis, and some of the various characteristics of bridges that are studied using FEM.

\subsection{FE studies of Load Distribution Factors}

Tarhini and Frederick (1992) presented a wheel load distribution study using 3-D finite models subjected to static wheel loading to try and better understand the structural behavior of the bridges as well as improve the design efficiency. The authors wanted to investigate how the span length and girder spacing affected the distribution factor when using the AASHTO H20 train test. The typical bridge type of concrete deck placed on steel I-girders was selected for study. 
The concrete superstructure was idealized as isotropic, 8 -node brick elements having 3 degrees of freedom at each node. The original model assumed composite action between the deck and girders, but three linear springs were also introduced at the interface nodes of the deck and girder with appropriate spring constant values which modeled noncomposite action between the deck and girder. It was interesting to note that although the presence of composite action had negligible effect on the wheel load distribution factors, the displacement increased by $100 \%$ when non-composite action was introduced.

The model created by Tarhini and Frederick allowed a load distribution formula to be produced that favorably matched the already published research and results, thus concluding that this type of model is satisfactory for static loading tests on concrete deck on steel girder bridges.

Mabsout et al. (1997) compared the performance of four different finite element techniques, which will be discussed in the following paragraphs, in evaluating the wheel load distribution factor in steel girder bridges. The bridge to be studied is a typical one span, simply supported, composite, two lane bridge superstructure. The two finite element packages ICES-STRUDL II and SAP90 (1992) were used to calculate the wheel load distribution factors of the bridges and then these values were compared with wheel load distribution factors computed using techniques from other studies or standards.

The first modeling technique (case 1) used SAP90 (1992) and was based on research performed by Hays et al. (1986) in which the concrete slab was idealized as a quadrilateral shell element and space frame members represented the steel girders. The centroid of the concrete slab coincided with the centroid of each steel girder. The second type of modeling (case 2) also used the software SAP90 (1992) and was based on research by Imbsen and Nutt (1978). Quadrilateral shell elements were used to represent the concrete slab which was eccentrically connected to the space frame members representing the steel girders. This model was much the same as the first type except rigid links were imposed to apply the eccentricity of the girders with respect to the slab. Research conducted by Brockenbrough (1986) inspired the third case of modeling (case 
3) with which the FE software SAP90 was once again used. This model idealized the concrete deck and girder web as quadrilateral shell elements while the girder flanges were modeled as space frame members and eccentrically connected to the deck using rigid links. Tarahini and Frederick's (1992) research was the basis for the fourth case of FE modeling (case 4) and the model was developed and analyzed using the general computer program ICES-STRUDL II. Isotropic 8-node brick elements idealized the deck and quadrilateral shell elements were used in modeling the girders. Rollers and hinges were used as supports for each of the four modeling cases.

A difference in the calculation of the total bending moment at critical sections when using the FE approach caused an adjustment to be made in the calculation of the wheel load distribution factors. These four FE models all produced distribution factors similar to the National Cooperative Highway Research Program 12-26 (Nutt et al. 1987) values, but all also produced values less than the 1996 AASHTO specifications (AASHTO, 1996). The researchers concluded that modeling case 1 can be used to accurately model the load carrying capacity of steel girder bridges. Mabsout et al. (1997) found that the NCHRP 12-26 distribution factors can be applied to the design and analysis of single and multispan, composite and noncomposite straight steel bridges, while the AASHTO 1996 standards were shown to be conservative compared to NCHRP 12-26 and FE values.

Tarhini et al. (1995) used the same modeling techniques that were used by Mabsout et al. (1997) in predicting the actual behavior of I-girder bridges. The researchers concluded that engineers can model bridge structures, which are typical one-span composite I-girder bridges, using quadrilateral shell elements for the deck and space frame elements for the steel girders. Rigid links between the girder and the deck can be used to account for the eccentricity. Cases 3 and 4 presented earlier could be used for special bridge crosssections to represent the actual geometry, but they require more time to create and input as well as run on the computer.

Mabsout et al. (1998) also investigated the effect of continuity on wheel load distribution factors in bridges using the computer programs ICES STRUDL II and SAP 90 (1992). A 
group of typical 2-span, continuous, composite steel girder bridges with three, four, and five girders of different spacing and total lengths were chosen for analysis. AASHTO HS20 standard truck loading was placed in two locations on the bridge to induce maximum positive and negative bending moment in the bridge.

Two bridge idealizations presented by Mabsout et al. (1997) were again used for modeling the bridge. The software SAP 90 (1992) was used to model the bridge according to case 1 discussed earlier. The external supports were located along the centroid axis and hinges and roller were applied to represent simply supported boundary conditions. Next, ICES STRUDL II was used to model the bridge according to case 4 presented the earlier study.

Both of the FE results calculated the wheel load distribution factor with a reasonable degree of accuracy as compared to the procedures suggested by NCHRP 12-26 (Zoakie et al. 1991) and the standard AASHTO empirical formula (AASHTO, 1996). Compared with the FE results, AASHTO (1996) results are less conservative than NCHRP 12-26 results for short span bridges (up to $60 \mathrm{ft}$.) with a girder spacing of 6 feet, but as the span length and girder spacing increase, NCHRP 12-26 correlates well with the FE results and AASHTO becomes conservative. The results support the use of NCHRP 12-26 with a $5 \%$ reduction factor and AASHTO (1996) standards with a $15 \%$ reduction factor for determining wheel load distribution factors. Just as in the study by Mabsout et al. (1997), it is concluded that either of these two modeling techniques can be used to acquire data that is comparable to the published standards.

Mabsout et al. (2000) also investigated the effect of span length, slab width, and wheel load conditions on simply supported, one-span, reinforced concrete slab bridges. Finite element results were obtained for one-, two-, three-, and four-lane bridges with span lengths varying span lengths. The two loading conditions investigated were design trucks assumed to be traveling in the center of each lane and the design trucks placed close to one edge of the slab with a minimum spacing between them. 
The FEA program SAP90 (1992) was once again used to generate the model. The concrete slabs were modeled using quadrilateral shell elements. The girders of the bridge were not modeled in this study. Simply supported boundary conditions were also simulated in the model.

The average bending moment in the slab calculated using FEA at the critical cross section was compared with the AASHTO empirical bending moment (1996). For one-lane bridges with central and edge loading, AASHTO overestimates FEA results for a $25 \mathrm{ft}$. span, but is in agreement for larger spans. For bridges with more than one lane under edge and central loading, the AASHTO results overestimate the FEA moment for $25 \mathrm{ft}$. spans. Central loading of multispan bridges produces FEA and AASHTO agreement for $35 \mathrm{ft}$. spans. All other testing on multispan bridges shows that AASHTO underestimates the FEA moment.

The effects of many different loading conditions on the stresses in continuous concretesteel spread box girder highway bridges were studied by Samaan et al. (2002). This parametric study consisted of 60 continuous, two-span prototypes in which parameters such as span length, number of spread boxes, number of lanes, and number of cross bracing were varied during analysis. Eleven different loading conditions were applied to each model. Also, five bridges were tested with load tests to verify the results from the finite element model.

The finite element modeling performed in this study was conducted using the finite element software ABAQUS (1998). The concrete deck, steel webs, steel bottom flanges, and end diaphragms were all idealized using 4-node shell elements with six-degrees of freedom at each node. Also, the top steel flanges, cross bracing, and top chords were modeled using 3-D two-node beam elements. The top flanges were connected to the concrete deck in a way that assumes composite action between the two. The bridge supports were modeled with both the vertical and lateral displacements at the lower-end nodes of each web at the two simply supported ends constrained, while all displacements 
were constrained at the lower-end nodes of each web at the hinged pier support in the middle of the bridge.

This finite element model was verified by comparing theoretical results for support reactions, longitudinal strains, and deflections under concentric and eccentric loading with the experimental results gathered from five bridges that were instrumented to measure deflection and strain. The comparison showed favorable matches between experimental and theoretical, so this modeling procedure was applied to the other prototype bridges.

The various loading cases in the parametric study consisted of AASHTO HS20-44 truck loading as well as lane loading. Two different types of loading, full and partial AASHTO truck loading, were used to determine maximum response.

The formulas obtained for several distribution factors by the finite element modeling proved to be reliable and simple to apply. They also agreed with information already available in design codes and their use would lead to more reliable and accurate design.

\subsection{FE Investigation of Bridge Capacity}

Over the past decade, a few bridges have been constructed in Canada that are absent of any internal reinforcement in the deck. Mufti et al. (1993) tested to failure 4 half-scale models of composite steel-free deck bridges subjected to concentrated loads in different positions. The mode of failure as well as the load at which the bridge failed was investigated by the researchers.

These experimental results were later used by Salem et al. (2002) as a means to validate their 3D FE model of a steel-free deck bridge. FE scale models were used to determine the effects of slab thickness, depth of deck slab haunch, strap spacing, strap stiffness, and cross frame spacing on the capacity of the reinforcement free bridge. The authors verified the model against previously obtained experimental results and used it to perform 
a parametric study on the aspects of the new design believed to significantly affect its behavior.

The finite element model proposed in this study idealized the steel girders and the concrete deck slab as four node shell elements with six degrees of freedom per node. For

models that have haunched deck slabs over the steel girders, eight node continuum solid elements with three degrees of freedom per node are used to model the concrete deck. The cross frames, diaphragms, and straps are modeled using beam and truss elements. To account for the missing degrees of freedom between beam-shell elements and solidtruss elements, multipoint constraint equations are introduced. Also, the nonlinearities of the bridge structure are considered in the modeling. The pre-processing, solution, and post-processing of the model is done by the FE package COMOS/M.

The FE analysis found that the thickness of the deck significantly effects the capacity of the steel-free deck system, the haunced deck is generally more effective than a regular flat deck, the failure load significantly decreases with the decrease in strap spacing, and that the strap stiffness has a greater effect on the capacity for strap spacing to girder spacing ratios of less than 0.6. However, FEA also found that the effect of cross-frame distribution on the load capacity is not as significant as strap distribution.

The finite element model proposed in this study was verified against experimental data that was collected by other researchers. Verification analysis was performed that showed the model can predict the failure load and the displacement at failure of the steel-free deck system with considerable accuracy

\subsection{Bridge Design Using the Finite Element Method}

$\mathrm{Fu}$ and $\mathrm{Lu}$ (2003) proposed a method more realistic than the age-old transformed area method for composite bridge design using nonlinear finite element analysis. The FEM idealized the flanges of the steel girders as plate elements and the webs as plane stress elements, and 8 node-isoparametric quadrilateral elements are used for the girders. The 
shear studs were modeled as bar elements which can be seen as 2 independent linear springs with a separate stiffness parallel and perpendicular to the longitudinal axis providing a dimensionless connection between the deck and the girder. The reinforcement within the concrete deck was idealized as a $2 \mathrm{D}$ smeared membrane layer with equivalent thickness modeled by an isoparametric plane stress element. A procedure was presented to model the concrete deck as an isoparametric shell element that considers the nonlinearity of the material.

An analysis was done on a continuous, two span bridge with point loads placed at the middle of each span using both the transformed area method and the proposed finite element method in order to draw a comparison between the two. The deflection results obtained from the proposed finite element method match the experimental results computed by Yam and Chapman (1972) much more closely than the results from the transformed area method. This study demonstrates the superior performance of the FEM and the importance in considering the nonlinearity of the concrete deck.

\subsection{Using Finite Element in Determining Bridge Strength and Stability}

Sharooz et al. (1994) tested a full scale bridge to examine the reliability of non-linear finite element in assessing the strength and stiffness of a three-span reinforced concrete slab bridge which had experimental results obtained from loading the bridge to failure in field testing.

The approximate strength and stiffness of the bridge was determined from nondestructive and destructive tests run on the actual bridge. However, before the destructive testing was performed predictive analyses aimed at establishing strength and stiffness bounds were carried out at the University of Cincinnati (UC) and Delft University of Technology (DUT) in the Netherlands which lead the researchers to investigate other issues.

The non-linear finite element analysis conducted at the University of Cincinnati used the microcomputer based software 3DSCAS (Lee et al. 1991). To preserve continuity, the 
entire slab-pier-abutment system was modeled. The bridge deck was modeled using RC shell elements, the pier and pier caps were modeled using 32, five-spring RC beamcolumn elements, and the concrete leading blocks were idealized by concentrated loads over the areas covered by the blocks. The horizontal movement of the deck was constrained because of the presence of shear keys and the rotational stiffness observed during modal tests was simulated using linear rotational springs.

The software DIANA (van Mier, 1987) was used to conduct the nonlinear finite element analysis at Delft University. This study idealized the deck with 144, eight-node degenerated plate/shell elements. The reinforcement was modeled using an embedded approach with identical interpolation functions for concrete and steel. This case discretized the loading as two live loads on the edges of the two adjacent elements with all of the nodes beneath the live loads constrained to have the same vertical displacement. Only the deck was modeled and not the abutments or piers because they were recognized as having no effect on the failure load in this analysis. The supports at the piers and abutments were assumed to be hinges or rollers.

The analyses conducted at UC and DUT differed from the experimentally obtained results. The study carried out at UC indicated a significant influence of the tensile behavior of concrete in the postcracking range. Both studies showed that a very important aspect of the modeling is the assumed horizontal support conditions which contribute to the level of slab membrane force. The support conditions at the abutments were found to be by far the most significant factor influencing the computed response of the test bridge.

Huria et al. (1993) presented a step-by-step modeling procedure for nonlinear finite element analysis of complete constructed facilities using the microcomputer based software 3DSCAS which was also developed in this study. The analysis of an existing reinforced concrete slab bridge is used to demonstrate the procedure. The FE analysis was used in the prediction of failure modes as well as determining the affects of various modeling parameters on the structural response. 
Only one half of the bridge is modeled and the continuity is represented by elastic springs. The deck was discretized using 66 nine-node RC shell elements. The boundary conditions at the abutments are represented by linear and rotational springs connected to the middle plane of the shell elements. Beam-column elements rigidly connected to the deck support the deck at all nodes along the pier line and represent the pier.

A sensitivity analysis was conducted varying twenty different modeling parameters individually and comparing the computed response to a reference analysis. Of all of the modeling parameters that were varied, the modeling of the boundary conditions was found to be the most critical parameter affecting the bridge response.

The validation of this modeling procedure was conducted by using 3DSCAS to simulate the response of a bridge that was tested to failure by Aktan et al. (1992) because of similar geometric and support characteristics. The comparison with this field experiment confirmed many of the observations presented by the authors regarding nonlinear behavior of RC slab bridges based on nonlinear finite element analysis.

\subsection{FE Models Developed to Predict Global Behavior and Bridge Response}

The objectives of the study conducted by Biggs et al. (2000) were to establish and demonstrate a methodology for analyzing reinforced concrete structures, specifically concrete bridge decks, develop a way to predict stress and strain through the concrete bridge deck thickness, and develop a finite element model that could be used to accurately represent global bridge behavior and predict strains, stresses, and displacements in the deck.

The researchers modeled a three-span continuous bridge with steel girders and a reinforced concrete deck using the software ABAQUS (1998). The parts of the bridge were modeled as follows: reinforced concrete deck as shell and rebar elements, steel girders and parapets as beam elements, diaphragms as truss elements, interactions as 
simple supports or multipoint constraints, and static loading as surface pressure loads. The load that was applied to the deck was the tire loads of a standard AASHTO-type, multiaxle truck with the pressure load representing the five footprints.

Although there was no experimental data available for comparison, by looking at displacement, stress, and strain plots as well as contours, the researchers concluded that ABAQUS (1998) was an effective tool to represent the behavior of a realistic structure and to predict displacements, strains, and stresses while minimizing unnecessary complexities.

Womack et al. (2001) tested a curved steel girder bridge in Salt Lake City, Utah, USA to provide data to validate a computer model. The authors also examined the potential for dynamic testing as a NDE technique, but this will not be reviewed in as it did not deal with the finite element modeling.

The tests performed on the bridge were done so in three phases, with the first phase being the as-is condition of the bridge. The next two phases had "damage" introduced by altering the boundary conditions. Namely, the integral deck and abutments were freed by cutting the concrete in the deck. The third phase involved replacing the bronze bearings at the girder ends with frictionless stainless steel bearings and a neoprene pad and greasing the bearings over the piers.

The static testing that was used to verify the model was performed on the bridge using truck loads and displacements were recorded using LVDT's and strain was recorded using strain gages placed on the bridge.

The model was developed using SAP2000. The linear model used 4 node shell elements to model the girders, stiffeners, diaphragms, and deck. Eight-node block elements were used to model the parapet. The behavior between the deck and upper girder flange is modeled using two node beam elements with high axial stiffness and a flexural stiffness that models the interface between the deck and the girders. 
The boundary conditions were adjusted accordingly within the model to simulate the boundary conditions associated with each of the three separate tests.

The model developed predicted the maximum mid-span deflections within an error of 5\% and the tensile bending strains in the lower flanges to within $20 \%$ accuracy. The authors also noted that the model revealed that removing the diaphragms resulted in up to a $9 \%$ increase in stress on the bottom flanges. The authors finally concluded that this linear model replicated reasonably well the non-linear behavior of the actual bridge.

\subsection{FE Models Verifying Structural Health Monitoring Procedures}

Marzougi et al. (2001) developed a detailed finite element model of a typical highway bridge using the finite element software package LS-DYNA (Hallquist, 1997). The development of this model was aimed at providing an improvement in the ability to use numerical models to verify the effectiveness of approaches for structural health monitoring of highway bridges.

The authors modeled the girders and cross frame members using shell elements while solid elements were used to represent the deck and the wearing surface. The detailed geometry of this model allowed for the significant improvement in the ability to provide accurate response prediction for the bridge.

Because of the nonlinearity present in the structure, selecting the appropriate constitutive material formulation for the bridge's components was important. The wearing surface of the bridge was assumed as a visco-elastic material to account for the time rate dependent behavior. The cross members and girders were idealized using the isotropic piecewise linear elastic-plastic material model.

The loads placed on this model were to imitate moving traffic loads. This was accomplished using concentrated nodal loads along with the appropriate load curves. 
These ambient traffic loading sets were created by Livingston et al. (2001a) specifically for use with this model. Because real-world data sets that represent the random traffic crossing a bridge are rarely available, the researchers developed a stochastic model using the Poisson distributed pulse processes with distributed input parameters to generate continuous time histories of the multi-lane ambient traffic loadings with variable vehicle arrival rates, types, and speeds to be used for this study. The bridge's actual roller and bearing supports were also accurately modeled.

These models were later used by Livingston et al. (2001b) to produce simulated data sets as a result of the aforementioned ambient traffic loading. The response data generated by these simulated tests was analyzed using a chaos theory and then was used to identify chaotic systems, extract the system invariants, and ultimately detect damage in the structure.

The amplitudes and widths of the graph of the simulated response from a set of traffic loading are consistent with the values measured on a $39 \mathrm{~m}$ highway section instrumented by Vorha et al. (1998). This validates the use of the FE model to simulate the actual bridge response.

The FE model proved that a typical highway bridge can indeed have chaotic system behavior. Also, when using the simulated response data from a damaged and undamaged nonlinear model and the Lyapunov spectrum approach discussed in this study, the location of the damage within the structure can be detected.

\subsection{FE Models of Integral Abutment Bridges}

Using the finite element method to model integral abutment bridges presents different problems that must be solved during the idealization stage. Integral abutment bridges are jointless bridges having the deck and the girders rigidly connected to the concrete abutment walls. The piles, which are drilled into the soil and rigidly connected to the abutment walls, provide vertical support for the entire bridge structure. The nonlinear 
reaction of the soil behind the abutment walls and surrounding the piles has a significant effect on the response of the bridge and therefore must be accounted for in the FE model.

\subsubsection{Soil - Abutment Interaction}

Backfill present behind the abutment walls of an integral abutment bridge will continually apply a pressure upon the wall acting perpendicular to the surface. There are standards that are available which can be used to compute the pressure that the soil will exert on the abutment walls for different backfill types at different depths. The pressure expended by the soil can be calculated according to the amount that the abutment has deflected by consulting an $\mathrm{f}-\mathrm{d}$ curve. The most widely recognized $\mathrm{f}-\mathrm{d}$ curves are the NCHRP (1991) design curves which are used by Faraji et al. (2001), Jayaraman et al. (2001), Khodair and Hassistis (2003), Taciroflu et al. (2003), Greimann et al. (1986) and Basu and Knickerbocker (2005) in their studies of integral abutments. The depth below the soil surface, the type of backfill present, and the deflection of the abutment all factor into the formulation of these $f-d$ curves. Researchers implement these nonlinear $f-d$ curves into the properties of a series of nonlinear springs that attach perpendicularly to the abutment walls and exert a pressure representing the pressure exerted by the soil backfill.

\subsubsection{Soil - Pile Interaction}

As the vertical piles of integral abutment bridges encounter transverse loading, bending of the piles will occur. As the piles deflect transversely, the soil surrounding the piles will resist their movement horizontally. However, unlike the abutment walls, if the piles are not displaced then no pressure will be exerted from the soil. This is due to the fact that soil is present on both sides of the vertical piles while it is only present on one side of the abutment. If there is no movement, there will be equal soil compaction on each side of the pile resulting in no net force on the pile. The forces of soil on embedded piles are also represented as force versus deflection curves, or in this case, p-y curves. The oil industry has been known to do the most sophisticated modeling of lateral pile behavior. 
Therefore, Faraji et al. (2001), Jayaraman et al. (2001), Khodair and Hassistis (2003), Taciroglu et al. (2003), Greimann et al. (1986), and Basu and Knickerbocker (2005) base the formulation of the p-y curves used in their research on the standards set by the American Petroleum Institute (1993). Just as with the soil - abutment interaction, these p-y curves are derived into the use of nonlinear springs which are attached perpendicular to the piles and provide resistance equal to that of the appropriate backfill substance.

\subsubsection{Bridge Idealization}

Basu and Knickerbocker (2005) developed a FE bridge model using the software ANSYS (2002) to be used for in depth understanding of the behavior of candidate jointless HPC bridges under different external influences. Different types of beam elements were used to model the steel piles, the precast concrete girders, and the steel cross bracings between girders. The 8-node concrete element SOLID65 was used in modeling the abutments, wingwalls, backwalls, diaphragms, pier, and deck. Complete composite action was assumed between the deck and the girder and was modeled as rigid links between the two.

Jayaraman et al. (2001) studied the lateral loading of vertical piles within an integral abutment bridge system. The piles are modeled as elastic beam column elements while the soil is represented by a series of uncoupled 'Winkler' springs using the nonlinear p-y curves. The pile response curves are obtained using commercial software such as LPILE (Reese, 1993) and COM624P (Wang and Reese, 1993). The nonlinear spring supports are then modeled using FE software packages such as GTSTRUDL (1991), SAP200NL (2001), and STAAD Pro.

Pile-soil interaction and piling stresses in an integral abutment bridge system were studied by Greimann et al. (1986). The researchers used beam-column elements to model the piles accounting for the geometric and material nonlinearities of the piles. Once again, a series of nonlinear springs were used to represent the soil backfill. The spring system included vertical springs, lateral springs, and point springs at the tips of the 
piles. The nonlinear curves used in determining the spring stiffness were the p-y (pressure versus lateral displacement) curves, f-z (skin friction versus relative vertical displacement) curves, and the $\mathrm{q}-\mathrm{z}$ (bearing stress at the pile tip versus pile tip settlement) curves. Two computer programs, IAB2D and IAB3D, were developed to solve two and three dimensional pile-soil interaction problems and were proven efficient by solving example cases of experimental bridges.

Taciroglu et al. (2003) performed a study which developed one-dimensional interaction elements to simulate soil response under cyclic loading of a soil-pile system. This one dimensional system consists of a drag element which models the frictional forces along the side of the pile, a gap element which models the behavior of gaps that occur between the soil and pile, and an elastoplastic p-y element that models the lateral force exerted by the soil for a lateral pile deflection.

Khodair and Hassiotis (2003) also performed research that used nonlinear finite element modeling to study the stresses in piles and the pile soil interaction of an integral abutment bridge in Trenton, New Jersey. The bridge was instrumented during construction and the temperature-induced lateral displacements were applied to the piles in the FE analysis. For this study, each pile is modeled using over 3000 eight-nodded continuum solid elements using ABAQUS/Standard (1998) with the boundary conditions on top of the pile ensuring rigid translation. Also, the non-linear response of the soil was modeled using over 7000 continuum solid elements. The FE results for lateral loading favorably match the finite difference results obtained from LPILE (Reese, 1993). The finite element results for the pile bending stresses compare favorable with the LPILE and experimental results.

The study by Faraji et al. (2001) uses the FE software GTSTRUDL (1991) to create a full scale model of an integral abutment bridge with specific emphasis on the soil-abutment interaction subjected to a uniform temperature loading. The bridge deck is modeled using bending and stretching plate elements and the girders and diaphragms are modeled as beam elements. The pier caps and concrete columns at the piers were also modeled 
using beam elements. The abutment walls are modeled as plate elements while the piles are modeled as beams rigidly connected to the abutments. The soil reaction behind both the abutment walls and piles is modeled using uncoupled nonlinear springs. The structure was analyzed using four different soil conditions behind the abutment and piles: loose/dense, loose/loose, dense/loose, and dense/dense. A thermal loading increment of $\Delta \mathrm{T}=44^{\circ} \mathrm{C}$ was applied to the structure to study the effect of different backfill densities on the response of the bridge.

Horvath (2002) studied the efficiency of using different materials or combinations of different materials as backfill for a standard integral abutment bridge when subjected to temperature change. The model created by Horvath used the computer software SSTIPNH ${ }^{\mathrm{TM}}$, which is a version of SSTIPN developed by the author. The stiffness of the backfill behind the abutment was modeled using linear springs as opposed to nonlinear springs which are most widely used for this modeling. Interfaces were only particularly modeled where it was important to account for inter-material slippage. The superstructure was modeled using bar elements in $\mathrm{SSTIPNH}^{\mathrm{TM}}$ which are linear elastic springs having stiffness equivalent to longitudinal stiffness of the entire structure to thermal-induced length change. 


\section{CHAPTER THREE}

\section{FINITE ELEMENT MODEL OF EVANSVILLE BRIDGE}

\subsection{Introduction}

This chapter describes a three-dimensional finite element model created using the software package ADINA (Bathe, 2002) to investigate the behavior of the three span section of a skew, integral abutment bridge constructed in Evansville, WV. This bridge carries WV Route 92 over the Little Sandy Creek in Preston County, West Virginia. Three of the bridges seven girders are modeled representing the section of the bridge that was instrumented by Dr. Samir Shoukry and his research team in the summer of 2003. The models basic feature is the detail with which the structure is modeled in order to compare FE results with the actual results of the sensors placed throughout the bridge, and the main objective is to investigate the effects of changing temperature on the behavior of the structure. This includes step-by-step modeling of the construction sequence of the actual bridge. Material models, boundary conditions, material loading, soil-abutment interaction, soil-pile interaction, contact interfaces, and loading conditions are presented. The results from thermal loading ranging from $-20^{\circ} \mathrm{C}$ to $+20^{\circ} \mathrm{C}$ on the finite element model match very favorable with the results obtained from the instrumentation.

\subsection{Bridge Structural Model}

As was mentioned previously, only three girders and the corresponding deck of the Evansville Bridge were modeled in this study. The section modeled represents the lane that carries traffic on WV 92 in the southbound direction. The reason that only three girders were modeled is threefold. First, half of the bridge will accurately represent the behavior of the entire bridge since it contains a full traffic lane. Second, this three girder wide section was constructed prior to the construction of the northbound lane and 


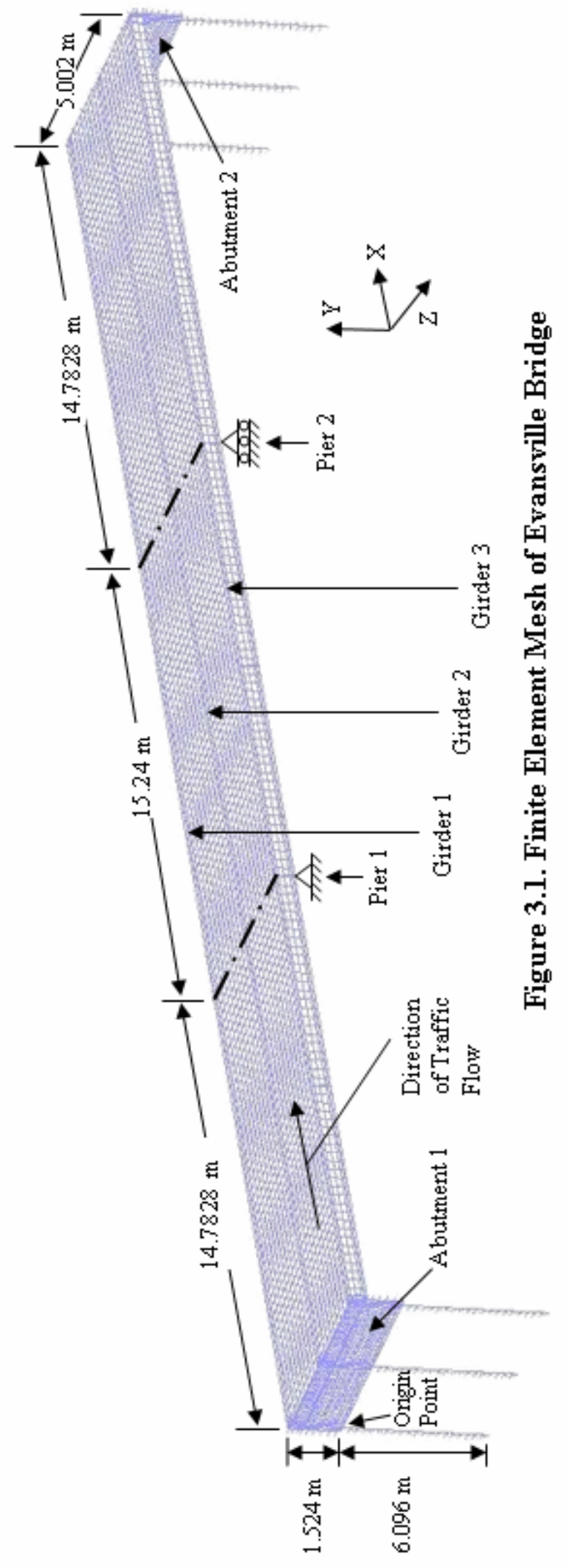


remained the only section of the bridge carrying traffic for the first 8-9 months of the bridges life. Third, all of the instrumentation that was placed on the bridge was placed in this section during the first stage of construction. A schematic of the FE model can be seen in Figure 3.1.

Four node shell elements were chosen in modeling a majority of the structure to ease the modeling process as well as shorten the computational time of the model. The $44.81 \mathrm{~m}$ (147 ft.) long girders, along with the stiffeners present along their length, are modeled using shell elements. Shell elements are also used to model the $44.81 \mathrm{~m}$ (147 ft.) long, $5.00 \mathrm{~m}$ (16.41 ft.) wide, and $0.203 \mathrm{~m}(8 \mathrm{in}$.) thick section of the bridge deck that is supported by the three girders. The abutment walls, with a height of $1.52 \mathrm{~m}(5 \mathrm{ft}$.$) , a$

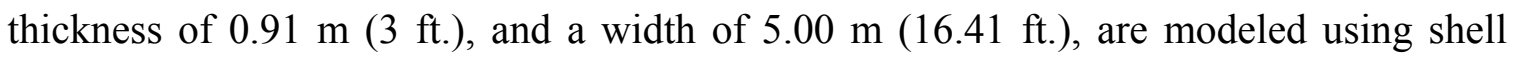
elements as well. Finally, the cross members which are present between the girders at both pier 1 and pier 2 must be modeled using four node shell elements because the Ibeam sections possess stiffeners along their length which does not allow them to be modeled using beam elements. A total of 8,818 shell elements are present in the model.

The remaining parts of the physical bridge structure are modeled using Hermitian beam elements. An attractive feature in using beam elements is that the user can specify the cross section of the member and set this cross section as a property of the beam. This greatly reduces the time involved in modeling as well as the computational time. Cross members not located at the piers on the bridge are C-channel members specified as $\mathrm{C} 15 \mathrm{x}$ 33.9 and are modeled as beam elements. Also, the vertical piles, which are $6.10 \mathrm{~m}(20$ $\mathrm{ft}$.) long I-beams with their weak axis aligned parallel to the abutment wall and cross section defined as $\mathrm{H} 12$ × 53, are modeled using beam elements. The model has 126 total beam elements.

Selecting the element size used to model different bridge components is done in a manner that minimizes computing time, simplifies model creating, and accurately models bridge response. The size of the elements making up the bridge deck is set to $0.0641 \mathrm{~m}^{2}$ which 
allows all of the instrumentation at each location to be represented by one element. The elements making up the girder flanges have a longitudinal length of $0.305 \mathrm{~m}$ and a width of $0.127 \mathrm{~m}$ (area of $0.0387 \mathrm{~m}^{2}$ ). The longitudinal size was varied between $0.305 \mathrm{~m}$ and $0.1524 \mathrm{~m}$ and the difference in the readings were negligible, so the larger elements were used to expedite the solving of the model. Since the response of the girder web is not of paramount importance for this study, the element sizes representing the web were chosen as large as possible which would still allow proper cross - bracing connections. The top and bottom layer of web elements have an area of $0.031 \mathrm{~m}^{2}$, while the middle elements have an area of $0.0724 \mathrm{~m}^{2}$. The element sizes of the abutment walls vary greatly and are chosen in order to line nodes up to create the appropriate connections with the girder ends and the vertical piles. The vertical piles are modeled in $0.305 \mathrm{~m}$ sections so that the calculation of the soil - pile response is not too tedious.

Finally, spring elements are used throughout the model to create interfaces between different materials. Nonlinear spring elements are used to represent the reaction of the soil behind both the abutment walls and around the vertical piles. The formulation of these spring elements and their nonlinear stiffness will be discussed further later in this chapter. Normally, in bridge construction, full composite action is assumed between the top flange of the girders and the bottom of the bridge deck. However, from the readings gathered from the instrumentation on the Evansville Bridge, it is believed that full composite action is not present along the full length of the bridge. For this reason, the connection between the girders and the deck is modeled using spring elements allowing the stiffness to vary in an attempt to model partial composite action. This too will be discussed in a later chapter. In total, 16,488 spring elements are implemented in this model.

\subsection{Material Model}

The modeling of material properties for steel is simplified for this study because general properties will be sufficient for the encountered loading conditions. However, the material properties used in the FE model for the deck concrete are presented in the report 
by Shoukry et al. (2005) and determined by performing strength tests on concrete cylinders gathered from the actual concrete used for deck casting. The only two materials modeled in this study, concrete and steel, are modeled as elastic isotropic materials. Elastic isotropic materials are adequate for this study because the loading conditions will likely not place the structure in a critical state and the temperature loading is in the range of $-20^{\circ} \mathrm{C}$ to $+20^{\circ} \mathrm{C}$, a range within which the material properties will not be sensitive to temperature (William, 2003). Table 3.1 gives all of the material properties for concrete and steel which are required for input into the ADINA model.

Table 3.1. Material Properties used in FE model

\begin{tabular}{l|c|c|} 
& Steel & Concrete \\
\hline Modulus of Elasticity (GPa) & 199.995 & 30.23 \\
\hline Poisson's Ratio & 0.3 & 0.24 \\
\hline Density (Kg/m $\left.{ }^{\mathbf{3}}\right)$ & 7750.4 & 2395.7 \\
\hline Coefficient of Thermal Expansion $\left(/{ }^{\circ} \mathbf{C}\right)$ & $1.22 \times 10^{-5}$ & $1.126 \times 10^{-5}$ \\
\hline
\end{tabular}

\subsection{Boundary Conditions}

Choosing the boundary conditions is a very important step in developing a finite element model of a structure such as a bridge. As noticed during the course of this study, the slight alteration of boundary conditions can greatly affect the response of a large structure such as a bridge. In this case, the boundary conditions were chosen to simulate as closely as possible the actual constraints that are present on the structure. The support locations referred to in this section can be seen in Figure 3.1.

The modeling of the concrete piers was omitted for this study because it was deemed that their modeling was unnecessary in this case and their effects would be negligible under the desired loading conditions. At pier 1, the girders are connected to the concrete pier by a pinned support. To model this pinned support, all rotational and translational degrees of freedom at the locations corresponding to the position of contact between the 
bottom flange of the girder and the pier were constrained. However, the connection between the girders and the pier at pier 2 was not fully constrained. From the bridge plans, it is seen that at pier 2 the girders are able to translate slightly in the longitudinal direction ( $\mathrm{X}$ direction in Figure 3.1) and rotate about the transverse axis ( $\mathrm{Z}$ direction in Figure 3.1). Therefore, on the bottom flange of the girders at the point of contact with pier 2, x-translation and z-rotation degrees of freedom are left free while all other degrees of freedom are fixed. Although the girders at pier 2 do not have infinite freedom in these free directions on the actual bridge as has been modeled for this study, the movement at this location is small enough that the simulated translations and rotations will not exceed the limits of the actual values on the bridge.

The support for the bridge at the two abutments comes from the vertical piles, the concrete abutment walls, and the soil backfill. The vertical piles are driven into the ground and then rigidly connected to the concrete abutment walls when the concrete is cast around the top of these piles. All degrees of freedom for the bottom of the steel piles are assumed to be fixed for this study. The support provided in the longitudinal and transverse directions by the surrounding soil is represented by nonlinear spring elements.

\subsection{Soil - Abutment Interaction}

Integral abutment bridges (IAB's) differ from simply supported bridges in that the abutments do not have expansion joints present that will allow the structure to expand and contract without resistance. Instead, the girders of IAB's are rigidly connected to the concrete abutment walls with soil backfill providing constant pressure on the abutments. This force is nonlinear in nature and can be classified as active, passive, or at-rest. An extensive literature review was conducted which revealed that the most accurate way to model the behavior of the soil backfill is by using a set of nonlinear springs known as a "Winkler" model. The literature review also concluded that the most widely used standards for computing the response curves of the soil backfill come from design manuals such as Clough and Duncan (1971), NCHRP (1991), and Husain and Bagnariol (1996) which are all based on the finite element analysis by Clough and Duncan (1971). 
For this study, the process outlined in NCHRP (1991) was used in modeling the nonlinear response of the soil backfill.

The nonlinear behavior of the springs representing the soil is modeled by defining the spring stiffness with a nonlinear force versus deflection curve ( $\mathrm{f}-\mathrm{d}$ curve). The amount and direction of the abutment wall deflection will determine the amount of force exerted back on the wall by the backfill. When the abutment translation or rotation is in the direction of the backfill, the backfill will be in the passive pressure state. Conversely, when the abutment moves away from the soil, the backfill will be in the active pressure state. In the instance that the abutment is not moving, the pressure will be in the at-rest state. Naturally, the passive pressure applied by the backfill will be significantly greater than the active pressure under equal deflection in the opposite direction.

According to NCHRP (1991), the Rankine Theory can be used for calculating active and passive earth pressures on retaining walls when the wall friction angle is equal to the slope of the backfill surface, which is true in this case because the back of the abutment is vertical. First of all, when creating an f-d curve for soil force on a retaining wall, the type of soil behind the abutment wall must be known. In this study, the soil backfill is of type medium dense sand with an internal friction angle of $\varphi_{\mathrm{f}}=36^{\circ}$. Next, the approximate displacements required to reach minimum active and maximum passive earth pressure must be determined. For medium dense soil, the values are obtained from Clough and Duncan (1971) to be

Table 3.2. Minimum active and maximum passive earth pressures

\begin{tabular}{lcc}
\hline & Active & Passive \\
\hline $\boldsymbol{\Delta} / \mathbf{H}$ & 0.002 & 0.02 \\
\hline
\end{tabular}

where $\Delta$ is the movement of the top of the wall required to reach minimum or maximum pressure state and $\mathrm{H}$ is the height of the wall.

Now the coefficient of at-rest earth pressure, $K_{\boldsymbol{o}}$, is calculated according to the equation 


$$
K_{o}=1-\sin \phi_{f}
$$

which is the value for the coefficient of lateral earth pressure when there is no wall deflection. The value for $K$ at the minimum active earth pressure, $K_{a}$, is calculated from the equation

$$
K_{a}=\frac{1-\sin \phi_{f}}{1+\sin \phi_{f}}
$$

while the value for the maximum passive pressure, $K_{p}$, is determined using

$$
K_{p}=\frac{1+\sin \phi_{f}}{1-\sin \phi_{f}}
$$

These three values are used in a MATLAB (Mathworks, 2004) program to create a graph and a function value to calculate the coefficient of earth pressure at any state. The graph contains $\Delta / H$ values versus $K$ values. It should be noted that for any values of $\Delta / H$ beyond the values required to reach minimum active and maximum passive pressure the value for $K$ will not increase beyond $K_{a}$ and $K_{p}$ respectively. Figure 3.2 shows an example of the graph of the relationship between the wall movement and earth pressure coefficient used in this study.

The values for $K$ interpolated using this process are used to determine the passive and active earth pressures exerted on the abutment walls using the equations:

$$
\begin{aligned}
& p_{a}=K_{a} z \gamma \\
& p_{p}=K_{p} z \gamma
\end{aligned}
$$




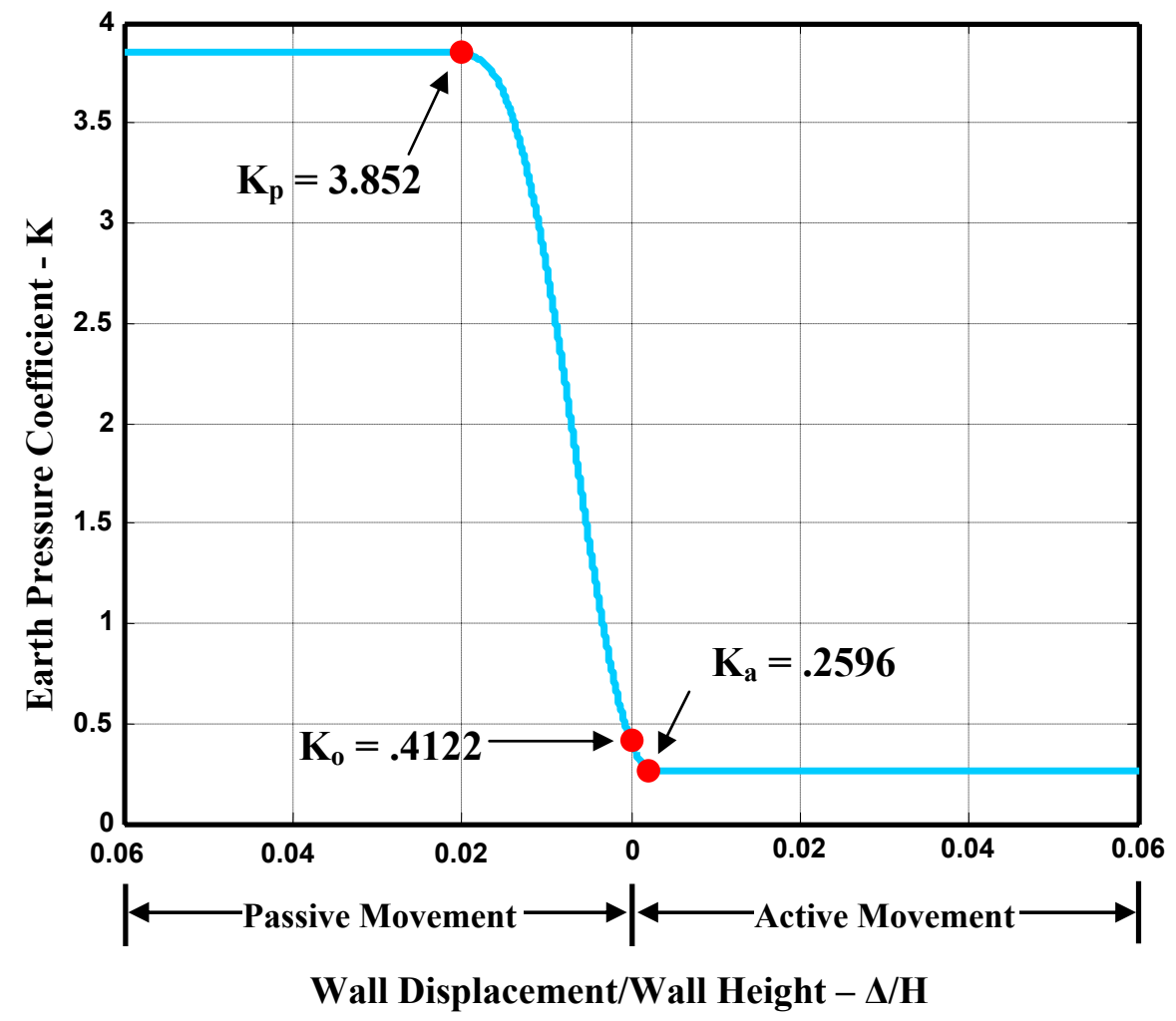

Figure 3.2. Relationship between abutment movement and earth pressure coefficient

where $\gamma$ is the unit weight of the soil (force/length ${ }^{3}$ ) and $\mathrm{z}$ is the depth below the soil (length). For medium dense sand, the value for $\gamma$ is $17.62 \mathrm{kN} / \mathrm{m}^{3}$. However, since ADINA requires a force vs. deflection curve for specifying the nonlinear spring stiffness, this pressure must be multiplied by the area of the element the spring in question is acting upon; thus, the equations become:

$$
\begin{aligned}
& F_{a}=K_{a} \gamma A z \\
& F_{p}=K_{p} \gamma A z
\end{aligned}
$$

where $A$ is the area $\left(\right.$ length $^{2}$ ) of the element being acted upon by the spring element. 


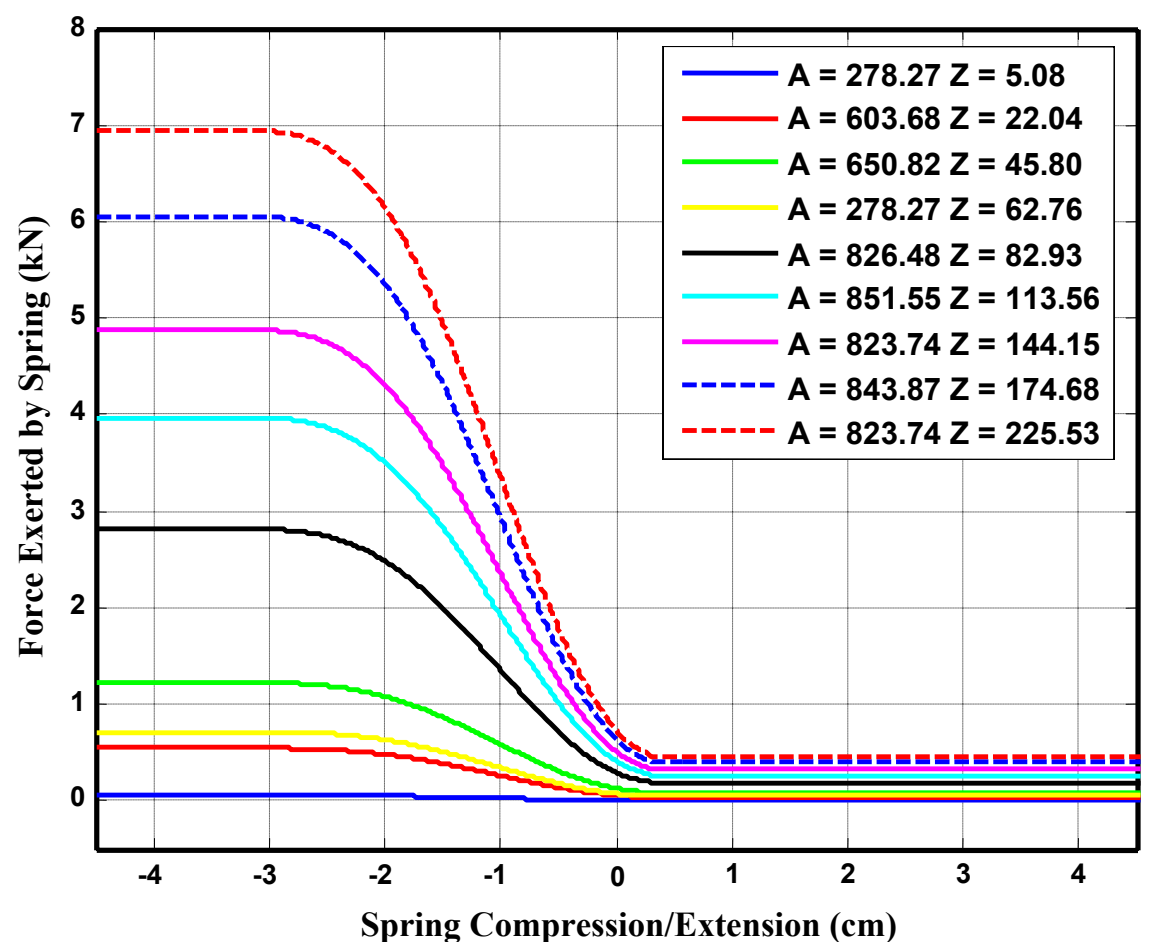

(a) Element width $15.5 \mathrm{~cm}$

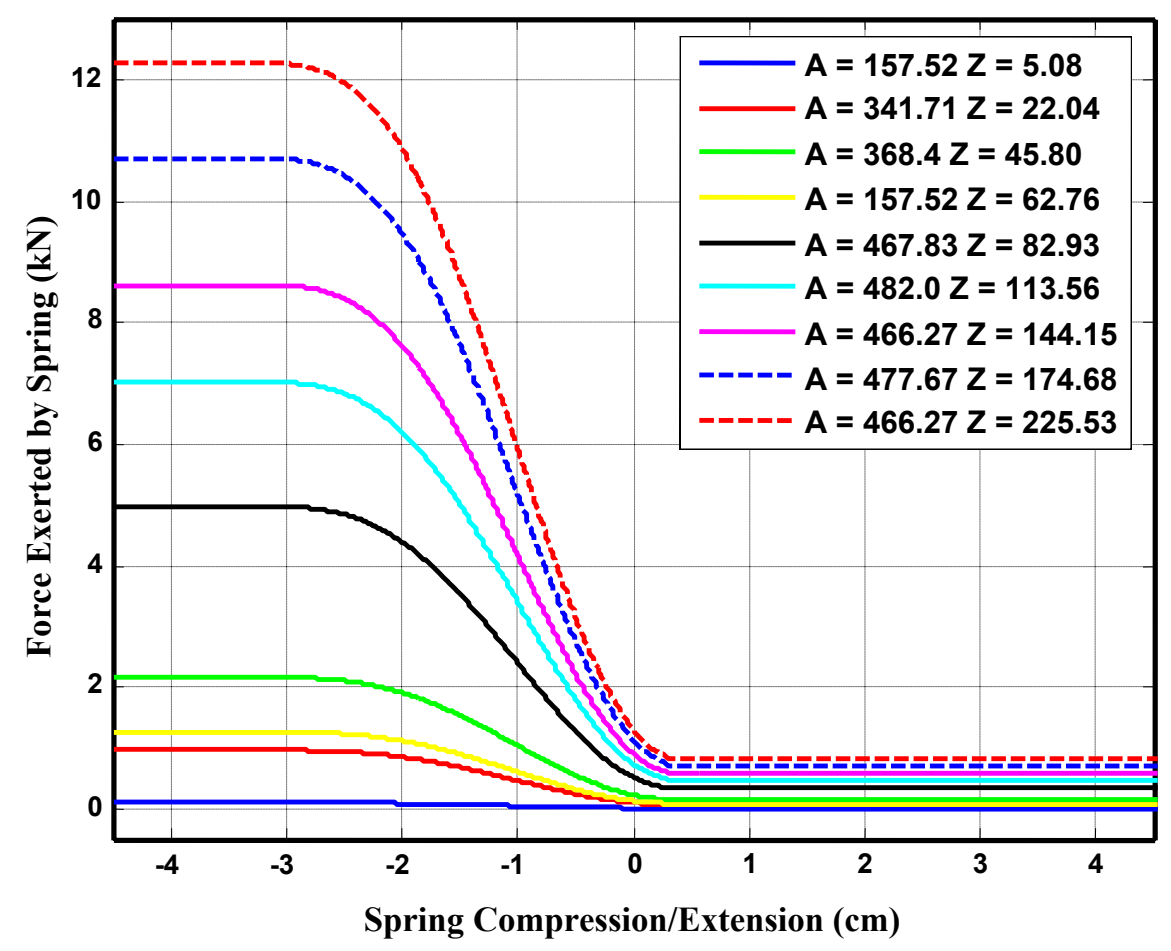

(a) Element width $67.57 \mathrm{~cm}$

Figure 3.3. F-d curves for nonlinear spring elements representing soil-abutment interaction 
Since the value for $K$ is dependent on the wall displacement, the force value will vary with the movement of the wall. For the spring - abutment system employed in this study, a negative spring displacement corresponds to passive earth pressure while a positive displacement corresponds to active earth pressure. The force-deflection curves are calculated for different sized elements at different depths along the abutment wall using a program written in MATLAB. The force deflection curves for springs acting upon different sized elements at different depths can be seen in Figure 3.3 where $A\left(\mathrm{~cm}^{2}\right)$ is the area of the element and $Z(\mathrm{~cm})$ is the depth from the top of the soil.

Finally, nonlinear springs are also attached to the sides of the abutments to model the soil resistance in the transverse direction. The transverse movement of the abutments becomes significant under ambient temperature loading due to the skewed nature of the structure. Figure 3.4 shows an example some of the nonlinear springs connected to abutment 1 in the FE model.

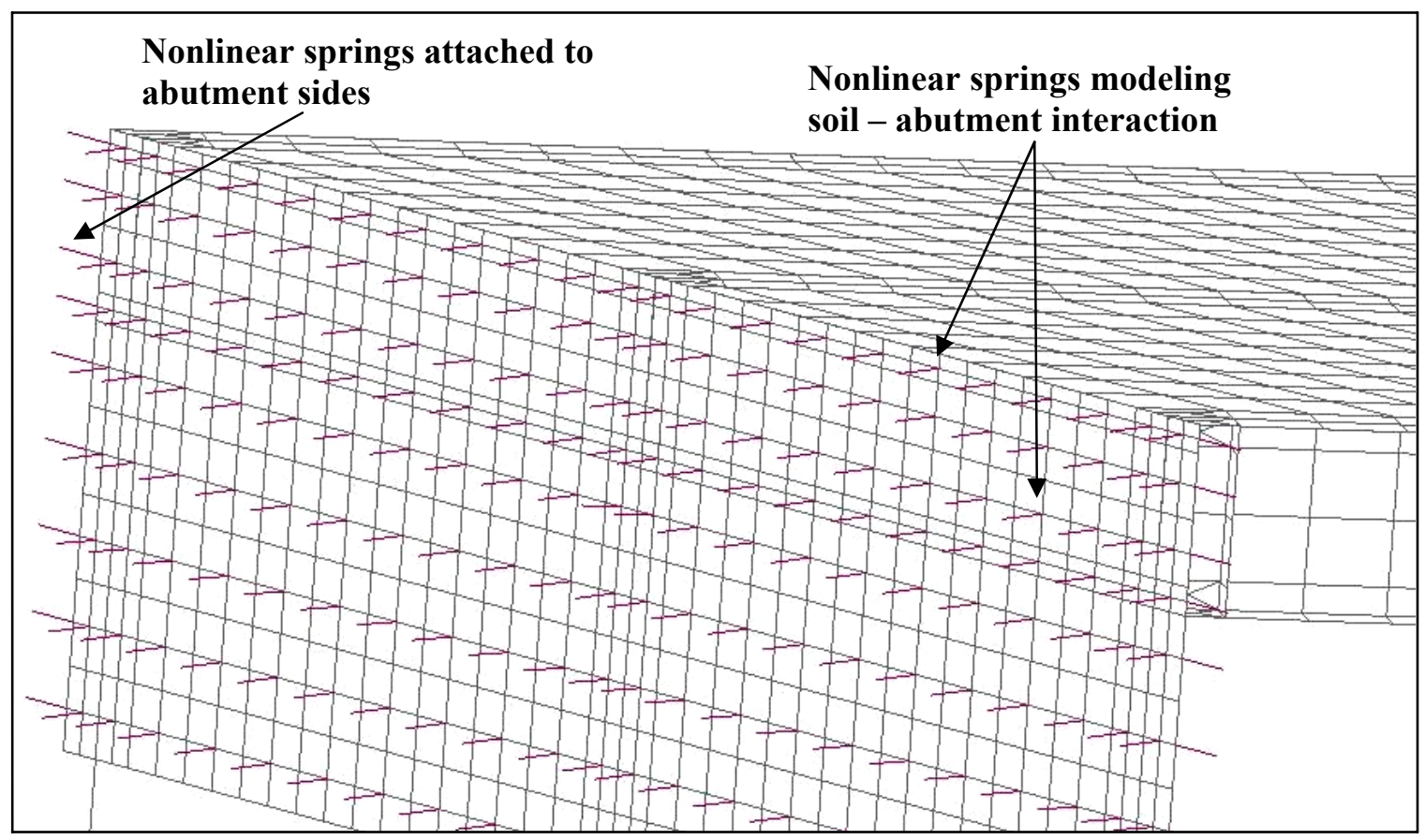

Figure 3.4. Example of nonlinear springs attached to abutments 


\subsection{Soil - Pile Interaction}

Loading effects on an integral abutment bridge causing volumetric changes in the superstructure will result in horizontal forces on the substructure. As the volume of the superstructure changes due to loading such as temperature loading, the piles used in the abutment foundations will be laterally loaded at the base of the abutment. Due to the skewed nature of the Evansville Bridge, under volumetric changes the piles will be loaded not only in the longitudinal but transverse directions. The response of the piles to these loading conditions depends on the stiffness of the piles as well as the stiffness of the surrounding soil along with the boundary and fixity conditions of the piles.

The soil response surrounding the piles is modeled in a similar way to the soil response behind the abutments. A major difference is the fact that the piles are surrounded by soil on all sides so there are no active or passive states of response. The approach of using py curves based on a Winkler model using nonlinear springs to represent the lateral soil structure is widely used. The approach has been characterized by the American Petroleum Institute (1993) and is outlined in Basu and Knickerbocker (2005).

The first step is to select the smaller of the two values $p_{u d}$ and $p_{u s}$ given by Equations 3.8 and 3.9 and setting this equal to $p_{u}$, which is the ultimate bearing capacity (force/length).

$$
\begin{aligned}
& p_{u d}=\left(C_{1} X+C_{2} D\right) \gamma^{\prime} X \\
& p_{u s}=C_{3} D \gamma^{\prime} X
\end{aligned}
$$

where $p_{u s}$ is ultimate bearing capacity for shallow foundations, $p_{u d}$ is ultimate bearing capacity for deep foundations, $\gamma^{\prime}$ is the effective soil weight (mass/length ${ }^{3}$ ), $X$ is the depth, $D$ is average pile diameter along the length, and $C_{1}, C_{2}$, and $C_{3}$ are coefficients determined by equations developed by Basu and Knickerbocker (2005) as functions of $\phi^{\prime}$, the angle of internal friction in sand. The equations for the $C$ coefficients are: 


$$
\begin{aligned}
& C_{1}=0.1239 e^{0.0911 \phi^{\prime}} \\
& C_{2}=0.5885 e^{0.0503 \phi^{\prime}} \\
& C_{3}=0.6622 e^{0.1256 \phi^{\prime}}
\end{aligned}
$$

Another parameter, the initial modulus of subgrade reaction $(k)$, which is dependent upon the value for the effective soil weight, can be approximated using the equation by Basu and Knickerbocker (2005):

$$
k=22.889 \phi^{\prime}-649.24
$$

Also, the parameter $A$, which varies according to the depth within the soil, is used in calculating the effective soil pressure. This parameter has different values for cyclic and static loading. The value for cyclic loading is assumed to be 0.9. However, since this study does not involve cyclic loading, $A$ is determined from the expression

$$
A=3.0-0.8 \frac{X}{D} \geq 0.9
$$

which shows that the value for $A$ for static loading will not be below the value of 0.9 for cyclic loading.

Finally, the design curve at any given soil depth, $z$, recommended by the API (1993) is the hyperbolic tangent curve

$$
p=A p_{u} \tanh \left[\frac{k z}{A p_{u}} y\right]
$$

where $y$ is the lateral deflection of the soil. From the above Equations 3.8-3.15 it is shown that the pressure exerted by the soil on driven piles is dependent upon the effective soil weight $\gamma^{\prime}$, the angle of internal friction $\phi^{\prime}$, and the depth below the soil surface, $z$. 
Since the piles are modeled using one-dimensional beam elements, the value for $p$ must be multiplied by the length of the respective element to convert this value to force so it will be in the correct form to be input into ADINA.

The $6.10 \mathrm{~m}$ ( $20 \mathrm{ft}$.) long piles of the bridge are modeled using 20 beam elements of length $0.305 \mathrm{~m}$ ( $1 \mathrm{ft}$.) each. Therefore, there are 20 nonlinear spring elements attached evenly spaced along the length of each pile every $0.305 \mathrm{~m}(1 \mathrm{ft}$.) both parallel and perpendicular to the direction of the piles strong axis. This spring orientation requires that when the springs have a negative deflection, the resulting spring force will be positive and vice versa.

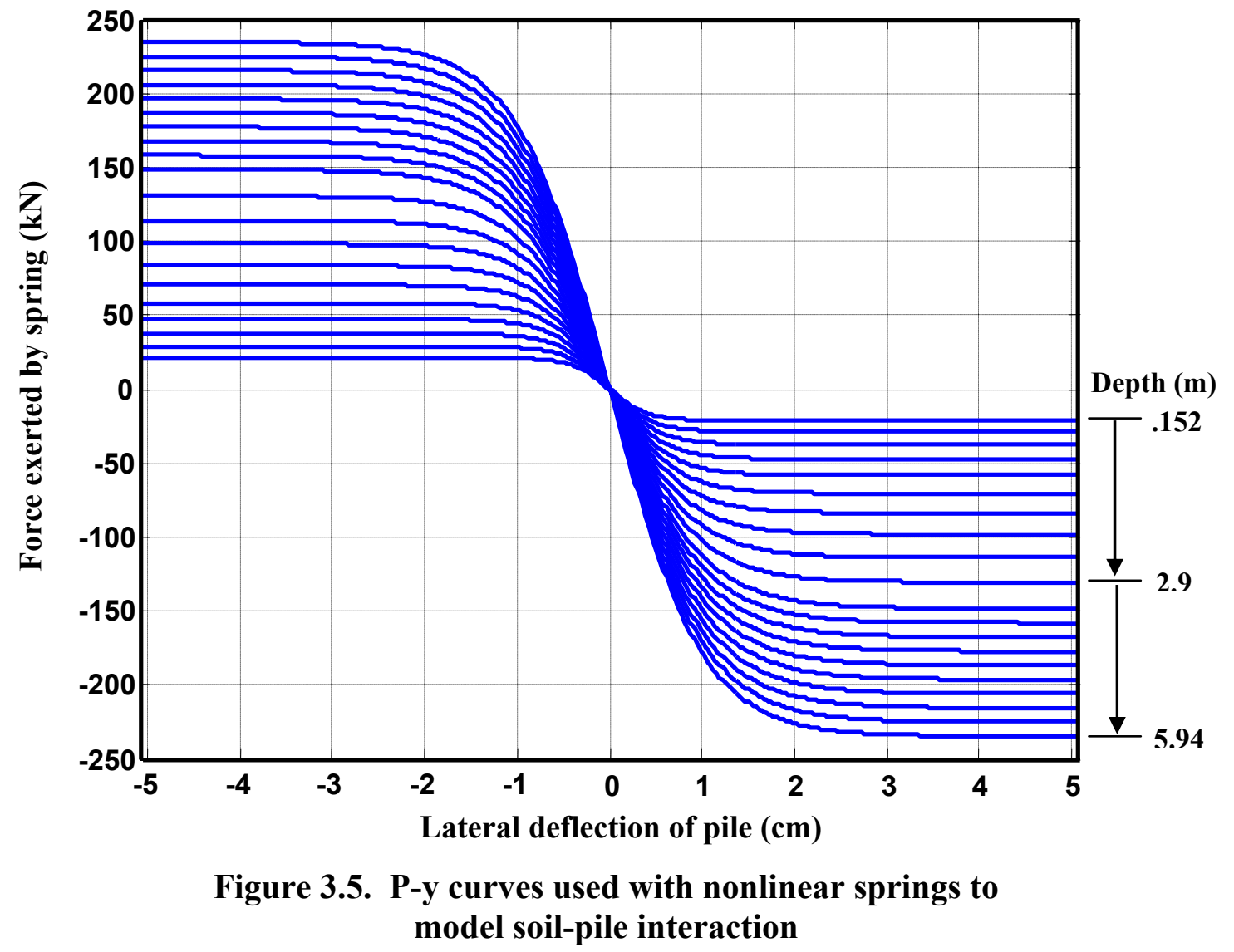

Using the equations provided above and the generalization that the soil type surrounding the piles is a medium dense sand with $\gamma^{\prime}=913.25 \mathrm{~kg} / \mathrm{m}^{3}\left(.03299 \mathrm{lb} / \mathrm{in}^{3}\right)$ and $\phi^{\prime}=36^{\circ}$, a MATLAB program was written to calculate the $p-y$ curves of the springs attached to each 
element along the depth of the piles. The resulting set of curves can be seen in Figure 3.5 and an example of one of the pile - spring systems can be seen in Figure 3.6.

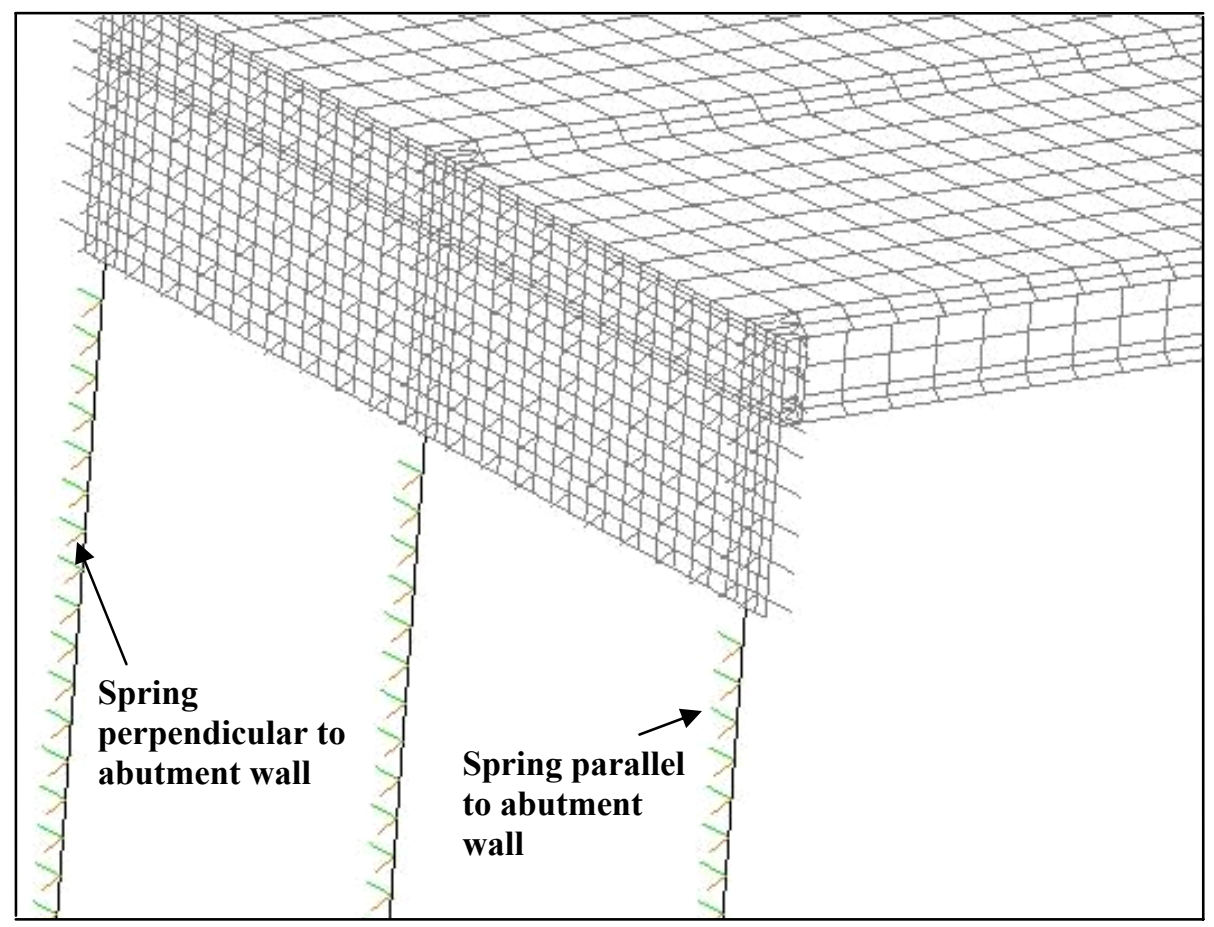

Figure 3.6. Example of nonlinear springs attached to abutment 1

\subsection{Contact Interfaces}

The girders of the Evansville Bridge are equipped with $10.16 \mathrm{~cm}$. (4 in.) steel studs that are attached to and extend upward from their top flanges. Once the concrete deck is poured and has cured, these studs that are incased within the deck are designed to provide complete composite action between the superstructure and the substructure, meaning that the top surface of the girder and the bottom surface of the deck will act as though they are rigidly connected. A structure exhibiting complete composite action between the superstructure and the substructure would provide a linear strain profile when the structure is under pure bending. In the case of full composite action between the girders and the deck, a completely tied interface could be used in FE analysis to model the connection between the two. 
However, from studying the results obtained from the instrumentation on the Evansville Bridge, it is concluded that full composite action does not exist between the deck and girders of this structure. The difference in the strain profiles of a section having full composite action and one with less than full composite action subjected to a bending load is exhibited in Figure 3.7.

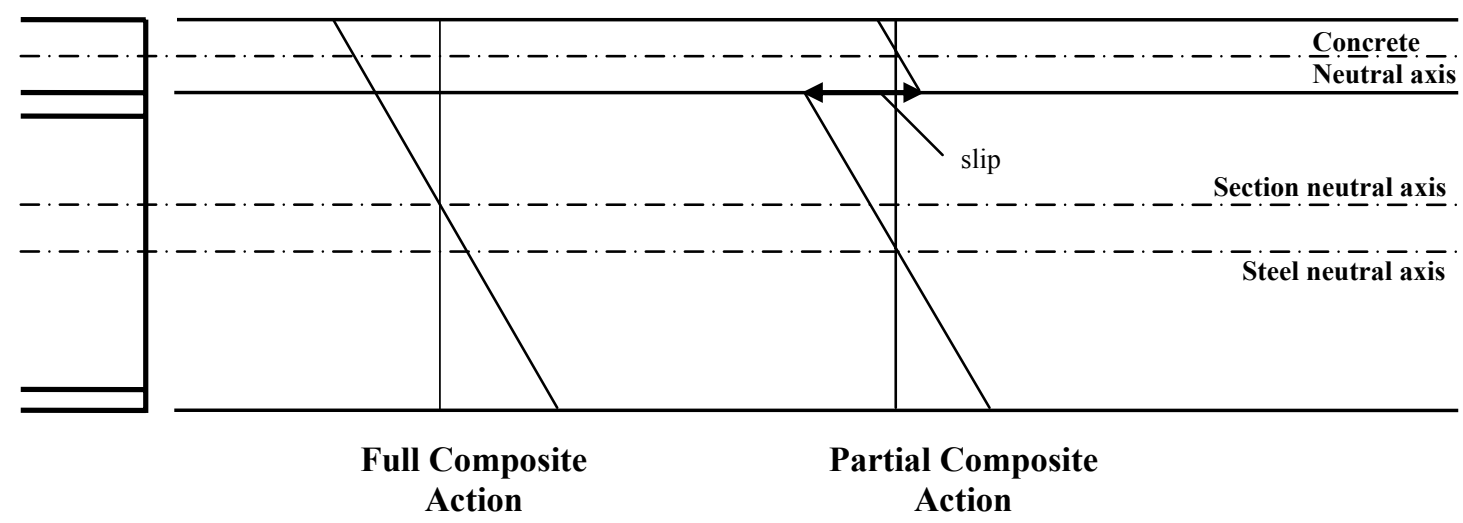

Figure 3.7. Strain profiles for composite sections with full and partial composite action subjected to a bending moment

The data acquired from the bridge instrumentation is used to determine the level of composite action that is present within the Evansville Bridge. Initially, a reference time is chosen at a time far enough after the date of concrete pouring that the strains in the deck due to curing and shrinkage of concrete are no longer changing significantly. This time is chosen to be 100 days after the deck was poured. The time of maximum temperature loading for this day is found and the strains at this time are subtracted by the strains at the reference time in order to effectively eliminate the strains due to shrinkage and curing. At four locations along girder 2, the strain profiles throughout the section are plotted in Figure 3.8.

Figure 3.8 clearly shows that the Evansville Bridge lacks full composite action. Figures 3.8 (a) - (d) shows that slipping is occurring between the concrete deck and the top flange of the girder. Slipping is present when the strains on the top flange and at the bottom surface of the deck are not identical at the same location which is shown theoretically in Figure 3.7. Also, the graphs clearly indicate that even in the absence of 
slipping, the strain profile through the section would not be linear because the slopes of the profiles through the decks are not the same as those through the girders. In fact, Figures 3.8 (a) and (b) show that the slope of the strain profiles in the deck and the girder at Pier 1 and Mid-Span 2 are of opposite sign. This phenomenon may be due to the constraints placed on the bottom surface of the bridge deck by the stay-in-place forms and the shear studs. While the bottom surface of the deck is somewhat constrained, the top surface has more freedom to expand and contract under changing temperatures.

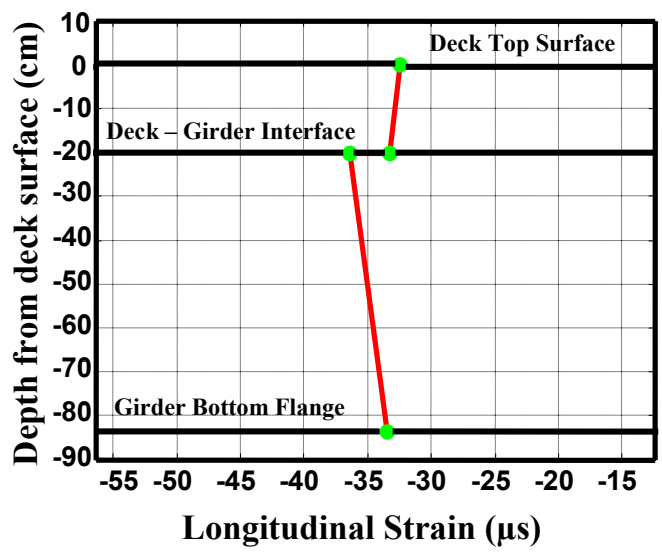

(a) Abutment 1

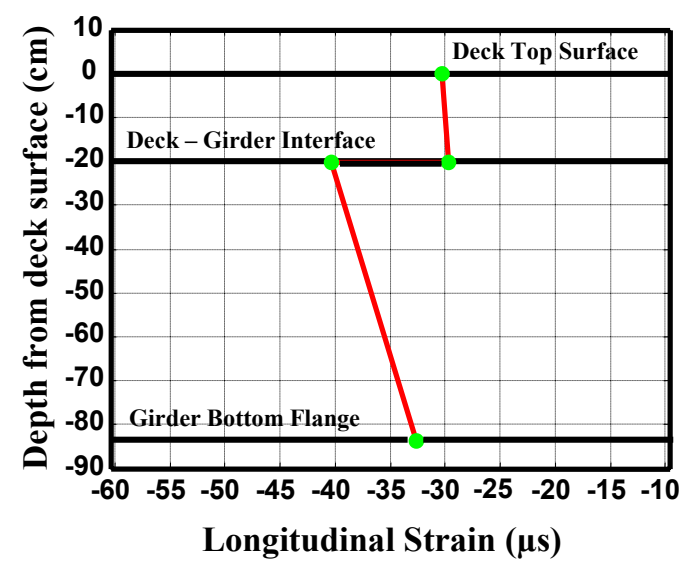

(c) Pier 1

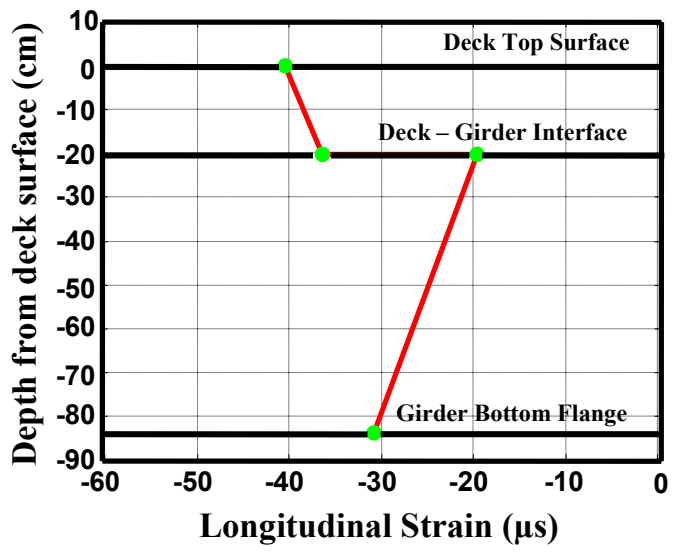

(b) Mid-span 1

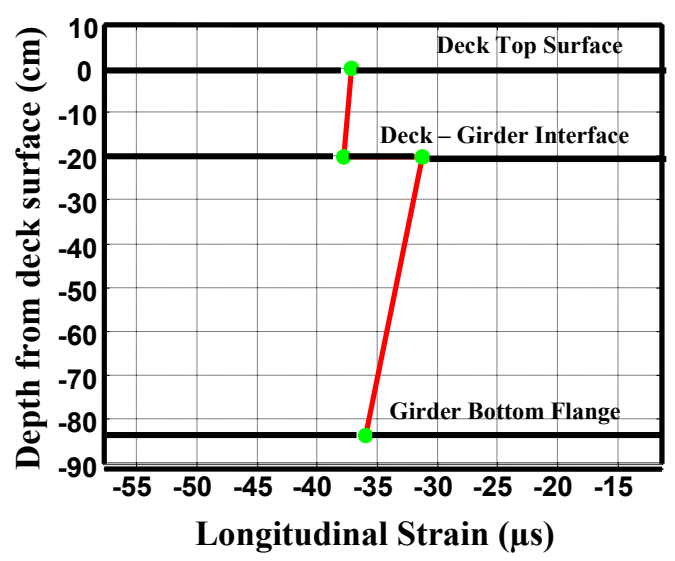

(d) Mid-span 2

Figure 3.8. Strain profiles induced by temperature loading along girder 2, 100 days after concrete deck pouring

In order to create an FE model having the highest degree of accuracy possible, it is apparent that the deck-girder interface must be modeled neither as completely tied nor 
completely untied. A solution to this problem was found by using spring - tied elements as the connection between the girder and the deck. These spring-tied elements will provide a connection at the interface while also allowing movement between the two sections according to the stiffness $(k)$ of the spring elements. There are a total of 12,096 spring elements that make up the deck-girder interface.

A simple method was used in determining what value to use for the stiffness of the spring elements making up the deck-girder interface. The method involved running several versions of the FE model having interface conditions varying from fully tied to nearly free. The results are compared with the values obtained directly from the instrumentation in the deck and on the girders to determine the most accurate $k$ value to be used at the interface. A spring stiffness of $175.1 \mathrm{GN} / \mathrm{m}\left(1 \times 10^{9} \mathrm{lb} / \mathrm{in}\right)$ is used to model the deck-girder interface of this model.

The final interface condition idealized in this model is the connection between the girders and the abutment walls. Although the concrete of the abutment walls is cast around the end of the girders, the connection between the two is not always completely rigid. During the modeling process, it was discovered that if this connection was assumed to be rigid from time step 1, the deflection shape of the structure would be severely affected. This is primarily due to two factors. This is because the final section of concrete cast on the structure was the top section of the abutments which encase the girder ends. As a result, the girders are allowed to deflect under their own weight as well as the weight of the deck before they are encased within the abutment walls. However, once the top of the abutment walls are cast, the connection between the girder ends and the abutments acts as a rigid connection.

To accommodate these varying conditions at the girder ends, two types of fixation are employed at this location. For the time steps corresponding to the time when the top section of the abutment was not cast, the connection between the girder ends and the abutment is modeled using spring-tied elements. However, once the girders are assumed to be rigidly connected to the abutments, rigid links are created between the girder and 
the abutments. A total of 432 spring-tied elements and 432 rigid links are used in modeling this connection.

An acceptable value for $k$ is chosen by varying the spring stiffness between the girders and the abutment and comparing the effect of the deck weight on the longitudinal strain in the middle girder using both experimental and theoretical values. The spring stiffness that yields the most accurate match between the FE values and the values measured by the instrumentation is found to be $7004 \mathrm{kN} / \mathrm{m}(40000 \mathrm{lb} / \mathrm{in})$ and is used as the $k$ value for the deck-abutment connection in this study.

\subsection{Loading Conditions}

The purpose of this study and the construction of the FE model are to investigate the effect of ambient temperature change on the Evansville Bridge. The study uses strains calculated by the FE model in comparison with the strains recorded by field instrumentation. Because the instrumentation was placed on the structure and readings were taken during the construction process, it is necessary to model the construction sequence of the bridge for an accurate comparison. For these reasons, the two loading conditions initially placed upon the FE model are gravity loading and ambient temperature change.

\subsection{Modeling Sequence}

Before discussing the loading applied to the model it is necessary to present the sequence in which the different bridge components were added to the model. Adding the components of the bridge in sequence is intended to model the actual sequence of construction of the bridge so that the values taken from the model will compare accurately with the experimentally measure values.

For this study, the modeling of the bridge simulating in-situ takes place in essentially four steps. The first step involves the construction of the entire substructure, abutments, 
girders, and placement of gravity loading. The second stage consists of the placement of the concrete deck upon the girders. Third is the placement of the soil backfill behind both abutment walls. The fourth and following steps all include adding the temperature loading to the structure in $\pm 5^{\circ} \mathrm{C}$ increments.

\subsection{Gravity Loading}

A condition of loading that remains mainly constant throughout the life of the bridge is the loading due to its own weight, or gravity loading. In the case of bridges, the amount of gravity loading increases as the different parts of the structure are added during the construction sequence. Initially, the girders alone incur loading due to their own weight before the deck is laid upon them and the backfill constrains their ends. Therefore, the first time step in the FE analysis introduces the gravity loading of the substructure using the mass proportional loading type in ADINA. A description of what is involved in each time step of the FE analysis can be seen in Table 3.3.

\section{Table 3.3. Actions at each time step of FE analysis}

\begin{tabular}{c|l}
\hline Time Step & Addition or loading applied to finite element model \\
\hline 1 & Gravity loading for substructure, abutment walls, and piles \\
\hline 2 & Gravity loading for deck \\
\hline 3 & Addition of deck \\
\hline 4 & Addition of abutment backfill \\
\hline $5+$ & Temperature loading \\
\hline
\end{tabular}

Adding the effect of the weight of the deck is not as simple as modeling the deck and using the mass proportional load. As the deck is poured, the entire structure is being further loaded by the weight of the liquid concrete; yet, the concrete is not incurring any strains nor providing any constraint to the girder deflection. In theory, upon completion of concrete pouring the strains throughout the deck should be minimal while already having the deflected shape of the top flange of the girders subjected to the gravity load of the entire structure. To accurately model this sequence for the FE analysis, a pressure load equivalent to the weight of the deck is applied across the length of the top flanges of 
the girders. Girders 1 and 3 are loaded with a pressure load of $217.21 \mathrm{kPa}$ (3.1504 psi) while Girder 2 is loaded with a pressure of $386.65 \mathrm{kPa}$ (5.608 psi) during time step 2 of the analysis. Upon completion of this time step, the model has simulated the effect of the gravity of the entire bridge on the substructure.

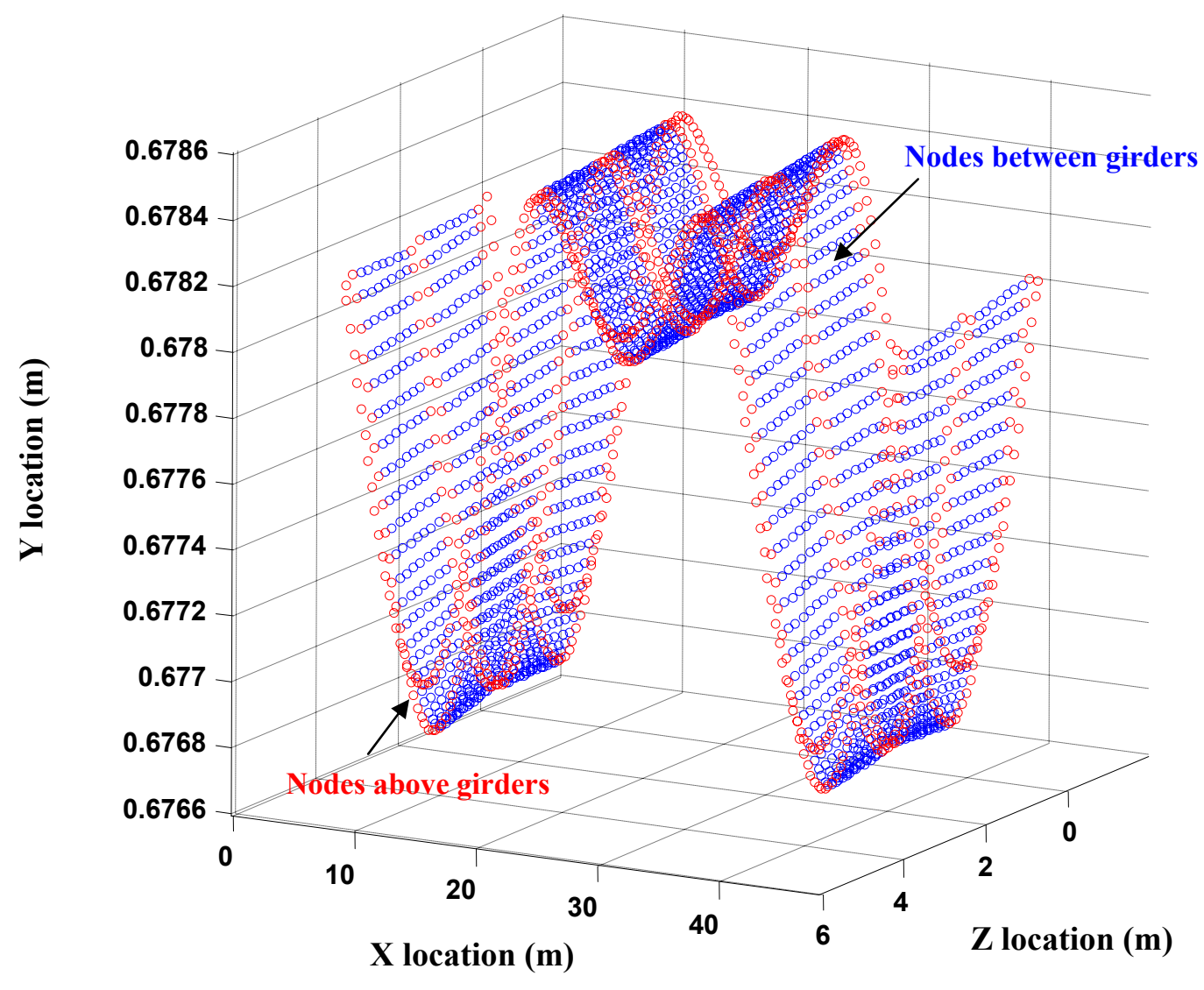

Figure 3.9. Coordinates of deck nodes after initial displacement

Now, before backfill or temperature loading is introduced in the model, the deck must be added to the structure. This becomes more difficult due to the fact that the deck must be placed on top of girders that already have been deformed. To accomplish this, a MATLAB program was written which uses the deflected values of the nodes along the top flange of each girder to interpolate the amount of initial displacement in the $\mathrm{x}, \mathrm{y}$, and $z$ directions that must be applied to each node of the deck so that the shell element will be contoured to sit along the top flanges of the three girders. A three dimensional graph of the deflected nodes of the deck can be seen in Figure 3.9. The birth time command is 
then used to apply a birth time of 2.01 for each element of the deck so that it is not introduced until time step 3. The initial displacement values are applied to the deck nodes as initial conditions and the spring tied interface is introduced at time 2.01. All of these steps define time step 3 which introduces the deck into the FE model.

Because the last step in constructing this bridge section was placing the backfill, the springs must be introduced after the rest of the structure is modeled and gravity loading applied. As was presented earlier in this chapter, the soil is represented by a group of nonlinear spring elements. By using the birth time command and having the elements of the nonlinear springs "born" at a time of 3.01, they do not appear within the model until the fourth time step. This final step completes the modeling of physical components of the Evansville Bridge.

\subsection{Ambient Temperature Loading}

The final step in analyzing the Evansville Bridge is applying an ambient temperature load. The aim of the investigation is to evaluate the effect of a temperature increase and decrease of $20^{\circ} \mathrm{C}$. In the first four time steps, there is no temperature change within the structure. However, at time step 5, the temperature of the entire bridge is set to be either $+5^{\circ} \mathrm{C}$ or $-5^{\circ} \mathrm{C}$. In the subsequent time steps, the temperature is increased or decreased by $5^{\circ} \mathrm{C}$ according to which loading curve is being used. After completing the $\mathrm{FE}$ analysis of the bridge for both a temperature drop and increase, the response of the entire bridge at temperature changes ranging from $-20^{\circ} \mathrm{C}$ to $+20^{\circ} \mathrm{C}$ at $5^{\circ} \mathrm{C}$ intervals can be fully understood. The results of this analysis will be compared with the results measured from the bridge instrumentation in the following sections. 


\section{CHAPTER FOUR}

\section{EVANSVILLE BRIDGE INSTRUMENTATION}

\subsection{Introduction}

The suitable method for validating the response of a finite element model is comparing the theoretical values with experimentally measured ones obtained under the same loading conditions. In most modeling cases, actual experimental data is not readily available, making the validation difficult. However, the Evansville Bridge under investigation in this study contains a highly sophisticated instrumentation system to monitor its long term performance under the effects of environmental conditions and traffic loading. These field measurements can be used to evaluate the performance of the integral abutment bridge as well as to check the validity of the finite element results. Since the strains measured in the structure are due to many factors other than temperature including shrinkage, construction curling, creep, and environmental conditions, strain readings are post processed to reflect the response of the bridge so that an appropriate comparison can be made with the FE calculated values.

\subsection{Instrumented Bridge Section}

The test section for this study consists of half of the Evansville Bridge in Preston County, West Virginia which carries WV Route 92 over the Little Sandy Creek. Dr. Samir Shoukry and his research team instrumented this bridge section during the first phase of construction in June 2003 (Shoukry et al., 2005). Figure 4.1 shows the Evansville Bridge following the completion of construction Phase 1. The section of the bridge completed during phase 1 is a $44.8 \mathrm{~m}(147 \mathrm{ft})$ long and $5.00 \mathrm{~m}(16.41 \mathrm{ft})$ wide three-span, skewed, integral abutment bridge section with a skewed angle of $55^{\circ}$. The section consists of a $0.203 \mathrm{~m}$ (8 in.) thick reinforced concrete deck placed upon three $44.8 \mathrm{~m}(147 \mathrm{ft})$ long steel W 27x84 I-beam girders. The cross bracings present in the middle of each span are 
C-channel sections (C 15x33.9) while the ones at each pier are I-beams (W 18x35) with two stiffeners on each side. The integral abutment walls are constructed of reinforced concrete with a height of $1.52 \mathrm{~m}(5 \mathrm{ft})$, a length of $5.00 \mathrm{~m}(16.41 \mathrm{ft})$, and a width of 0.91 $\mathrm{m}(3 \mathrm{ft})$. Three $6.07 \mathrm{~m}(20 \mathrm{ft})$ long HP 12x53 vertical piles are drilled into the soil at each abutment having their strong axis parallel to the abutment wall and rigidly connected to the bottom of the abutment to help support the bridge at the ends. At Pier 1, each girder is pinned to the pier while at Pier 2 the girders are free to translate in the longitudinal direction.

Only one-half of the length of the bridge section completed during phase 1 consisting of the area from abutment 1 to the middle of span 2 is instrumented because of the skewsymmetric nature of the structure. The instrumentation includes strain gages, thermistors, displacement transducers, and inclinometers from which the data is continually monitored at 20 minute intervals in an attempt to observe the damage and deterioration of the bridge as it ages as well as to compare the real life behavior of the structure to theoretical predictions. The selection of the sensors was based upon their functional characteristics, sensitivity, accuracy, and reliability from past experiences.

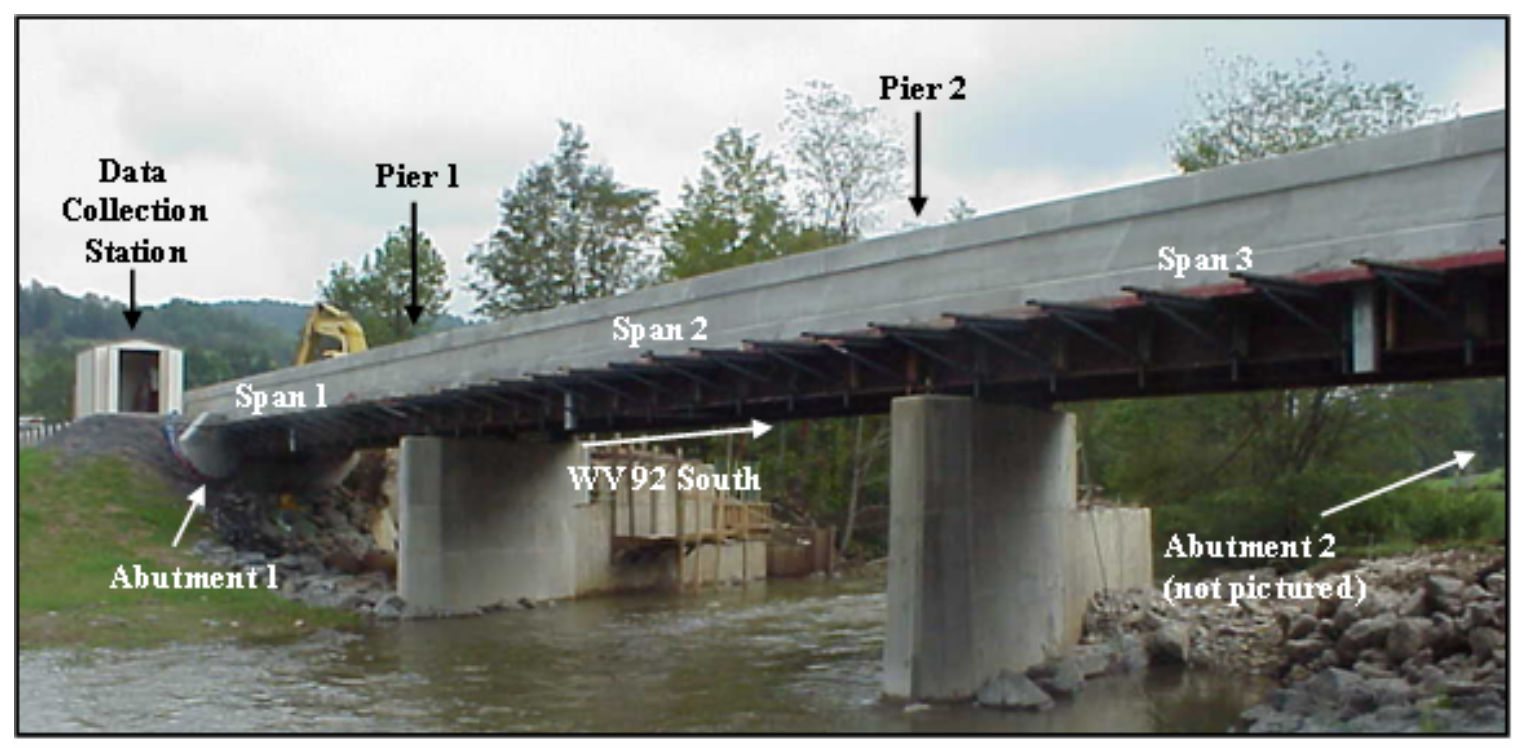

Figure 4.1. Evansville Bridge in Preston County, WV following phase 1 of construction 

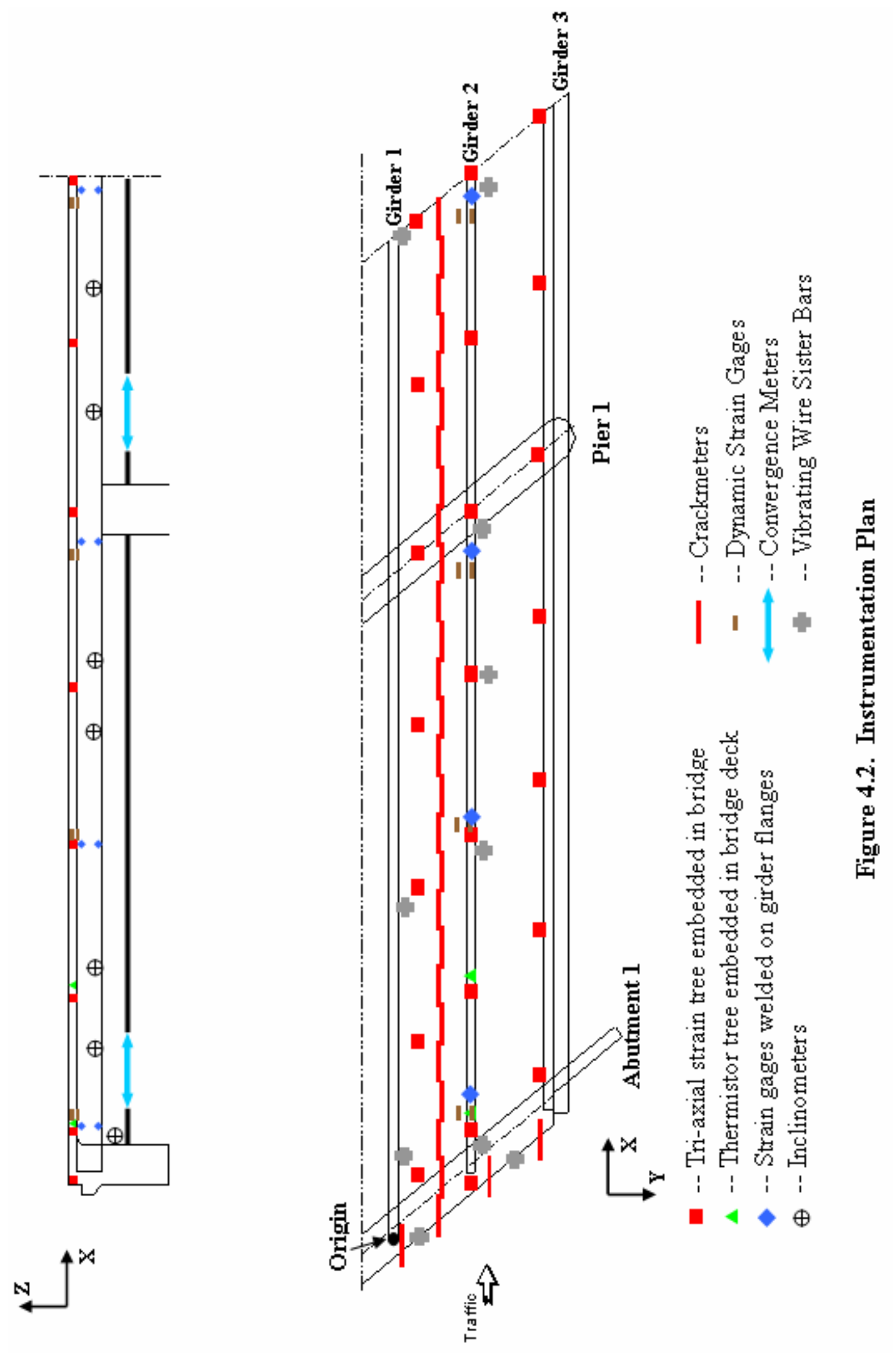


\subsection{Instrumentation}

First of all, in order to know the exact location of each sensor after the completion of construction, a coordinate system must be established to track the location of the sensors. The coordinate system established for the Evansville Bridge has its origin at the northeast corner of the instrumented section with the $\mathrm{X}$ axis in the longitudinal direction, the $\mathrm{Y}$ axis in the transverse direction, and the $\mathrm{Z}$ axis in the vertical direction. This coordinate system is illustrated in Figure 4.2 along with the location of all of the various sensors on the Evansville Bridge.

The instrumentation system on the Evansville Bridge allows continual monitoring of the response of the structure to traffic loading and seasonal weather conditions. This response is determined through the measurement of strain histories, temperatures, relative displacement of supports, girder slopes, and relative inclination of abutments using a total of 232 sensors installed at various locations.

Two strain gage types were used to record the strain histories at several critical locations: vibrating wire strain gages measure long-term strain due to static loading and environmental effects and wire resistant strain gages measure short term dynamic response caused by dynamic loads such as traffic moving across the structure. Geokon VCE-4200 vibrating wire strain gages are embedded within the bridge deck at 22 locations shown in Figure 2. A strain gage tree at each of these locations is made up of 6 sensors (5 in some locations) measuring strains in the longitudinal, transverse, and vertical directions. A typical strain tree setup can be seen in Figure 4.3. Along girders 1 and 3, the strain trees are placed $7.62 \mathrm{~cm}$ (3 in) and $15.24 \mathrm{~cm}(6 \mathrm{in})$ from the top surface of the deck recording readings along the top and bottom deck surface. Above girder 2, the sensors are located at depths of $3.81 \mathrm{~cm}(1.5 \mathrm{in})$ and $12.7 \mathrm{~cm}(5 \mathrm{in})$. Each VCE-4200 provides a temperature reading via an internal thermistor in each gage allowing temperature compensation to be performed, which is necessary since the gages and concrete have differing coefficients of thermal expansion. Geokon model 4911 vibrating wire sister bars are placed within the concrete deck in an effort to measure the strain in 
the steel reinforcement. The sister bars contain a vibrating wire element, plucking coil, and thermistor encased in high strength steel between two $59.3725 \mathrm{~cm}$ (23.375 in) sections of steel reinforcement. These sister bars are tied to the actual reinforcement using iron clamps at the locations indicated in Figure 4.2. An example of sister bars placed before pouring of the deck can be seen in Figure 4.3.

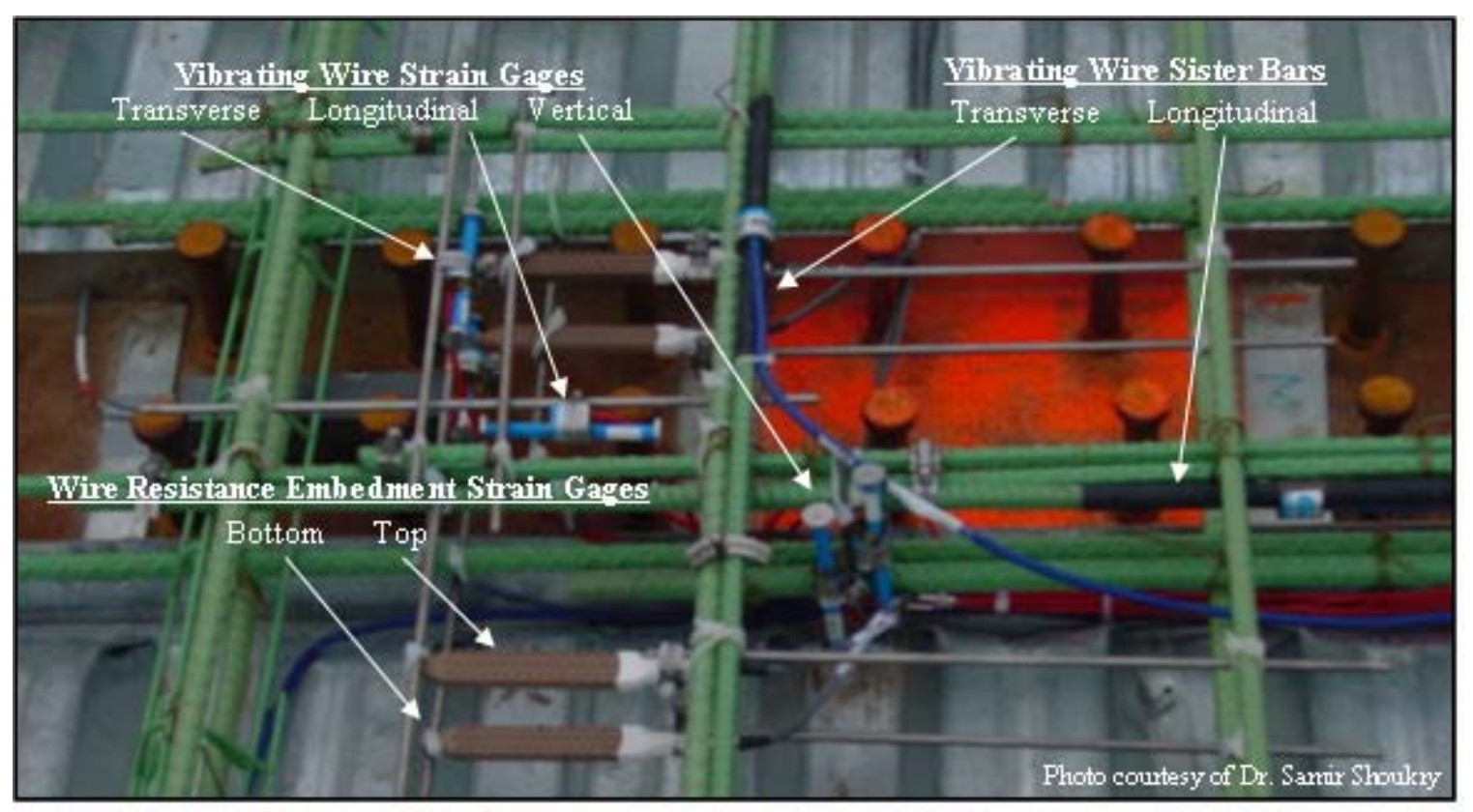

Figure 4.3. Typic al instrumented section within Evansville Bridge deck

A different type of sensor is placed throughout the concrete deck to measure the response to dynamic stimulation. This different type of sensor comes in the form of a Micro Measurements model EGP-5-120 wire resistance embedment type strain gage. Sixteen of these gages are installed at four different locations near the vibrating wire strain trees within the bridge deck. Two sensors are placed parallel with the top layer of reinforcement approximately $30.48 \mathrm{~cm}$ (12 in) apart and two sensors are placed the below these parallel with the bottom layer of reinforcement.

A total of eight weldable Geokon model VSM 4000 vibrating wire strain gages were placed at four locations along the girder 2 (Figure 4.2) of the test section to measure static loading effects on the girders. At each of the four locations, one strain gage was placed 
on the top flange of the girder and one on the bottom flange. These strain gages also contain thermistors for temperature readings. The gages are attached to the steel girders by placing them within mounting blocks which are welded into position on the girder.
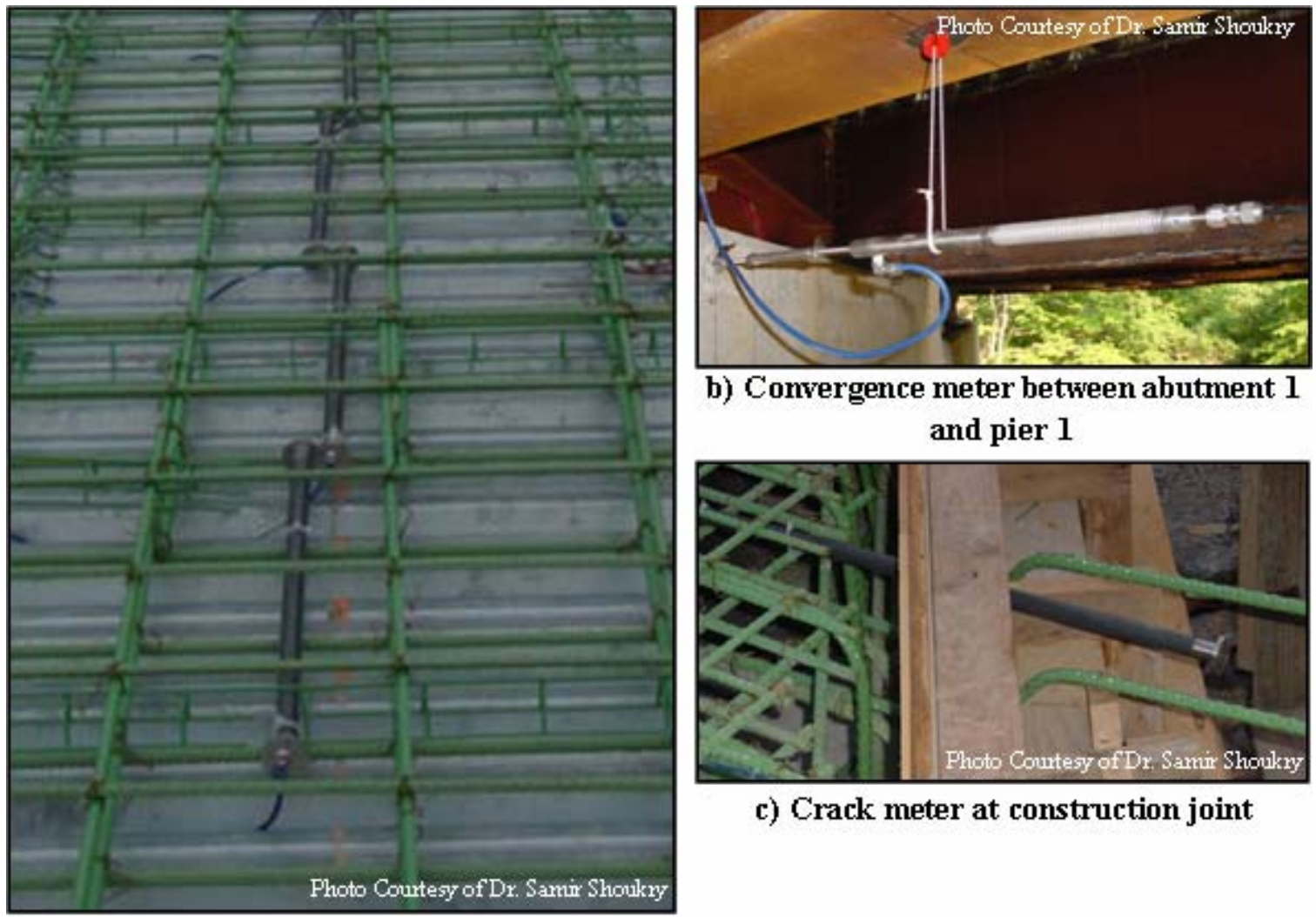

b) Convergence meter between abutment 1 and pier 1

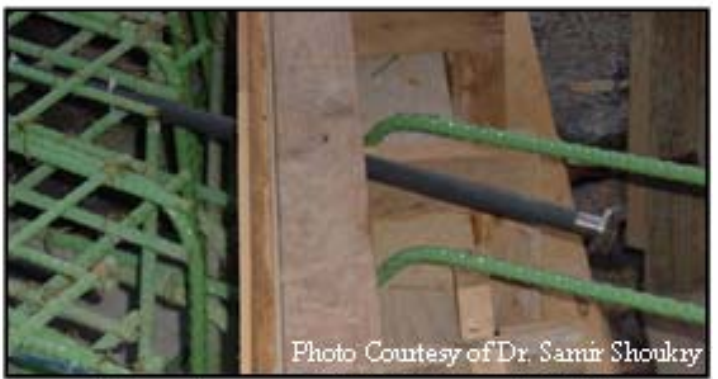

c) Crack meter at construction joint

a) Crack meters arranged in series along longitudinal axis of deck

Figure 4.4. Displacement transducers installed on Evansville Bridge

The displacement transducers placed upon the Evansville Bridge come in two forms: crack meters and convergence meters. A total of 30 Geokon model 4430 deformation meters, or crack meters, were placed on the bridge to measure crack growth within the deck as well as axial deformation. Four crack meters were placed at the construction joint between the approach slab and the deck and the remaining 26 were placed in series between girders 1 and 2 along the full length of the test section as shown in Figure 4.2. As these sensors deform along the longitudinal axis of the concrete, their output can be used to visualize the deformation pattern. One convergence meter was placed between 
abutment 1 and pier 1 while the other was placed between pier 1 and pier 2 as shown in Figure 4.2. The convergence meters used in instrumentation are Geokon model 4425 vibrating wire convergence meters which are designed to measure deformation between two anchor points. In this case, the convergence meter between abutment 1 and pier 1 will measure the relative displacement between these to parts of the bridge. Likewise, the other convergence meter measures the relative displacement between the two piers. The displacement transducers on the Evansville Bridge are shown in Figure 4.4.

The inclination or slope of the middle girder is measured using a set of Jewell LCI inclinometers. A total of seven inclinometers are mounted on the structure: six along the bottom flange of the middle girder and one on the wall of the abutment (abutment 1). These inclinometers have the ability to be used for dynamic and static testing and are sensitive to rotations to one microradian. Figure 4.5 shows an inclinometer mounted on the bottom flange of the middle girder.

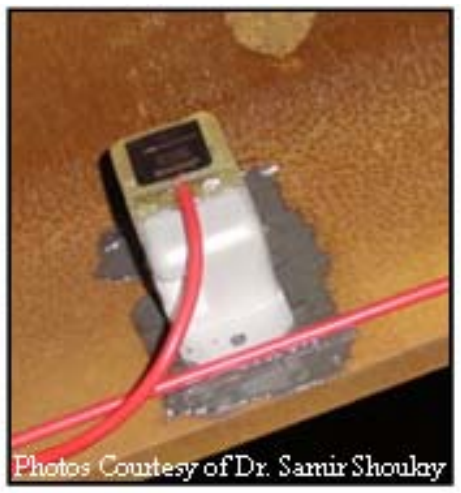

Figure 4.5. Inclinometer mounted on bottom flange of girder

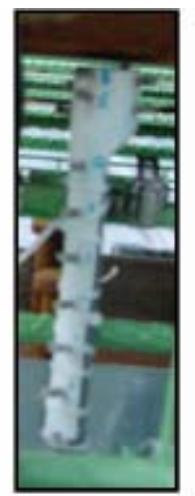

Figure 4.6. Thermistor tree in bridge deck

The temperature gradient that is present through the thickness of the concrete deck can lead to additional strains on the deck and the structure. To investigate the actual temperature profile in the deck and the effect on the bridge response, two thermistor trees were placed at the locations indicated in Figure 2. These thermistor trees were constructed by Dr. Shoukry's research team using 17 thermistors mounted in a $20.32 \mathrm{~cm}$ ( 8 in) long and $2.54 \mathrm{~cm}(1 \mathrm{in})$ diameter PVC pipe section. In each tree, eight of the 
thermistors were placed in the top $2.54 \mathrm{~cm}(1 \mathrm{in})$ of the tube and the rest ere placed in a line in $2.54 \mathrm{~cm}(1 \mathrm{in})$ intervals down the remainder of the tube. Figure 4.6 shows one of the thermistor trees installed on the bridge before the concrete deck was poured.

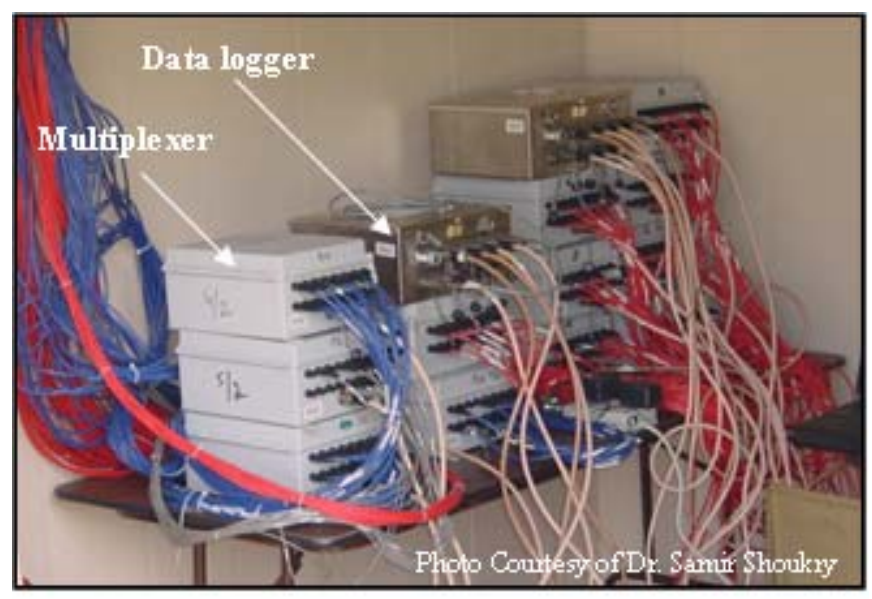

Figure 4.7. Data acquisition system

\subsection{Data Acquisition System}

The data acquisition system implemented at the Evansville Bridge to store data from all 232 sensors consists of three basic components: data loggers, multiplexers, and interfaces. All of the data is recorded on two Campbell Scientifics CR10X measurement control modules. These units are attractive because of their durability, programmability, and memory capabilities. The data loggers were programmed using the Multilogger software provided by Campbell Scientific to fit the specific needs of this project. Twelve Geokon model 8032 multiplexers are present in the data acquisition system to acquire the data from all of the sensors and transmit the results to be saved on the data logger. A Canary system multi sensor interface is used by the data acquisition system allowing the CR10X data logger to connect to and control multiple sensors with various inputs and outputs. The data loggers are powered by a marine battery which is charged by a solar panel along with another marine batter placed as a stand by. Data collection began just before the pouring of the concrete deck and continues to date at a rate of one reading every 20 minutes. A phone line was installed at the site allowing remote uploading of data from the data loggers from anywhere in the world. This allows researchers to 
continually monitor the behavior of the bridge as well as any problems that may arise with the system. 


\section{CHAPTER FIVE}

\section{FINITE ELEMENT MODEL VALIDATION}

\subsection{Introduction}

Given that the main objective of this study is to investigate the effects of changing temperature on an integral abutment bridge, a method of validation must be developed that shows the accuracy of the finite element model in predicting the response of the actual structure to temperature loading. The data extracted from the bridge instrumentation serves as an excellent set of experimental values to compare with the FE results. The experimental and analytical responses used for validation include the following:

1. Bending moment in the middle girder of the test section due to the weight of the bridge deck.

2. Longitudinal strain induced within both the girder flanges and the deck due to changes in temperature.

3. Transverse strains induced in the bridge deck by temperature variations.

\subsection{Sensor Data Interpretation}

First of all, the data gathered from the instrumentation system over the life of the structure must be interpreted in a way which makes comparison with the finite element results possible and accurate. Considering the FE output is a result of varying temperature loading on the structure, the sensor data is analyzed to reveal the response of the Evansville Bridge to specific temperature changes. A program in MATLAB is created capable of extracting the change in any sensor measured value due to changing temperature. 
As was discussed earlier in Chapter four, each sensor contains a thermistor capable of recording the temperature at that sensor location. For the sensor in question, beginning at approximately day 50 (significant time to allow concrete deck curing), the MATLAB code cycles through the temperature reading to find the locations of the peaks and valleys of the signal to determine the location of local maximums and minimums. Once the program has the location within the array of the maximum and minimums, the temperature decrease or increase can be recorded along with the change in the value measured by the sensor over the same time interval. These values are then used to create a scatter plot which reflects the change in the sensor measurement as the temperature changes and is used in the comparison with FE results.

\subsection{Model Validation}

\subsubsection{Gravity Load}

The gravity load of the bridge will remain constant on the structure throughout its life. Therefore, before the case of varying temperature loading is investigated, it is necessary to explore the response of the structure and the finite element model to a gravity load. However, since the data collection began after the deflection of the girders under their own weight, the only experimental readings available do no account for the effect of the girder weight. As a result, the bending moment in the middle girder caused by only the deck's weight will be compared using experimental and FE results.

Experimental values can be determined by simply looking at the plot of recorded strain during the first day of data collection. Data collection began just before large strain changes were induced in the girders by the pouring of the concrete deck. By determining when the pouring of the deck began $\left(\mathrm{T}_{1}\right)$ and when it was completed $\left(\mathrm{T}_{2}\right)$, the longitudinal strain in the girder due to the weight of the concrete deck can be evaluated as the change in the strain between times $\mathrm{T}_{1}$ and $\mathrm{T}_{2}$. Figure 5.1 shows the time history of the longitudinal strain in the top and bottom flanges of the middle girder at mid-span 1 and the change in strain introduced by the deck weight. Notice that in the initial stages of 
deck casting the top flange at mid span 1 is in tension before settling into a state of compression, while the opposite is true of the bottom flange. This is expected because the deck is cast starting at the bridge end opposite the instrumented section and moves along the length until the deck is cast all in one stage.

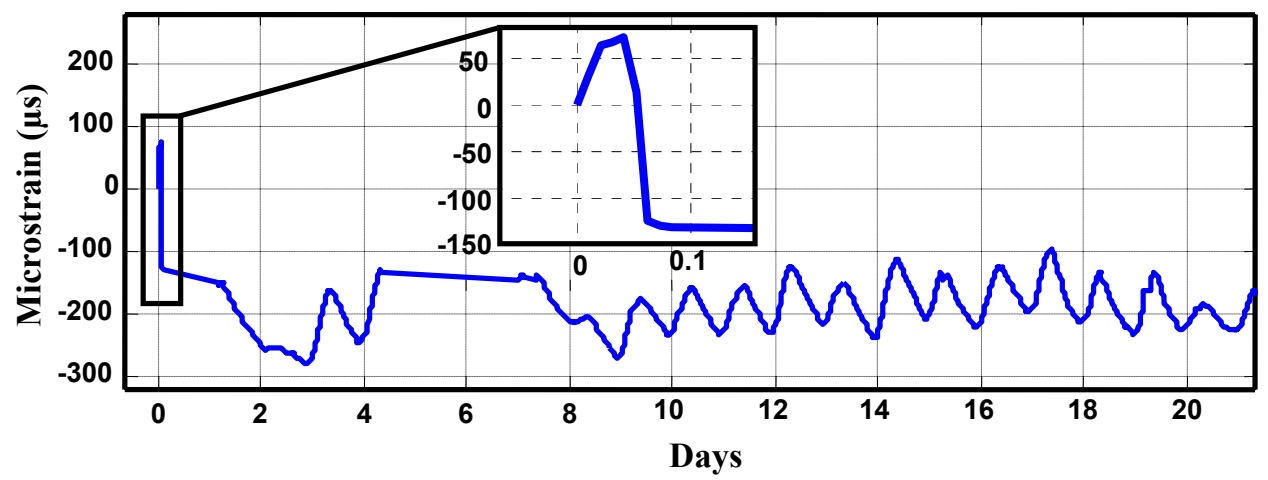

a) Top flange

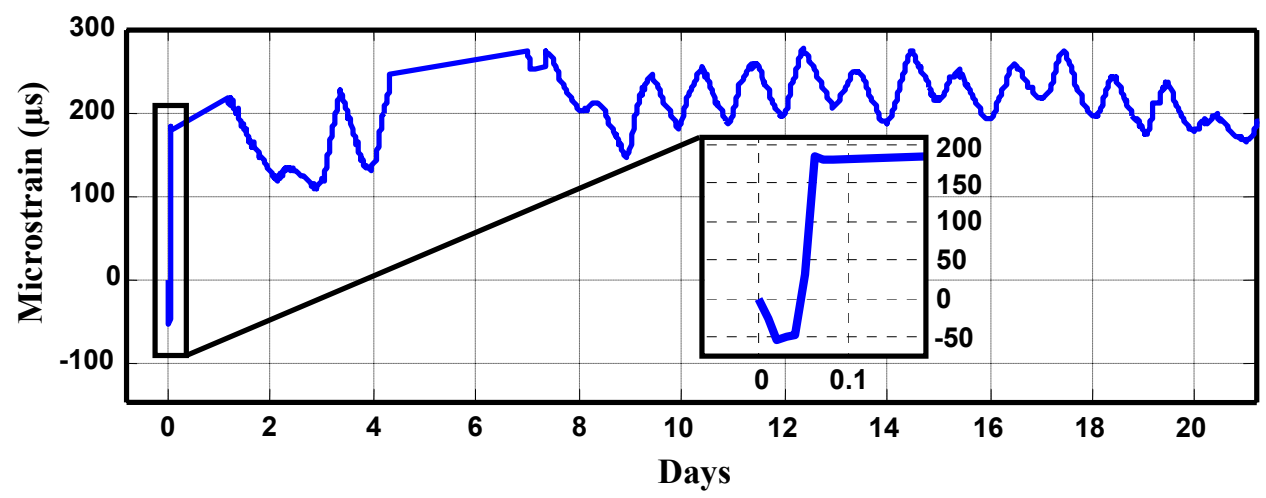

b) Bottom flange

Figure 5.1. Strain histories for middle girder at mid span 1 highlighting effect of deck weight

Strains measured by the instrumentation, such as those shown in Figure 5.1, can be used to calculate the stress in the girders at sensor locations using the thermo-elastic relation:

$$
\sigma=E(\varepsilon-\alpha \Delta T)
$$

where $E$ is the modulus of elasticity of the steel, $\varepsilon$ is the measured strain, $\alpha$ is the coefficient of thermal expansion, and $\Delta T$ is the measured temperature change. In this 
case, since the strain change occurs over a short period of time, the temperature change is negligible and $\Delta T$ can be assumed as zero. The longitudinal stresses in the girder flanges are used to calculate the bending moments in the middle girder according to the equation:

$$
M_{b}=I / d\left(\sigma_{b}-\sigma_{t}\right)
$$

where $M_{b}$ is the bending moment at a specific location, $I$ is the moment of inertia of the girder section, $d$ is the depth of the girder, $\sigma_{b}$ is the stress on the bottom flange, and $\sigma_{t}$ is the stress on the top flange. Equations 5.1 and 5.2 are used to calculate the bending moments within the middle girder caused by the placement of the concrete deck.

The closed form solution for the bending moment in the girder section is evaluated using the three moment equation for continuous beam analysis. Following the pouring of the deck, the supports at the girder ends will exhibit partial fixation. In this case, these supports will more closely resemble pinned supports than fully fixed supports. For this reason, and to greatly simplify the analysis, pinned supports are assumed at each girder end when computing the closed form solution for bending moments caused by the deck weight.

The finite element model bending moment values are obtained by placing the longitudinal stress output from the model within Equations 5.1 and 5.2. The measured and finite element bending moment profiles are created by interpolating parabolas over each span using the appropriate stress values. The experimental, closed-form, and finite element profiles for the bending moment induced in the middle girder by the weight of the bridge deck are compared in Figure 5.2.

Figure 5.2 shows the excellent agreement between experimental, finite element, and closed form solution bending moment values. Figure 5.2 also shows a slight difference in the bending moment values at the abutment centerline. The finite element and experimental values are $-30 \mathrm{kN} \cdot \mathrm{m}$ and $-40 \mathrm{kN} \cdot \mathrm{m}$ respectively while the closed form solution value is $0 \mathrm{kN} \cdot \mathrm{m}$. This is to be expected because the pinned supports assumed 
when computing the closed form solution will free the girder ends of any bending moment. On the other hand, the finite element analysis modeled the actual condition of partial fixation of the girder ends which will create a bending moment at the end supports. Also, because the closed form bending moment is calculated assuming no composite action between the deck and girders, the good match between these analyses further demonstrates the lack of composite action between the deck and girders.

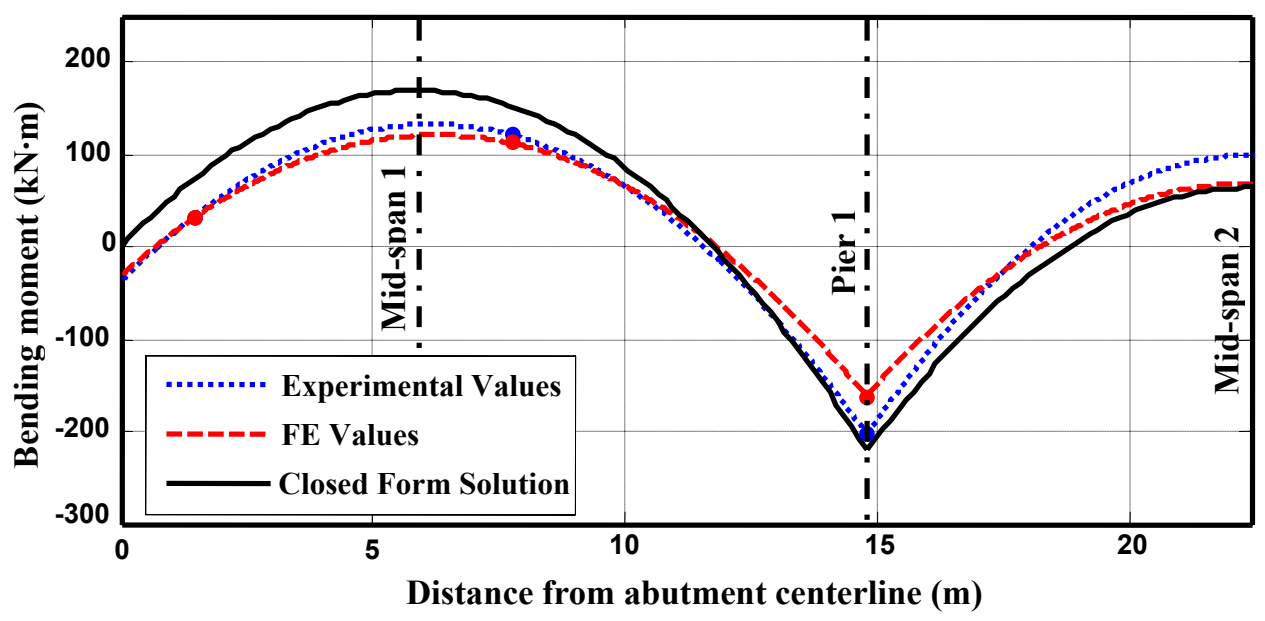

Figure 5.2. Bending moment profile along middle girder induced by concrete deck weight

\subsubsection{Temperature Load}

Thermal loading conditions will constantly vary throughout the life of a structure, creating ever changing states of stress within the bridge. The increase and decrease of ambient temperature will cause the components of the bridge to expand and contract at different rates due to their differing coefficients of thermal expansion. These expansions and contractions induce consistently changing states of strain on the integral abutment bridge. At each sensor location, the strain and temperature are recorded at regular intervals allowing the response of the structure to changing temperatures to be investigated. A method for validating the finite element model is comparing the strains at 
Longitudinal Direction

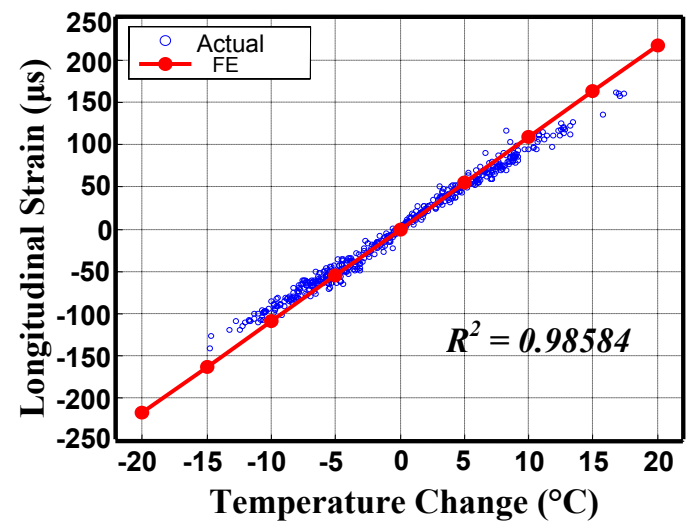

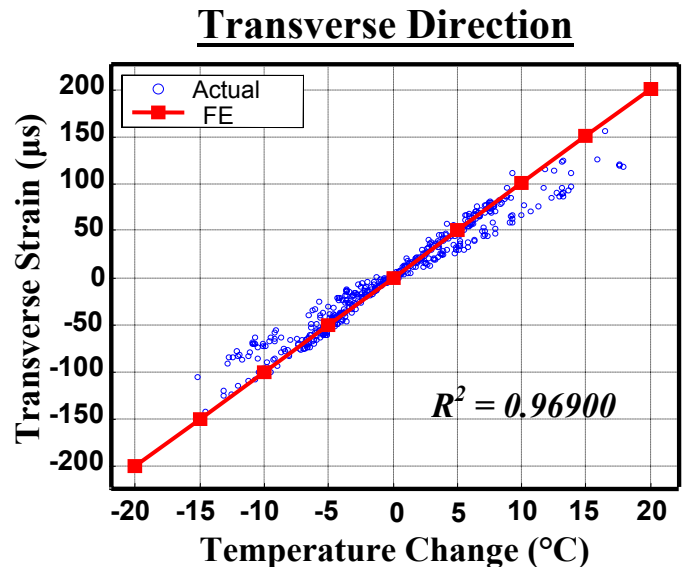

(a) Location 1
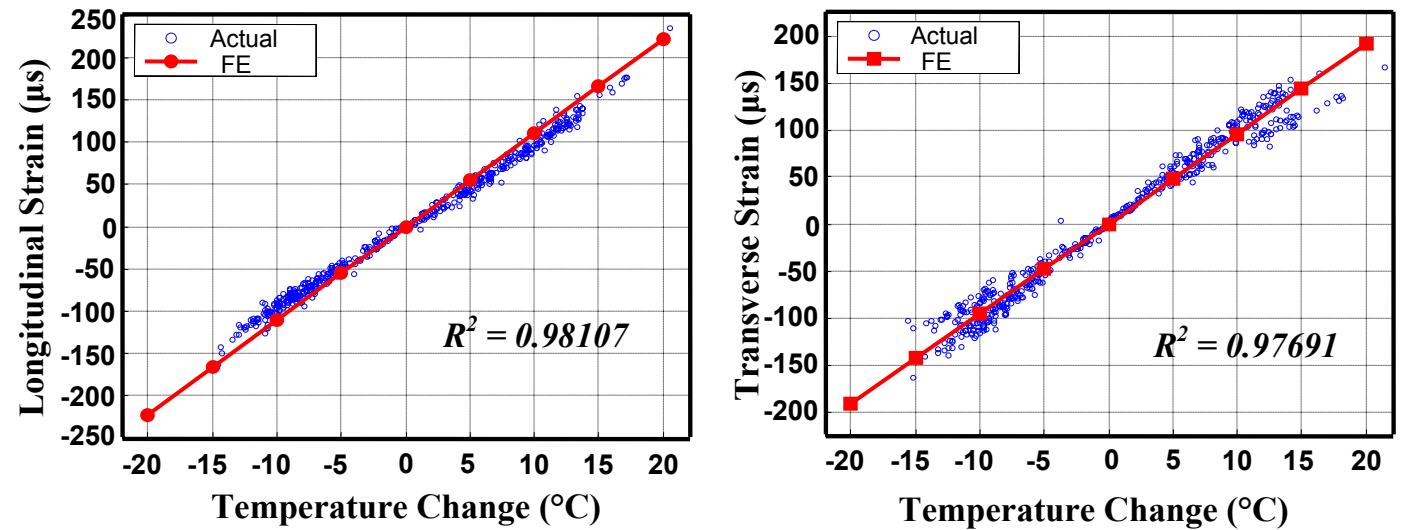

(b) Location 2
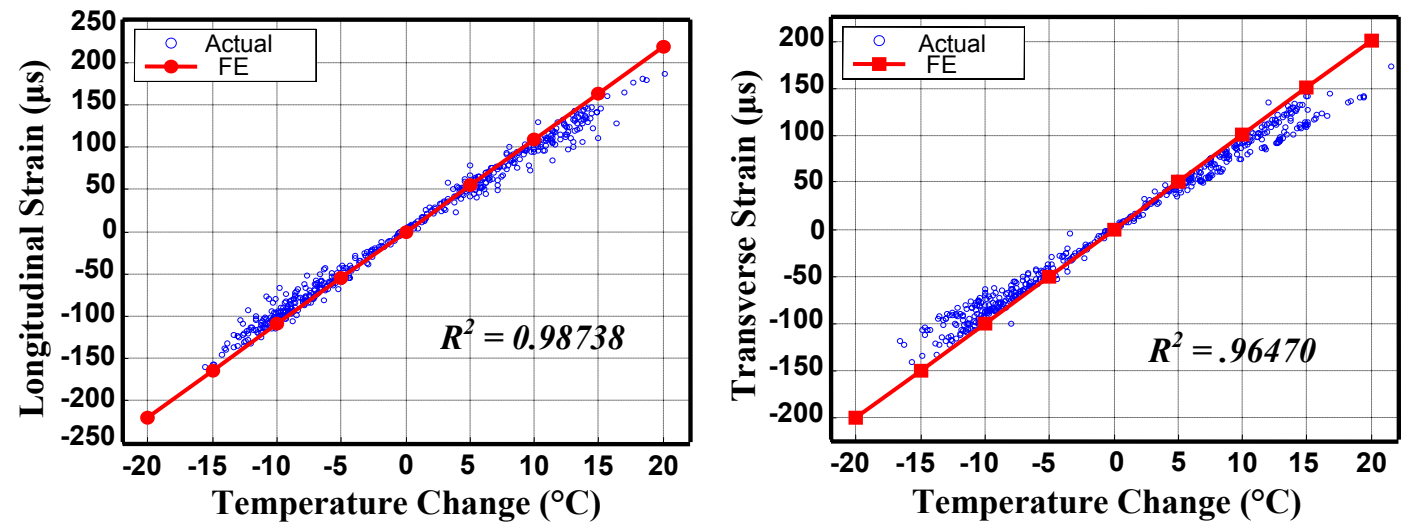

(c) Location 3

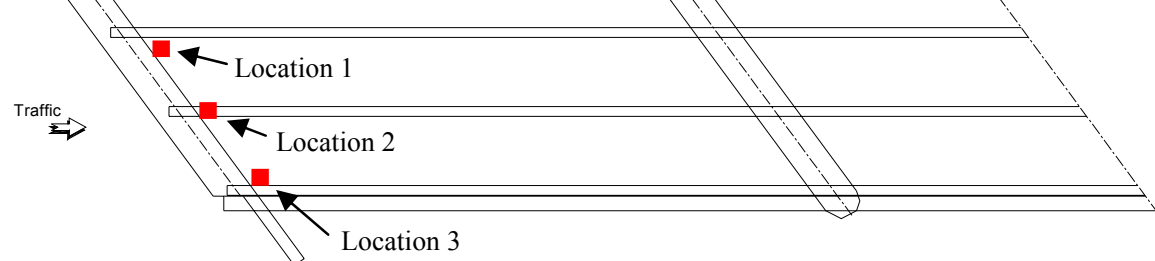

Figure 5.3. Comparison of longitudinal and transverse strains due to temperature change at abutment 1 
Longitudinal Direction

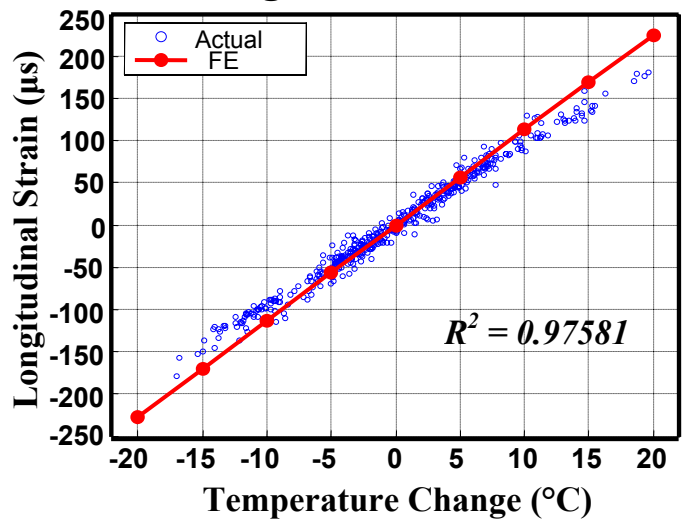

Transverse Direction

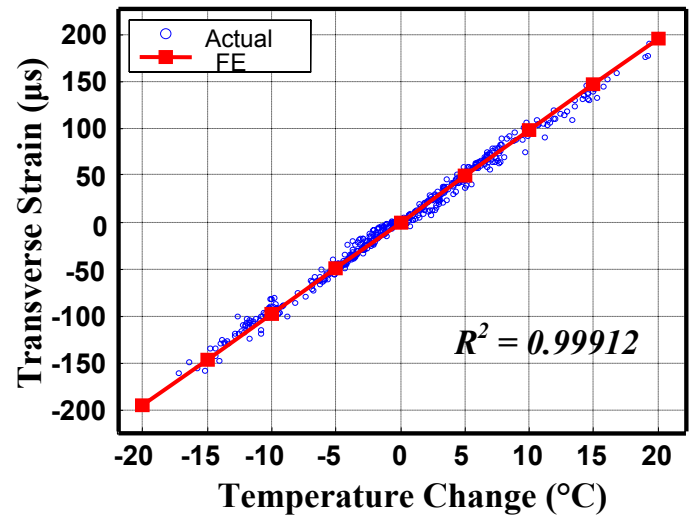

(a) Location 1
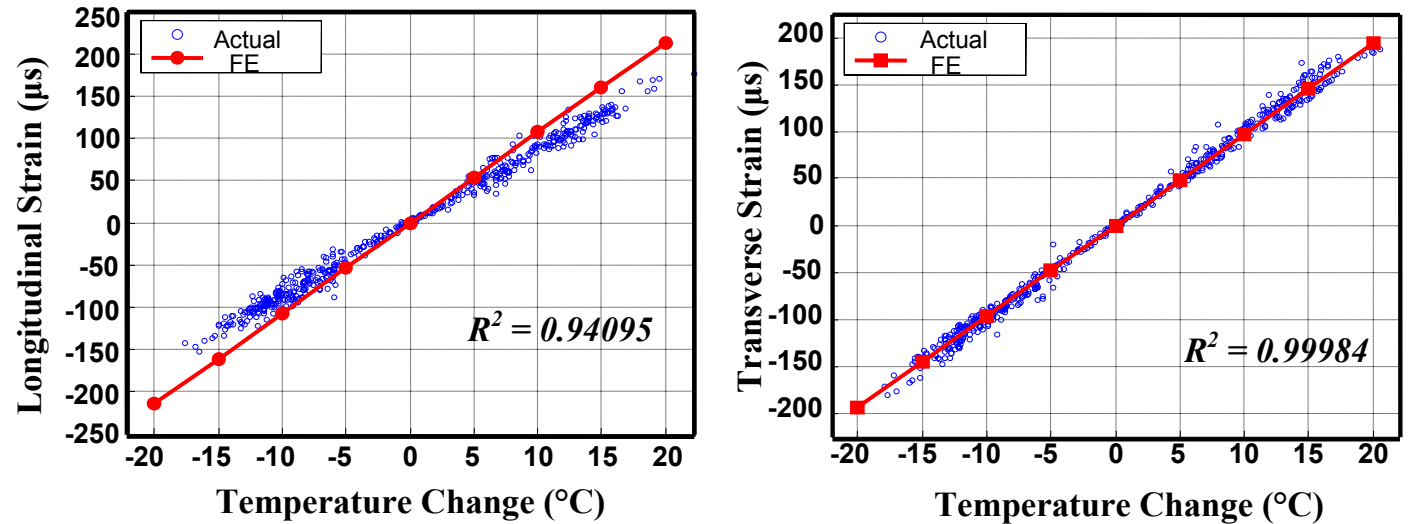

(b) Location 2
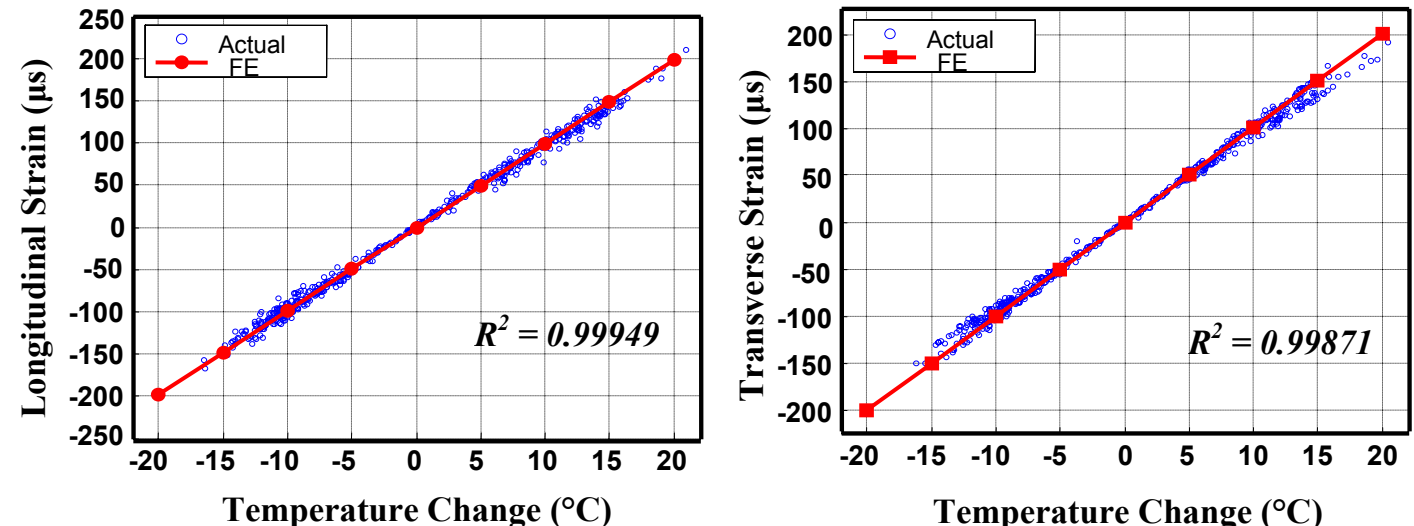

(c) Location 3

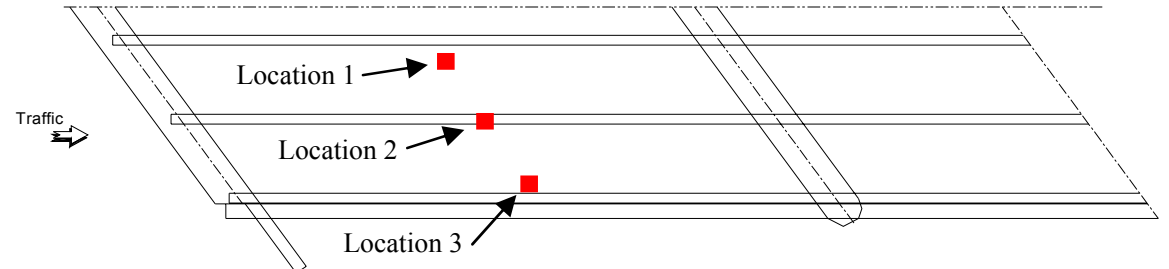

(d) Instrumented bridge section

Figure 5.4. Comparison of longitudinal and transverse strains due to temperature change at mid-span 1 
Longitudinal Direction

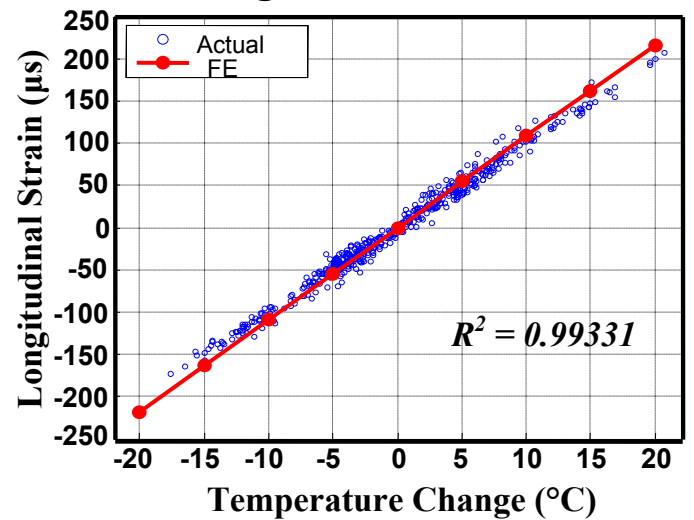

(a) Location 1
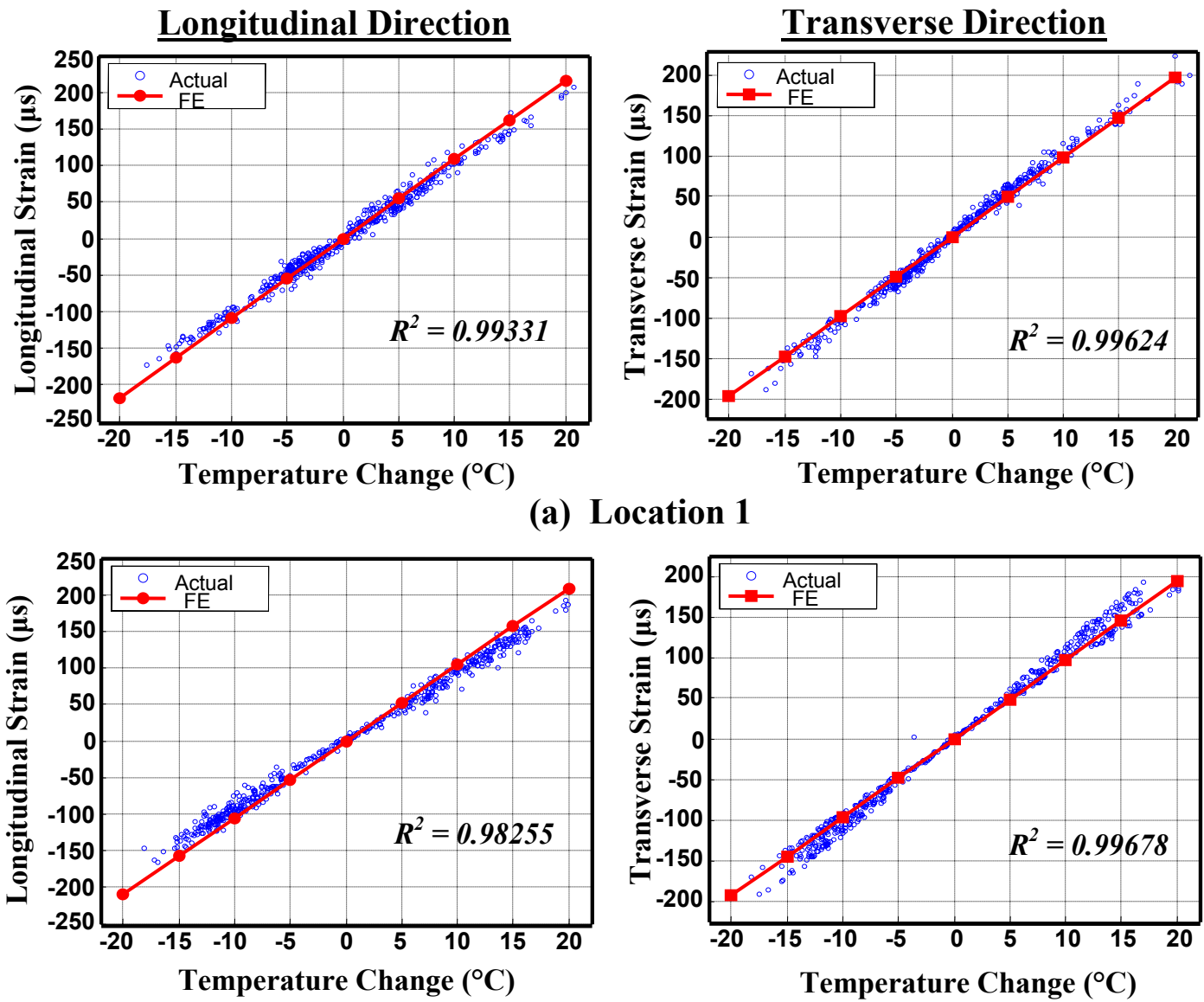

(b) Location 2
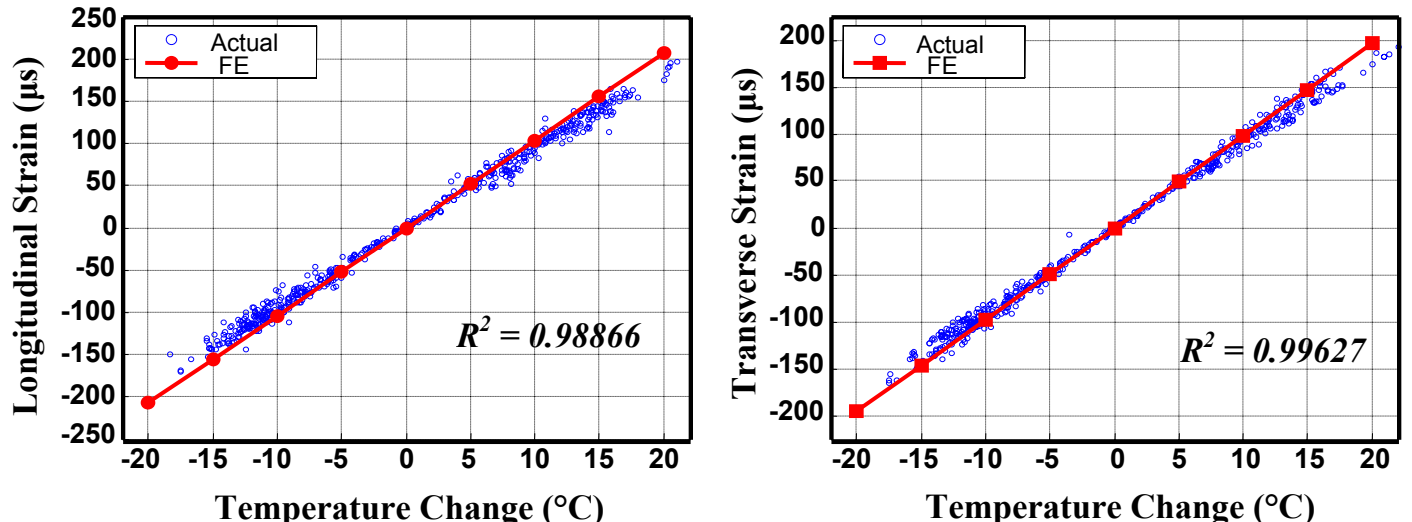

(c) Location 3

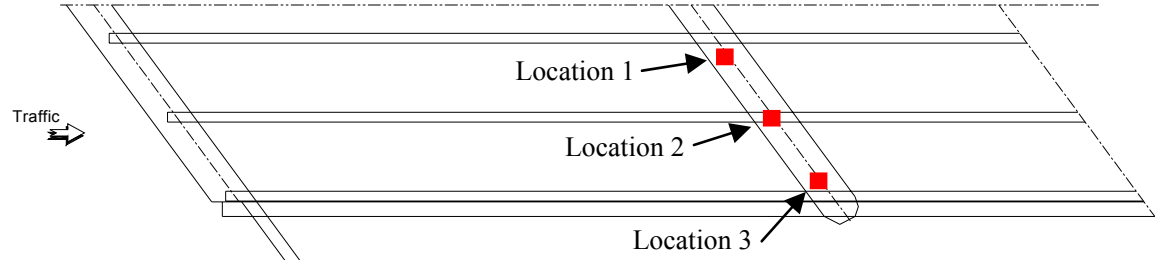

(d) Instrumented bridge section

Figure 5.5. Comparison of longitudinal and transverse strains due to temperature change at pier 1 
Longitudinal Direction

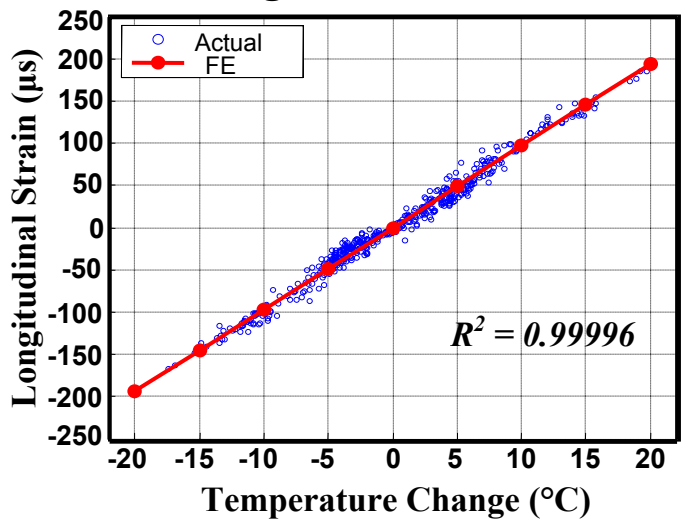

Transverse Direction

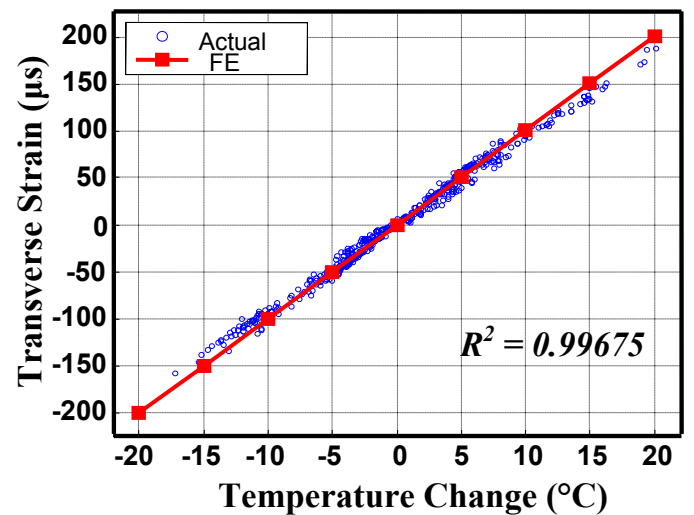

(a) Location 1

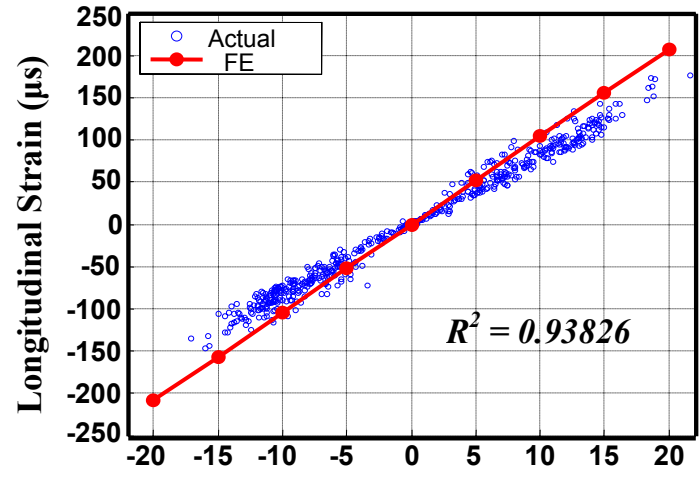

Temperature Change $\left({ }^{\circ} \mathrm{C}\right)$

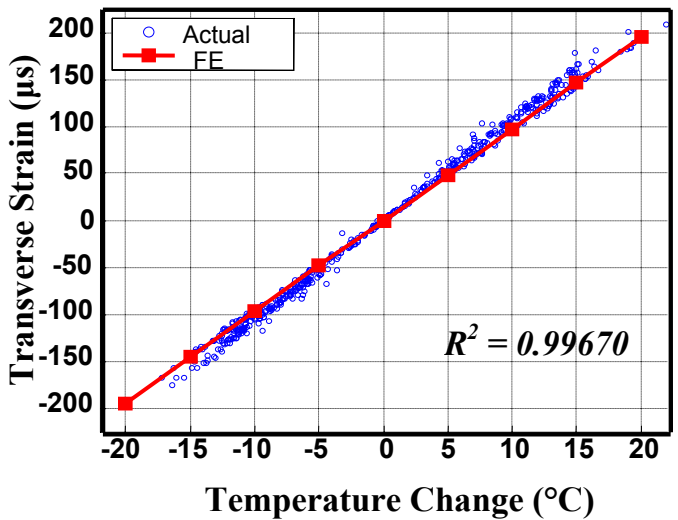

(b) Location 2
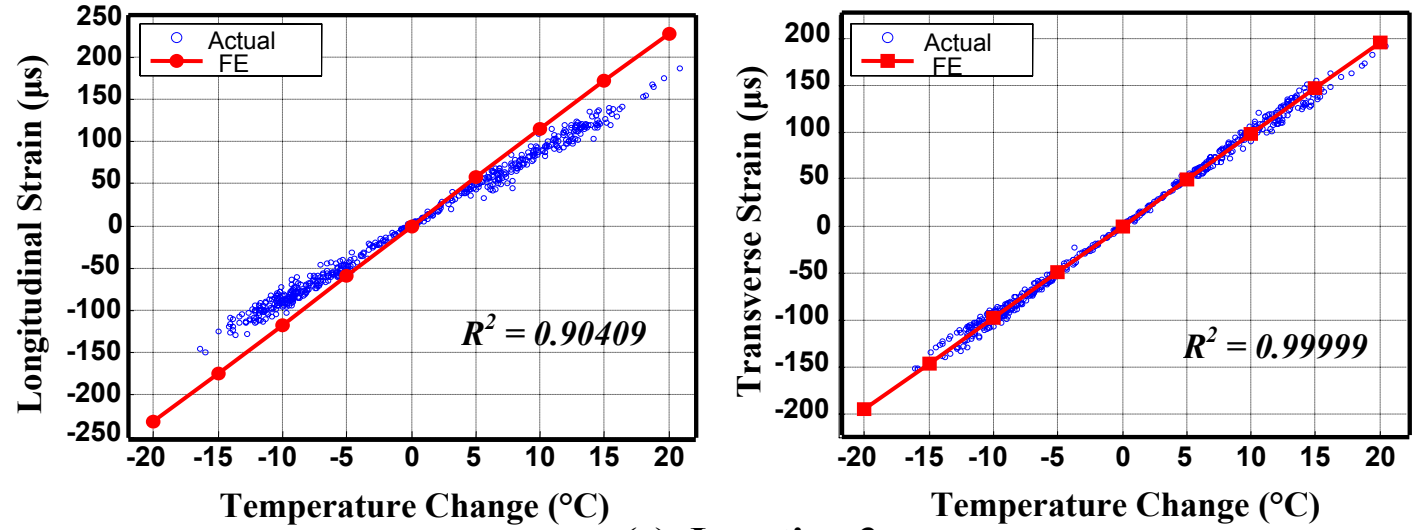

(c) Location 3

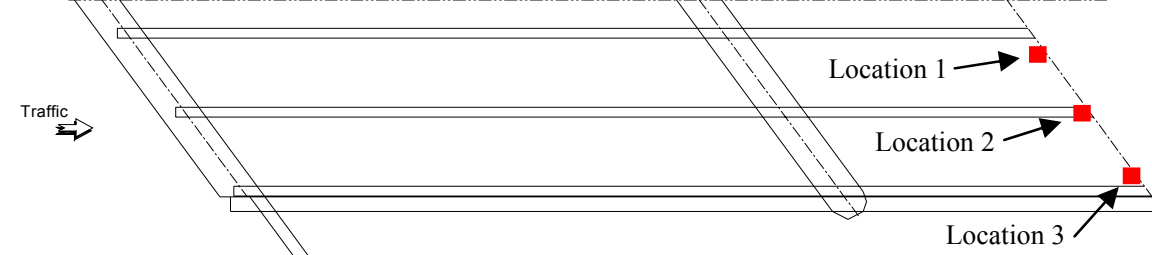

(d) Instrumented bridge section

Figure 5.6. Comparison of longitudinal and transverse strains due to temperature change at mid-span 2 


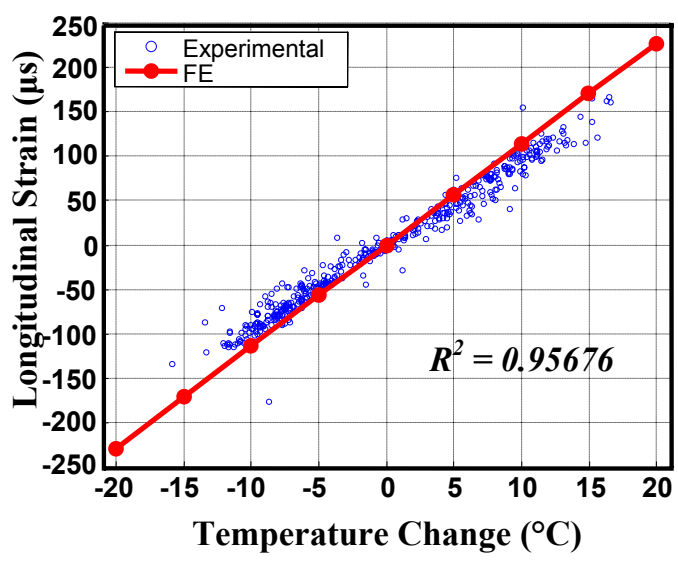

(a) Abutment 1 - top flange

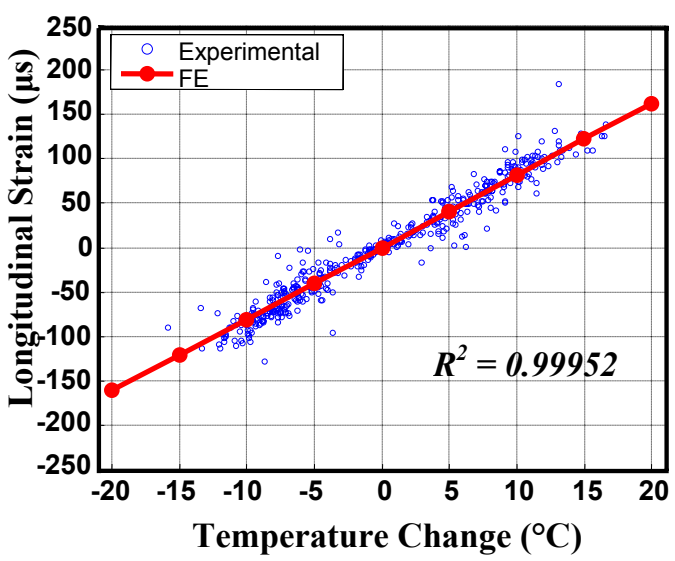

(b) Abutment 1 - bottom flange

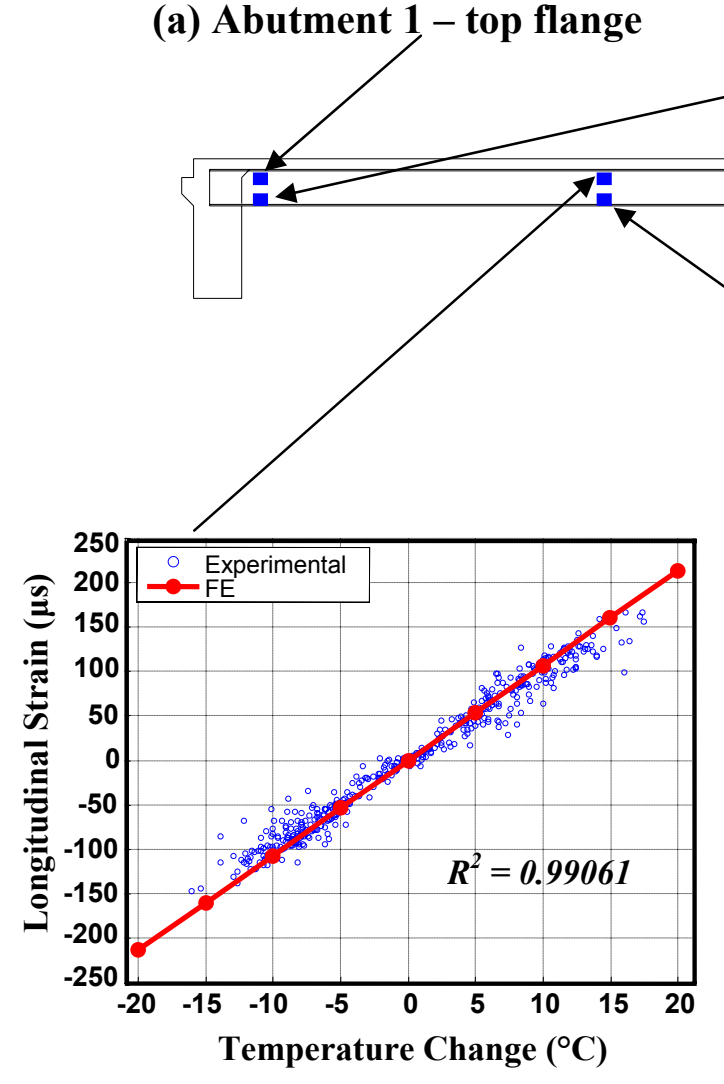

(c) Mid-span 1 - top flange
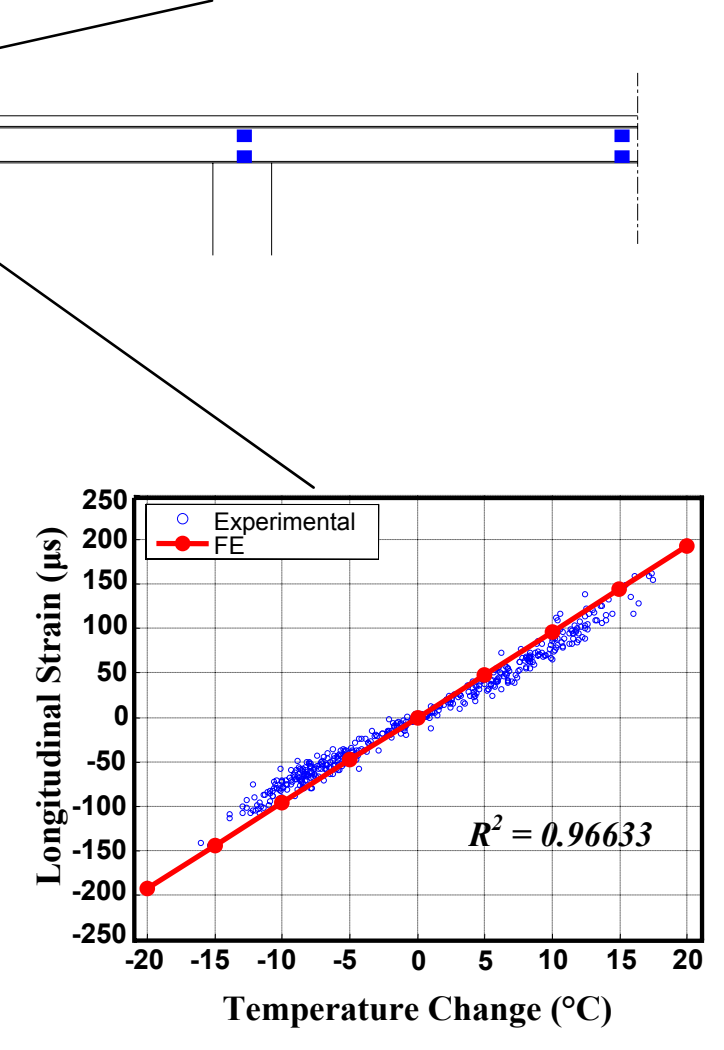

(c) Mid-span 1 - bottom flange

Figure 5.7. Comparison of longitudinal strain in the middle girder due to temperature change at abutment 1 (a-b) and mid-span 1 (c-d). 


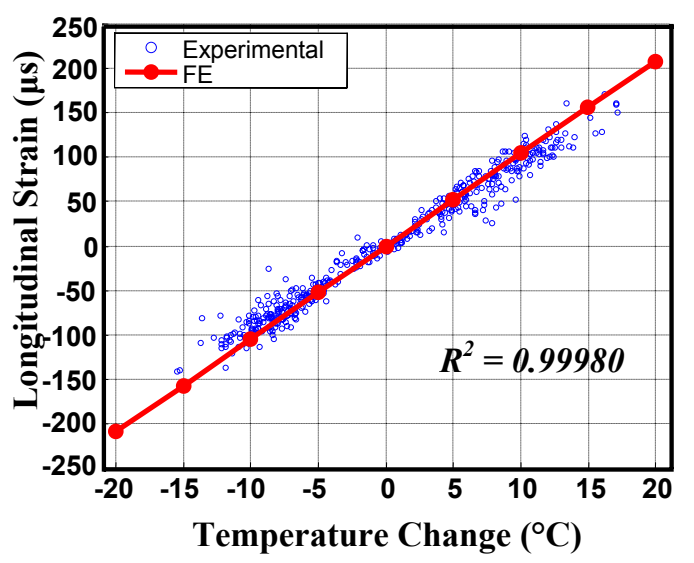

(a) Pier 1 - top flange

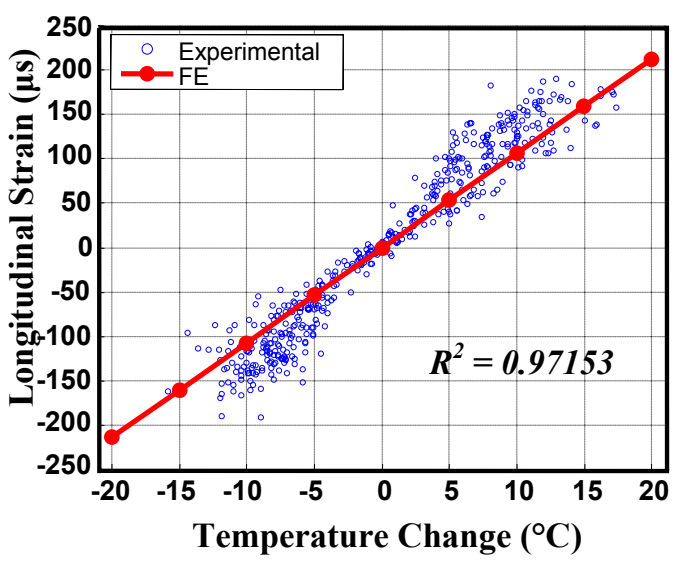

(b) Pier 1 - bottom flange

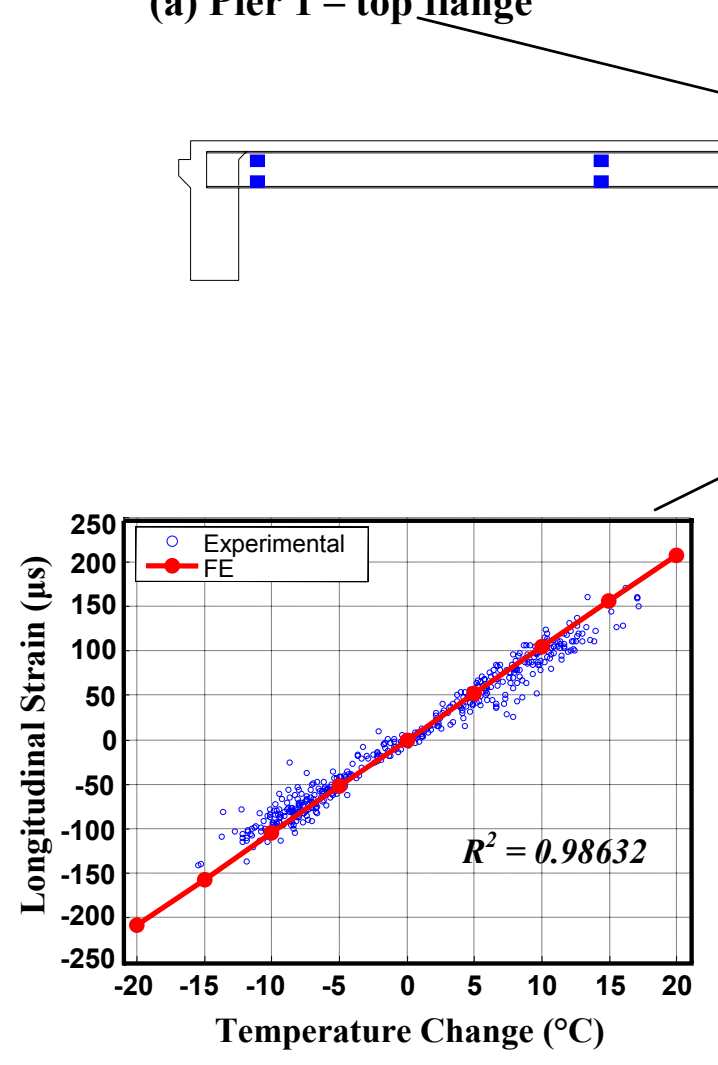

(c) Mid-span 2 - top flange

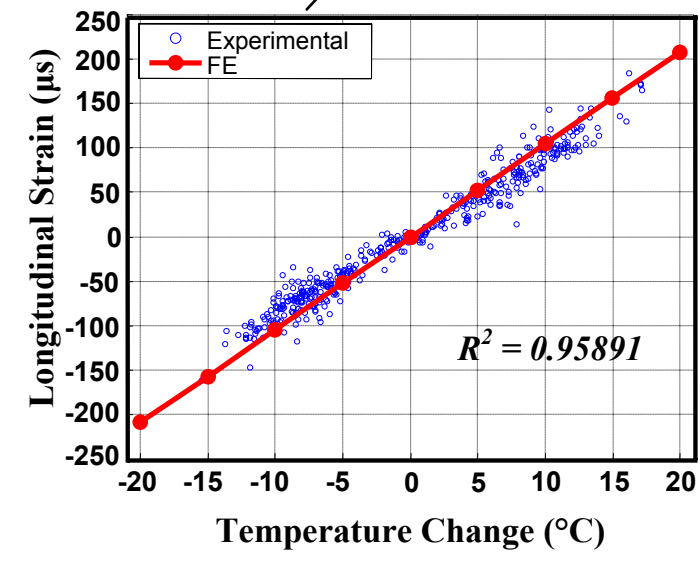

(c) Mid-span 2 - bottom flange

Figure 5.8. Comparison of longitudinal strain in the middle girder due to temperature change at pier 1 (a-b) and mid-span 2 (c-d). 
various locations due to changing temperature using instrumented measurements and $\mathrm{FE}$ results. The experimental results are obtained according to the procedure outlined in the "Sensor Data Interpretation" section of this chapter and the FE results are obtained directly from the FE output. Figures 5.3 - 5.6 present the comparison between the finite element and experimental values of the longitudinal and transverse strain in the bridge deck caused by changing temperature. The comparison of the longitudinal strain in the girders caused by temperature variations is shown in Figures 5.7 and 5.8.

Each graph in Figures 5.3 - 5.8 includes a value for the coefficient of determination $\left(R^{2}\right)$ in the lower right hand corner. The coefficient of determination is a number between 0 and 1 that shows how close estimated values correspond to actual data. The closer $R^{2}$ is to 1 , the better the agreement between estimated and actual values. In this case, the estimated values are the finite element strain values and the actual values are obtained from the best fit line through the scatter plot of experimental data. It should also be noted that a small amount of error may be present within the experimental values. Although every precaution was taken during the placing of the sensors, it cannot be guaranteed that each sensor is aligned perfectly in all three directions. The sensors within the deck are also vulnerable to contact and slight movement during deck casting. Slight misalignments of the sensors as well as a gage sensitivity of $\pm 1 \mu \mathrm{s}$ may account for very small errors between the analyses. Considering all of these factors, each comparison having a coefficient of determination above 0.9 indicates outstanding agreement between the sensor measured and finite element values for strain on the Evansville Bridge caused by changing temperatures.

\subsection{Conclusions}

A finite element model has been developed to predict the response of the Evansville Bridge to structural and thermal loading conditions. Comparisons between FE-calculated and experimentally measured changes in strain due to the weight of the deck and changing thermal conditions indicate exceptional agreement. This agreement serves to 
validate the accuracy of the finite element model in calculating the response of the Evansville Bridge to dead loads and thermal loading. 


\section{CHAPTER SIX}

\section{EFFECT OF CHANGING THERMAL CONDITIONS ON EVANSVILLE BRIDGE}

\subsection{Introduction}

Integral abutment bridges are jointless bridges where the deck is continuous and connected monolithically to the abutment wall with a moment-resisting connection (Jayaraman et al., 2001). Since the bridge's superstructure is continuous with the abutments, the changing temperature of the structure will cause horizontal movement of the abutments. To account for these displacements, abutments are commonly supported on steel piles that are oriented with their weak axis perpendicular to the bridges longitudinal axis, allowing the piles to bend laterally along their weak axis while the abutment rotates rigidly during structure expansion and contraction (Civjan et al., 2004). Naturally, the soil backfill behind the abutments will resist the movement of the abutment walls, inducing additional stress in the bridge superstructure, which Roman et al. (2002) found can be significantly greater than those permitted by design specifications. Currently, there is no design standard for integral abutment bridges and AASHTO Standard Specifications for Highway Bridges (AASHTO, 2002) assumes that the movement of the integral abutments fully relieves the thermal stresses (William et al., 2005). However, instrumentation and modeling analyses have shown that stresses do arise in integral abutment bridges as a result of temperature loading. The response of the Evansville Bridge to changing temperatures as well as the influence of the backfill constraint on this response will be investigated in this chapter.

\subsection{Abutment Movement}

The plot in Figure 6.1 (a) shows the time history of ambient temperature at the Evansville Bridge site during the first 650 days after deck pouring. The changing thermal conditions cause the bridge to expand and contract resulting in span length changes. The span 
length changes of the edge and middle spans were recorded via two convergence meters and the sensor readings are plotted over time in Figures 6.1 (b) and (c) respectively.

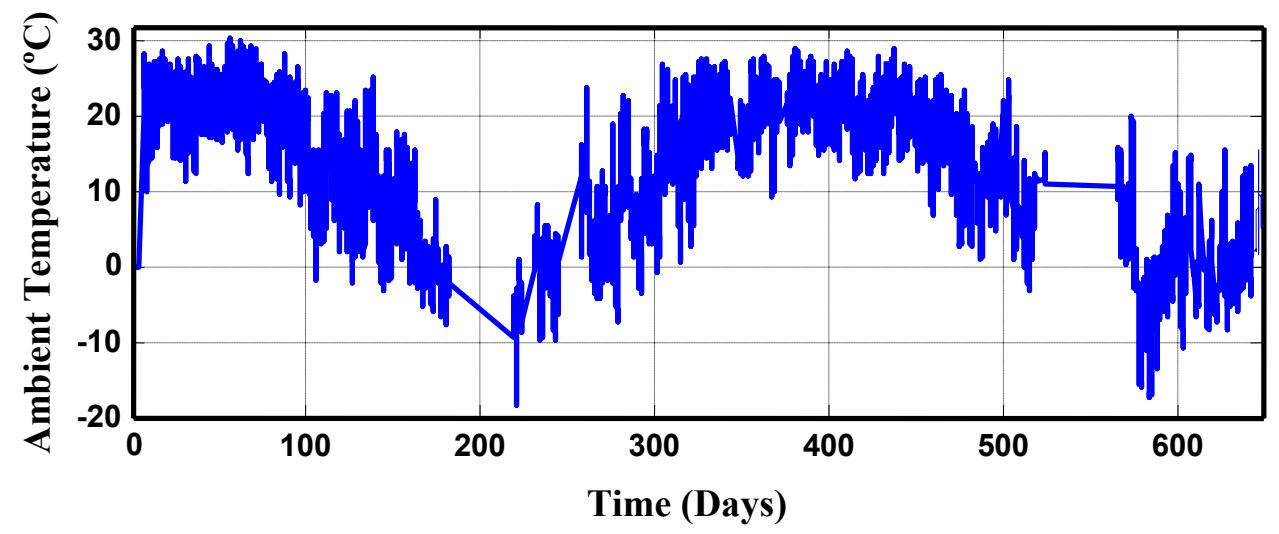

(a) Ambient temperature time history

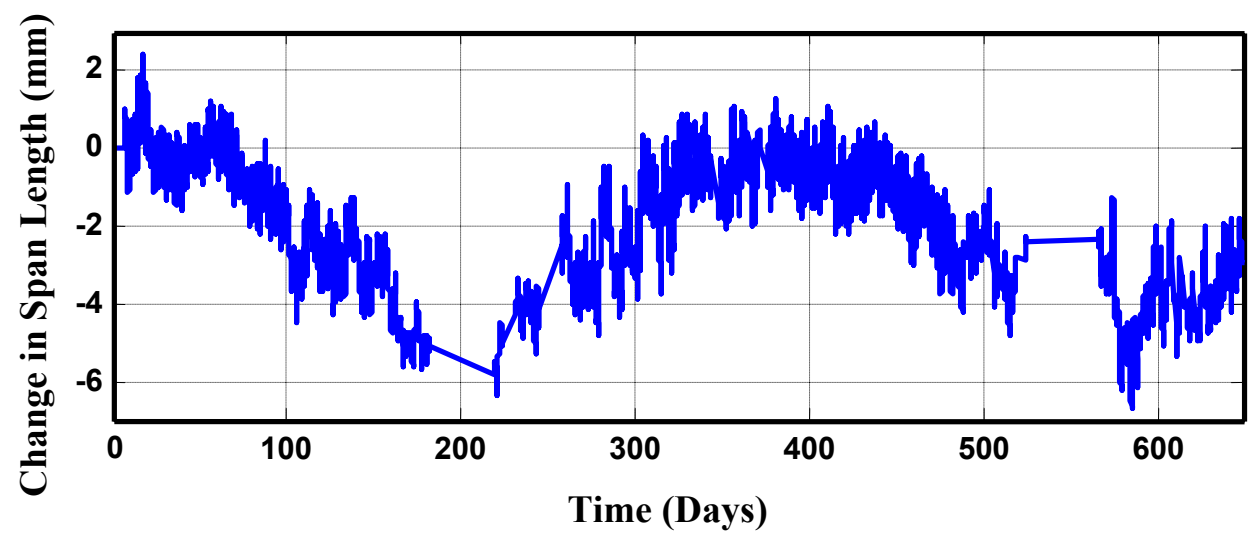

(b) Change in edge span length

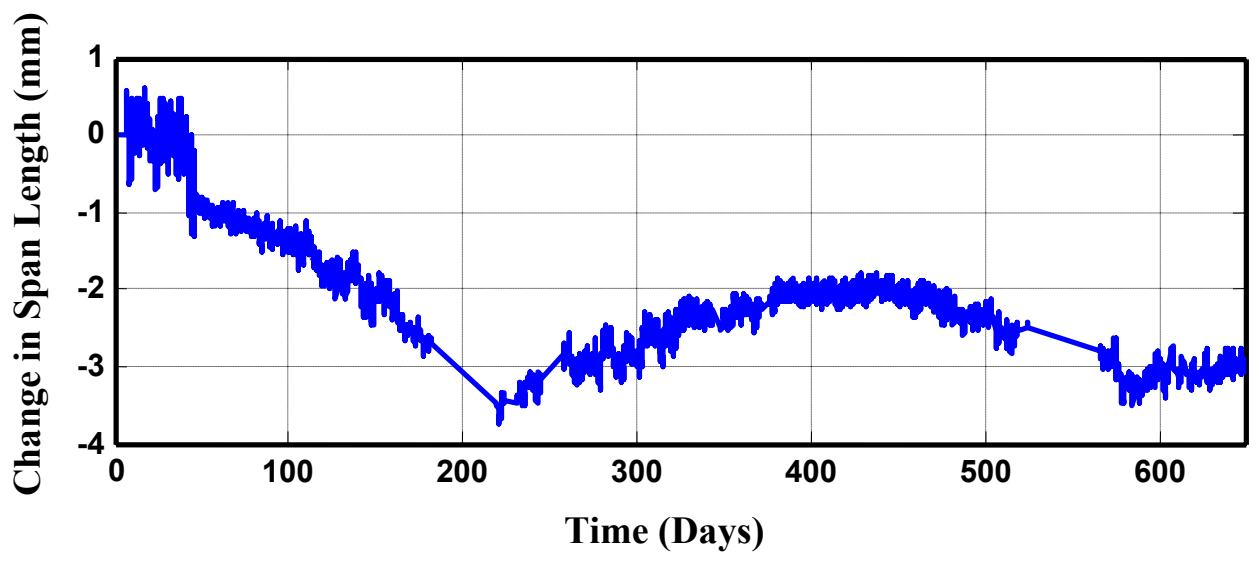

(c) Change in middle span length

Figure 6.1. Time histories of ambient temperature and span length changes 
Figure 6.1 shows a very good correlation between the ambient temperature and the changes in span length. As would be expected, the bridge appears to expand as the temperature increases and contract as the temperature decreases.

In order to understand the early age behavior of the integral abutments, the signal in Figure 6.1 (a) must be more closely examined during the first 30 days of data recording. The connection between the deck and the abutment wall was cast on day 7 causing the structure to act as a statically indeterminate frame. At this point, the bridge weight along with temperature changes caused the abutment to deflect horizontally outwards approximately $1.3 \mathrm{~mm}$ as shown in Figure 6.2. However, at day 17 the abutment backfill was placed and compacted. Following the placement of the backfill, the abutment will return to its original position and will be compacted by the soil pressure as well as changing temperatures. Figure 6.2 shows a compression in the main girder of approximately $1.8 \mathrm{~mm}$ due to the earth pressure.

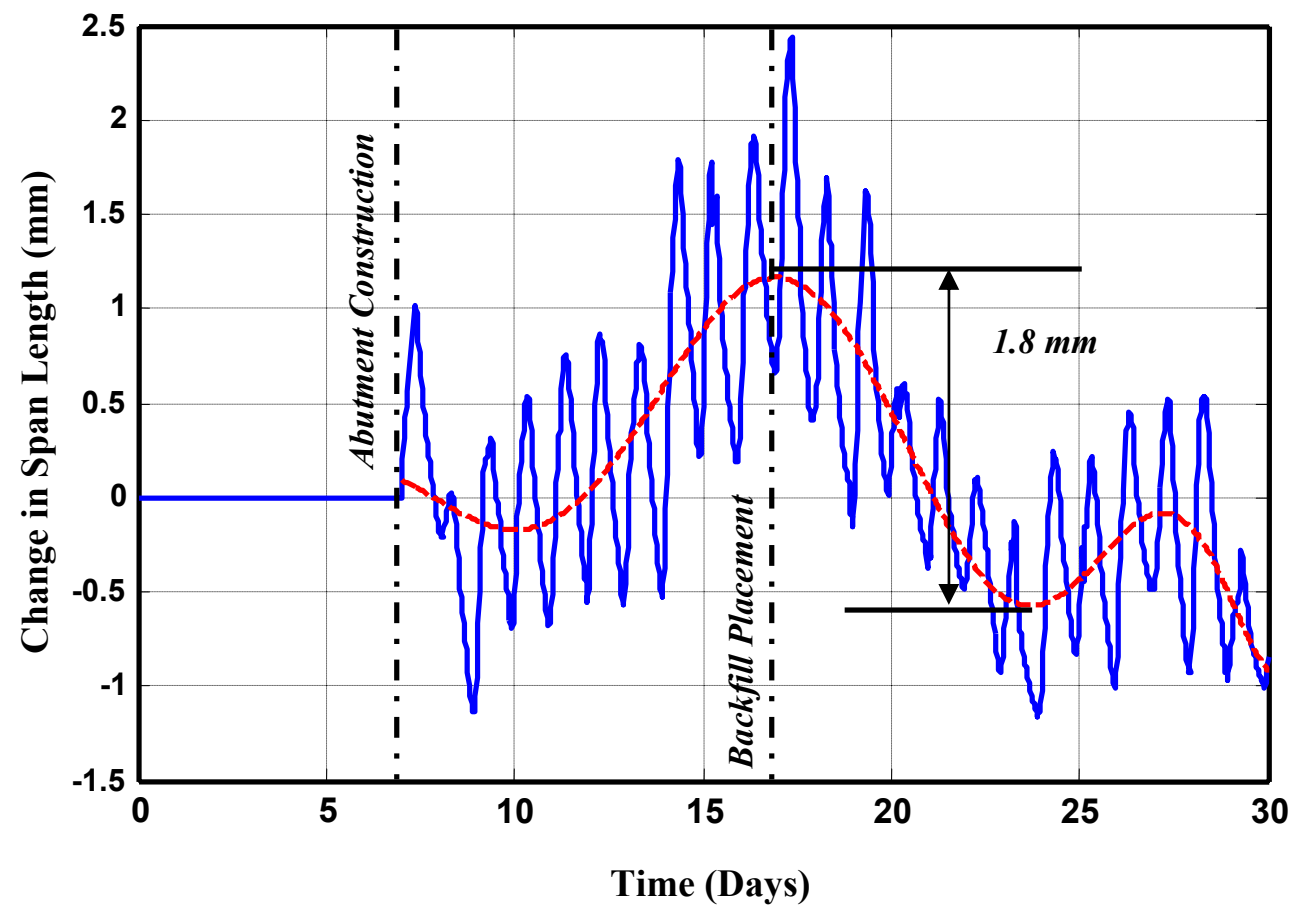

Figure 6.2. Change in edge span length during first month of data collection 
The force of the backfill acting axially on the abutment wall will cause compression in the main girder and the magnitude of this compression can be calculated theoretically. The edge span can be idealized as a simply supported beam with an axial load compressing the beam from the roller end. The equations describing the amount of compression are:

$$
\begin{aligned}
& F=1 / 2 k_{p} \gamma h^{2} b \sin (\psi) \\
& \delta=F L / E_{s} A_{s}
\end{aligned}
$$

where $k_{p}$ is the passive earth pressure (3.85 for angle of internal friction $\varphi=36^{\circ}$ ), $\gamma$ is the unit weight of soil $\left(17.6 \mathrm{kN} / \mathrm{m}^{3}\right), h$ is the height of the abutment wall and bridge superstructure $(2.74 \mathrm{~m}), b$ is the girder spacing $(2.06 \mathrm{~m}), L$ is the span length $(14.78 \mathrm{~m})$, $E_{s}$ is the modulus of elasticity of steel $(200 \mathrm{GPa}), A_{s}$ is the cross sectional area of the girder $\left(0.016 \mathrm{~m}^{2}\right)$, and $\psi$ is the skewed angle of the bridge $\left(55^{\circ}\right)$. The theoretical value yielded from Equation 6.2 due to passive earth pressure is $1.98 \mathrm{~mm}$ which reasonably matches the field measured values shown in Figure 6.1. This displacement creates compressive stresses in the girder which are discussed further in the following sections

\subsection{Backfill Constraint}

The initial compression of the main girder by the soil backfill is followed by permanent constraints on the expansion and contraction of the structure by the backfill. The bridge superstructure consists of steel girders which are assumed perfectly tied to a steel reinforced concrete deck. Theoretically, if the bridge is free to expand and contract axially under temperature loading as is assumed during design, the change in girder span length, $\Delta_{b}$, can be computed from the equation (Girkon et al., 1989):

$$
\Delta_{b}=\frac{\alpha_{c}\left(\Delta T_{c}\right) E_{c} A_{c}+\alpha_{s}\left(\Delta T_{s}\right) E_{s} A_{s}}{E_{c} A_{c}+E_{s} A_{s}} L
$$


where $\alpha_{c}$ and $\alpha_{s}$ are the coefficients of thermal expansion of concrete and steel, $E_{c}$ and $E_{s}$ are the moduli of elasticity for concrete and steel, $A_{c}$ and $A_{s}$ are the cross sectional areas of the concrete and steel sections, $\Delta T_{c}$ and $\Delta T_{s}$ are the temperature changes in concrete and steel, $L$ is the span length.

Equation 6.3 is valid under the assumption that there is full composite action at the deckgirder interface, meaning that at any point along the interface, the displacement of the bottom of the concrete deck and the top surface of the girder are identical. However, it has been previously shown that the deck-girder interface on the Evansville Bridge does not exhibit full composite action. If there is no composite action at the interface, the change in span length can be computed as:

$$
\Delta_{b}=\alpha_{s} \Delta T_{s} L
$$

Although the shear studs do not provide full composite action between the deck and the girders, there is some degree of connection between the two surfaces. Theoretically, the actual change in span length under temperature loading should fall between the values from Equations 6.3 and 6.4 .

Figure 6.3 (a) plots the change in the length of the edge span due to uniform temperature loading calculated from experimental measurements, FE analysis, and Equations 6.3 and 6.4. First of all, this plot clearly shows that the FE values match the experimental values more accurately than do the values computed using Equations 6.3 and 6.4. However, the plot also shows that neither the FE nor experimental values fall between the values for a fully composite and fully non-composite section as would be expected. In the cases of both temperature increase and decrease, the magnitudes of the FE values for length change are smaller than those for Equations 6.3 and 6.4, indicating that the movements of the bridge in the FE and experimental cases are constrained. The presence of these constraints clearly contradicts the assumption used during design that the movement of the integral abutments relieves all strains that may arise due to the expansion and contraction of the bridge under changing thermal conditions. 


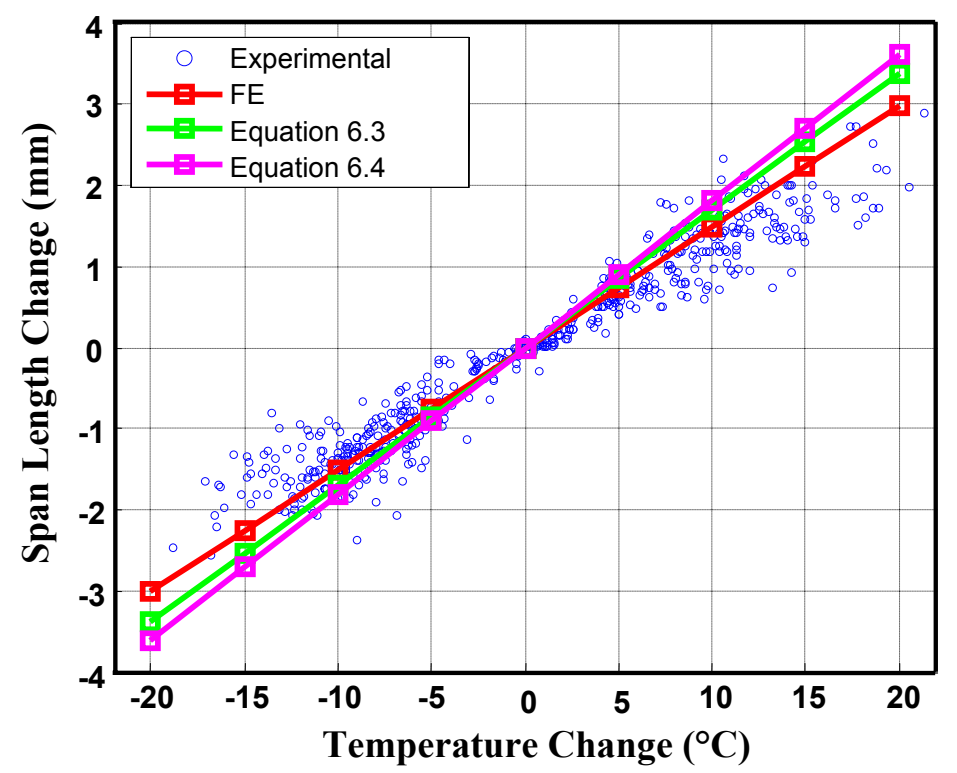

(a)

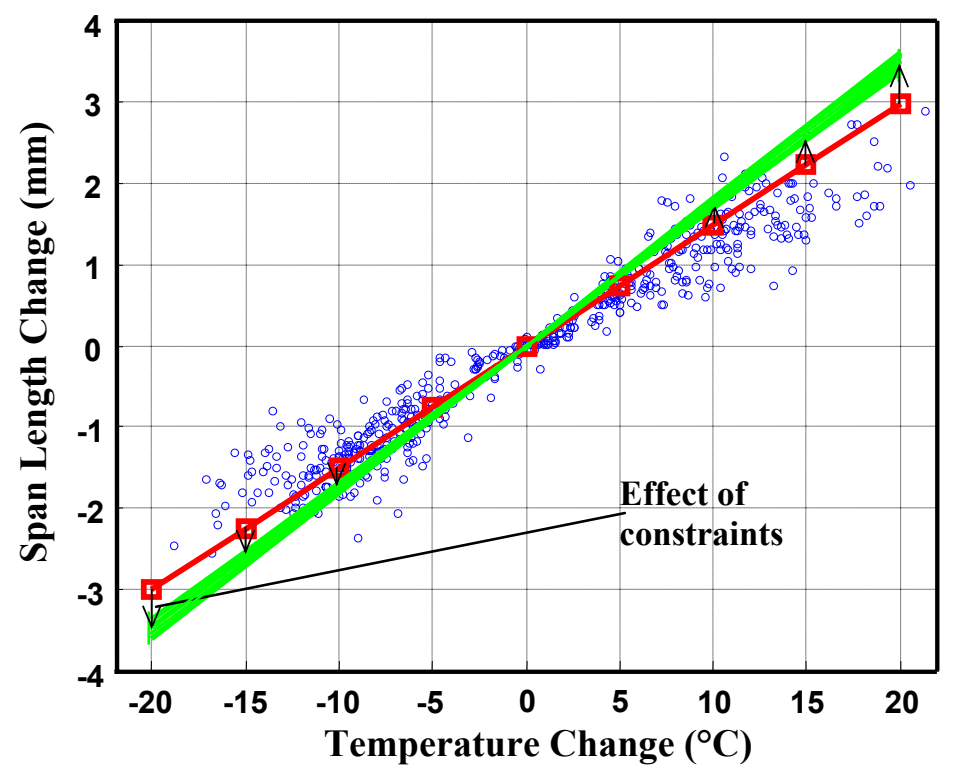

(b)

Figure 6.3. Change in length of span 1 due to uniform temperature changes

Since the exact degree of composite action between the deck and the girder is unknown, where exactly the theoretical values for span length change should fall between the Equation 6.3 and 6.4 values is also unknown. However, Figure 6.3 (b) graphically shows that the effect of external constraints due to integral abutments on the span length change 
will be the difference between the constrained values indicated by the red line and the unconstrained values somewhere in the green area representing the area between the values obtained from Equations 6.3 and 6.4. Thus, the value for the amount of displacement prevented by the constraints on the structure cannot be exactly calculated nor can the amount of additional stress these constraints add to the girder from the information given in this plot. This problem will be addressed in the following sections of this chapter.

\subsection{Experimentally Measured Girder Stresses}

The previous section clearly shows that there are factors present providing resistance to the thermal increase and decrease of the Evansville Bridge length. Considering that these restraints will cause stresses unaccounted for during the design of the structure, it is of interest to determine the magnitude of these stresses. The sensors used to experimentally monitor the strain on the Evansville Bridge collect data at a very low frequency (every 20 minutes), thereby making the response recorded by the sensors void of any influence of traffic loading. Therefore, the girder strain profiles recorded throughout the life of the structure are a result of thermal loading and the weight of the bridge deck.

Strains measured by each sensor can be used to determine the stress at that location using the thermo-elastic relation:

$$
\sigma=E(\varepsilon-\alpha \Delta T)
$$

where $E$ = modulus of elasticity, $\varepsilon$ is the measured strain, $\alpha$ is the coefficient of thermal expansion, and $\Delta T$ is the corresponding temperature change at that location. By using measured strains and temperature in Equation 6.5, experimental time histories for the stresses in the bridge girders can be developed. Figures 6.4 and 6.5 plot the longitudinal stresses in the top and bottom flanges of the main girder and the ambient temperature for the first 600 days after deck pouring as measured by the instrumentation. 


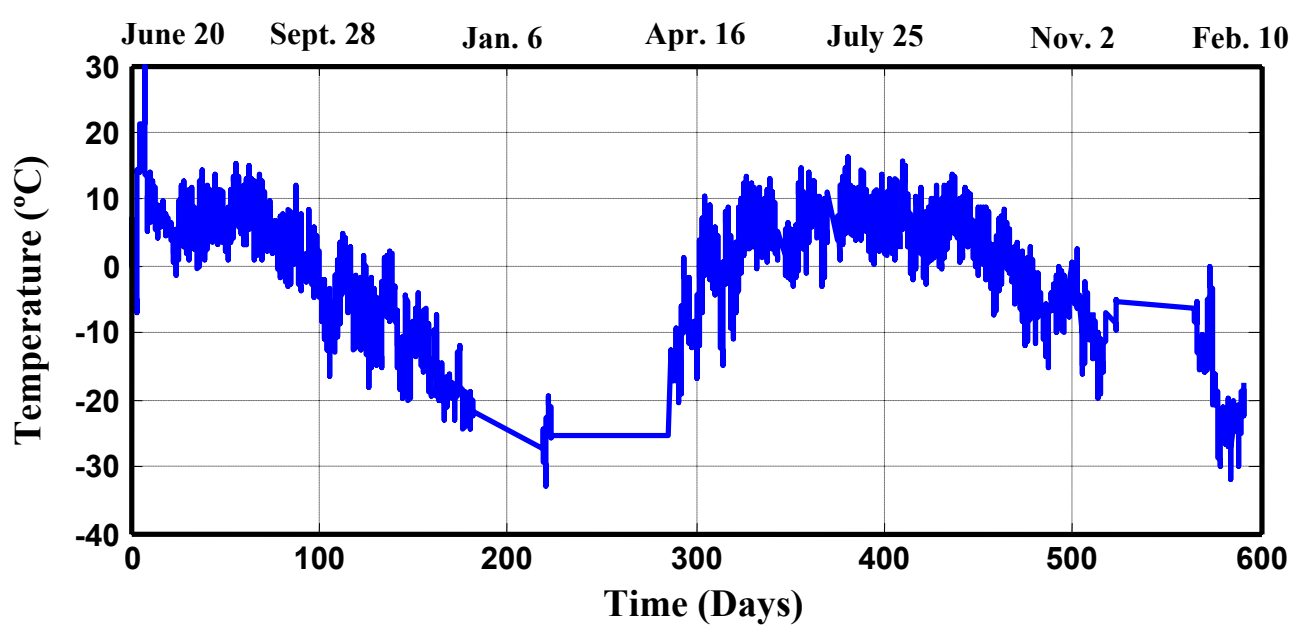

(a) Temperature

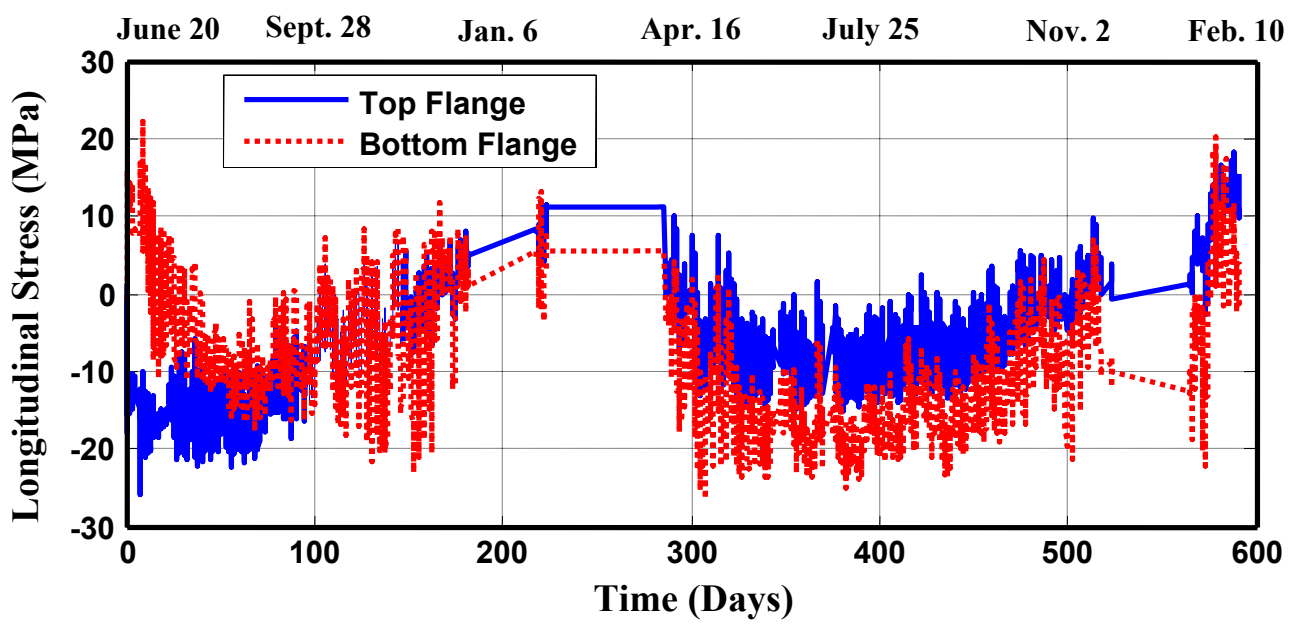

(b) Near abutment 1

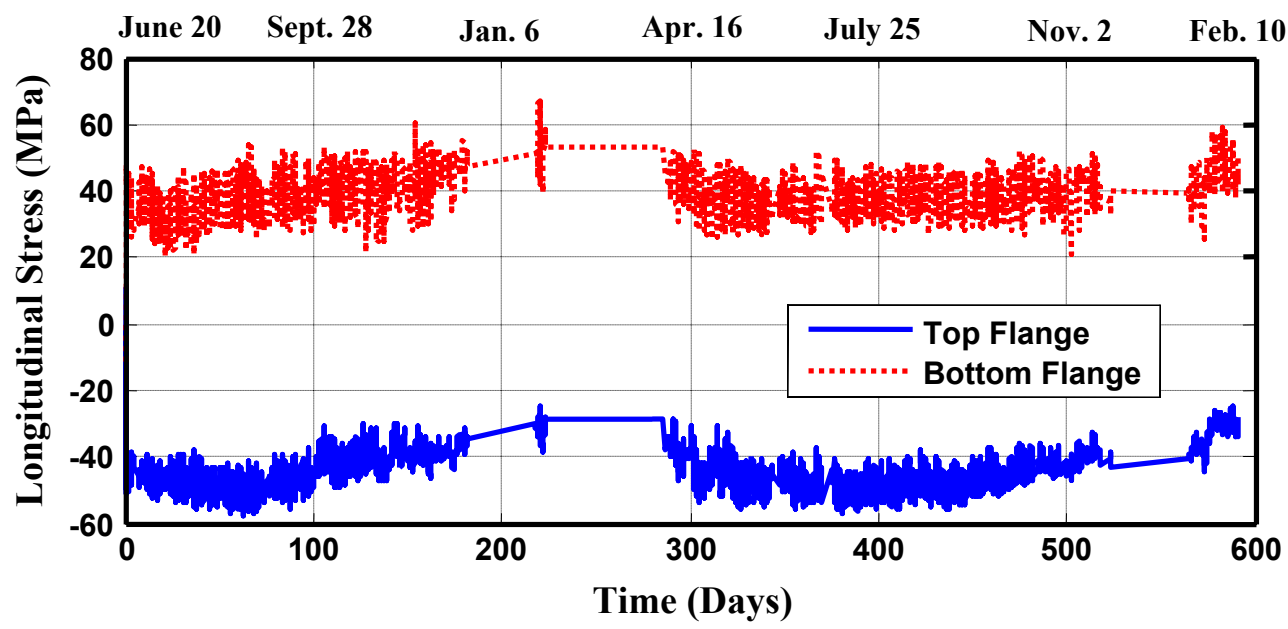

(c) Mid-span 1

Figure 6.4. Experimentally measured longitudinal stresses on middle girder near abutment 1 and at mid-span 1 


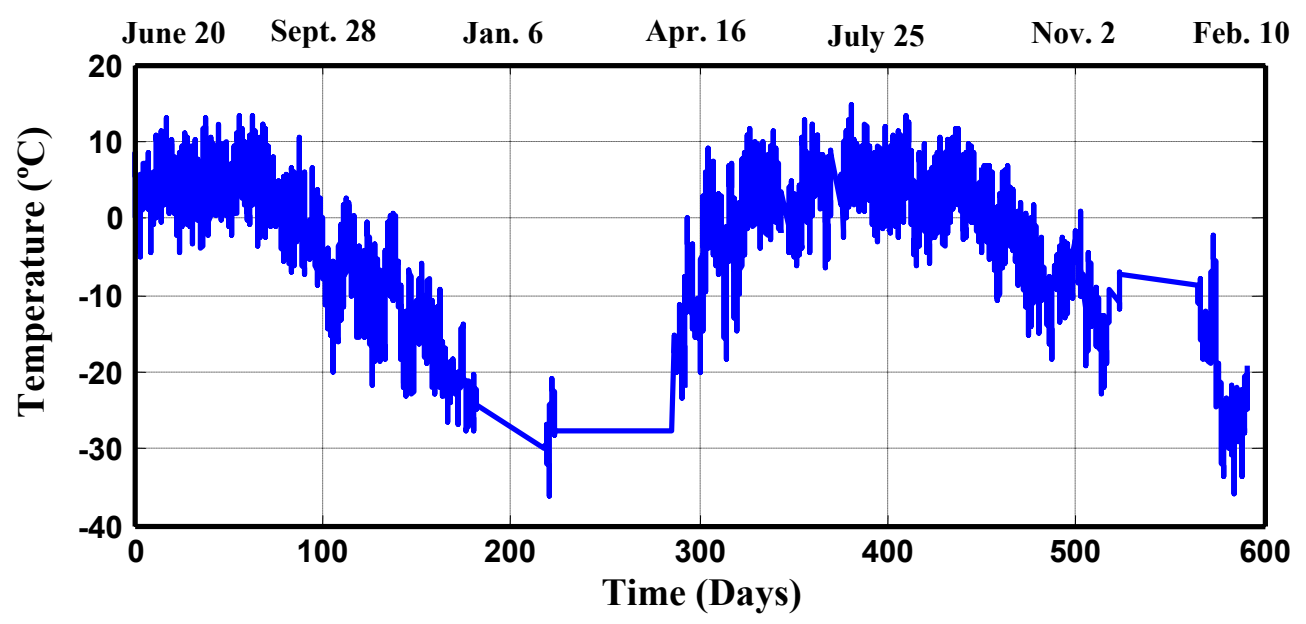

(a) Temperature

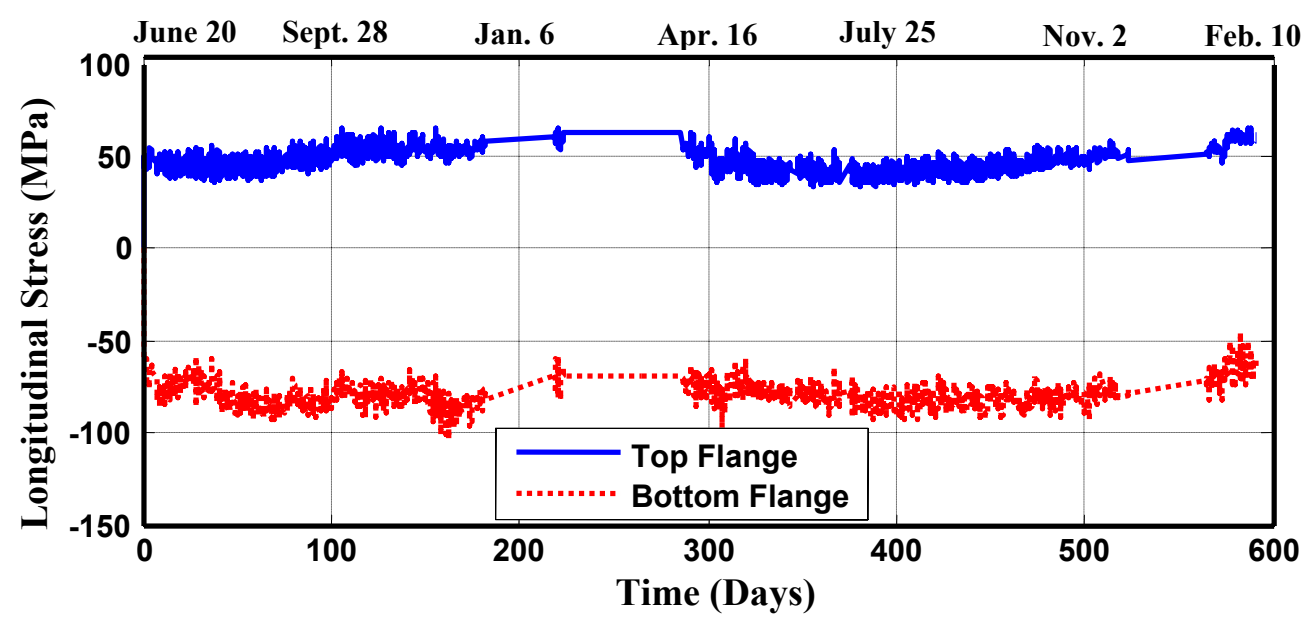

(b) Pier 1

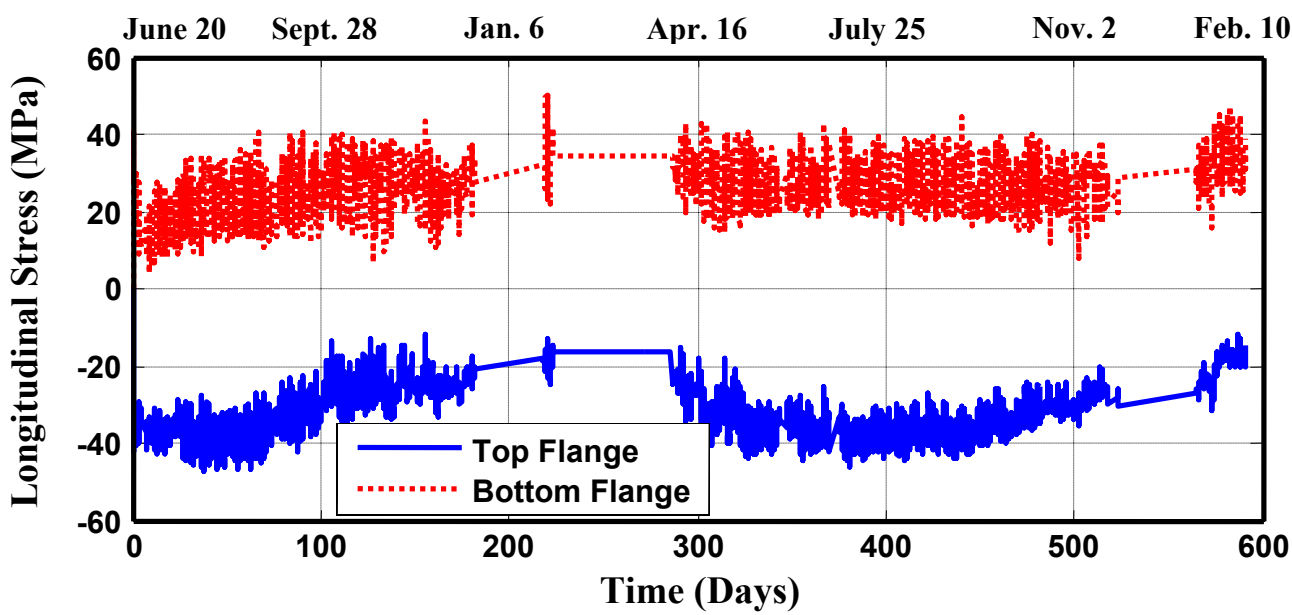

(c) Mid-span 2

Figure 6.5. Experimentally measured longitudinal stresses on middle girder at pier 1 and mid-span 2 
The initial offset from zero of the stress readings at each location is a result of the initial stresses placed on the girders by the weight of the concrete reinforced deck. The following fluctuations in stresses are a consequence of changing temperature conditions. Constraints in the Evansville Bridge cause an increase in stress as the temperature decreases and a stress decrease as the temperature increases as shown in Figures 6.4 and 6.5. As the bridge tends to shrink under temperature decrease, the abutment connection, the supports at the piers, and the girder-deck connection restrains the girders from full shrinkage creating tensile stress in the girders. Conversely, as the bridge expands due to increasing temperature, the same components act to restrain the expansion of the girders which causes compressive stresses to arise. At each location along the length of the girder, the strains on the top and bottom flanges are in opposite states of compression and tension indicating that bending is occurring in the girder. The amount of bending in the girders is mainly the result of the weight of the bridge deck loading with a small amount resulting from the temperature difference of the top and bottom girder flanges.

It is of interest to investigate the magnitude of the axial stress in the girders due to temperature loading because designers assume that these stresses are fully relieved by the expansion and contraction of the structure allowed by the integral abutment system. Using the stresses on the top and bottom flanges of the girders, the total stress in the cross section of the girder at any point can be computed. This total cross sectional stress in the I-beam girders is composed of two components, axial and bending stresses, which are described in Equations 6.6 and 6.7.

$$
\begin{aligned}
& \sigma_{A}=\left(\sigma_{B F}+\sigma_{T F}\right) / 2 \\
& \sigma_{B}=\left(\sigma_{B F}-\sigma_{T F}\right) / 2
\end{aligned}
$$

where $\sigma_{A}$ is the axial stress, $\sigma_{B}$ is the bending stress, $\sigma_{B F}$ is the longitudinal stress on the bottom flange, and $\sigma_{T F}$ is the longitudinal stress on the top flange. The addition of the axial stress and the bending stress will yield the total stress in the cross section. 
The effects of each type of loading on the girders can be easily extracted from the experimental and finite element stress data. Bending stresses recorded in the cross section are primarily caused by the weight of the concrete deck on the girders. A small amount of bending stress can be attributed to a temperature gradient through the girder cross section, meaning that the temperatures on the top and bottom girder flanges are not the same. However, these bending stresses are very small in comparison to deck weight bending stresses. The majority of stresses caused by thermal loading are axial stresses caused by uniform temperature changes in the cross section. Therefore, the amount of stress induced in the girders as a result of the constraining of structure expansion and contraction under changing thermal conditions can be determined by examining the axial stresses in the cross section. Plots in Figure 6.6 show axial stresses that reach a magnitude of approximately $28 \mathrm{MPa}$ during summer months indicating that the magnitude of stress in the main girder caused by temperature fluctuations is significant.

The same technique that was used in Chapter 5 to create scatter plots of the experimental data representing longitudinal strain due to changing temperatures is also applied to the experimental axial stress time histories to determine if the FE model accurately predicts axial stresses in the girders under temperature loading. The comparison plots can be seen in Figure 6.7 and the r-squared values shows that the FE model accurate predicts the axial stresses in the bridge girders under thermal loading. Figures 6.6 and 6.7 show that, contrary to design assumptions, the integral abutments of the Evansville Bridge do not free the structure for expansion and contraction during seasonal temperature variations. In fact, additional stresses arise in the girders as a result of the integral abutments. It is of particular importance to investigate the magnitudes of these compressive axial stresses placed on the girder during temperature fluctuations because they are not accounted for when initially determining the stability of the structure. Actually, William et al. (2005) state that under the effect of such axial stresses combined with traffic loads and vertical weights used in design, the steel main girders may not satisfy AASHTO (2002) stability and yield criteria. The stability of the main girder under self-weight, temperature, and traffic loading will be further investigated later in this study. 

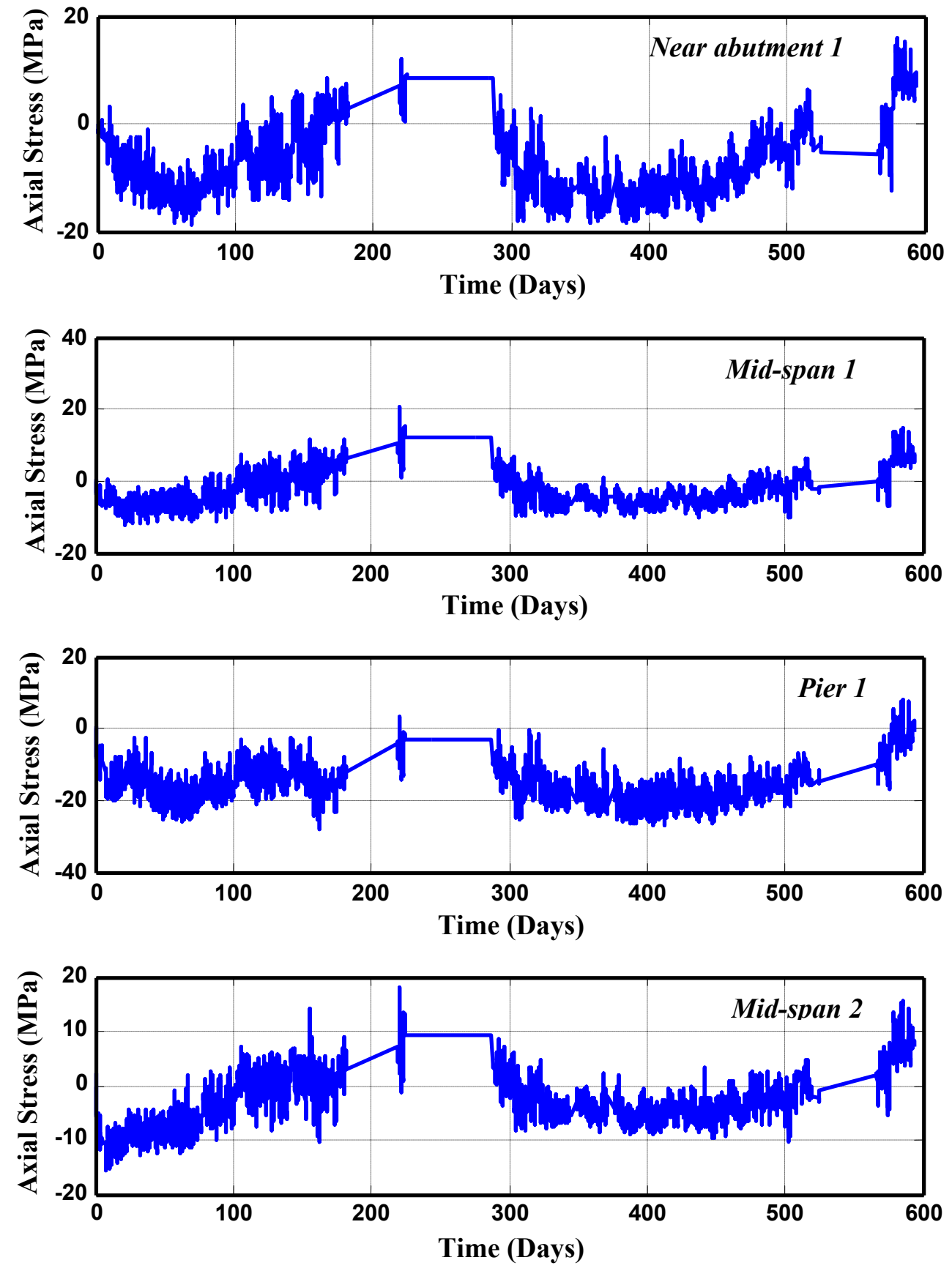

Figure 6.6. Axial stress time histories for middle girder 

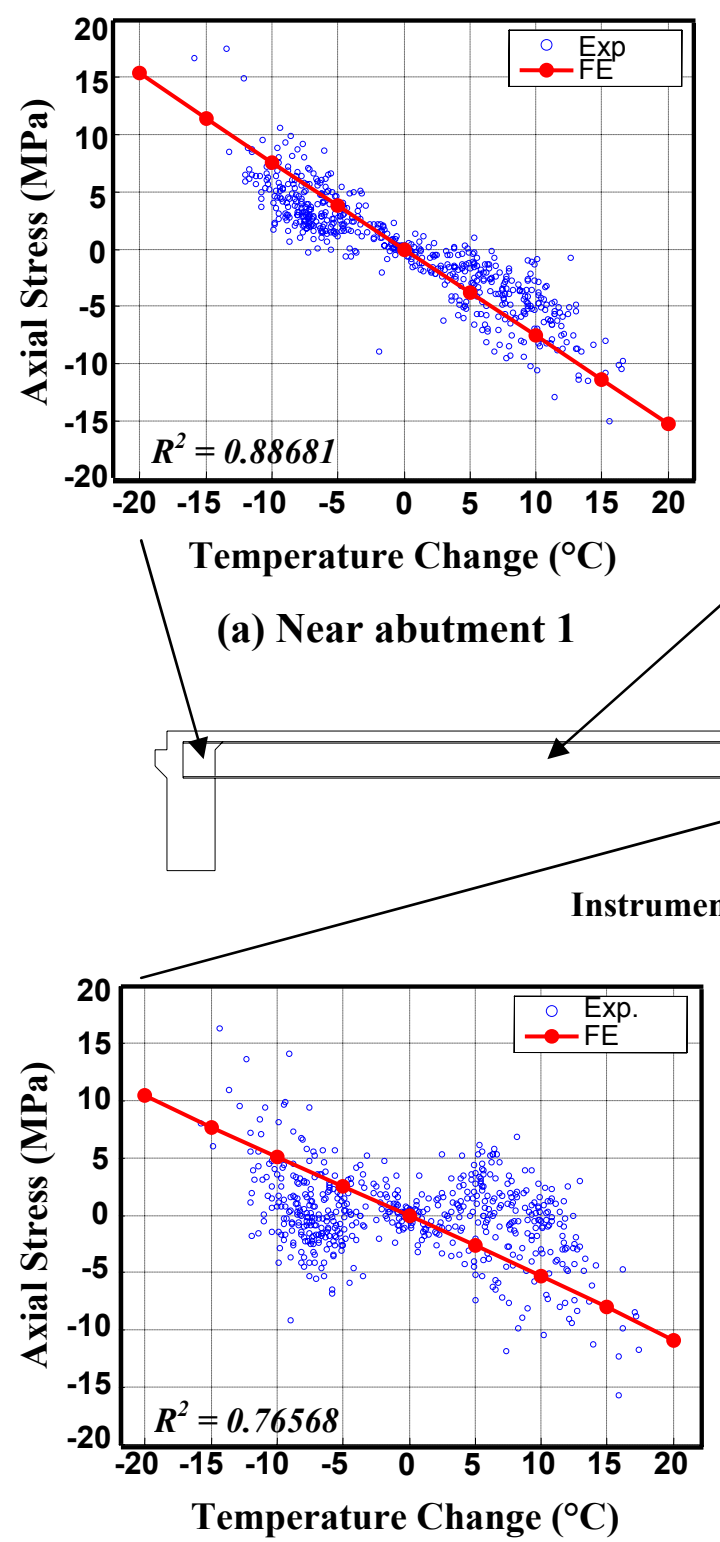

(c) Pier 1

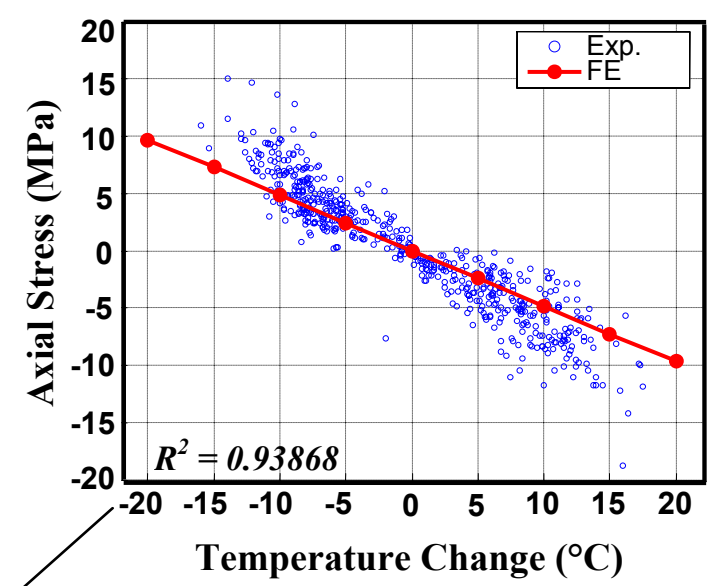

(b) Mid-span 1

Figure 6.7. Comparison of axial stresses induced in girder 2 by changing thermal conditions

\subsection{Stresses in the bridge Deck}

The triaxial state of strain in the concrete reinforced bridge deck as well as the temperature at the strain gage locations was recorded at several locations which were outlined in Chapter 4. These strains, along with the mechanical properties of concrete, determined from material testing and reported by Shoukry et al. (2005), are used in 
Equation 6.8 to determine the state of longitudinal stress at specific locations within the deck.

$$
\sigma_{x}=\frac{E}{(1+v)(1-2 v)}\left[\varepsilon_{x}(1-v)+v\left(\varepsilon_{y}+\varepsilon_{z}\right)-(1+v) \alpha \Delta T\right]
$$

In equation $6.8, E$ is the modulus of elasticity of concrete ( $30.23 \mathrm{GPa}), v$ is the Poisson's ratio for concrete $(0.24), \alpha$ is the coefficient of thermal expansion of concrete (11.26 e-6 $\left.{ }^{\circ} \mathrm{C}\right), \Delta T$ is the recorded temperature change, and $\varepsilon_{x}, \varepsilon_{y}$, and $\varepsilon_{z}$ are the longitudinal, transverse, and vertical measured strain respectively. Using these values, longitudinal stress time histories at the top and bottom layer of steel reinforcement over girders 1, 2, and 3 (see Figure 3.1) at mid-span 1, pier 1, and mid-span 2 are plotted in Figures 6.86.10 .

Throughout the life of the bridge, Figures 6.8-6.10 shows that the sign of the stresses at the top and bottom layer of reinforcement are the same, meaning that the deck is in either tension or compression at both levels. These readings show that the deck as a whole experiences volumetric temperature changes under changing thermal conditions. It is also of interest to note that at mid-span 1 and 2, the stresses at the top surface of the deck are higher than those at the bottom layer. This can be attributed to the constraints placed upon the bottom deck surface expansion and contraction by the girder shear studs and the galvanized steel stay-in-place forms placed between the girders.

The black dash-dot line in the plots of Figures 6.8-6.10 represents the tensile strength of the concrete in the deck. This value is determined experimentally by performing tensile testing on concrete specimen that were gathered during the casting of the bridge deck by Dr. Samir Shoukry and his research team. Shoukry et al. (2005) reported that the tensile strength of the concrete making up the Evansville bridge deck is $4.66 \mathrm{MPa}$ and the compression strength is $44.5 \mathrm{MPa}$. Figures 6.8-6.10 show that during the early age of the bridge deck life, the stress in the deck exceeds the concrete tensile strength. Therefore, 


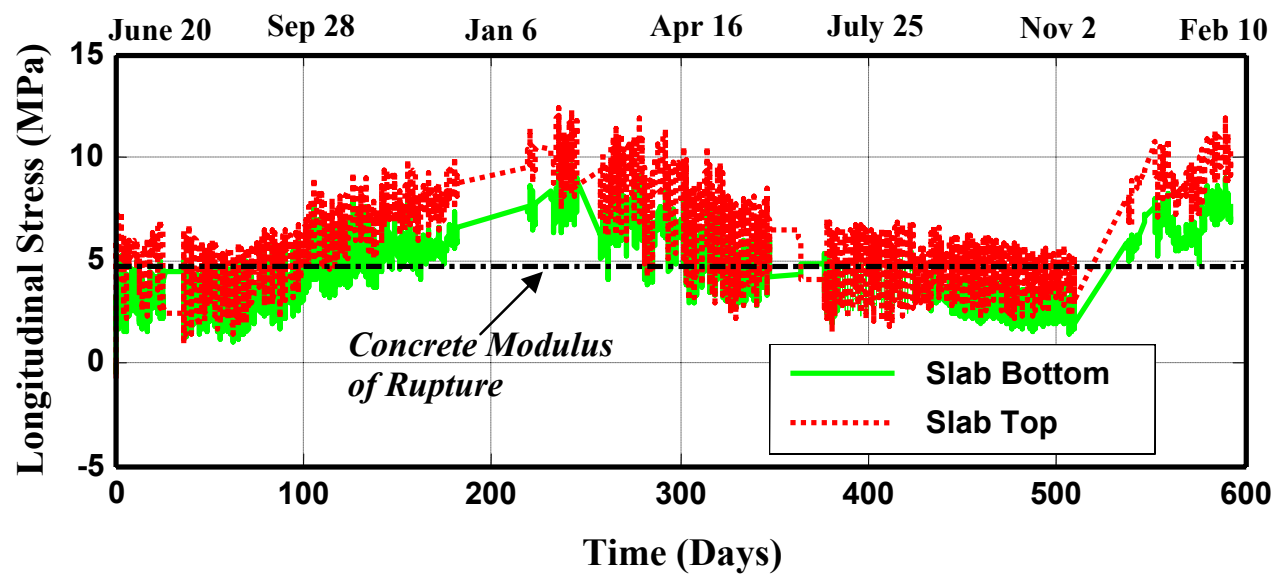

(a) Mid-span 1

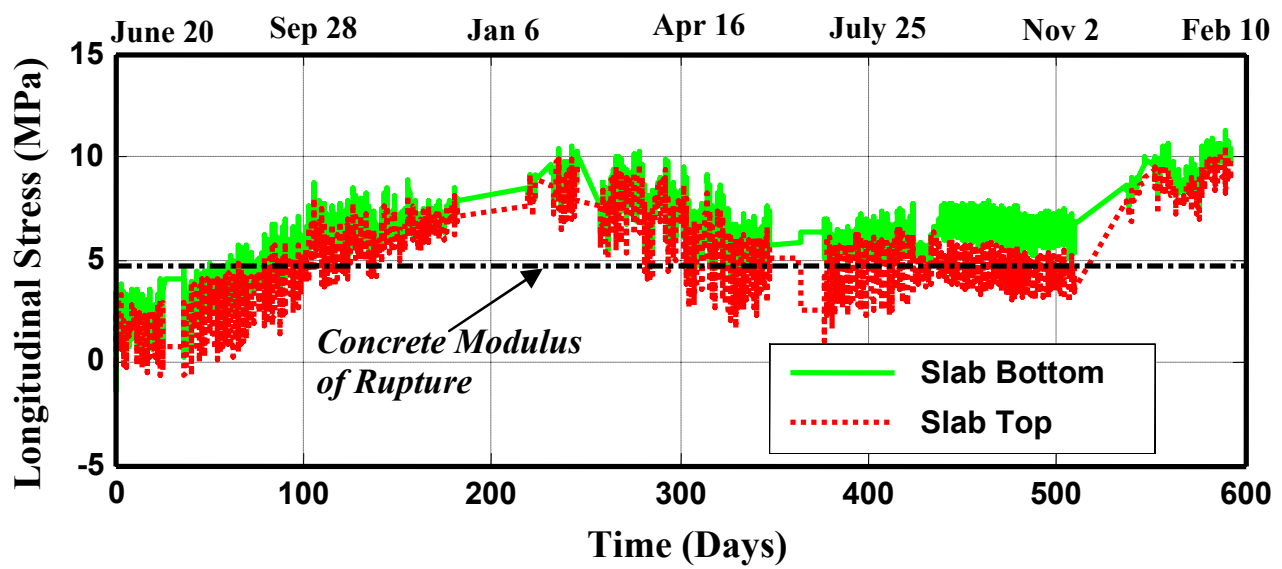

(b) Pier 1

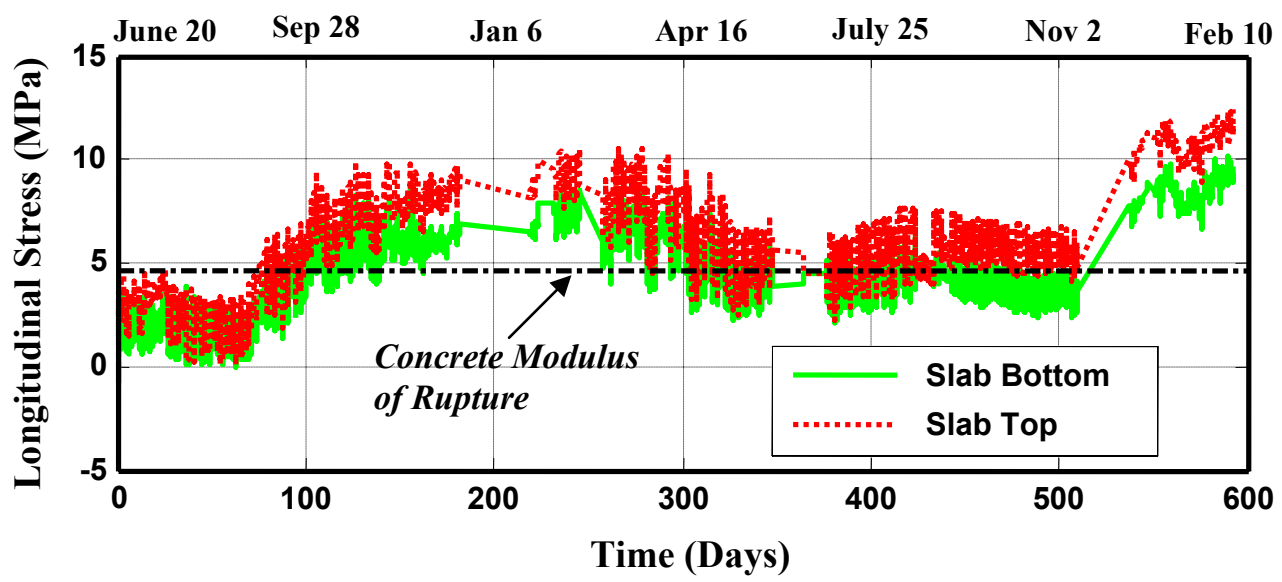

(c) Mid-span 2

Figure 6.8. Longitudinal stress time histories for concrete reinforced bridge deck above girder 1 


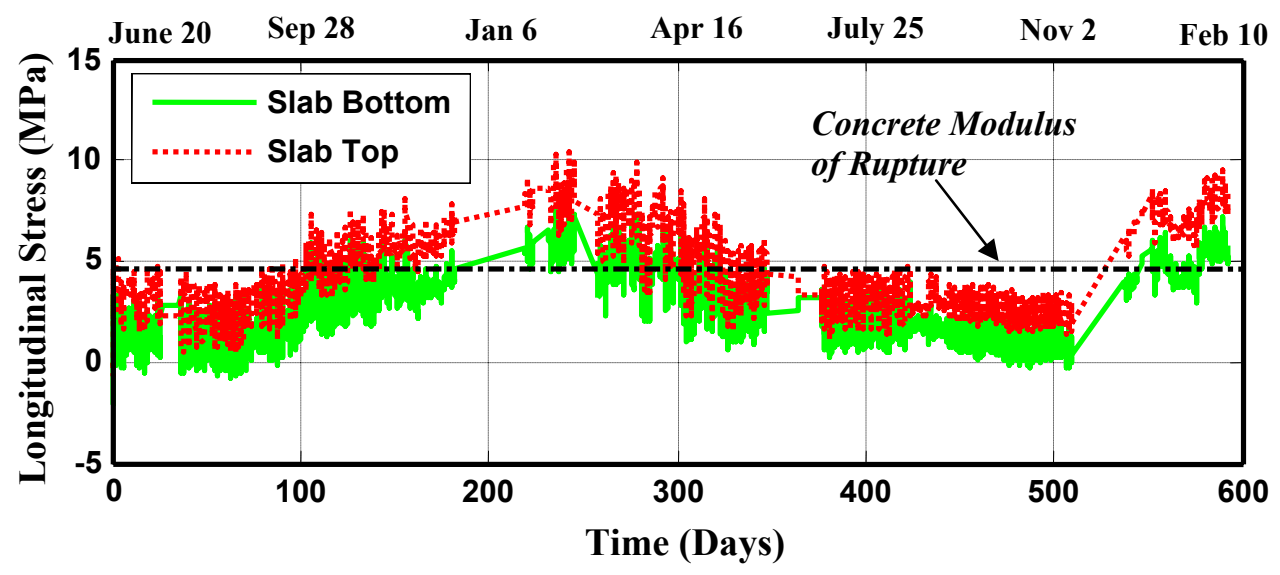

(a) Mid-span 1

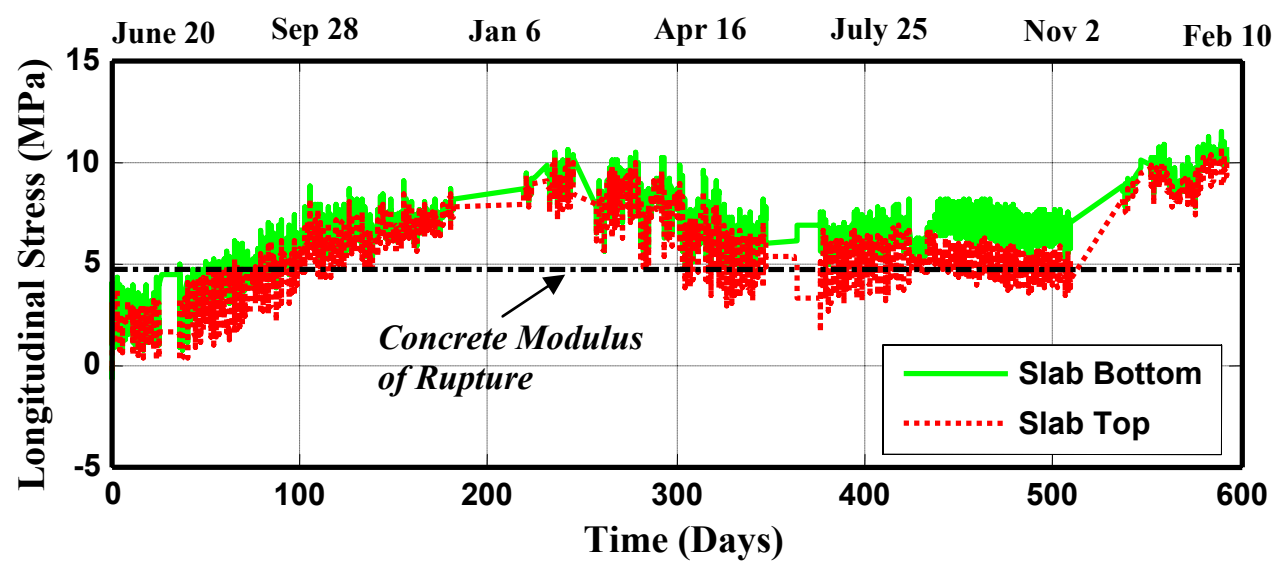

(b) Pier 1

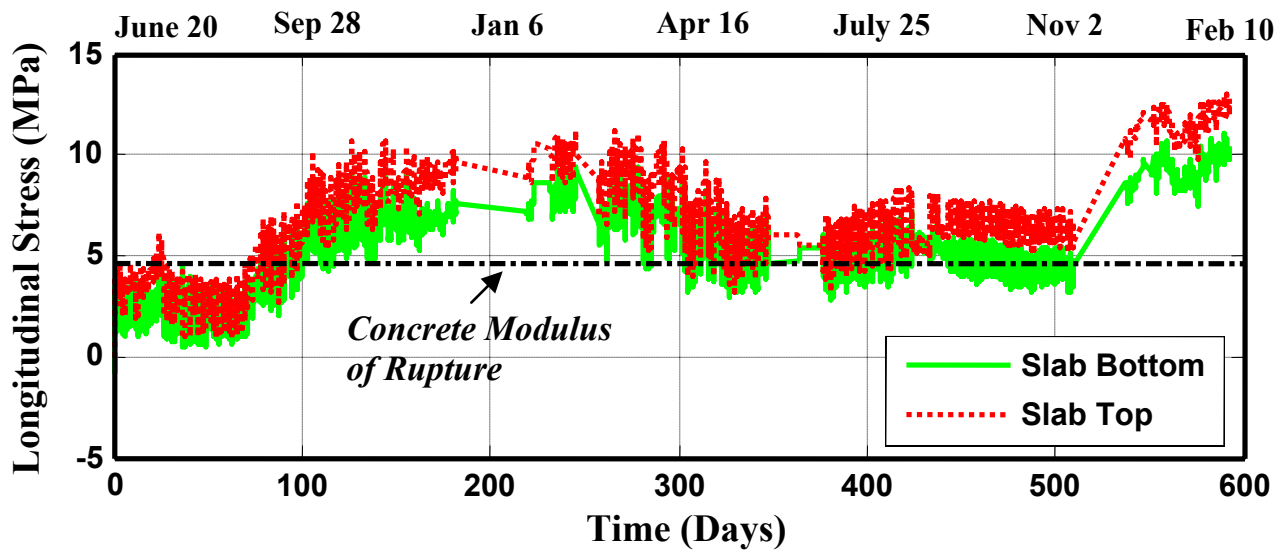

(c) Mid-span 2

Figure 6.9. Longitudinal stress time histories for concrete reinforced bridge deck above girder 2 


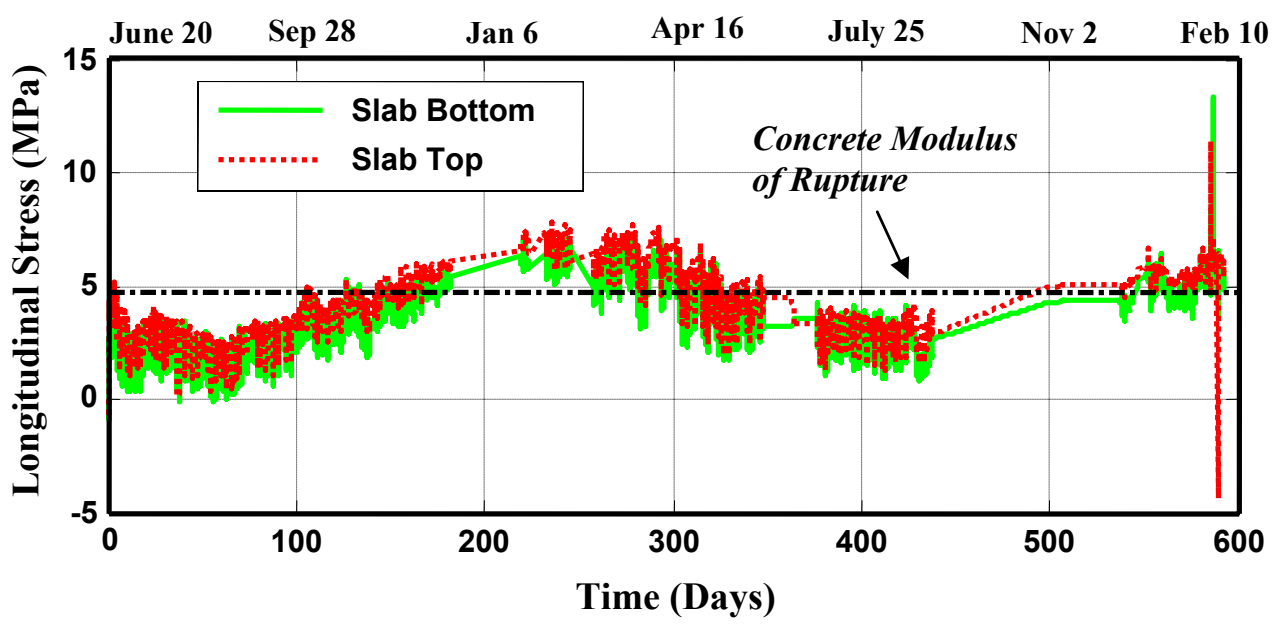

(a) Mid-span 1

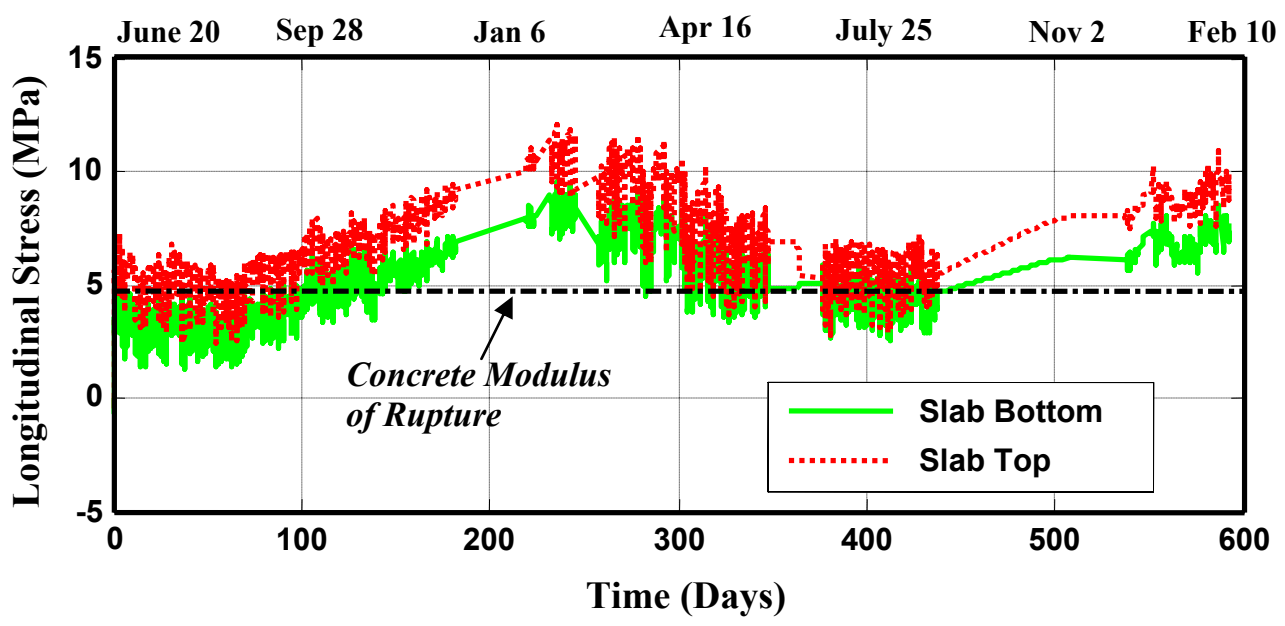

(b) Pier 1

Figure 6.10. Longitudinal stress time histories for concrete reinforced bridge deck above girder 3

this level of stress will result in cracking in the bridge deck at the locations where stresses reach this critical level.

\subsection{Early Age Cracking}

To fully understand the state of stress in a concrete bridge deck it is necessary to investigate the stresses that arise within the deck during concrete curing. Previous sections have shown that constraints cause stresses to arise in the bridge girders under 
temperature loading and the same will be true for the concrete reinforced deck. Stresses will also be induced in the deck by during shrinkage, volume growth, and moisture changes. Theoretically, if a structure undergoes a cyclic temperature load where the initial temperature and end temperature are equal, the stresses induced in the structure should be zero at the end of the cycle. However, due to other volumetric changes in the concrete slab, this is not the case.

To visually illustrate this phenomenon, Figures 6.11-6.13 plot the axial stress versus the measured temperature at each instance of data collection after 1, 3, 7, 14, and 28 days. Inspection of these plots reveals that during the first day of the deck life, tensile stresses develop in the deck despite the fact that the concrete is experiencing a temperature increase which should result in compressive stress. This indicates that as the concrete dries from a semi-liquid state to a solid, the shrinkage of the concrete is constrained causing tensile stress to develop. This indicates that the effects of constrained volumetric changes from drying shrinkage on the bridge deck are greater than the effect of the temperature changes during the first hours of the deck life. The deck is constrained from shrinkage by the corrugated stay-in-place forms placed between the girders as well as the shear studs on the girders.

The magnitude of the initial stresses incurred by the concrete deck is quantified by fitting the data in Figures 6.11-6.13 with a linear relation. Where this line intercepts the vertical axis (where $\Delta \mathrm{T}=0$ ) represents the amount of tensile stress developed in the deck due to restrained drying shrinkage. Moreover, the slope of the linear relation represents the amount of stress in the concrete caused by the constrained expansion and contraction under temperature changes. The report by Shoukry et al. (2005) states that locations along the Evansville Bridge deck have varying thermal properties which, along with the varying amount of constraints along the deck, explain the differences in the effects of restrained during shrinkage at each location. 


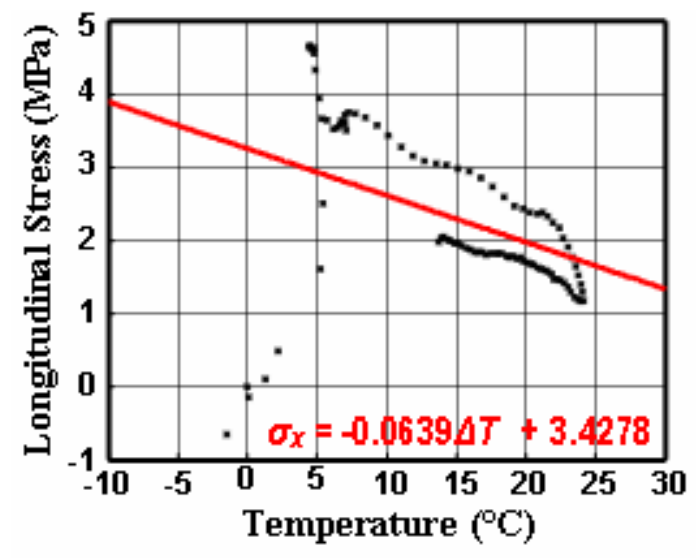

(a) After 1 day

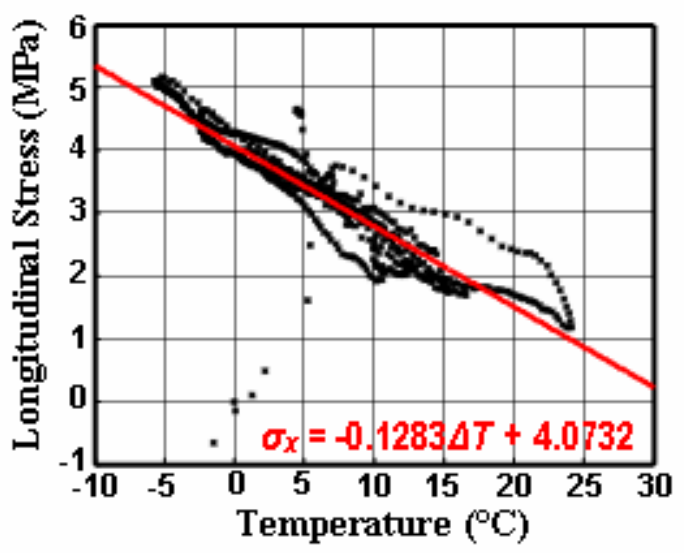

(c) After 7 days

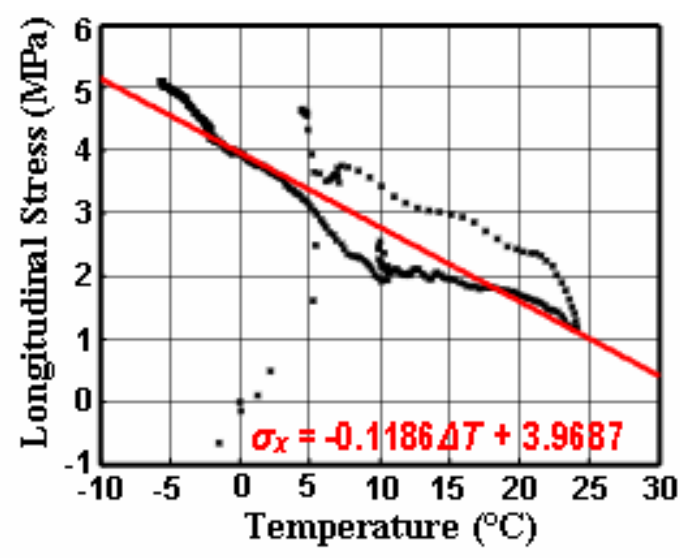

(b) After 3 days

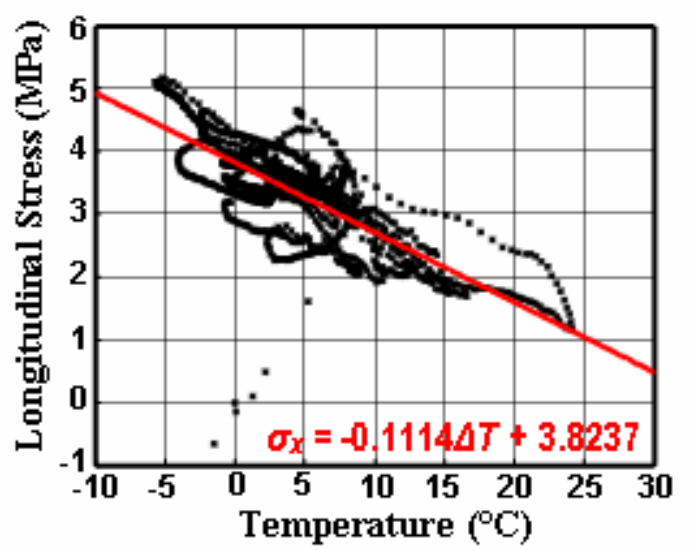

(d) After 14 days

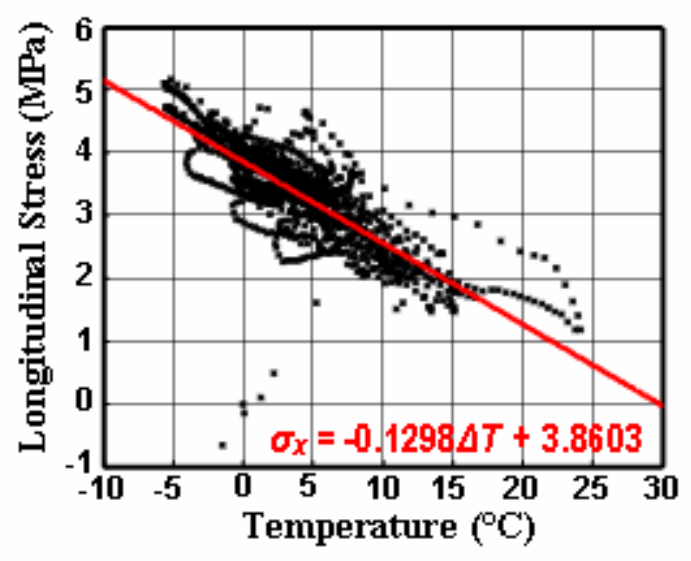

(e) After 28 days

Figure 6.11. Early age stress versus temperature change at mid-span 1 


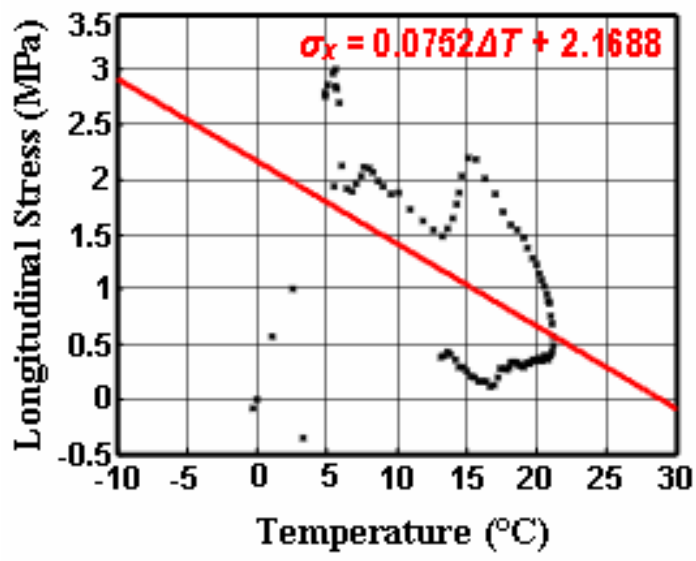

(a) After 1 day

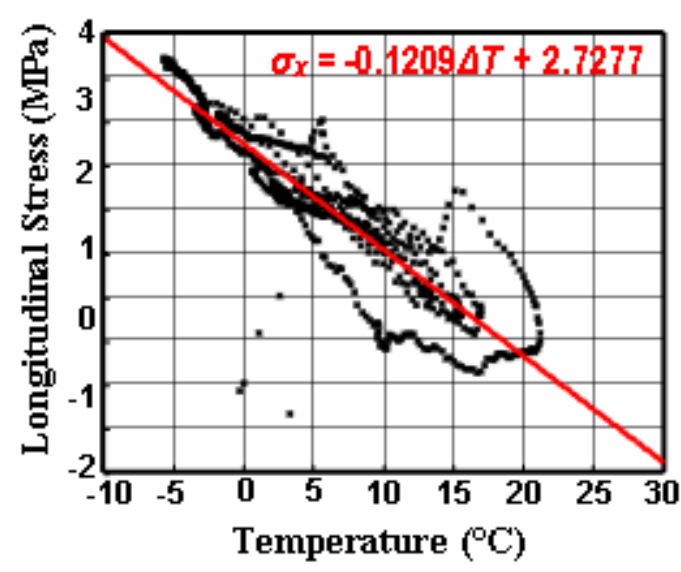

(c) After 7 days

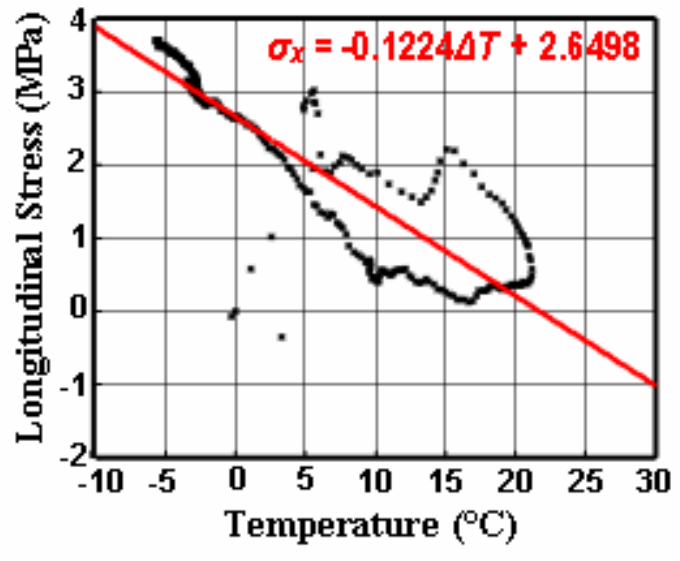

(b) After 3 days

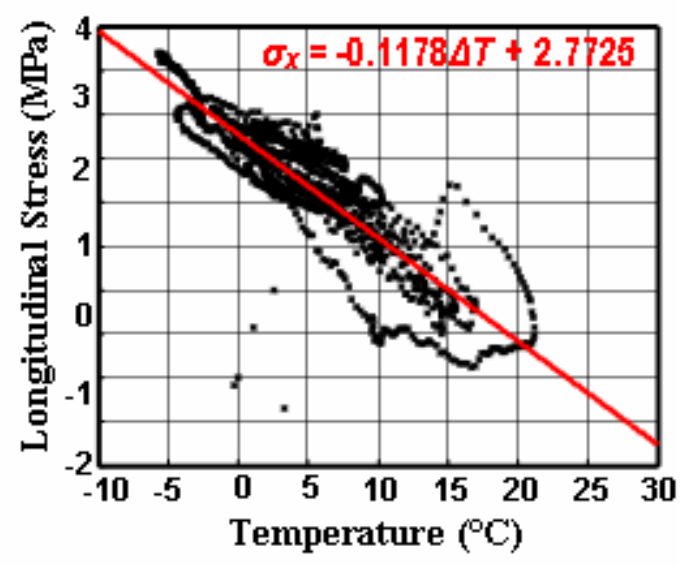

(d) After 14 days

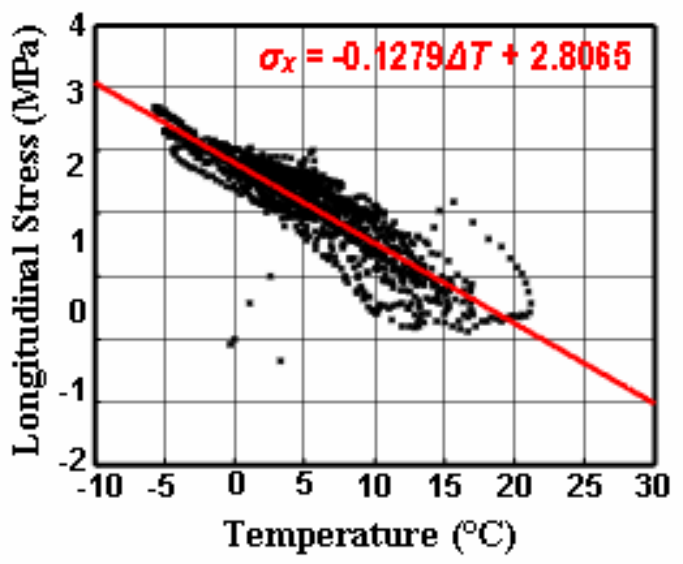

(e) After 28 days

Figure 6.12. Early age stress versus temperature change at pier 1 


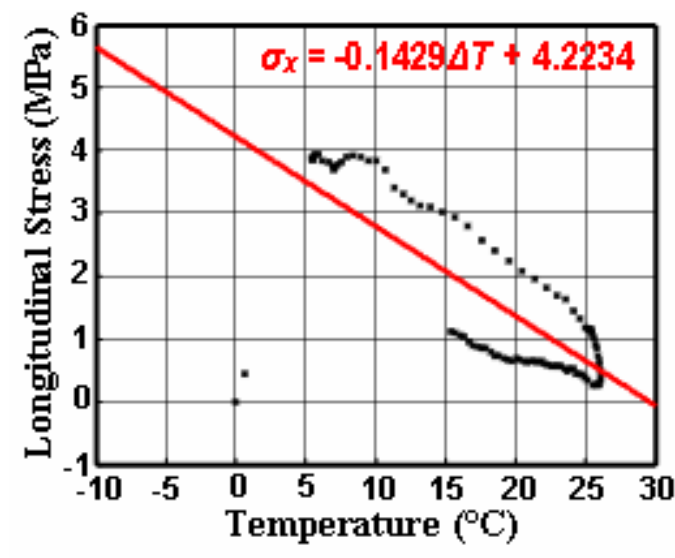

(a) After 1 day

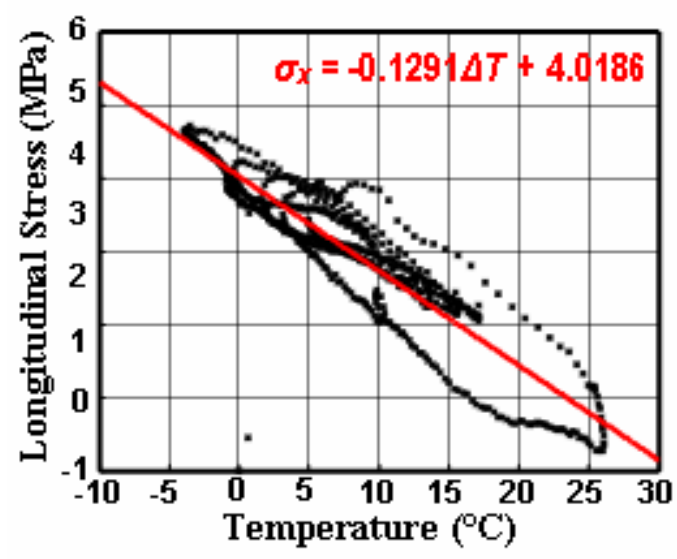

(c) After 7 days

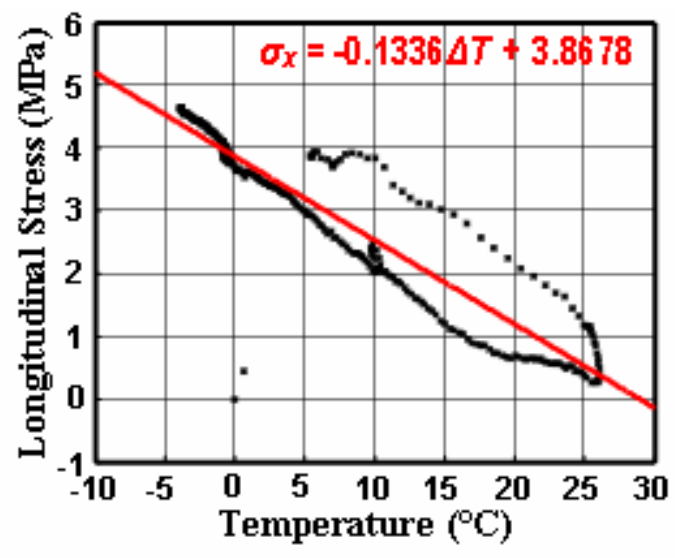

(b) After 3 days

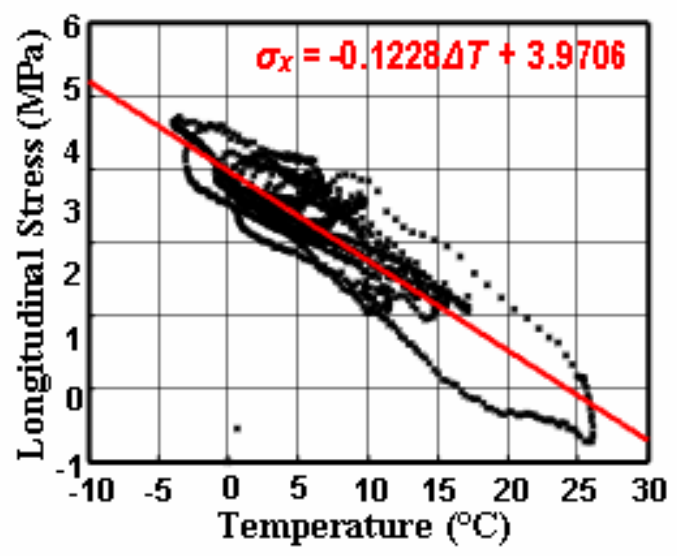

(d) After 14 days

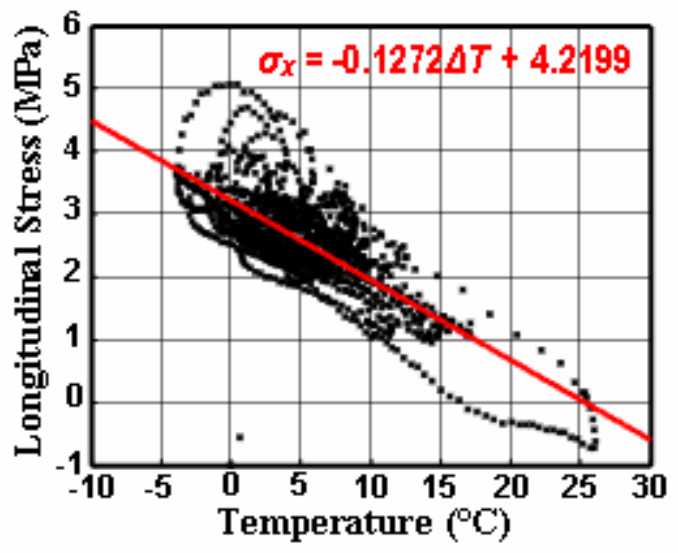

(e) After 28 days

Figure 6.13. Early age stress versus temperature change at mid-span 2 


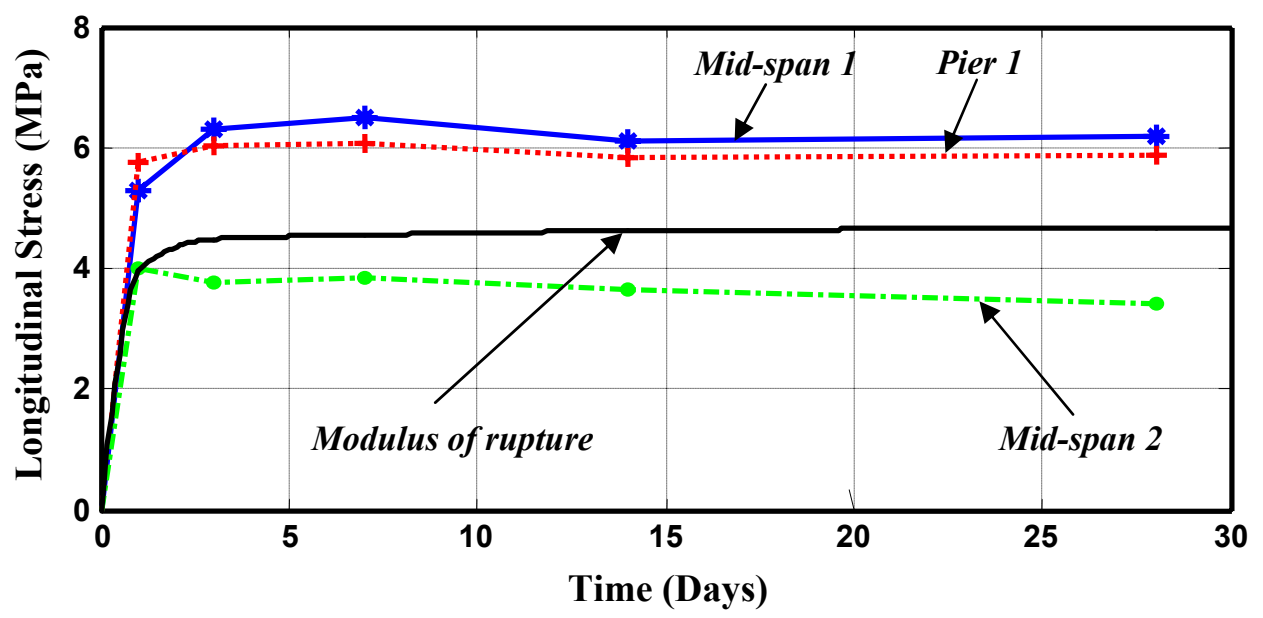

(a) Deck Section over girder 1

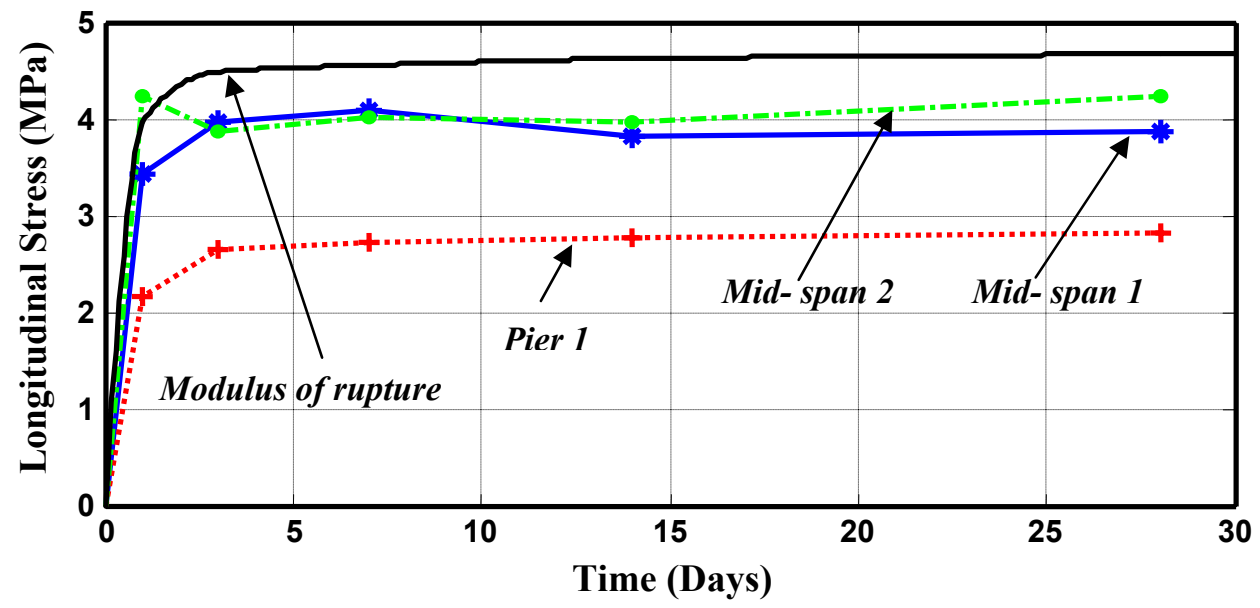

(b) Deck Section over girder 2

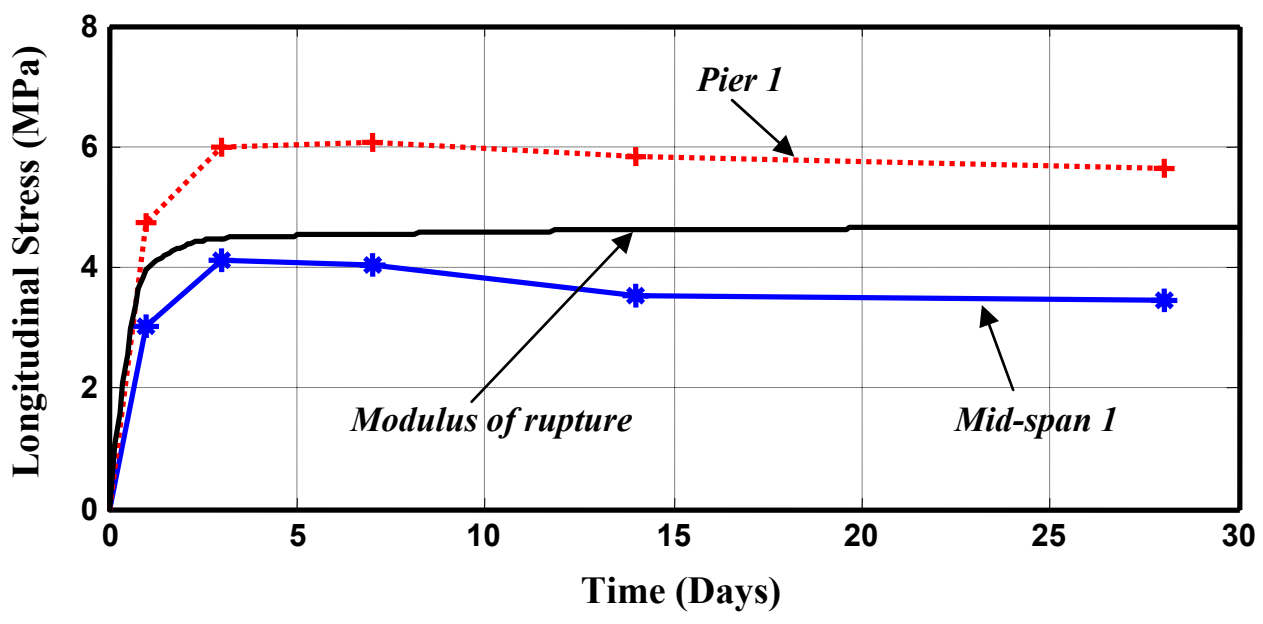

(c) Deck Section over girder 3

Figure 6.14. Magnitude of longitudinal stress caused by constrained drying shrinkage over the first 28 days of the deck life 
Figure 6.14 plots the values for the stresses caused by drying shrinkage at locations in the deck above each of the three girders of the instrumented section. It can be noticed that as the concrete ages and fully cures, the magnitude of the stresses induced by constrained dying shrinkage will stabilize. Figure 6.14 also shows that, at some locations, these stresses exceed the concrete modulus of rupture which will result in cracks occurring within the deck. This stress is the primary cause of cracks appearing during the early age of concrete because the concrete has not yet developed enough tensile strength or great enough bond strength with the rebar to handle the magnitude of these stresses. The stresses caused by the constrained drying shrinkage of the concrete deck will be present throughout the life of the structure and will greatly contribute to the appearance of cracks in the bridge deck.

The deck longitudinal stresses that are computed by the finite element model are a result of temperature and dead loading only and there is no known technique that for accurately modeling drying shrinkage stresses. However, a comparison is made in Figure 6.15 between FE and measured stresses resulting from temperature loading without the influence of initial curing stresses or dead weight in the deck above girder 2. Because the bridge deck is idealized as a two-dimensional shell in the finite element model, the total stress in the cross section is computed and used in comparison with the FE results. The total cross section stress is evaluated by adding the measured axial and bending stress in the cross section (Equations 6.7 and 6.8). The experimental scatter plot data represents the change in longitudinal stress versus changing temperature computed from the recorded stress time histories in Figure 6.9. There is no comparison near abutment 1 because the readings at this location are relatively small. The R-squared values indicate an agreeable match between FE and measured values for longitudinal stresses showing that the FE model accurately computes the longitudinal temperature induced stresses in the bridge deck. An accurate representation of the actual stresses in the bridge deck can be developed by considering the stresses from drying shrinkage as initial stresses and adding them to the stresses caused by temperature change and dead loading. 

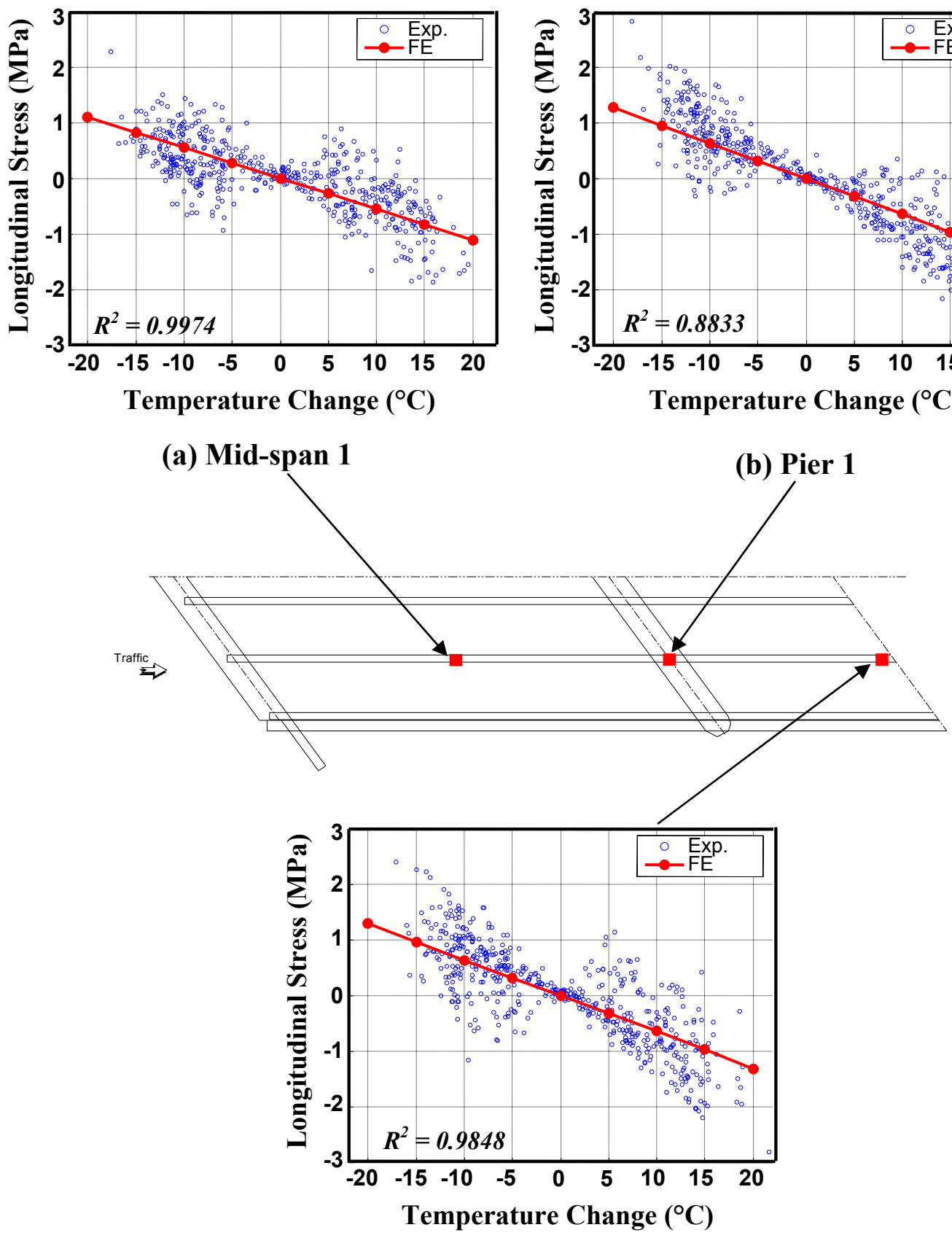

(c) Mid-span 2

Figure 6.15. FE and experimental values of longitudinal stress in deck cross section above girder 2

Figure 6.16 plots the stress state of the bridge deck under changing thermal conditions. This stress state consists of the stress resulting from prescribed temperature drops as well as the initial stresses from constrained deck shrinkage during curing. Once again, no 
value for the shrinkage stress at the sensor near abutment 1 was available because of the corrupted sensor values during the early age of the deck. Figure 6.16 shows that the tensile stresses in the deck section exceed the modulus of rupture of the concrete simply due to the constrained shrinkage of the deck because of temperature decrease. Therefore, even devoid of traffic loading, the bridge deck will begin to exhibit cracks once the deck has cured as the temperature fluctuates.

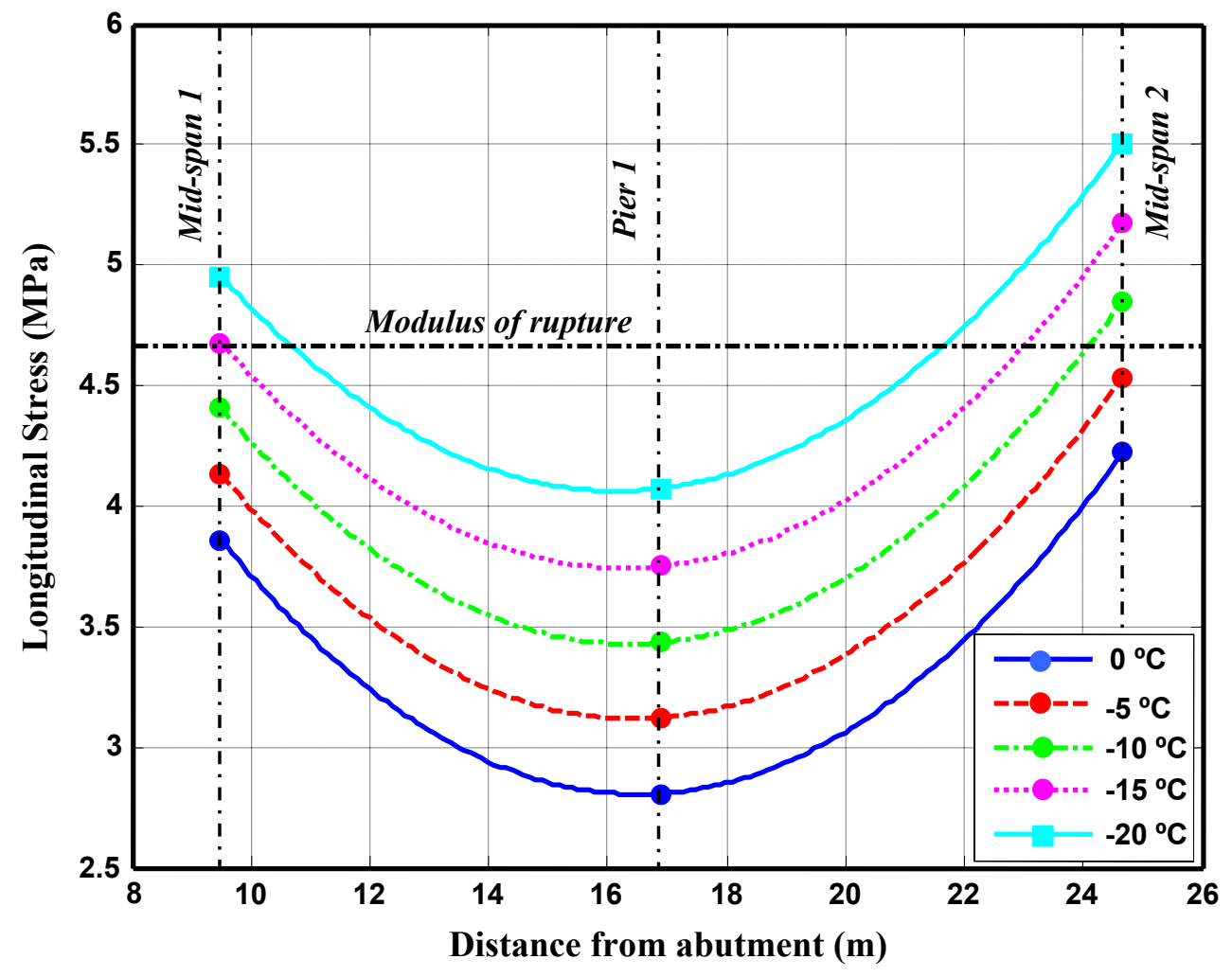

Figure 6.16. FE measured longitudinal stress plus initial drying shrinkage stress in bridge deck over girder 2

\subsection{Conclusions}

Contrary to the assumptions used when designing integral abutment bridges, the integral abutment system does not allow the bridge to expand and contract feely to relieve thermal stresses on the structure. The constraints provided by the soil backfill, supports at piers, and deck-girder interface will cause stresses to arise due to changing thermal conditions. 
Significant stress levels are measured on the Evansville Bridge girders as a result of deck weight and temperature loading and should be investigated in conjunction with live loading cases to determine the stability of the girders. Furthermore, stress levels are high enough in the bridge deck from constrained drying shrinkage and temperature loading to lead to deck cracking in various locations. The deck state of stress should also be investigated under live loading to determine the condition of the deck under the actual working conditions of the bridge. 


\section{CHAPTER SEVEN}

\section{INVESTIGATION OF LIVE LOADING EFFECTS ON EVANSVILLE BRIDGE}

\subsection{Introduction}

The previous chapters have successfully shown that constraints on the Evansville Bridge that are not accounted for during design will cause additional stresses of significant magnitude to arise throughout the bridge structure under seasonal temperature changes. Mainly, integral abutment bridge design assumes that stresses that would arise due to temperature fluctuations are relieved by the integral abutment bridge system allowing the structure to fully expand and contract, which is not true and stresses will be induced under these conditions. Although these stresses in the bridge girders are not critical, the temperature induced stresses within the deck are shown to reach values that would indicated that cracking of the concrete will occur. This chapter adds live loading cases to the already considered dead weight and temperature loading on the Evansville Bridge in an attempt to investigate if the temperature fluctuations will have a significant effect on the stability and response of the structure.

\subsection{Characterization of Live Loading}

The instrumentation placed on the Evansville Bridge includes wire resistance strain gages that were installed to measure live loading effects on the bridge. However, controlled live loading tests could not be arranged for two reasons. First, loading tests using trucks of known weight could not be performed because of traffic constraints and lack of standard loading trucks of knows axel weight available for use. Second, measuring the strains caused by regular vehicles passing over the bridge could not be used because no system was in place to determine the weight of the vehicle. Therefore, the effect of live loading on the structure must be determined in another way. William et al. (2005) calculated the effects of design live load theoretically and added these values to 
experimentally measured ones. In this study, the effect of design live loading is going to be investigated by including the live loading in the FE model discussed in Chapter 3 .

The Evansville Bridge was designed to accommodate the live load AASHTO HL-93 (LRFD 3.6.1.2). This live load, specified for use with the LRFD design, is a combination of the AASHTO standard truck HS20-44 and a uniformly distributed lane load of 9.34 $\mathrm{kN} / \mathrm{m}$. On the other hand, the AASHTO Standard Specifications (AASHTO, 2002) specify either the truck or lane load to be used as live loading. Assuming that AASHTO HL-93 is overly conservative, this study calculates the effect of live loading based on the AASHTO standard truck HS20-44 (AASHTO 2002, Section 3.7.6). Figure 7.1 illustrates the arrangement and magnitude of the wheel loads for AASHTO HS20-44.
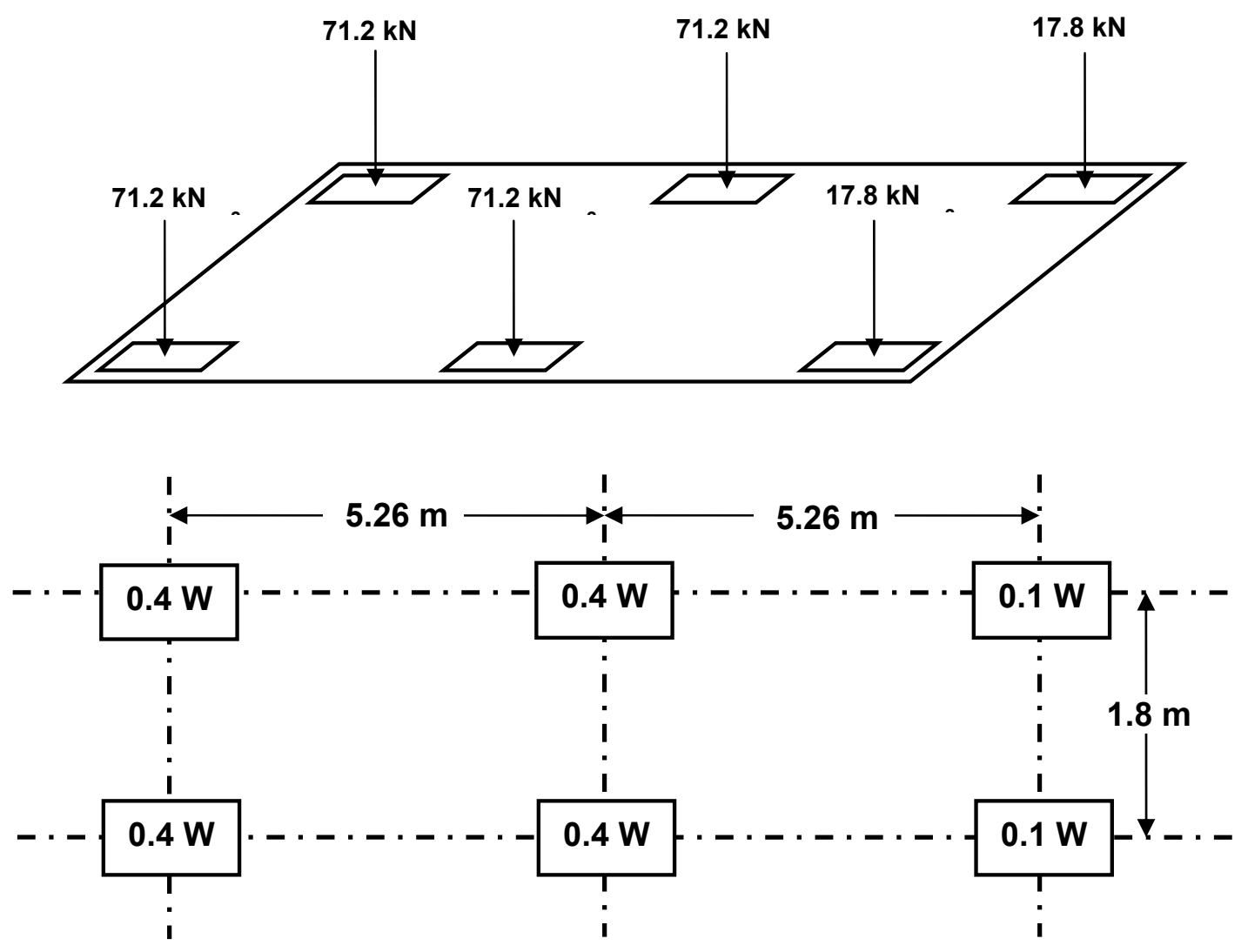

Figure 7.1. Wheel loads in AASHTO HS20-44 
This study places the truck loads at three locations along the deck that will create the maximum bending moment in the center girder at mid-span 1, pier 1, and mid-span 2. These locations were calculated by using the information presented by William et al. (2005). In each instance, the truck will be placed so that its centerline is directly over the centerline of the middle girder. The locations of the wheel loads along the longitudinal axis for each instance are shown in Figure 7.2.

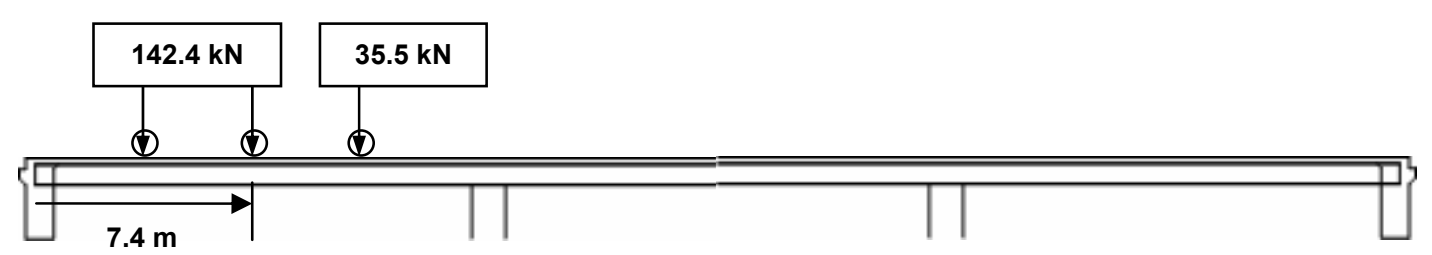

(a)

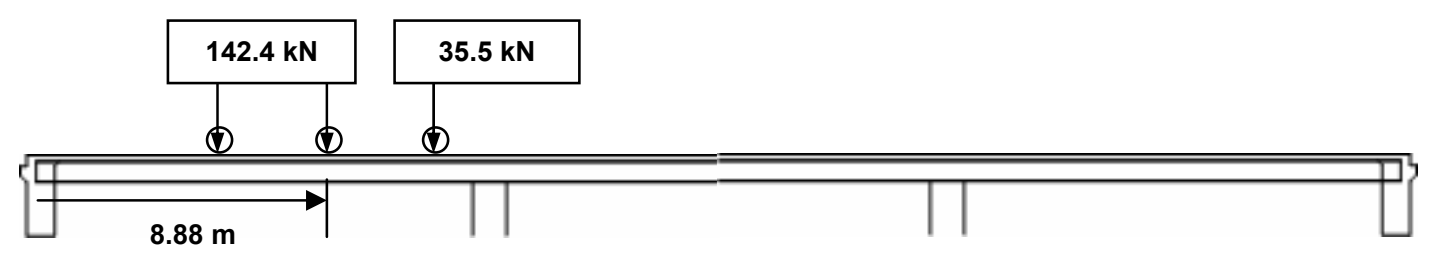

(b)

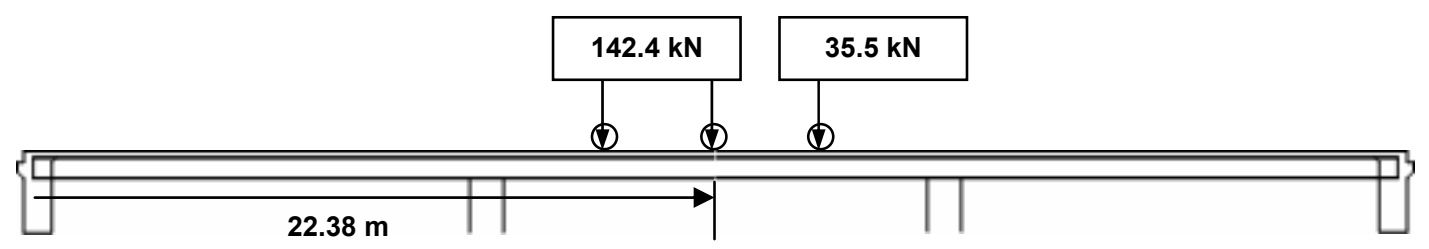

(c)

Figure 7.2. Location of wheel loads along the longitudinal axis to induce maximum bending moment at (a) mid-span 1, (b) pier 1, and (c) midspan2

The loading applied for this analysis will be a combination of the weight of the structure, a uniform temperature change, and a static truck load. Structure weight loading is first applied, followed by temperature increase or decrease up to $\pm 20^{\circ} \mathrm{C}$ applied in $\pm 5^{\circ} \mathrm{C}$ intervals, and finally AASHTO truck loading is added to the model. 


\subsection{Effect of AASHTO HS20-44 truck Loading on Girders}

Chapter six demonstrated that the finite element model created for this study is accurate in predicting the longitudinal stresses in the middle girder (girder 2) of the instrumented section. Therefore, it can be assumed that the stresses calculated by the FE analysis from the addition of AASHTO truck loading are representative of the actual bridge response to traffic loads. In reality, the vehicular loading on the Evansville Bridge will come in the form of a vehicle moving across the structure. This will create dynamic loads on the bridge along with the static loads from the weight of the vehicle. However, since the FE model only employs static truck loads, the stresses caused by the truck loading should be increased by $30 \%$ to account for the dynamic effect of a moving vehicle. This is accomplished by adding $30 \%$ of the stress magnitude induced by the truck loading only to the overall measured state of stress of the bridge. Figures 7.3 and 7.4 present the axial, bending, and total stress in the cross section of the middle girder calculated using FE measured stresses and Equations 6.6 and 6.7. The legend entries in Figures 7.3 and 7.4 of MS1, P1, and MS2 indicate the implementation of truck loading that creates maximum bending moments at mid-span 1, pier 1, and mid-span 2 respectively combined with structure weight and temperature loading and will be used in further plots throughout this chapter.

The plots for axial stress and bending stress in Figures 7.4 and 7.5 reveal that for each loading case the two are approximately equal along the length of the middle girder. The axial stresses are mainly a result of temperature loading on the structure while the bending stresses are primarily caused by the structure weight and truck loading. It is significant that the magnitude of axial stress and bending stress is equivalent because this indicates that the effects of temperature loading on the total stress of the girder cross section are comparable to the effects of live and dead loading. While the bending stresses are considered during the design of the structure, the axial stresses are assumed to be negligible. These plots indicate that, contrary to design assumptions, the stresses due to temperature loading are significant in comparison to the design stresses and the effect of the combination of these two loading conditions should be further investigated. 

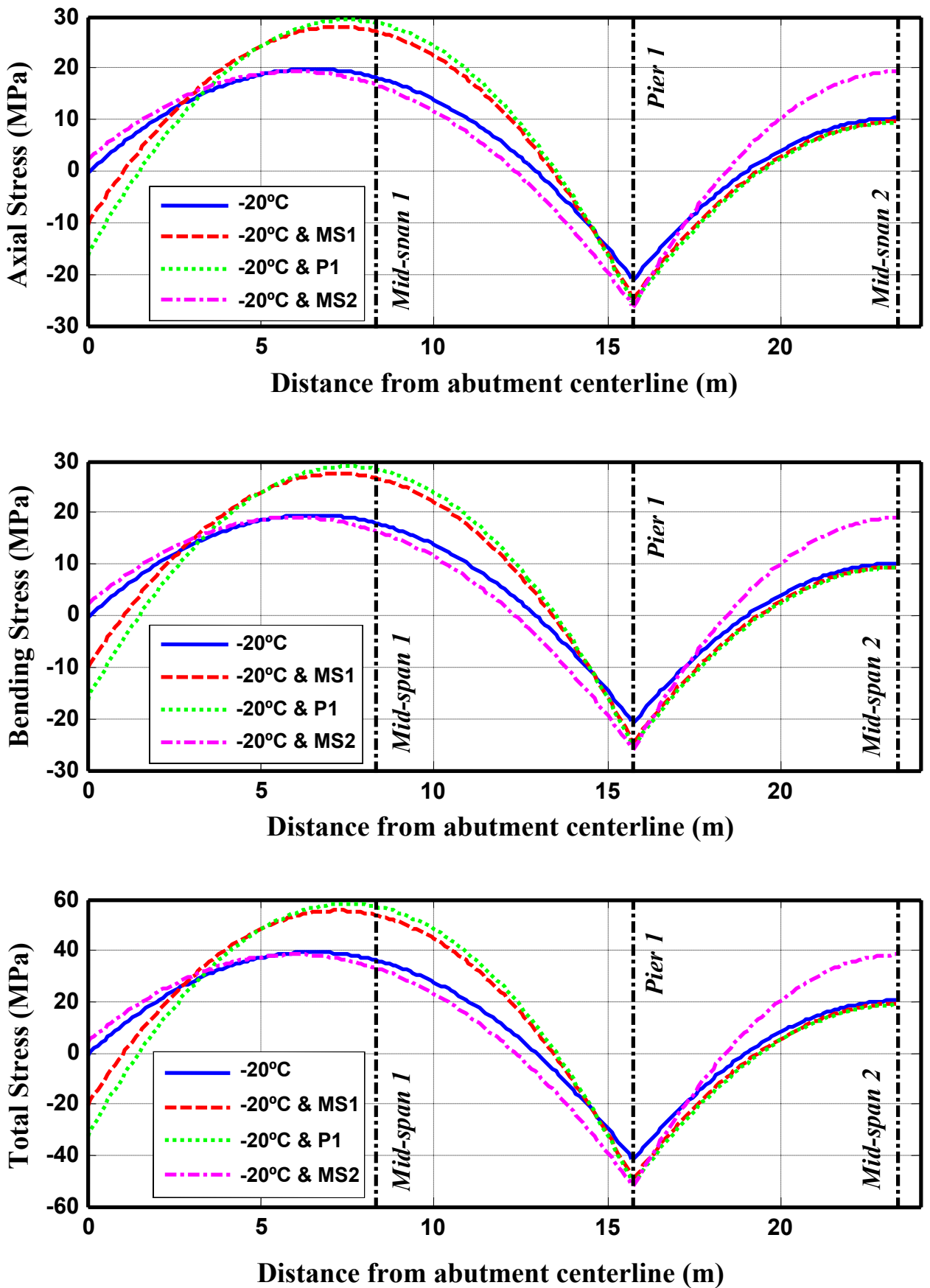

Figure 7.3. Axial, bending, and total stress in girder cross section induced by structure weight, temperature decrease, and AASHTO truck loading 

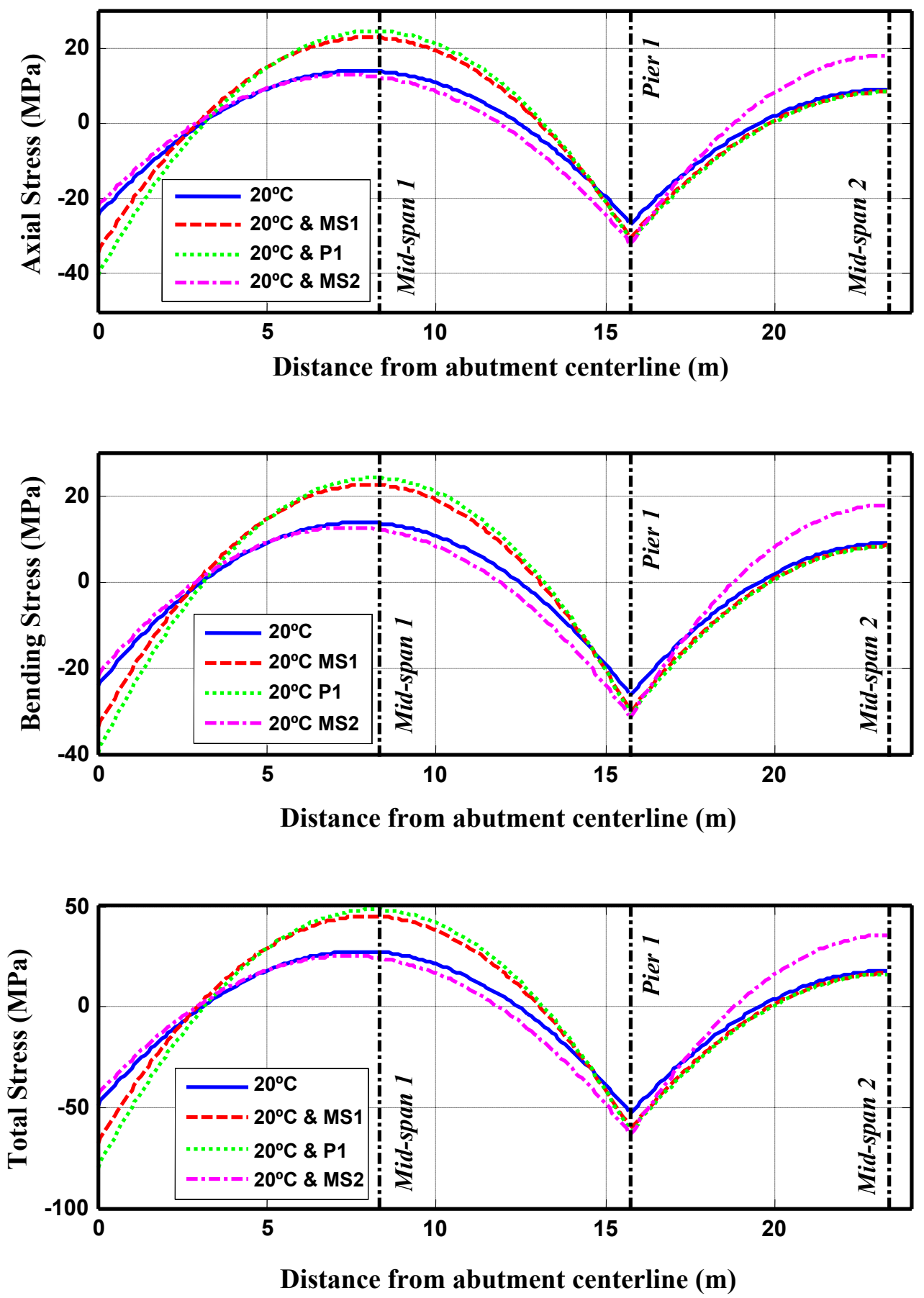

Figure 7.4. Axial, bending, and total stress in girder cross section induced by structure weight, temperature increase, and

AASHTO truck loading 


\subsection{Stability and Yield ratio analysis}

It is apparent from Figures 7.4 and 7.5, as well as the analysis performed in Chapter six, that the Evansville Bridge girders are subjected to both axial and bending stresses of significant magnitude. According to AASHTO Standard Specifications (AASHTO, 2002, Section 10.36), all members subjected to both axial compression and bending stresses shall satisfy the stability and yield ratio requirements in Equations 7.1 and 7.2 respectively.

$$
\begin{aligned}
& \frac{f_{a}}{F_{a}}+\frac{C_{m z} f_{b z}}{\left(1-\frac{f_{a}}{F_{e z}^{\prime}}\right) F_{b z}}+\frac{C_{m y} f_{b y}}{\left(1-\frac{f_{a}}{F_{e y}^{\prime}}\right) F_{b y}} \leq 1.0 \\
& \frac{f_{a}}{0.472 F_{y}}+\frac{f_{b z}}{F_{b z}}+\frac{f_{b y}}{F_{b y}} \leq 1.0
\end{aligned}
$$

- $f_{a}$ - computed axial stress;

- $\quad f_{b z}$ and $f_{b y}$ - computed bending stress about $\mathrm{z}$ and y axis, respectively;

- $\quad F_{a}-$ axial stress permitted if axial force alone existed;

- $\quad F_{b z}$ and $F_{b y}$ - compressive bending stress permitted if bending moment alone existed about $\mathrm{z}$ and $\mathrm{y}$ axis, respectively;

- $F_{e}{ }^{\prime}-$ Euler buckling stress divided by a factor of safety (2.12);

$$
\text { - } F_{e}^{\prime}=\frac{\pi^{2} E}{2.12\left(\frac{k_{b} L_{b}}{r_{b}}\right)^{2}}
$$

- $E$ - modulus of elasticity of steel

- $k_{b}$ - effective length factor in plane of bending

- $L_{b}$ - actual unbraced length in plane of bending

- $\quad r_{b}$ - radius of gyration in the plane of bending

- $\quad C_{m z}$ and $C_{m y}$ - coefficient about the z and y axis, respectively (both equal to 1.0 for beams with bending moments over supports whose movements are prevented); 
First of all, for this analysis it is assumed that the bending about the y axis (vertical axis) is negligible in comparison to the bending about the $\mathrm{z}$ axis (transverse axis) so the parts of Equations 7.1 and 7.2 dealing with bending in this plane can be neglected. The most conservative state of girder buckling will initially be analyzed for this study which assumes the supports of the buckling member as pinned-pinned making $k_{b}=1.0$ and $L_{b}=$ $7.62 \mathrm{~m}$. The radius of gyration $\left(r_{b}\right)$ is calculated using the moment of inertia and the area of the cross section and is equal to $0.0526 \mathrm{~m}$ for the girder cross section W27 x 84 . Also, for the girder cross section:

$$
C_{c}=\sqrt{\frac{2 \pi^{2} E}{F_{y}}}
$$

where $F_{y}$ is $338.4 \mathrm{MPa}$ according to AASHTO (2002). Furthermore, according to AASHTO (2002), if $k_{b} L_{b} / r_{b}>C_{c}$, then the value for $F_{a}$ is equal to $F_{e}$ ' calculated using Equation 7.3. The value from Equation 7.4 is 107 while the value for $k_{b} L_{b} / r_{b}$ is 145 ; therefore, the value for $F_{a}$ and $F_{e}$ ' is $44.31 \mathrm{MPa}$. Finally, $F_{b z}$ is equal to $186.2 \mathrm{MPa}$ according to Table 10.32.1A in the AASHTO Standard Specifications (AASHTO 2002).

The stability and yield ratios can be determined using Equations 7.1 and 7.2 with the values for FE computed axial and bending stresses at the four instrumented locations along the steel girder substituted into the equations. These values are best fit with second order polynomials to predict the stability and yield ratios along the length of the girder. The stability ratio profiles of the middle girder of the test section as computed from FE analyses are seen in Figure 7.6 while the yield ratio values are plotted in Figure 7.7.

Figure 7.6 (a) indicates that, using the most conservative analysis, the stability ratio of the main girder is approaching the critical value of 1 when the bridge is loaded with its self weight as well as the weight of a truck load. However, adding a temperature decrease to these loading conditions causes the stability ratio to exceed the critical value of 1 as shown in Figure 7.6 (b) signifying that the main girder does not meet the AASHTO 


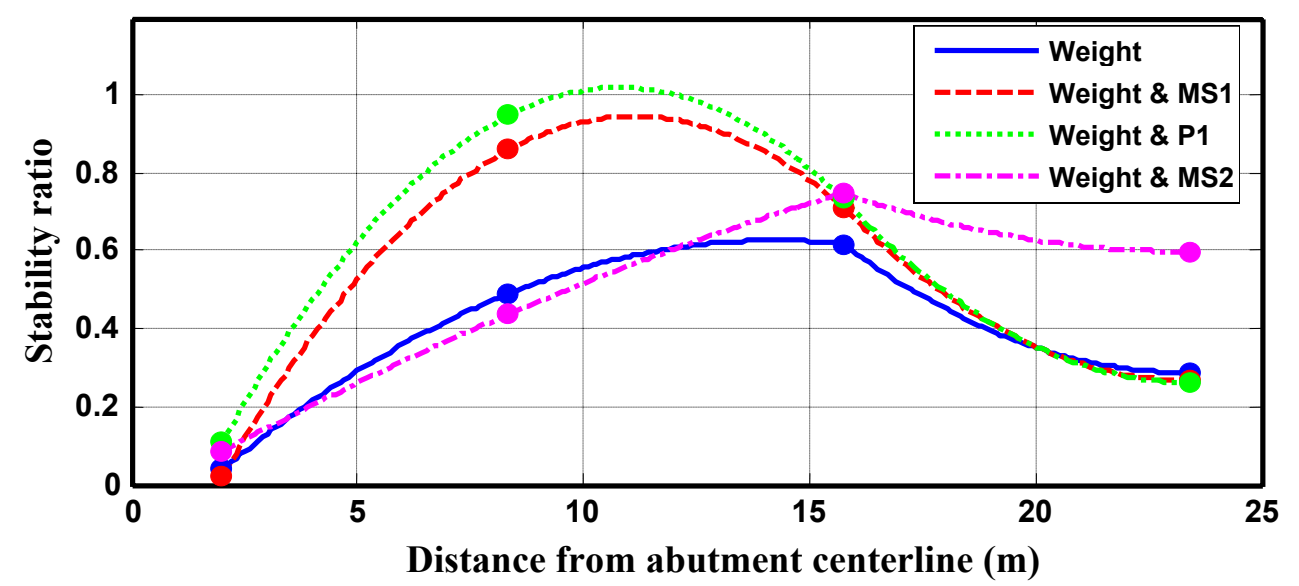

(a)

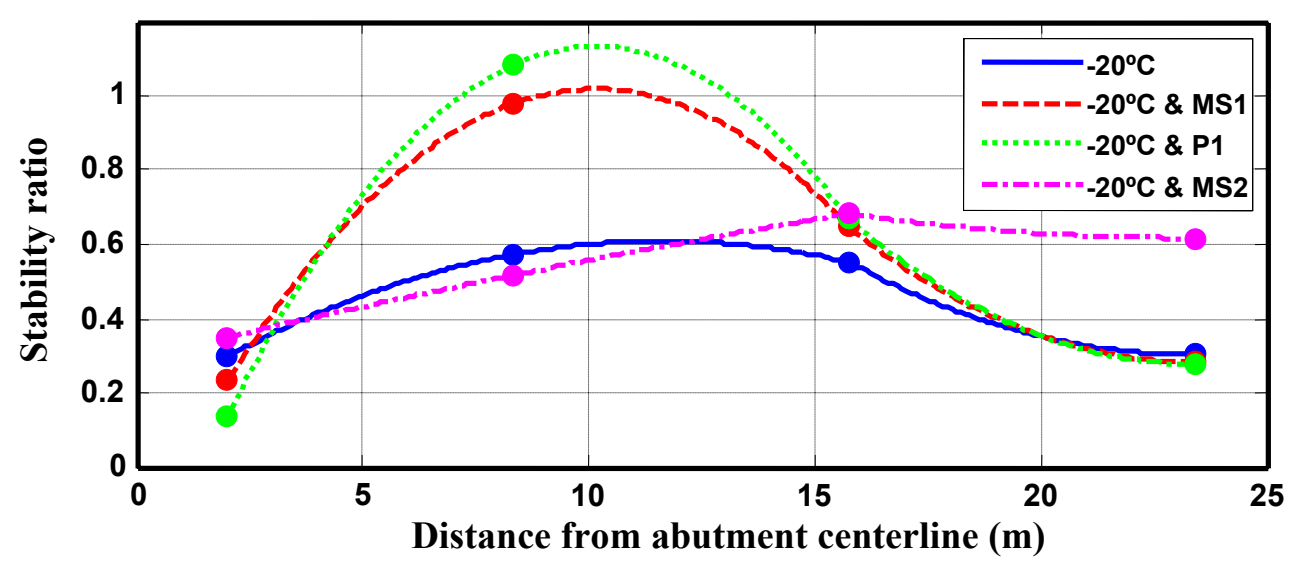

(b)

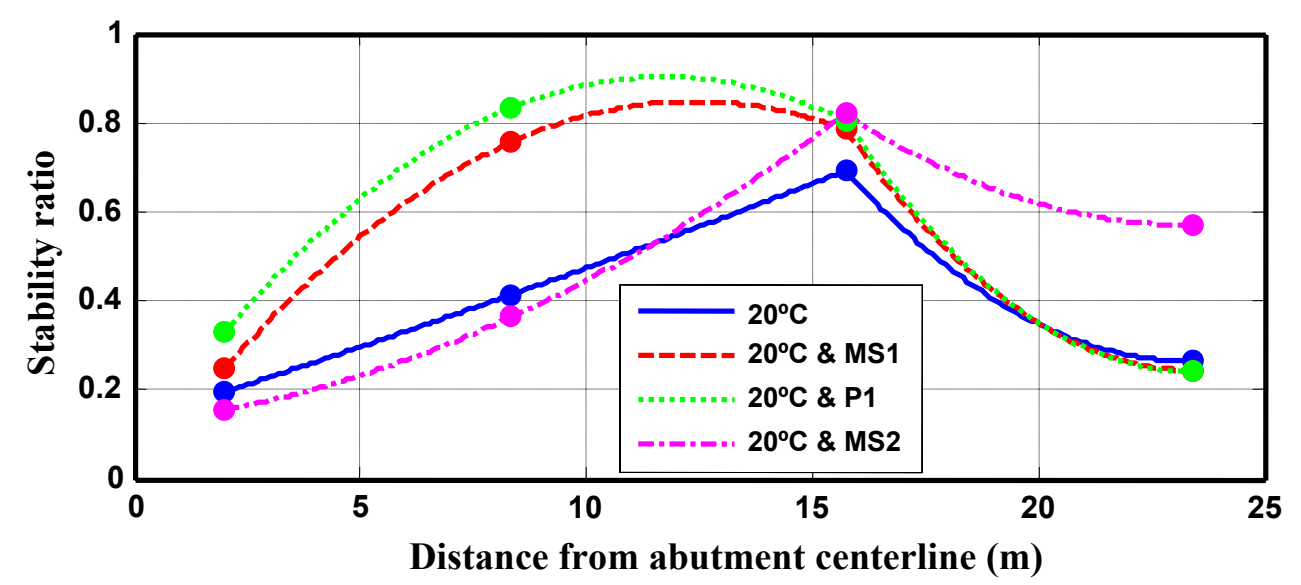

(c)

Figure 7.5. AASHTO stability ratio requirement with $\boldsymbol{k}_{b}=\mathbf{1 . 0}$ for (a) dead and live loading (b) plus temperature decrease (c) and increase 


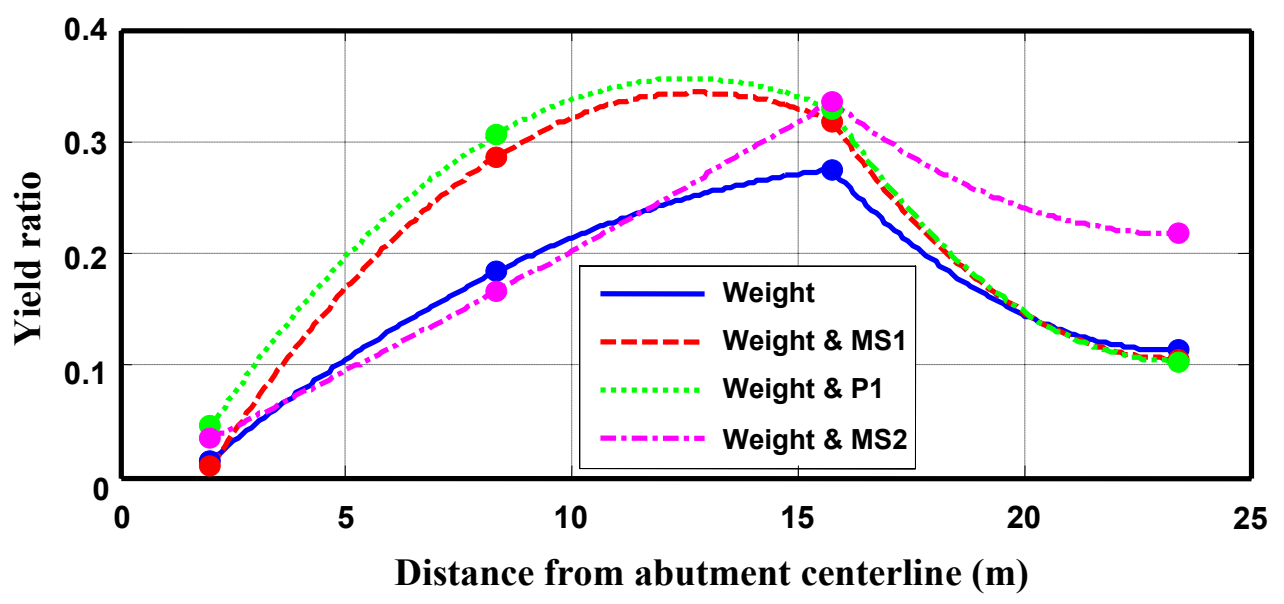

(a)

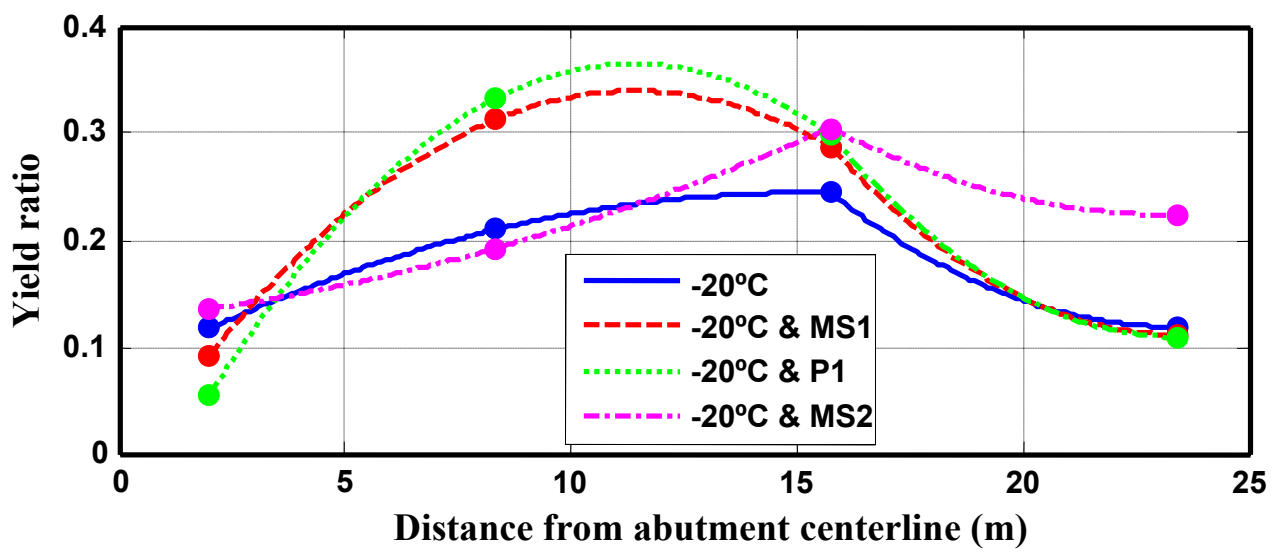

(b)

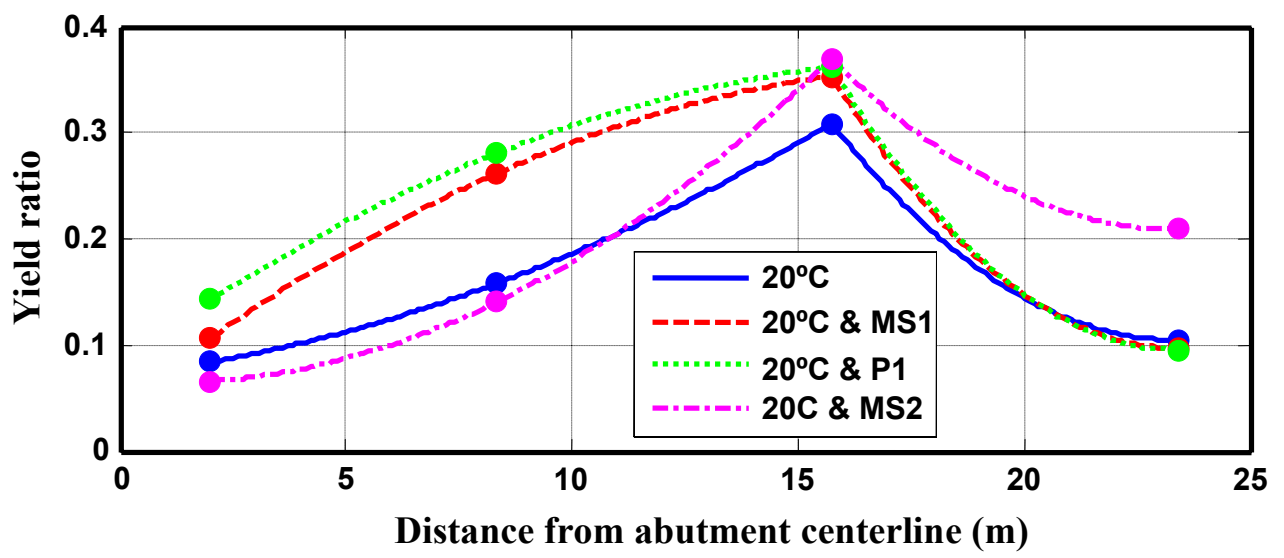

(c)

Figure 7.6. AASHTO yield ratio requirement for (a) dead and live loading (b) plus temperature decrease (c) and temperature increase 
stability requirements under in-service loading conditions using the most conservative value for effective length factor. William et al. (2005) also computed the stability ratio of the middle girder of the Evansville Bridge under the same loading conditions. Their analysis was performed by theoretically computing the stresses caused by the separate cases of truck loading at each instrumented location and adding this to the values recorded by the instrumentation. William et al. (2005) also use the most conservative analysis in which $k_{b}=1.0$ to compute the stability ratio. The results of this study also conclude that the middle girder exceeds AASHTO stability requirements under dead, live, and temperature loading. However, the yield ratio analysis in Figure 7.6 indicates that the Evansville Bridge girder meets the AASHTO yield ratio requirements under all of the loading conditions.

Although the most conservative stability ratio analysis is useful in determining the worstcase scenario of the effects that loading will have on the girder, this may not represent the actual state of the girders. To accurately determine the stability of the girder, the buckling shape of the girders under in-service loading conditions must be known which leads to the calculation of the girders actual effective length factor. The instrumentation placed upon the Evansville Bridge was not equipped to determine the actual deflection shape of the girder. However, the FE analysis can be used to determine the deflected shape of the girder; thus, allowing the actual buckling length $\left(L_{b}\right)$ and effective length factor $\left(k_{b}\right)$ to be calculated.

Figure 7.7 and 7.8 shows the deformed middle girder from the FE analysis under temperature and truck loading with the bottom flange highlighted, while Figure 7.9 plots the deflected girder shape along the longitudinal axis at the center of the bottom flange under two different loading conditions: Figure 7.9 (a) depicts the effects of self weight, truck loading, and a $20^{\circ} \mathrm{C}$ temperature load while Figure 7.9 (b) is a results of self weight, truck loading, and a $-20^{\circ} \mathrm{C}$ temperature load. The inflection points are labeled in Figure 7.9 (a) and are marked along the girder length in both plots in Figure 7.9. The inflection points indicate the location where the girder bending changes directions. From Figure 7.9, the buckling lengths for each instance of buckling in the middle girder can be 
computed as the distance between the inflection points indicated with blue dots. The buckling length of the entire girder is determined by taking the average of all of the buckling lengths for each loading case. The buckling length computed from the FE analysis is $7.862 \mathrm{~m}$.

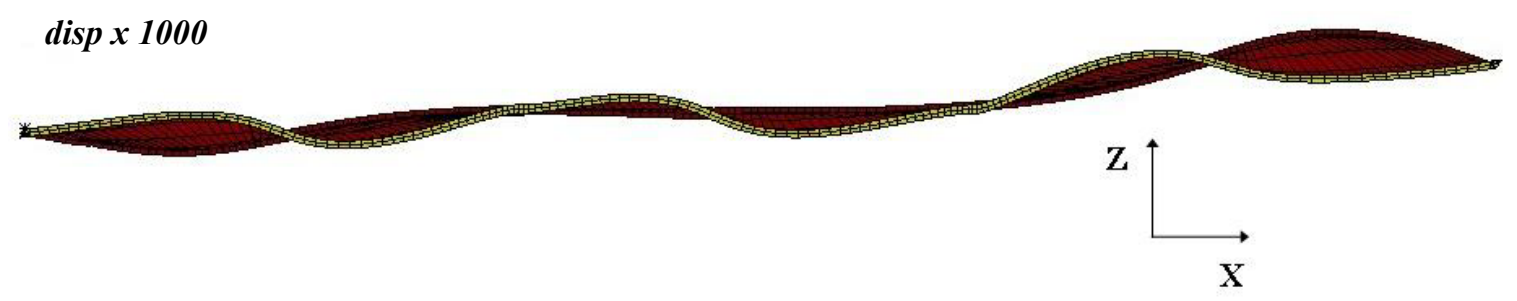

(a)

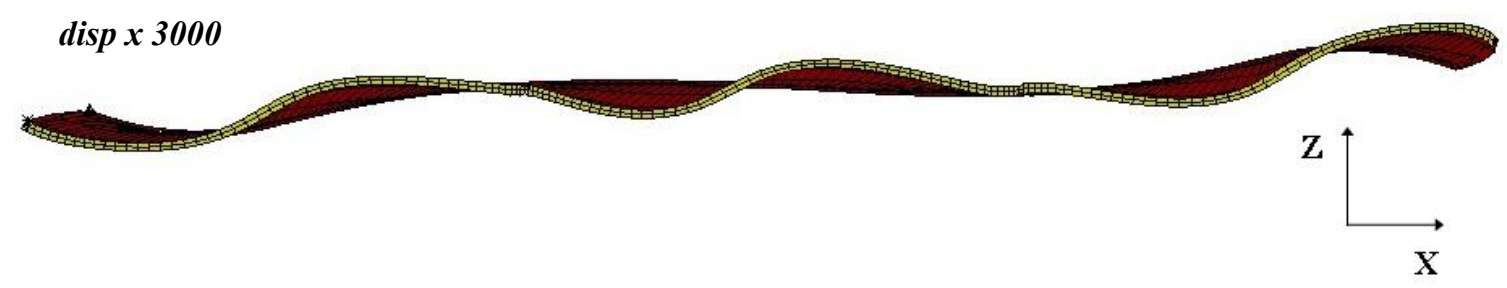

(b)

Figure 7.7. Deformed shape of middle girder under self-weight, truck loading, and (a) $-20^{\circ} \mathrm{C}$ temperature load, (b) $20^{\circ} \mathrm{C}$ temperature load

The buckling shape of the buckled sections of the bridge girders resembles the shape of a buckled column with fixed-pinned end supports. To calculate the effective length factor of the girder, each individual section of buckling must be analyzed individually (length between two blue dots in Figure 7.9). The value for $k_{b}$ is the ratio of the effective length of the beam section to the bucking length. The effective length is defined as the distance between two consecutive points of contra flexure or points of zero moment. In Figure 7.9, this distance is found as the distance between the green diamond and the end support resembling a pinned connection. Computing $k_{b}$ for each buckling length and taking the average value yields an experimental $k_{b}$ value of 0.588 for the Evansville Bridge girders. 


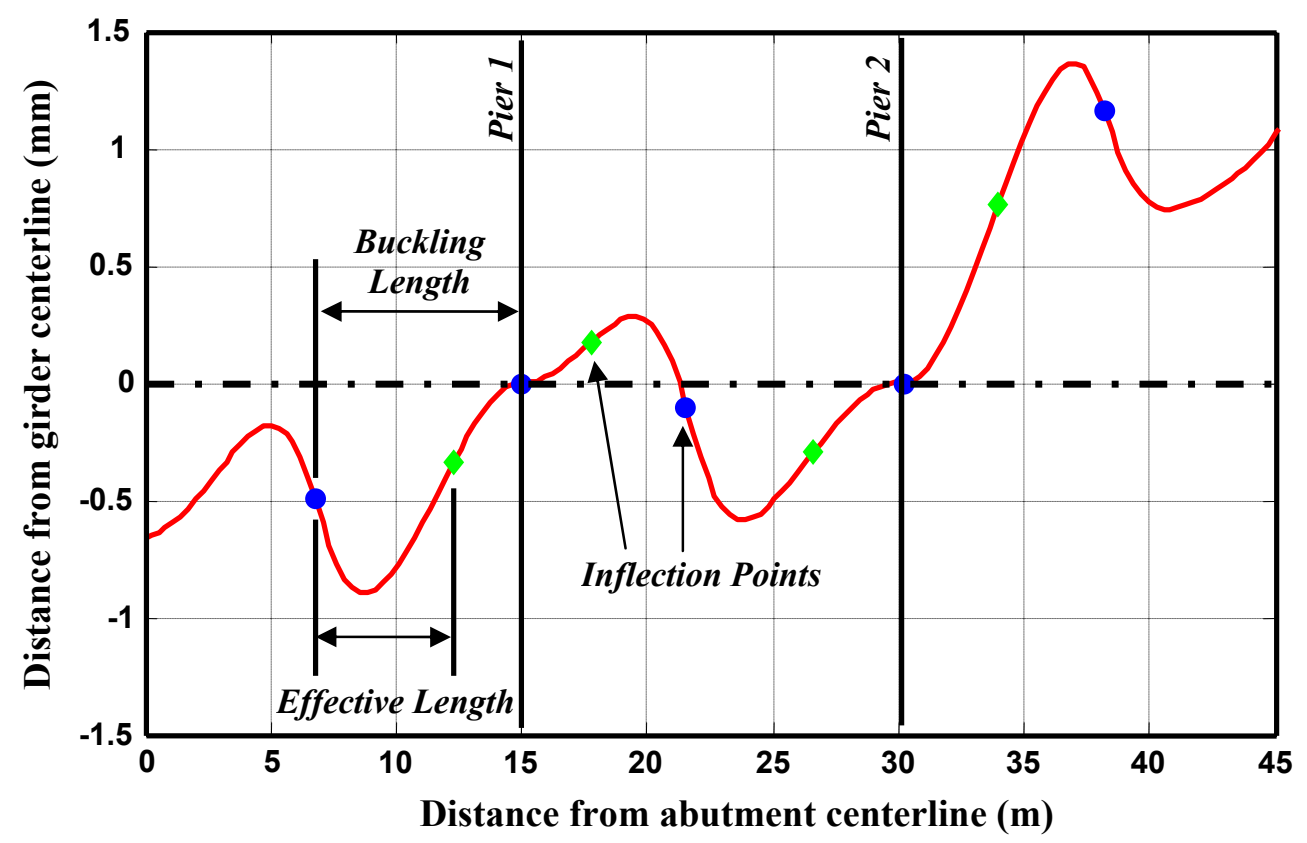

(a) Temperature increase

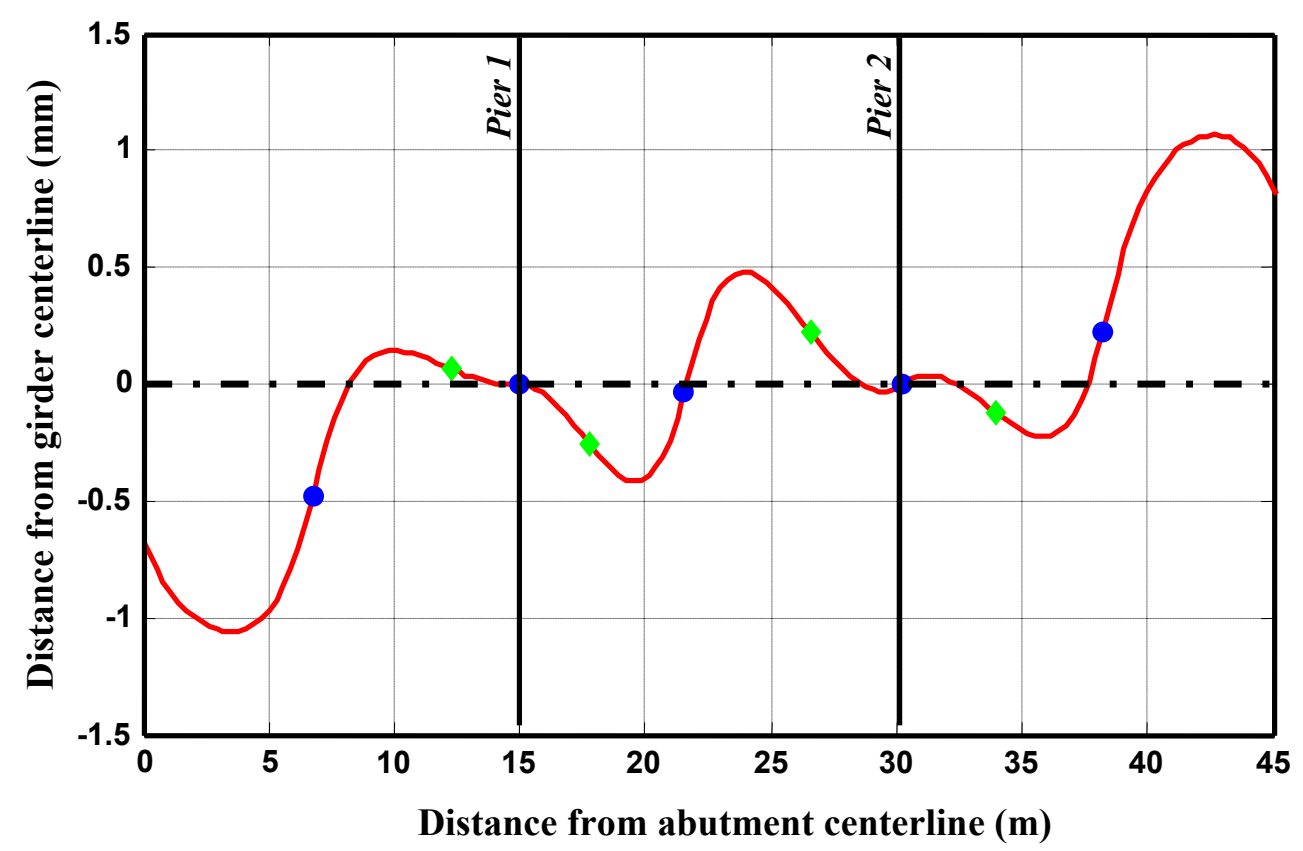

(b) Temperature decrease

Figure 7.8. Deflection shape of girder 2 under self-weight, truck loading, and $20^{\circ} \mathrm{C}$ temperature load (a) or $-20^{\circ} \mathrm{C}$ temperature load (b). 
Changing the values for effective length factor and buckling length will change the stability ratio calculations. Using the FE calculated values of $k_{b}=0.588$ and $L_{b}=7.862$ m., $k_{b} L_{b} / r_{b}$ becomes 87.9 , which is less than $C_{c}=107$. According to AASHTO (2002), when $k_{b} L_{b} / r_{b}<C_{c}$, the value for $F_{a}$ must be computed using the equation:

$$
F_{a}=\frac{F_{y}}{2.12}\left[1-\frac{\frac{k_{b} L_{b}}{r_{b}} F_{y}}{4 \pi^{2} E}\right]
$$

which makes $F_{a}$ equal to $106.8 \mathrm{MPa}$. The stability ratio is calculated using Equation 7.1 with the only different value being the newly calculated $F_{a}$. The plots of the stability ratio calculated using the values calculated from the FE deflected girder shape are shown in Figure 7.9.

Figures 7.6 and 7.10 show that, by changing the value for the effective length factor, the girder stability ratio values are significantly affected. Figure 7.6 indicates that under the full scope of loading with $k_{b}$ equal to 1.0 , the girders will not satisfy the AASHTO stability ratio requirement. The same conclusion was produced by William et al. (2005) using experimentally measured strains and theoretical truck loads. However, examining the deflection shape of the girder reveals that using $k_{b}=1.0$ is overly conservative and will cause the stability ratio to reach a value that does not represent the state of the girders. Changing the $k_{b}$ value to the value determined by the FE analysis $\left(k_{b}=0.588\right)$ causes the stability ratio to fall below the AASHTO prescribed value for girder stability of 1 . Therefore, the analysis concluded that although thermal loading adds stresses to the bridge girders which are not accounted for during design, these stresses will not cause the state of stress of the girders to reach a level that may cause damage or failure in the girders. 


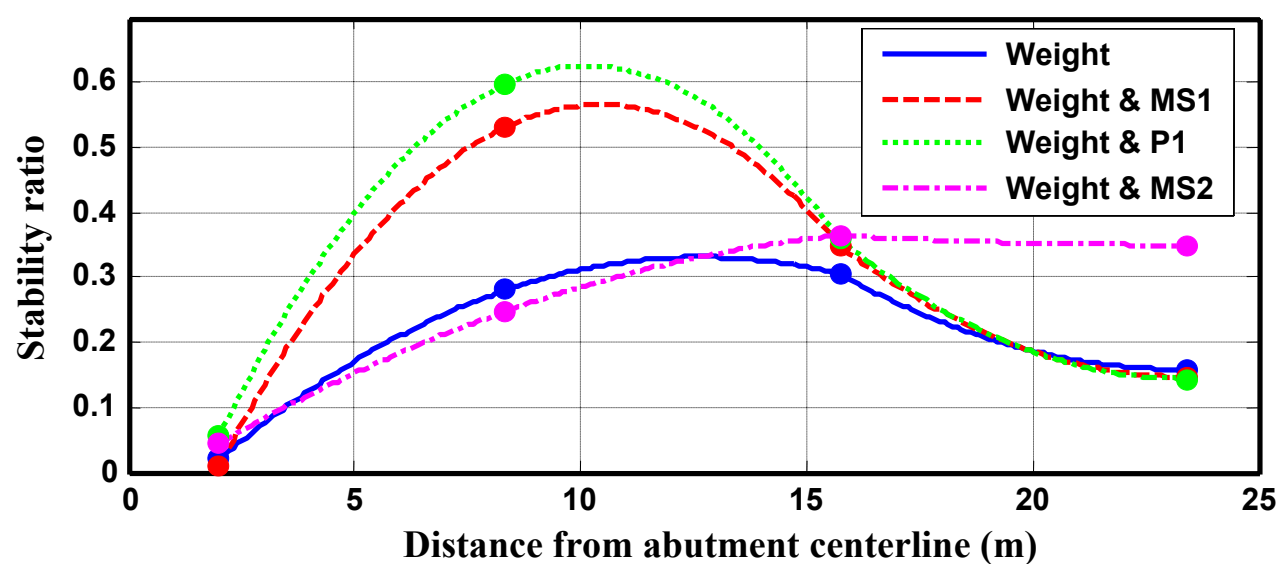

(a)

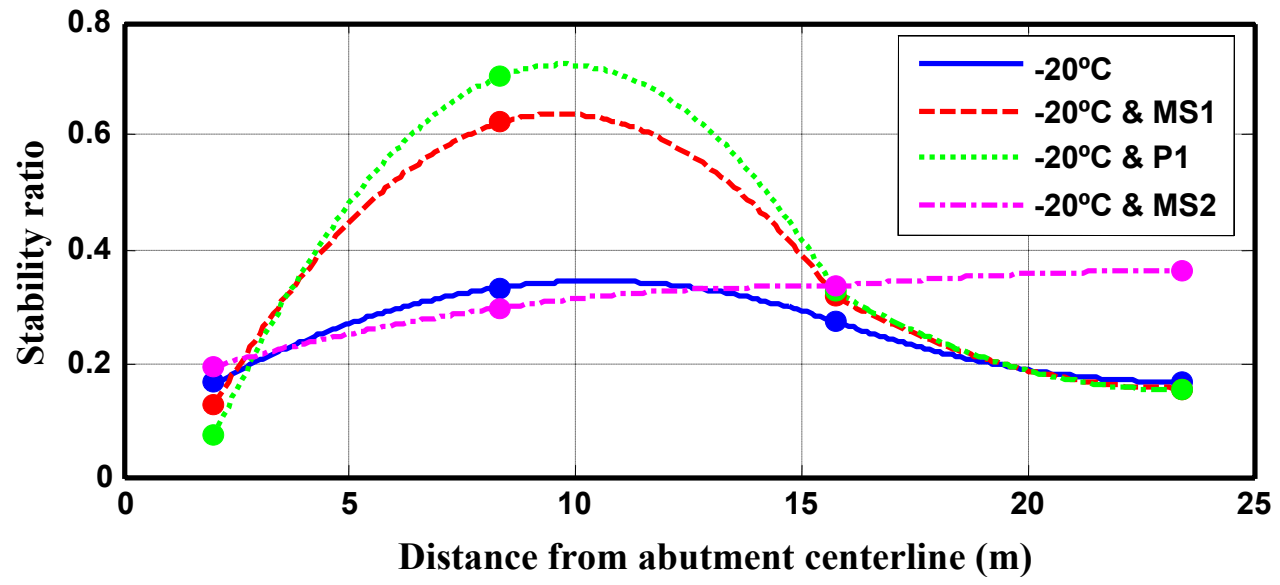

(b)

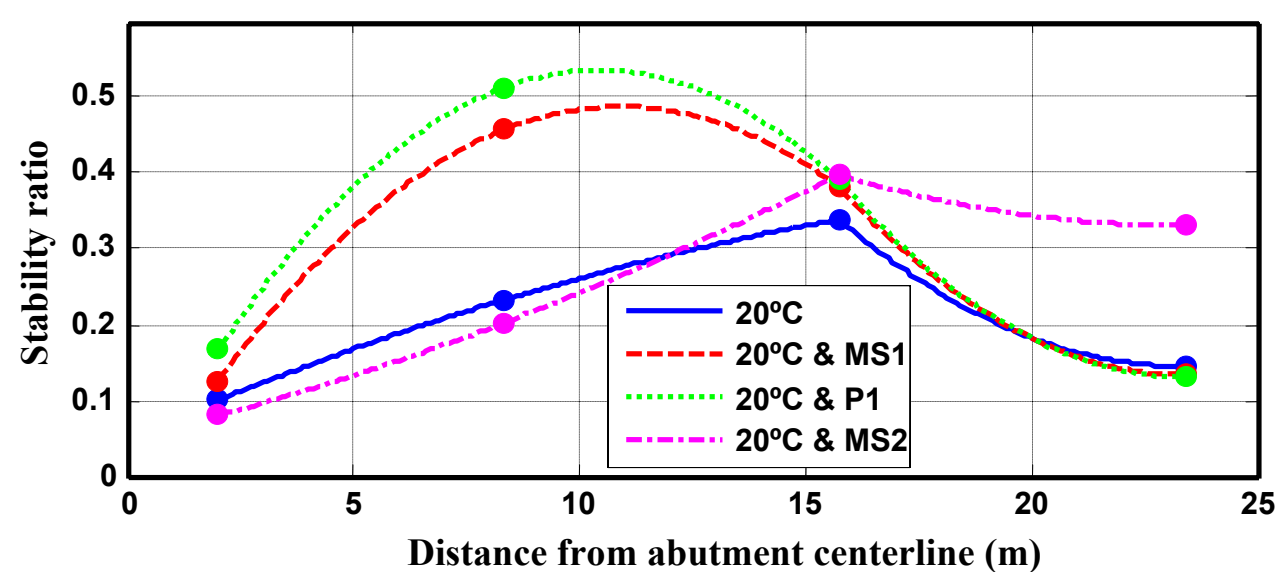

(c)

Figure 7.9. AASHTO stability ratio requirement with $\boldsymbol{k}_{b}=\mathbf{0 . 5 8 8}$ for (a) dead and live loading (b) plus temperature decrease (c) and increase 


\subsection{Effect of AASHTO HS20-44 Loading on Bridge Deck}

Chapter six successfully showed that the stress levels in the reinforced concrete bridge deck will exceed the concrete yield strength at some locations before any live loading is applied to the bridge. These stresses are caused only by the constrained shrinkage of the concrete during deck curing and the constrained expansion and contraction of the deck under temperature fluctuations. However, as traffic is introduced to the bridge, the structure will incur further stresses caused by the vehicles passing over the deck. The same AASHTO HS20-44 standard truck loading is used to simulate the traffic loading effect on the bridge deck with the vehicle-induced stresses increased by $30 \%$ to account for the impact effects.

The deck stresses computed by the FE model do not account for the effect of constrained drying shrinkage during deck curing. Therefore, in order to accurately depict the state of stress in the deck, the value for stresses induced during early age concrete curing (see Figures $6.11-6.13$ ) were added to the FE measured stresses at each sensor location. Figure 7.10 shows profiles of the longitudinal stress along the length of the bridge deck above the middle girder under thermal, dead, and live loadings.

Figure 7.10 shows the state of stress of the bridge deck under identical dead and live loading but with a positive temperature (Figure 7.10 (a)) and negative temperature (Figure 7.10 (b)) load applied. As has been discussed previously, a negative uniform temperature applied to the structure will cause the structure to contract. Because the deck is constrained from freely contracting, tensile stresses will arise in the deck under uniform temperature decrease. The opposite is true for uniform temperature increase as the constrained expansion of the bridge will create compressive stresses within the deck. The AASHTO truck loading applied to the Evansville Bridge will create tensile stresses to arise throughout the bridge deck. These tensile stresses coupled with the tensile stresses caused by a temperature drop will cause the stress in the bridge deck to exceed the modulus of rupture at many locations. Figure 7.10 shows the longitudinal stress values along the length of the deck from abutment 1 to mid-span 2, which is half of the 


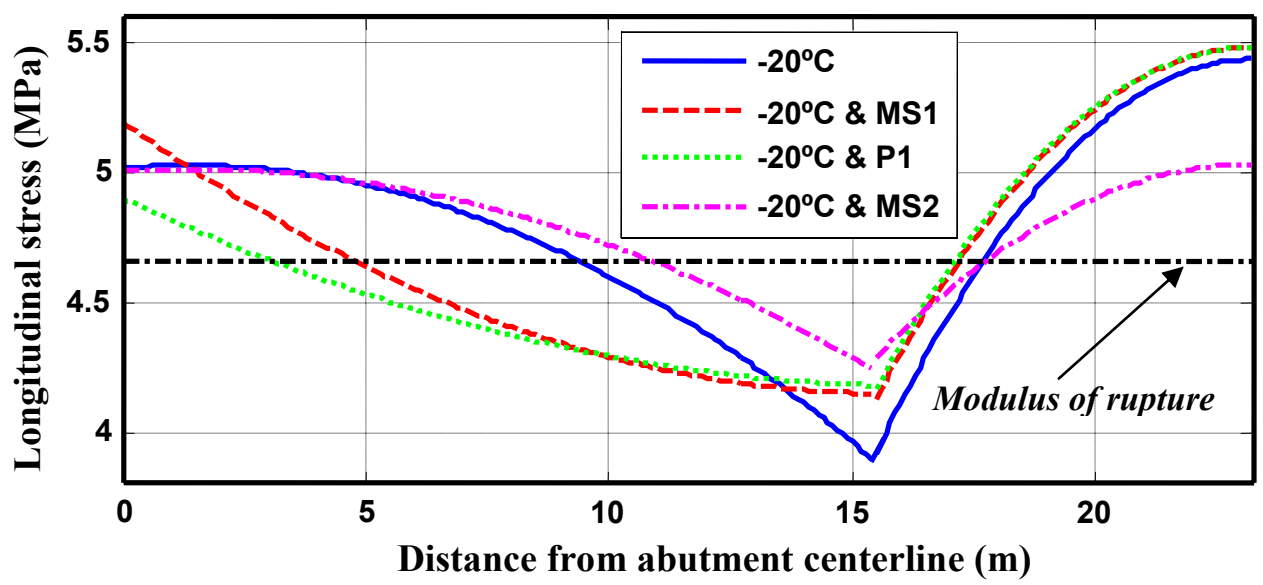

(a)

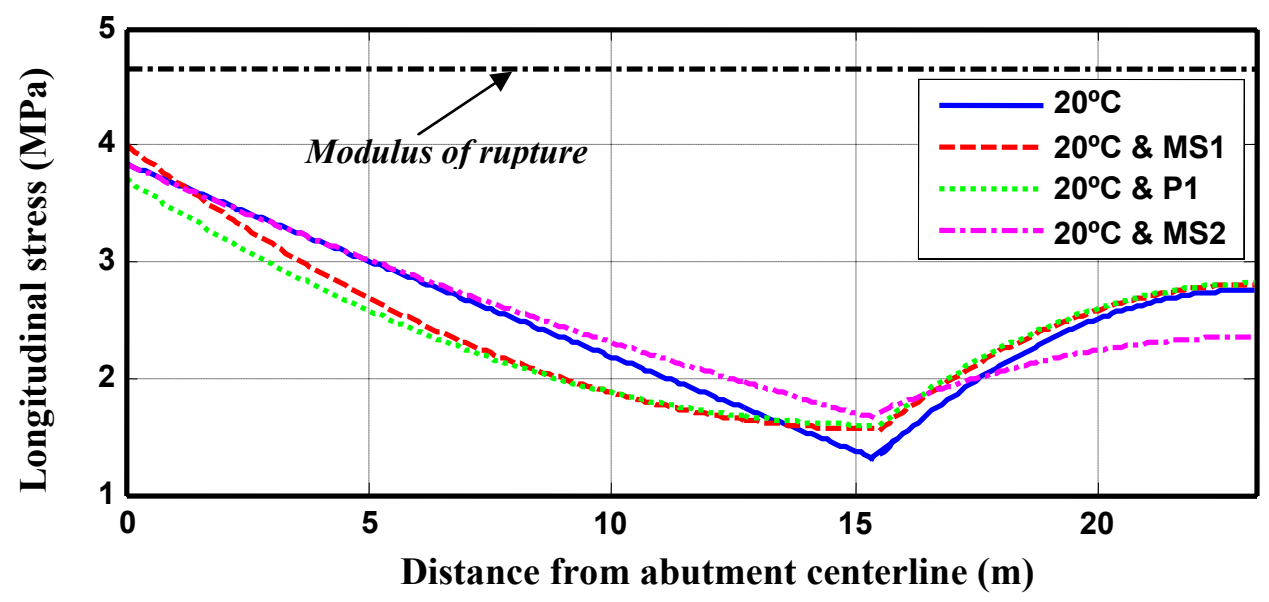

(b)

Figure 7.10. Longitudinal stress in bridge deck under selfweight, temperature, and AASHTO truck loading

bridge length. Since the bridge is symmetrical along its length, it can be assumed that his profile will also exist on the other non-instrumented half of the bridge. Figure 7.10 (a) shows that when a truck load is placed at mid-span 1, the stresses at mid-span 2 greatly exceed the concrete modulus of rupture and when a truck load is placed at mid-span 2 , the longitudinal stress values from abutment 1 well past mid-span 1 also exceeds the concrete modulus of rupture. It appears that as a vehicle crosses the Evansville Bridge when the temperature is low, i.e. during the winter months, the stresses in the bridge deck will exceed the concrete yield strength at each location along the longitudinal axis except 
for at each pier. This indicates that the stresses caused by thermal loading as well as traffic loading during the winter months will likely lead to cracks in the concrete reinforced deck.

\subsection{Conclusions}

AASHTO HS20-44 truck loading has been added to the FE bridge model to study the response of the Evansville Bridge to traffic loading in addition to gravity and thermal loading. The study found that the magnitude of axial stresses in the girders caused by changing thermal conditions can be comparable to bending stresses in the girders caused by the gravity and vehicle loading on the structure. Considering that thermal stresses can reach the same magnitude as design stresses, the stresses in the girders under constrained thermal loading should also be accounted for during bridge design.

Using the most conservative value for the effective length factor $\left(k_{b}=1.0\right)$ of the main girder, the Evansville Bridge main girder does not satisfy the AASHTO stability requirement under the full loading presented in this study. However, using the shape of the buckled girder, the FE analysis reveals that the effective length factor of the girder is actually 0.588 , which allows the main girder to satisfy the stability requirements. Therefore, it is concluded that under the in-service loading of the Evansville Bridge the girder stresses will remain within a safe range.

Finally, adding truck loading reveals that under cold temperature conditions the magnitude of longitudinal stress in the bridge deck will exceed the experimentally determined modulus of rupture for the concrete making up the bridge deck. These stress magnitudes will cause additional transverse cracks will appear along the length of the bridge as well as increasing the crack openings of already existing cracks. 


\section{CHAPTER EIGHT}

\section{CONCLUSION AND RECOMMEDATIONS}

\subsection{Conclusions}

The focus of this study is to examine how the state of stress of an integral abutment bridge is affected by changing thermal conditions. The response is evaluated using the information recorded from an expansive instrumentation system placed on the Evansville Bridge along with a detailed 3D finite element model of the instrumented section of the bridge validated by comparison with the experimentally measured data. The study included the investigation of the response of the Evansville Bridge to gravity loading, changing thermal conditions, and AASHTO standard truck loading. The following conclusions can be drawn from this study based upon the experimental and theoretical analyses:

1. The shear studs on the top flange of the Evansville Bridge girders do not create full composite action between the deck and the girders.

2. The addition of soil backfill behind the abutment walls will create a permanent compression in the bridge girders which will result in longitudinal stresses that will be present throughout the life of the bridge.

3. Contrary to design assumptions, integral abutment bridges are not free to expand and contract fully under changing thermal conditions. The soil backfill, shear studs, and corrugated stay-in-place forms provide constraints to the volumetric changes of the structure, inducing stresses not accounted for during design.

4. The constraints placed on the bridge expansion and contraction can cause axial compressive girder stresses measured by the instrumentation to reach a magnitude of approximately $28 \mathrm{MPa}$ during the summer months. 
5. The concrete reinforced deck experiences constrained volumetric changes under changing thermal conditions. The whole deck is constrained by the abutment connection while the bottom flange is further constrained by the shear studs on the girders and the stay-in-place forms between the girders.

6. During the first few days following deck casting, the concrete deck experiences stresses that exceed the concrete tensile strength. This is caused by the constraints placed upon the concrete during drying shrinkage by the shear studs and stay-inplace forms. These stresses result in early age concrete cracking and, although cracking will relieve some stress, some of the stress will remain on the deck throughout the life of the bridge.

7. Adding stresses caused by the constrained temperature induced volumetric changes to those from constrained drying shrinkage will cause stress levels to rise to a value indicating that more cracks will appear in the bridge deck.

8. Finite element results indicate that, for the bridge girders, axial stresses caused by uniform temperature loading are approximately equal in magnitude to bending stresses caused by dead and live loading.

9. Using the deformed shape of the middle girder under gravity, temperature, and AASHTO truck loading, the girder buckling length $\left(L_{b}\right)$ is determined to be 7.862 $\mathrm{m}$ and the effective length factor $\left(k_{b}\right)$ is 0.588 .

10. Using the previously mentioned $L_{b}$ and $k_{b}$ values calculated through FE analysis, the Evansville Bridge girders fully satisfy the AASHTO stability and yield criteria for all loading conditions investigated in this study.

11. During the winter months, when the ambient temperature is the lowest, the stresses caused by the truck loading combined with deal load and thermal stresses 
will cause the stress level of the concrete deck to exceed the concrete modulus of rupture along most of the deck length excluding the areas directly above the piers. These additional stresses may cause additional cracking to occur in the deck.

\subsection{Future work}

1. The thermal loading applied across the entire FE model is a uniform temperature change. However, in reality the thermal loading on the Evansville Bridge, as well as all structures, comes in the form of a temperature gradient. The model should be further investigated by applying measured temperature gradients to the deck and the girders and determining their effect on the bridge response.

2. As the bridge deck cracks due to excessive stresses, the stresses in the deck will be partially relieved and the strength of the concrete will be degraded. A concrete model could be developed that can account for concrete cracking and how this cracking will effect the total response of the bridge under in-situ conditions.

3. Further analysis could be performed to investigate if there is any way to predict the strength of the bond between the deck and the girders in relation to specifying the stiffness of the springs representing the deck-girder interface.

4. This study employs only one type of soil as the backfill for the abutments and piles. Different types of backfill could be modeled in an effort to determine to what degree different types of backfill will affect the overall response of the structure to loading. Along with this, different types of soil at different depths along the bridge abutment could be investigated which may more accurately represent actual conditions.

5. A standard should be developed which accounts for the temperature induced stresses in the girders during design. This should take into account different 
designs of integral abutment bridges with varying backfill conditions subjected to various ranges of temperature loading. 


\section{REFERECNCES}

1. ABAQUS/Standard User's Manual (1998). Hibbitt, Karlson, \& Sorensen, Inc., Version 5.8 (vols. I-III), Rhode Island.

2. Aktan, A. E. (1988). Present and Future RC Building Analysis, Proceedings of the $9^{\text {th }}$ World Conference on Earthquake Engineering

3. American Association of State Highway and Transportation Officials (2002). AASHTO Standard Specifications for Highway Bridges, $17^{\text {th }}$ ed., Washington D.C.

4. American Association of State Highway and Transportation Officials (1996). AASHTO Standard Specifications for Highway Bridges.

5. American Petroleum Institute (1993). Recommended Practice for Planning, Designing, and Constructing Fixed Offshore Platforms - Working Stress Design, $20^{\text {th }}$ ed., API RP2A-WSD, Washington, D.C.

6. ANSYS (2002). Reference Manual and Analysis Guide, Version 6.1, ANSYS, Inc., Southpoint, 275 Technology Drive, Canonsburge, PA 15317.

7. Barefoot, J. B. (1995). Development of Bridge Models to Predict and Evaluate Response. Masters Thesis, University of Virginia, Charlottesville, VA.

8. Barker, R.M., J. M. Duncan, K. B. Rojiani, P. S. K. Ooi, C. K. Tan, and S. G. Kim (1991). Manuals for the Design of Bridge Foundations, National Cooperative Highway Research Program (NCHRP), Transportation Research Board, Washington, D. C. 
9. Basu, P. K. and D. J. Knickerbocker (2005). Behavior of Jointless High Performance Concrete Bridges, Final Report, TNDOT Project No. TNSPRRES1 162, Vanderbilt University, Nashville, TN.

10. Bathe, K. J. (2002). ADINA Theory and Modeling Guide, Volume 1, ADINA R\&D Inc., 71 Elton Ave., Watertown, MA 02472.

11. Biggs, R. M., F. W. Barton, J. P. Gomez, P. J. Masserelli, and W. T. McKeel (2000). Finite Element Modeling and Analysis of Reinforced-Concrete Bridge Decks, Report No. VTRC 01-R4, Virginia Transportation Research Council, Charlottesville, VA, 29 pps.

12. Brockenbrough, R. L. (1986). Distribution Factors for Curved I-Girder Bridges, Journal of Structural Engineering, vol. 112, no. 10, pp. 2200-2215.

13. Burke, M. P. (1999). Cracking of Concrete Decks and Other Problems with Integral-Type Bridges. Transportation Research Record, vol. 1688, pp. 131138.

14. Civjan, S. A., S. F. Brena, D. A. Butler, and D. S. Crovo (2004). Field Monitoring of an Integral Abutment Bridge in Massachusetts, Transportation Research Record, vol. 1892, Transportation Research Board, Washington, D. C., pp. 160-169.

15. Clough, G. W. and J. M. Duncan (1971). Finite-Element Analyses of Retaining Wall Behavior, Journal of Soil Mechanics and Foundations Division, ASCE, vol. 97 , no. 12, pp. 1657-1673.

16. Clough, G. W. and J. M. Duncan (1991). Earth Pressures, Chapter 6 of Foundation Engineering Manual, $2^{\text {nd }}$ Ed. Edited by H. Y. Fang, Van Nostrand Reinhold, New York, pp. 223-235. 
17. Faraji, S., J. M. Ting, D. S. Crovo, and H. Ernst (2001). Nonlinear Analysis of Integral Bridges: Finite-Element Model, Journal of Geotechnical and Geoenvironmental Engineering, vol. 127, no. 5, pp. 454-461.

18. Fu, K. C. and F. Lu (2003). Nonlinear Finite-Element Analysis for High Bridge Superstructures, Journal of Bridge Engineering, vol. 8, no. 3, pp. 173-179.

19. Greimann, L. F., P. S. Yang, and A. M. Wolde-Tinsae (1986). Nonlinear Analysis of Integral Abutment Bridges, Journal of Structural Engineering, vol. 112 , no. 10 , pp. 2263-2279.

20. GTSTRUDL User's Manual (1991). Vol. 1, rev. M, GTICES Systems Lab, Georgia Institute of Technology, Atlanta, GA.

21. Hallquist, J. O. (1997). LS-DYNA Theoretical Manual, Livermore Software Technology Corporation.

22. Hallquist, J. O. (1997). LS-DYNA User's Manual, Livermore Software Technology Corporation.

23. Hays, C. O., L. M. Sessions, and A. J. Berry (1986). Further Studies on Lateral Load Distribution Using FEA, Transportation Research Record, vol. 1072, Transportation Research Board, Washington, D. C.

24. Hibbitt, H. D., B. I. Karlson, and E. P. Sorenson (1998). ABAQUS Version 5.8, Finite Element Program, Hibbitt, Karlson, and Sorenson, Providence, RI.

25. Horvath, J. S. (2002). Integral-Abutment Bridges: Problems and Innovative Solutions Using EPS Geofoam and Other Geosythetics, Research Report No. CE/Ge-00-2, Manhattan College, Manhattan, New York. 
26. Huria, V., K. L. Lee, and A. E. Aktan (1993). Nonlinear Finite Element Analysis of RC Slab Bridge, Journal of Structural Engineering, vol. 119, no. 1, pp. 89107.

27. Husain, I and D. Bagnariol (1996). Integral Abutment Bridges, Report No. SO96-01, Structural Office, Ministry of Transportation Ontario, Toronto, Canada.

28. Imbsen, R. A., and R. V. Nutt (1978). Load Distribution Study on Highway Bridges using STRUDL FEA, Proceedings of the Conference on Computing in Civil Engineering, American Society of Civil Engineers, New York, NY.

29. Jayaraman, R., P. B. Merz, and McLellan Pte. Ltd., Singapore (2001). Integral Bridge Concept Applied to Rehabilitate an Existing Bridge and Construct a Dual-Use Bridge, Proceeding of the $26^{\text {th }}$ Conference on Our World in Concrete and Structures, August 2001, Singapore.

30. Khodair, Y. A. and S. Hassiotis (2003). Analysis of Pile Soil Interaction, avaliable at: www.ce.washington.edu/em2003/proceedings/papers/686.pdf

31. Lawever, A., C. French, and C. K. Shield (2000). Field Performance of an Integral Abutment Bridge, Transportation Research Record, vol. 1740, pp. 108-117.

32. Lee, K. M. C. Chuntavan, V. Huria, and A. E. Aktan (1991). Computer Program for Three-Dimensional Static Collapse Analysis of Structures-(3DSCAS); version II, Report No. 01/91, Department of Civil and Environmental Engineering, University of Cincinnati, Cincinnati, Ohio. 
33. Livingston, R. A., S. Jin, and D. Marzougui (2001a). Stochastic Modeling of Ambient Traffic Loading in LS-DYNA Nonlinear FE Analysis. Proceedings of SPIE - the International Society of Optical Engineering, vol. 4337, pp. 422-431.

34. Livingston, R. A., S. Jin, and D. Marsougui (2001b). Application of Nonlinear Dynamics Analysis to Damage Detection and Health Monitoring of Highway Structures, Proceedings of SPIE - the International Society for Optical Engineering, vol. 4337, pp. 402-410.

35. Mabsout, M. E., K. M. Tarhini, G. R. Frederick, and C. Tayar (1997). FiniteElement Analysis of Steel Girder Highway Bridges, Journal of Bridge Engineering, vol. 2, no. 3, pp. 83-87.

36. Mabsout, M. E., K. M. Tarhini, G. R. Frederic, and A. Kesserwan (1998). Effect of Continuity on Wheel Load Distribution in Steel Girder Bridges, Journal of Bridge Engineering, vol. 3, no. 3, pp. 103-110.

37. Mabsout, M. E., R. Jabakhanji, K. M. Tarhini, and G. P. Frederick (2000). Finite Element Analysis of Concrete Slab Bridges, Computing in Civil and Building Engineering, vol. 2, pp. 1045-1050.

38. Marzougui, D., S. Jin, and R. A. Livingston (2001). Development of an LSDYNA Nonlinear Finite Element Model for use in Damage and Health Monitoring of Highway Bridges, Proceedings of SPIE - the International Society for Optical Engineering, vol. 4337, pp. 432-440.

39. MATLAB v. 7 (2004). The MathWorks, Inc. Natick, MA. 
40. Mufti, A. A., L. G. Jaeger, B. Bakht, and L. D. Wegner (1993). Experimental Investigation of Fiber-Reinforced Concrete Deck Slabs without Internal Steel Reinforcement, Canadian Journal of Civil Engineering, vol. 20, pp. 398-406.

41. Nutt, R. V., T. Zoakie, and R. A. Schamber (1987). Distribution of Wheel Loads on Highway Bridges, NCHRP Project No. 12-26, National Cooperative Highway Research Program, Transportation Research Board, National Research Council, Washington, D.C.

42. Reese, L. C. and S. T. Wang (1993). LPILE - Stress and Deformation Analysis of Piles Under Lateral Loading, Ensoft Inc. Austin, TX.

43. Roman, E., Y. Kodairm, and S. Hassioties (2002). Design Details of Integral Bridge, Proceedings of the Engineering Mechanics Conference.

44. Rouche, S. B., C. Orozco, F. W. Barton, J. P. Gomez, and P. Massarelli (2001). Finite Element Evaluation of the Structural Integrity of Composite Bridge Decks, Research Report No. UVACTS-14-13-8, Mid-Atlantic Universities Transportation Center, University of Virginia, Charlottesville, VA.

45. Salem, A. H., M. A. El-Aghoury, E. Y. Sayed-Ahmed, and T. S. Moustafa (2002). Composite Steel Free Deck Bridges: Numerical Modeling and Pilot Parametric Study, Canadian Journal of Civil Engineering, vol. 29, pp. 662678.

46. Samaan, M., K. Sennah, and J. B. Kennedy (2002). Distribution of Wheel Load on Continuous Steel Spread-Box Girder Bridges, Journal of Bridge Engineering, vol. 7, no. 3, pp. 175-183.

47. SAP2000NL (2001). Three Dimensional Static and Dynamic Finite Element Analysis and Design of Structures, Berkley, CA 
48. SAP90 User’s Manual (1992). Computer Structures Inc., Berkley, CA.

49. Shahrooz, B.M., I. K. Ho, A. E. Aktan, R. de Borst, J. Blaauwendraad, C. van der Veen, R. H. Idine, and R. A. Miller (1994). Nonlinear Finite Element Analysis of Deteriorated RC Slab Bridge, Journal of Structural Engineering, vol. 120 , no. 2 , pp. $423-441$.

50. Shoukry, S. N., G. W. William, and M. Y. Riad (2005). Early Age Cracks in Concrete Bridge Decks, Final Report, WVDOT Report No. T646-76-4.56, West Virginia Department of Highways, Charleston, WV.

51. Taciroglu, E., J. P. Stewart, and J. W. Wallace (2003). Robust Numerical Models for Cyclic Response of Columns Embedded in Soil, Proceedings of $16^{\text {th }}$ ASCE Engineering Mechanics Conference, July 2003, Seattle, WA.

52. Tarhini, K. M., and G. R. Frederick (1992). Wheel Load Distribution on I-Girder Highway Bridges, Journal of Structural Engineering, vol. 118, no. 5, pp. 1285-1294.

53. Tarhini, K. M., M. Mabsout, M. Harajli, and C. Taylor (1995). Finite Element Modeling Techniques of Steel Girder Bridges, Proceedings of the Congress on Computing in Civil Engineering, vol. 1, pp. 773-780.

54. Van Mier, J. G. M. (1987). Examples of Nonlinear Analysis of Reinforced Concrete Structure with DIANA, HERON, vol. 32, no. 3.

55. Vohar, S. T., C. C. Chang, B. A. Danver, B. Althouse, M. A. Davis, and R. Idriss (1998). Preliminary Results on the Monitoring of an In-Service Bridge Using a 32-Channel Fiber Bragg Grating Sensory System, Fiber Optic Sensors for Construction Material and Bridges, edited by F. Anasari, pp. 148-158. 
56. Wang, S. T. and L. C. Reese (1993). COM624P - Laterally Loaded Pile Analysis for the Microcomputer, Version 2.0, Report No. FHWA-SA-91-048, Springfield, VA.

57. William, G. W. (2003) Effect on Temperature Variations on Premature Cracking of Dowel Jointed Concrete Pavements, Ph. D. Dissertation, West Virginia University, Morgantown, WV.

58. William, G. W., S. N. Shoukry, and M. Y. Riad (2005). Thermal Stresses in Steel Girder Bridges with Integral Abutments, Bridge Structures, vol. 1, no. 2, pp. 103-118.

59. Womack, K., M. Halling, and S. Bott (2001). Static and Dynamic Testing of a Curved, Steel Girder Bridge in Salt Lake City, Utah, Report No. UT-00.31, Utah Department of Transportation, Research Division, Salt Lake City, Utah.

60. Yam, L. C. P., and J. C. Chapman (1972), The Inelastic Behavior of Continuous Composite Beams of Steel and Concrete, Proceedings of the Institution of Civil Engineers, vol. 53, pp. 487-501.

61. Zokaie, T., T. A. Osterkamp, and R. A. Imbsen (1991). Distribution of Wheel Loads on Highway Bridges, Rep. No. 12-26/1, National Cooperative Highway Research Program, Transportation Research Board, Washington, D. C. 
APPENDIX A
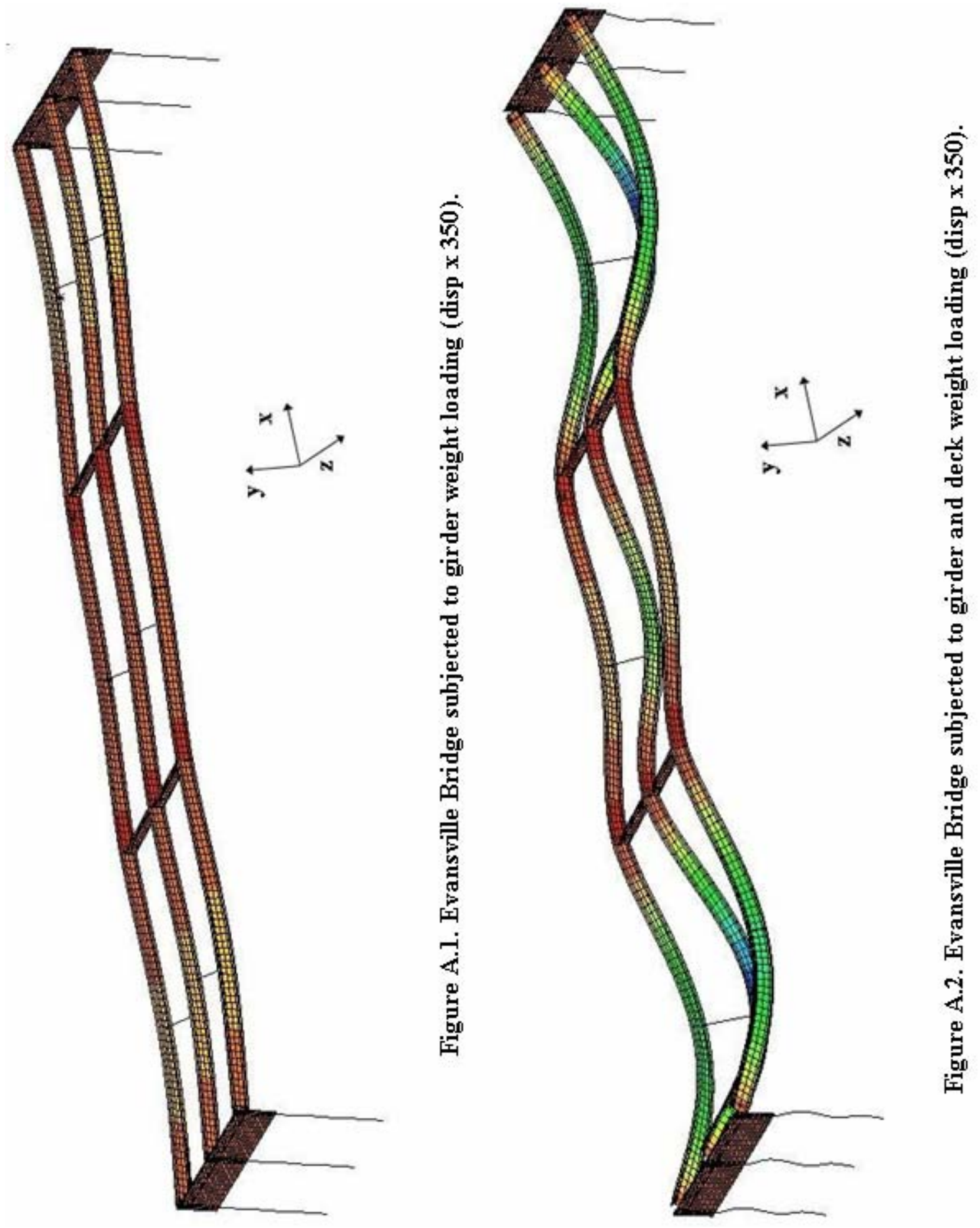

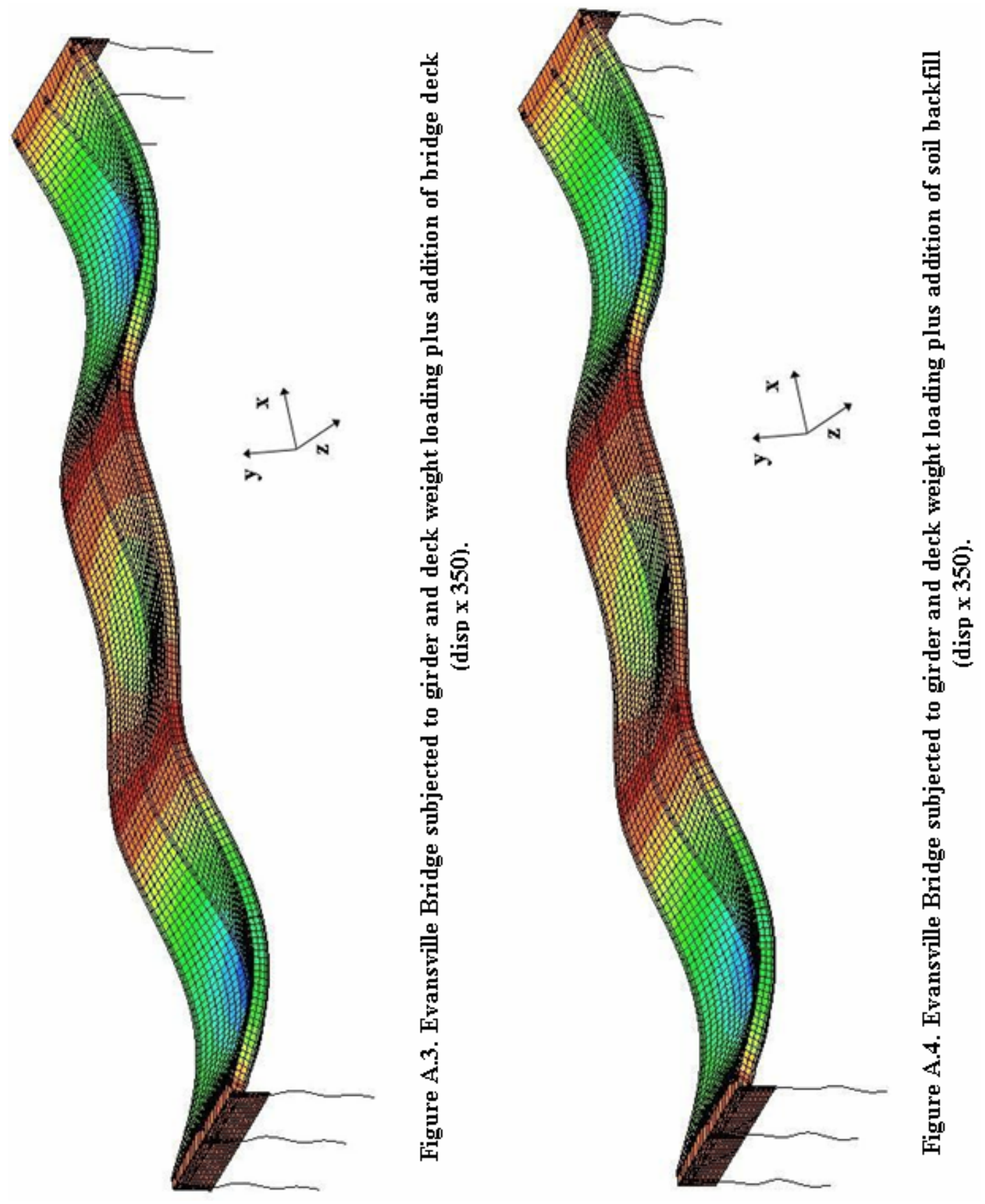

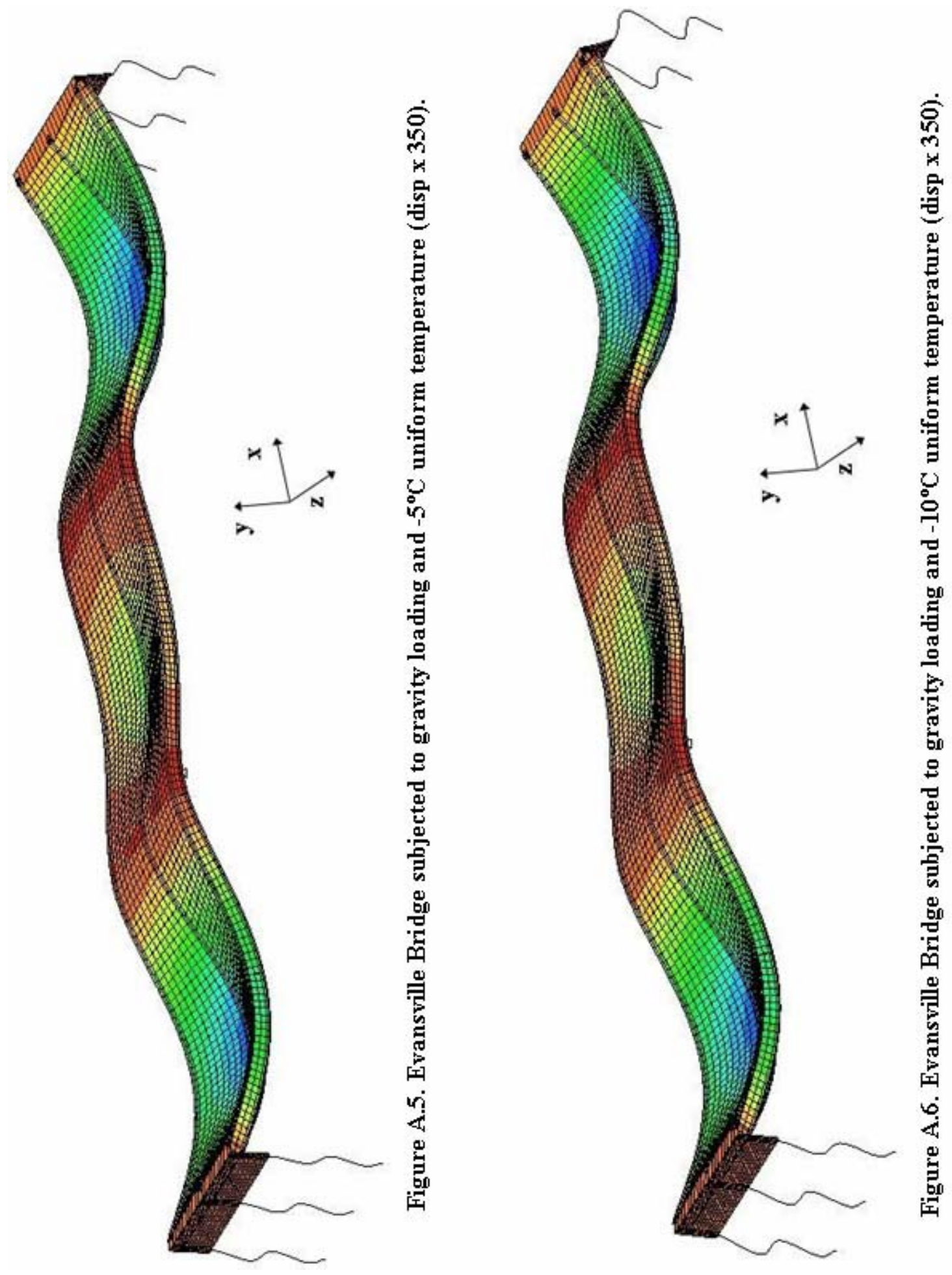

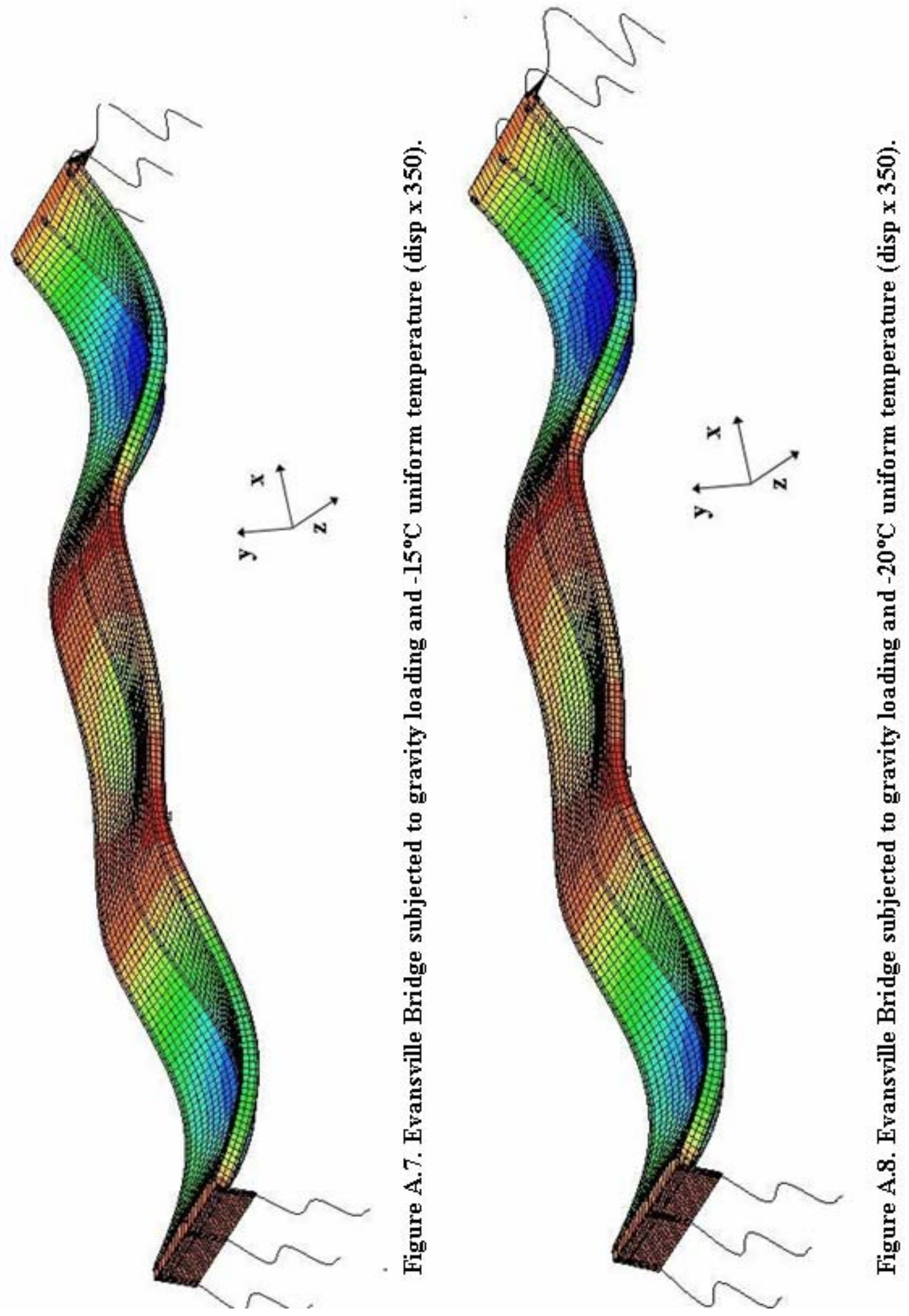

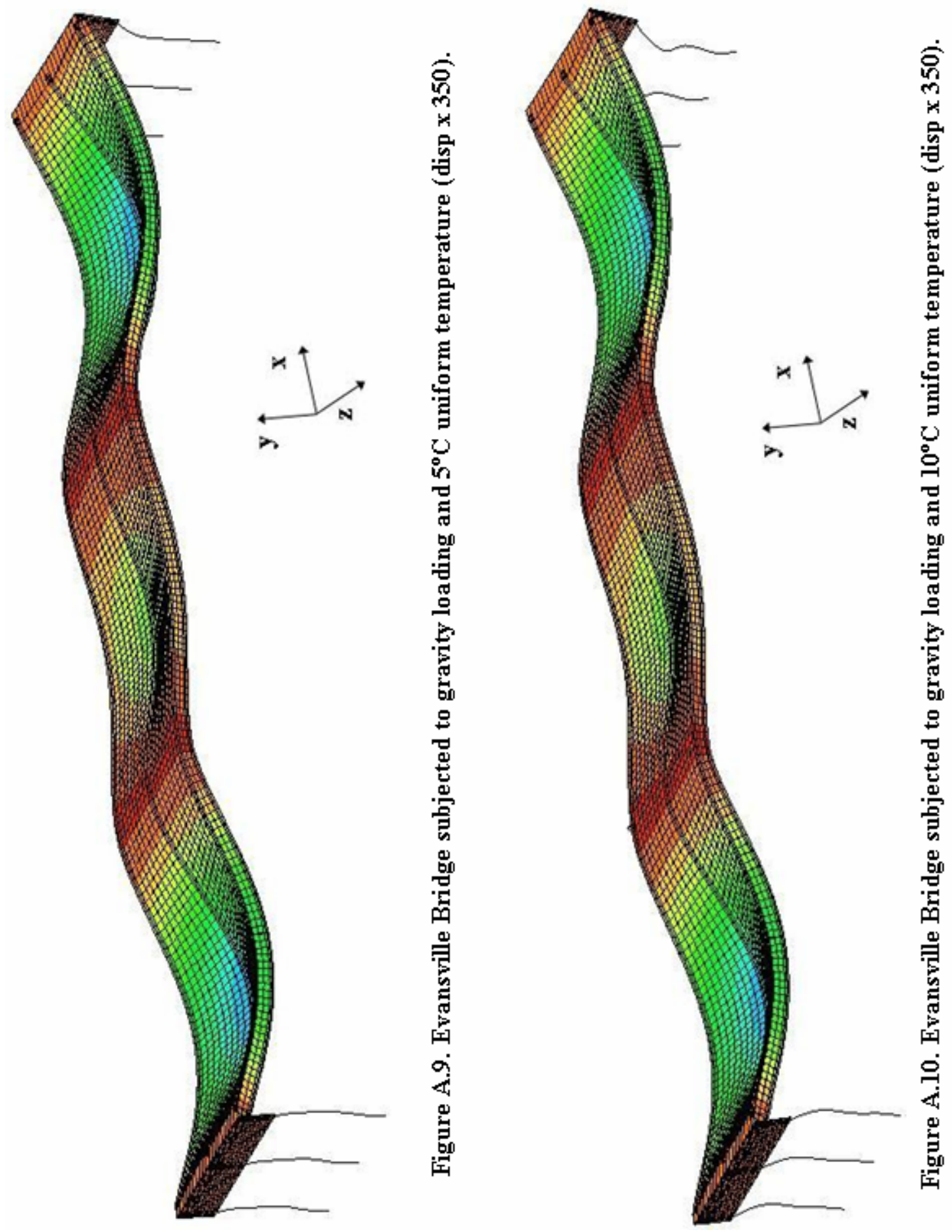

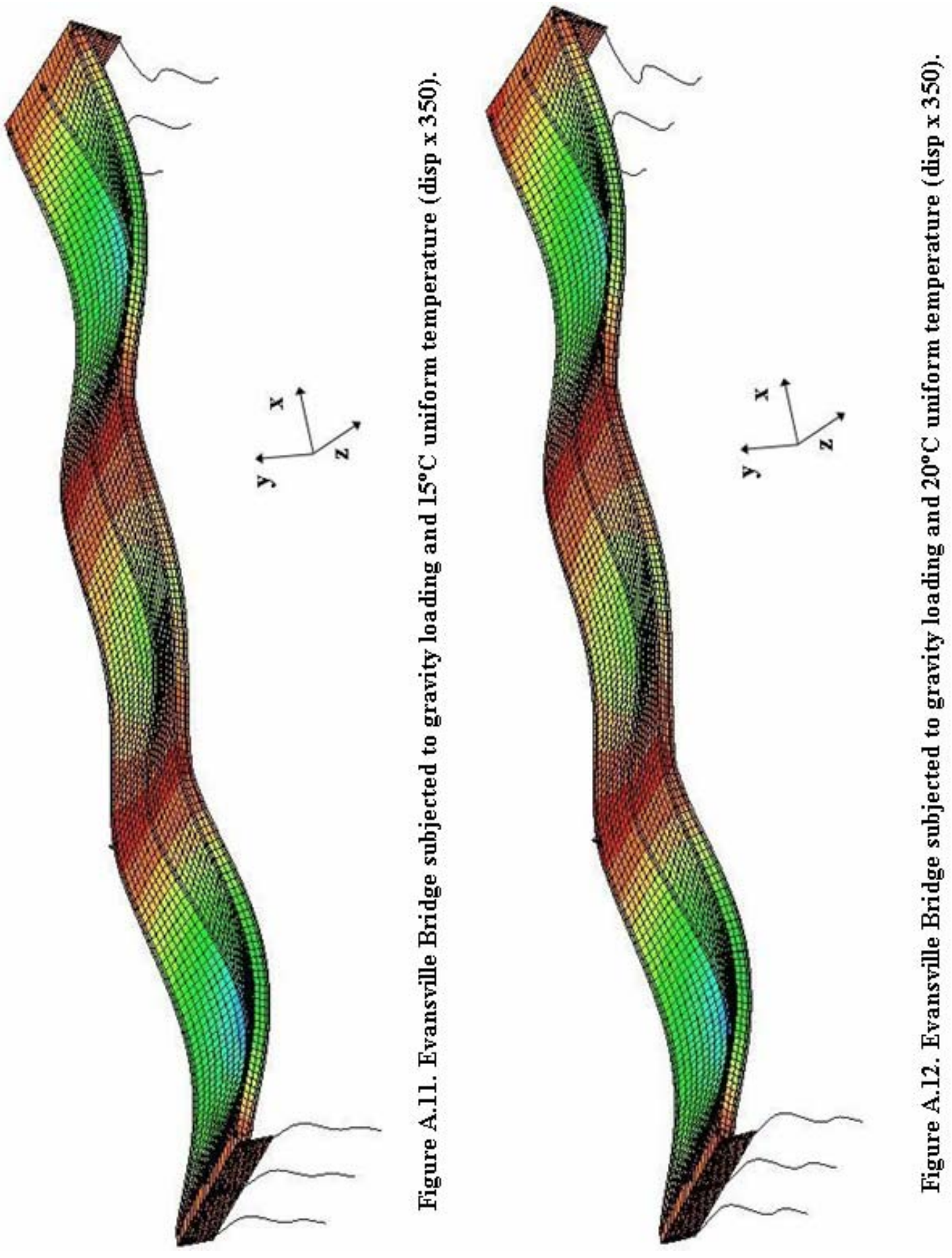

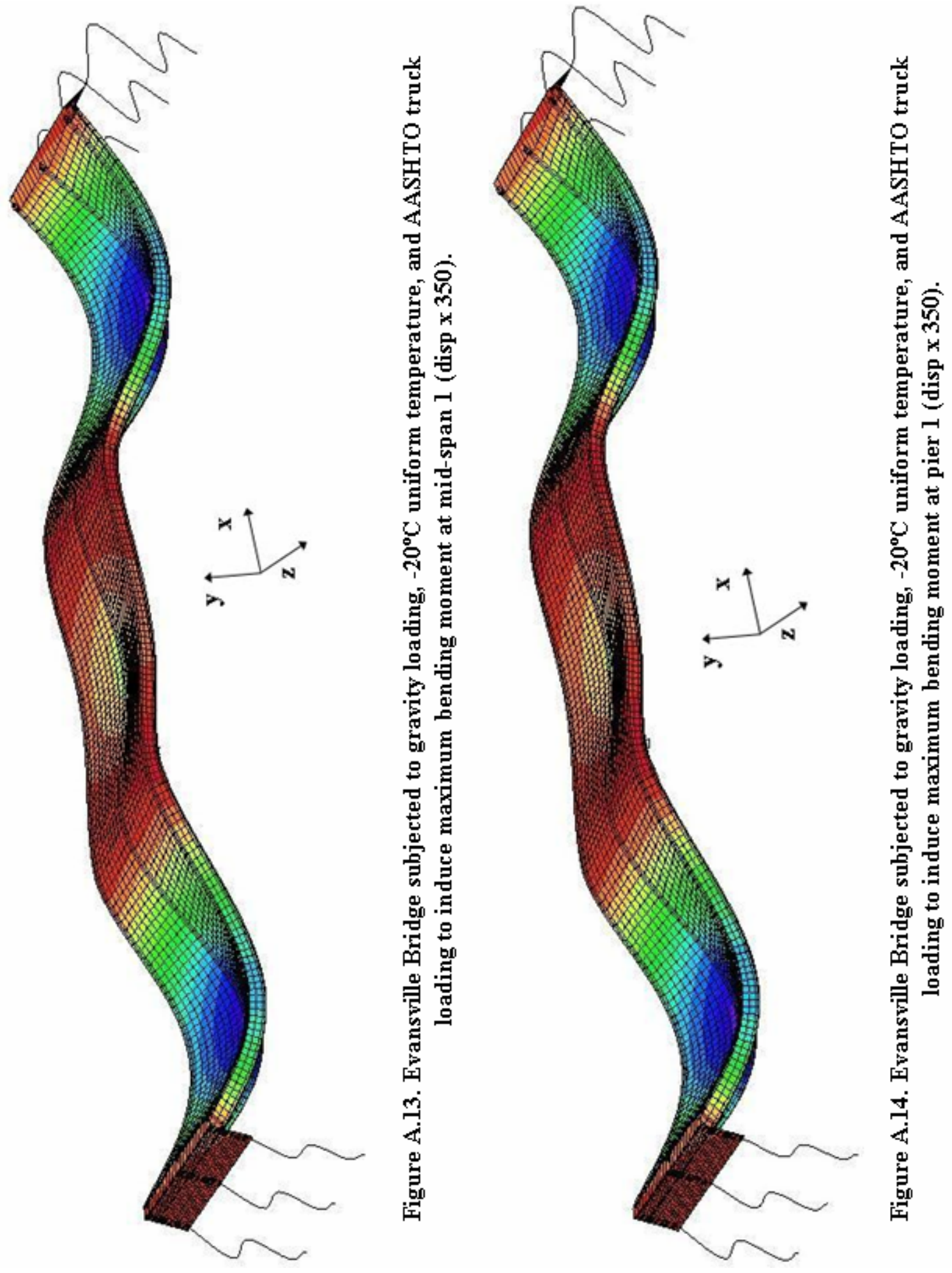

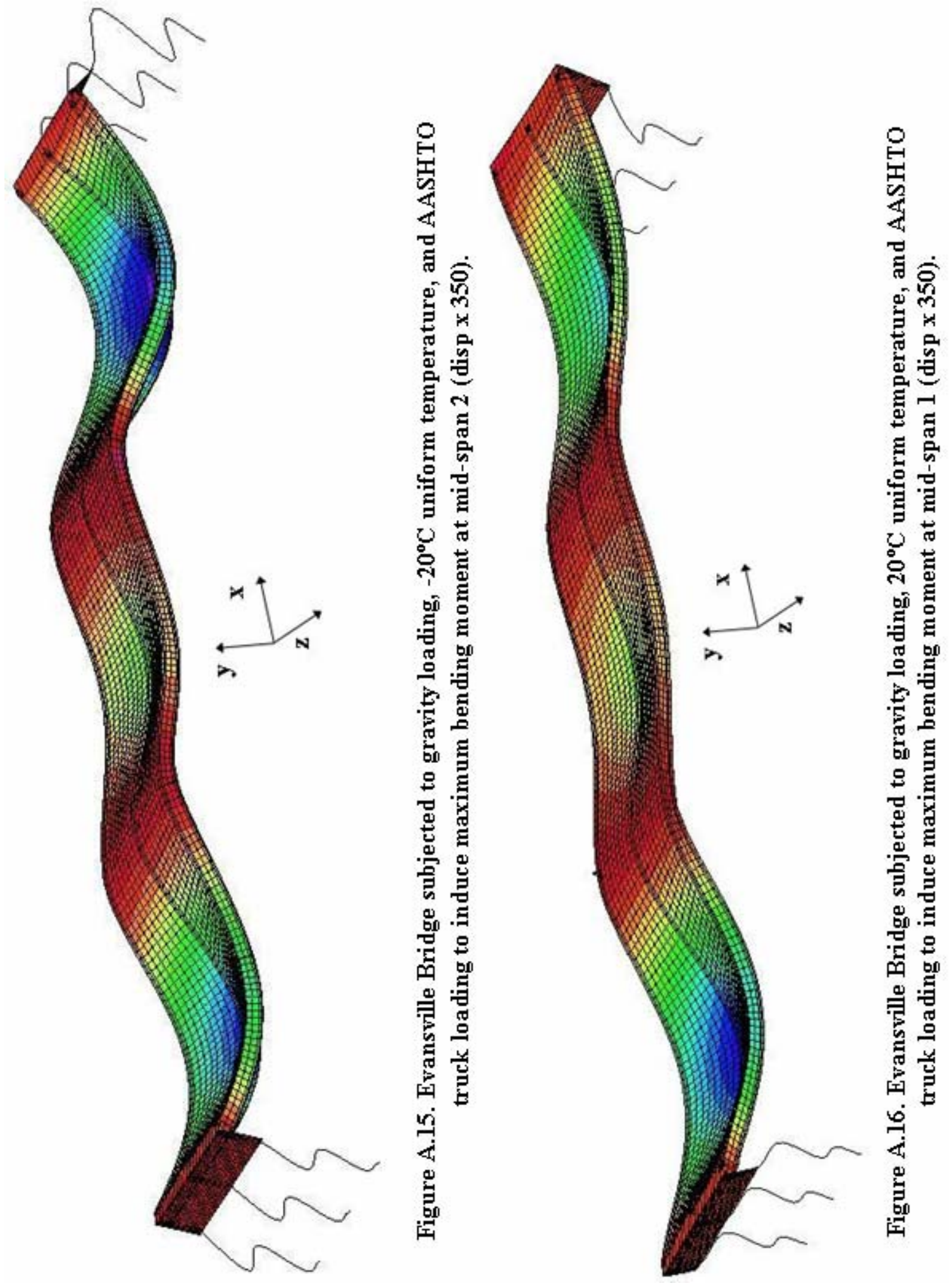


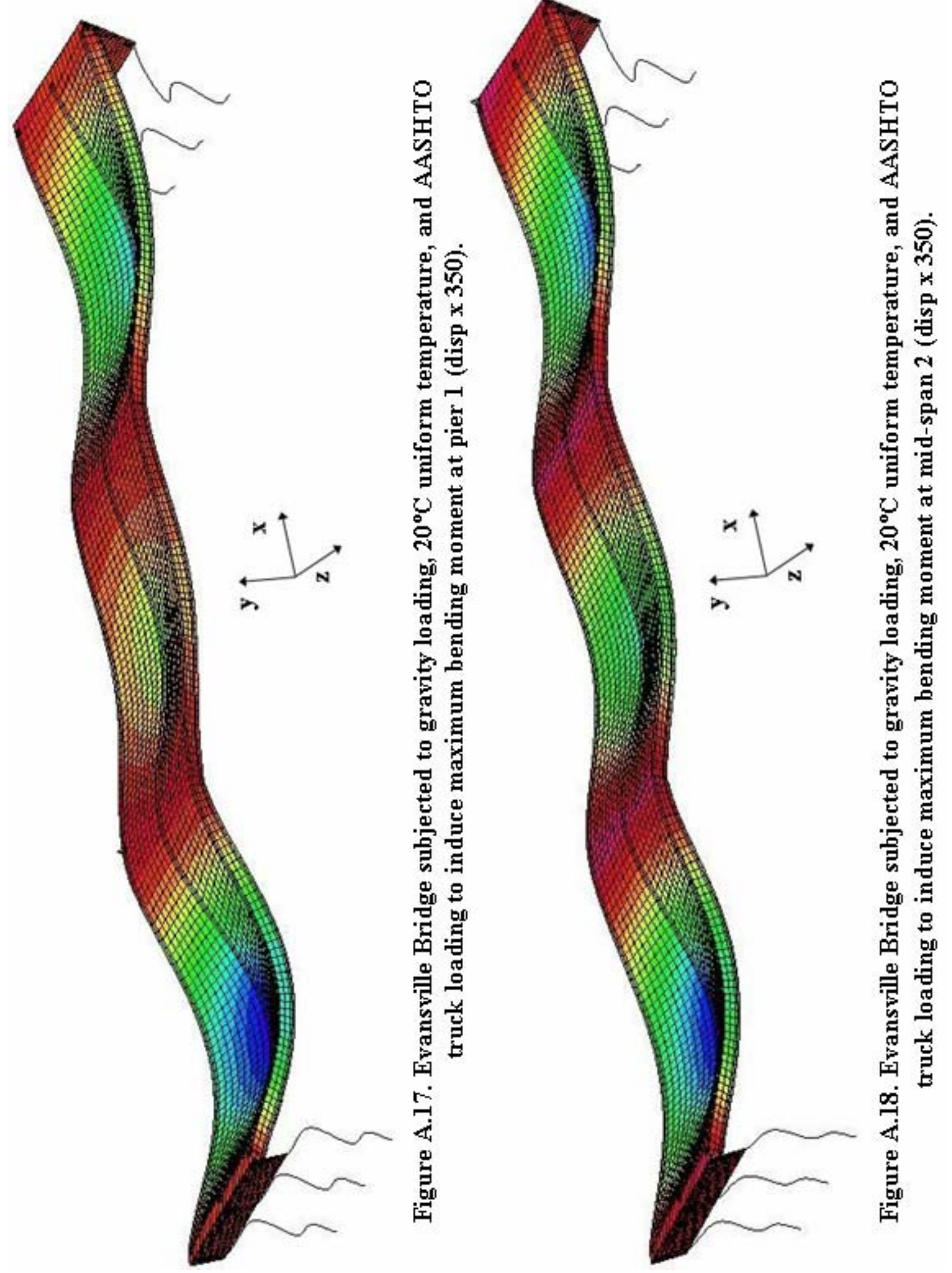

